\title{
Clinical relevance of dialysate constituents in hemodialysis treatment: focus on sodium and glucose
}

Citation for published version (APA):

Raimann, J. G. (2014). Clinical relevance of dialysate constituents in hemodialysis treatment: focus on sodium and glucose. [Doctoral Thesis, Maastricht University]. Datawyse / Universitaire Pers Maastricht. https://doi.org/10.26481/dis.20141002jr

Document status and date:

Published: 01/01/2014

DOI:

10.26481/dis.20141002jr

Document Version:

Publisher's PDF, also known as Version of record

\section{Please check the document version of this publication:}

- A submitted manuscript is the version of the article upon submission and before peer-review. There can be important differences between the submitted version and the official published version of record.

People interested in the research are advised to contact the author for the final version of the publication, or visit the DOI to the publisher's website.

- The final author version and the galley proof are versions of the publication after peer review.

- The final published version features the final layout of the paper including the volume, issue and page numbers.

Link to publication

\footnotetext{
General rights rights.

- You may freely distribute the URL identifying the publication in the public portal. please follow below link for the End User Agreement:

www.umlib.nl/taverne-license

Take down policy

If you believe that this document breaches copyright please contact us at:

repository@maastrichtuniversity.nl

providing details and we will investigate your claim.
}

Copyright and moral rights for the publications made accessible in the public portal are retained by the authors and/or other copyright owners and it is a condition of accessing publications that users recognise and abide by the legal requirements associated with these

- Users may download and print one copy of any publication from the public portal for the purpose of private study or research.

- You may not further distribute the material or use it for any profit-making activity or commercial gain

If the publication is distributed under the terms of Article $25 \mathrm{fa}$ of the Dutch Copyright Act, indicated by the "Taverne" license above, 


\section{CLINICAL RELEVANCE OF DIALYSATE CONSTITUENTS IN HEMODIALYSIS TREATMENT FOCUS ON SODIUM AND GLUCOSE}
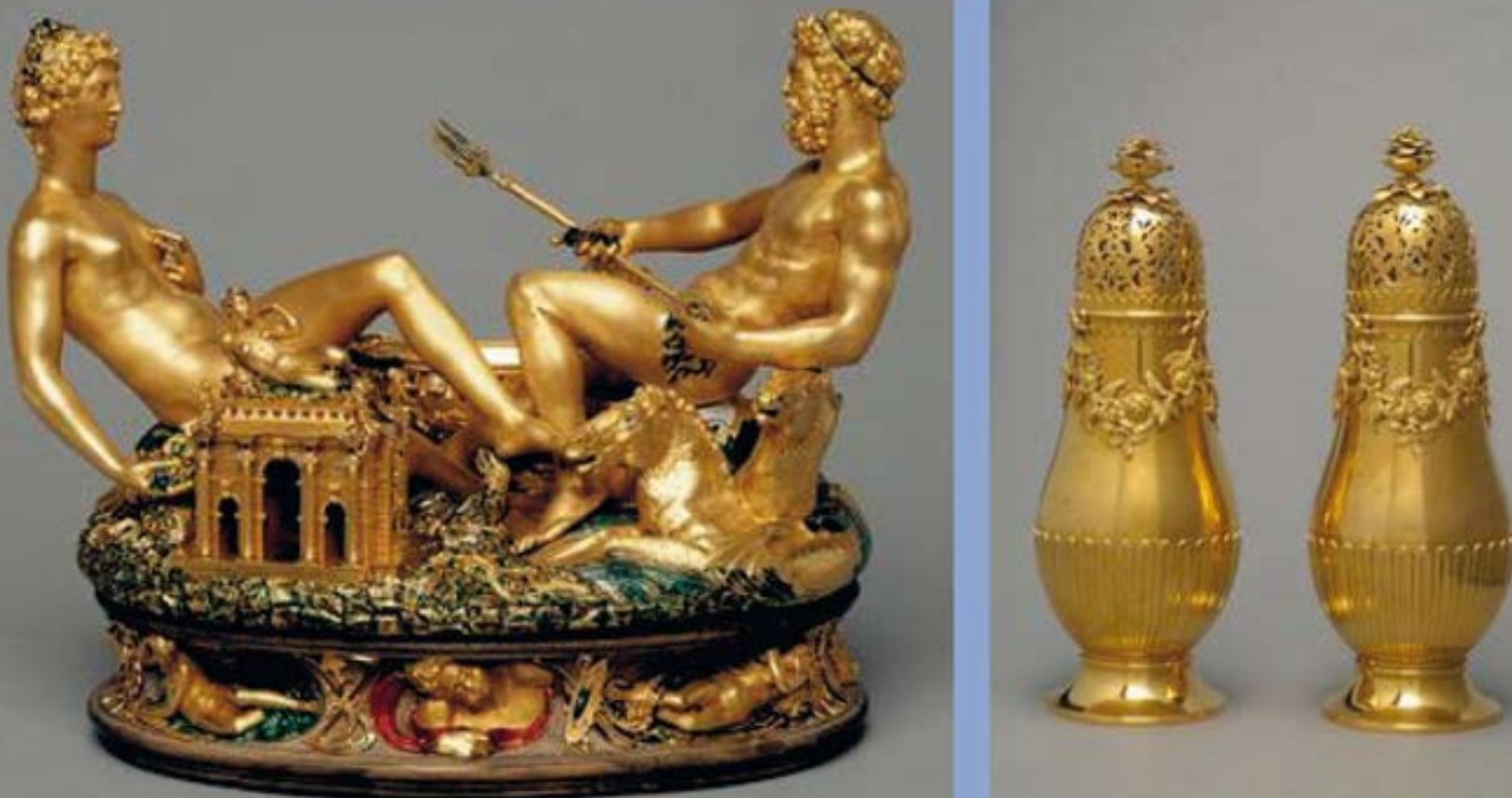

Jochen G. Raimann 
๑๐ Jochen G Raimann, Maastricht 2014

Cover picture credits: With kind permission of "Kunsthistorisches Museum Wien" (Museum of Art History Vienna).

Left Side: Cellini Salt Cellar ('Saliera'). Benvenuto Cellini (1540-1543)

Right Side: Sugar sprinklers from the surtout of Duke Karl Alexander of Lothringen.

Jakob van der Donk and Pieter Jozef Fonson (1755 with modifications done in 1770).

Layout: Tiny Wouters

Production: Datawyse | Universitaire Pers Maastricht

ISBN: 9789461593580 


\title{
Clinical relevance of dialysate constituents
}

\author{
in hemodialysis treatment: \\ focus on sodium and glucose
}

\author{
PROEFSCHRIFT \\ Ter verkrijging van de graad van doctor \\ aan de Universiteit Maastricht, \\ op gezag van de Rector Magnificus, \\ Prof. dr. L.L.G. Soete \\ volgens het besluit van het College van Decanen, \\ in het openbaar te verdedigen \\ op donderdag 2 oktober 2014 om 12:00 uur. \\ door \\ Jochen G Raimann
}

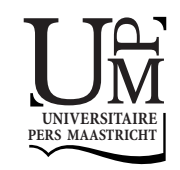




\section{Promotores}

Prof. dr. J.P. Kooman

Prof. dr. P. Kotanko, (Renal Research Institute, New York)

\section{Copromotores}

Prof. dr. N.W. Levin, (Renal Research Institute, New York) Dr. F.M. van der Sande

\section{Beoordelingscommissie}

Prof. dr. P.W. de Leeuw, voorzitter

Dr. O. Bekers

Dr. C.F. Franssen

Prof. dr. C.D.A. Stehouwer

Prof. dr. R. Zietse 


\section{Contents}

$\begin{array}{lll}\text { Chapter } 1 & \text { General introduction } & 7\end{array}$

Chapter 2 Metabolic effects of dialysate glucose in chronic hemodialysis: $\quad 27$ results from a prospective, randomized, cross-over trial

Chapter 3 Effects of dialysate glucose concentration on heart rate variability in chronic hemodialysis patients: results of a prospective randomized trial

Chapter $4 \quad$ Fatigue in hemodialysis patients with and without diabetes mellitus: Results from a randomized controlled trial of two glucose-containing dialysates

Chapter 5 Correction of serum sodium for glucose concentration in 69 hemodialysis patients with poor glucose control

Chapter 6 Sodium alignment in clinical practice - implementation and 73 implications

Chapter 7 Relationship between pre hemodialysis serum sodium concentration and blood pressure: Results from a retrospective analysis from the international Monitoring Dialysis Outcomes (MONDO) initiative

Chapter 8 Variability of pre-dialysis serum sodium and its association 99 with survival in incident hemodialysis patients: Results from a retrospective analysis from the international Monitoring Dialysis Outcomes (MONDO) initiative

Chapter 9 Relationship between levels and trends of blood pressure and survival: results of an observational cohort study in incident hemodialysis patients

Chapter 10 General discussion and summary

Valorization 



\section{Chapter 1}

Introduction 
Chapter 1 


\section{Introduction}

\section{Hemodialysis - a technique designed for blood purification}

In the $19^{\text {th }}$ century the Scottish chemist Thomas Graham (1805-1869) coined the term dialysis, which derives from the Greek words dia (through) and lysis (solution). Graham discovered that some solutes pass through semipermeable membranes (vegetable parchments coated with albumin in those days) and others do not ${ }^{1}$. Based on this principle translocation of crystalloids can take place while larger molecules (e.g. albumin amongst others) remain on the initial side. Knowledge of these basic principles was essential and formed the basis for work by Abel and colleagues who conducted decades later the first experiments in animals successfully removing uremic toxins from the circulation ${ }^{2}$. In 1924 Georg Haas in Giessen conducted the first hemodialysis (HD) treatment on a human being ${ }^{3}$ and later during World War II Willem Kolff further automated and developed the technique of blood purification ${ }^{4}$. Some years later Belding Scribner started the first HD maintenance treatments ${ }^{5}$ made possible due to the creation of a novel silastic arterio-venous shunt which could be repeatedly reused ${ }^{6}$. In the presence of early evidence of sustained iatrogenic replacement of lost kidney function which was essentially life-saving, a difficult problem arose: Who would receive $\mathrm{HD}$ and who would be doomed to the natural course of nature? Representing a major ethical, social and political problem in these early days, 'Admission and Policy Committees' decided which patients would be eligible for life-prolonging treatment. These so-called "death committees" were widely criticized at the time. As resources became generally available and the procedure became more established, governments recognized the need for financing the procedure and providing oversight. Countries differed in the degree of reimbursement and the availability of the techniques. The creation of large-scale provider networks was a consequence of this growing demand.

As per the 2013 Annual Data Report of the US Renal Data System (USRDS) around 400,000 chronic kidney disease patients received maintenance dialysis treatment in the US.

Dialysis as a technology is based on the principle of solute diffusion with membrane pore size largely limiting degree of diffusion and fluid ultrafiltration. Circulating blood passes through biocompatible lines and then through a hollow-fiber dialyzer, which consists of 8000 to 12000 extremely small (inner diameter of around $200 \mu \mathrm{m}$ ) hollow fibers. This currently used technique was, after numerous generations of different techniques, firstly proposed by the Polish nephrologist Zbylut Twardowski as the Capillary Dialyzer ${ }^{7}$, later developed, manufactured and made commercially available with fibers of much smaller internal diameters by Stewart, Lipps and Mahon as the Hollow-Fiber Dialyzer ${ }^{8}$. It was quickly established as the most effective dialyzer 
design $^{9,10}$. Today virtually every dialyzer used anywhere in the world is based on the same design and principle, but the properties of the fibers used vary widely.

The blood passing through the fibers is separated from purified water containing sodium, potassium, calcium, magnesium, bicarbonate, acetate and glucose in concentrations similar to those in serum. This maintains osmotic balance and creates a diffusive gradient for uremic toxins in the serum. The gradient is the main drive for the diffusion of toxins from the circulation, but this is accompanied by convective transport which comprises removal of a prescribed volume of fluid with an isotonic mass of serum constituents. Convective removal acts via mechanical alterations of the balance in pressure between the blood and dialysate sides of the dialysis membrane. Based on this principle the technique is also termed single-pass ultrafiltration. It is not entirely correct to consider the convective removal as isotonic since due to the kinetic relationship at the dialyzer and Gibbs-Donnan effects ${ }^{11}$ aiming to establish electroneutrality, some of the ultrafiltered solutes are dragged back into the plasma rendering the ultrafiltrate a slightly hypotonic solution.

The dialysate to serum gradient is maximal for those uremic toxins with molecular weights of which are less than the permeability limit of the membrane. However, it is also important that gradients between planned constituents in the dialysate such as glucose, sodium and many others, and consequent diffusive forces, depending on the molecular weight and other dialysis-related factors, are also present. For some of these a modifiable dialysate prescription determines the direction and magnitude of the solute mass transfer i.e. into or out of the blood stream and dialysate. In the following we will establish the importance of these gradients and the relationships to the outcomes caused by such differences.

\section{Dialysate composition}

Despite technological progress in dialysis the questions "What is adequate and optimal dialysis?" and "What should the optimal dialysate prescription be?" was repeatedly asked but not fully answered ${ }^{12}$. To quote the words of John Stewart Cameron describing the first decades of HD: "For the great majority of physician-scientists, dialysis was not science, but tinkering in basements."13.

Although this has certainly changed in recent decades, many aspects of the dialysis prescription are rarely individualized even today, and are prescribed on a one-size-fitsall basis. For a highly complex technological process such as HD where the aim of the therapy is to restore physiological conditions for the patient during short intermittent periods of time, this can be of substantial importance to the outcomes of therapy.

It may be difficult to determine what actually is physiological for a particular patient. Particularly this is so because levels of relevant substances should be kept in physiological ranges in terms of solute or volume removal until the next treatment two (or even three over the weekend) days later. This may even require substantial reductions (or increases) which may even exceed physiological ranges. 
Too often these questions are insufficiently addressed in clinical settings. An exempli gratia is volume management. To this date it is not clearly established what can be considered gold standards for volume estimation, since all currently available methods are not satisfactorily accurate and precise in dialysis patients ${ }^{14}$ and even in the normal population ${ }^{15}$. This lack of tools becomes particularly problematic in the determination of the actual dry weight, which is considered to be the physiologic volume state of the patient, with absolute certainty ${ }^{16}$. This is the case despite extensive effort and numerous proposed methods and approaches ${ }^{16,17}$. Another example is the quantitative prescription of vitamin $C$ supplements which also has remained unclear in the light of controversial literature of oxalosis following excessive intake, poor understanding of vitamin C dialysis kinetic, reports of deficiency in dialysis patients and the lack of adequately powered randomized studies providing evidence for an appropriate prescription $^{18}$.

A similar problem exists for solutes added to the dialysis water. Knowledge of the exact mathematical and kinetic relationship between plasma water and dialysate at the dialyzer membrane is crucial for the correct choice of concentrations of dialysate constituents $^{19}$. Approaches to perform such estimations in relationship to the distribution volumes in the body, allowing quantification and individualization of solute removal such as for urea have been formulated and are currently widely used for the quantification and prescription of the dialysis dose $\mathrm{Kt} / \mathrm{V}$ urea ${ }^{20,21}$.

Prescription of dialysate compositions need to be considered carefully since substantial solute mass may be transferred during the dialysis treatment from the dialysate to the patient and vice versa. The list of undetermined aspects of the dialysis prescription which are still under investigation and lacking consensus on what is optimal is unfortunately still long. Some of the main unsolved questions are the optimal composition of the dialysate in terms of bicarbonate, sodium, potassium, calcium, acetate, glucose, citrate, and more specifically the post-dialysis target ranges of these solutes and the optimal rate of removal of excess fluid. This need for additional research does not yet include aspects such as the use and prescription of drugs (antihypertensive medication, phosphate-binders, etc.) often requiring require different doses and frequencies of administration in dialysis patients. Also many dietary aims and recommendations are still under investigation and require more evidence.

In regard to the relatively frail constitution of dialysis patients, with accompanying high prevalence of co-morbidities coupled with a short life expectancy, render them a very distinct population. As a consequence too many aspects of management are not yet clear and cannot be translated without specific research in this population.

\section{Mass balance of glucose and sodium}

Mass balance is of importance for many solutes of interest. This is particularly true for those which have adverse effects if in excess or are lacking in the circulation. A formal definition of mass balance is phrased as follows: "The mass that enters a system must, 
by conservation of mass, either leave the system or accumulate within the system." Two major aspects need to be considered in the specific case of a dialysis patient: the dietary and the dialytic aspect. Dietary intake of glucose and sodium is the main source of input to the mass balance of these compounds. However, intradialytic mass transfer can also be substantial and requires equal consideration in the dialysis prescription.

In the context of the research questions asked and addressed here, the quantification of intradialytic mass transfer is necessary. To quantify the mass of a solute gained or lost by a patient during a dialysis treatment both the diffusive and the convective flux need to be estimated. Usually the convective removal of volume and with it an isotonic mass of solutes is substantially larger than what can be gained by diffusion. However, it is the diffusive component of intradialytic mass transfer which alters the biologically active serum concentration.

The easiest approach to estimation of mass transfer is to employ relatively simple relationships which require only the knowledge of some basic parameters. The main parameter is the flow-dependent clearance of the dialyzer which can be calculated using the well-established relationship ${ }^{19}$ :

$$
K=\frac{Q_{p} \cdot Q_{d} \cdot(1-f)}{Q_{p}-Q_{d} \cdot f}
$$

where $Q p$ is the effective plasma water flow (corrected for the void volume by the factor 0.93] in I/min, Qd the dialysate flow in I/min, KoA the flow-independent dialyzerspecifc mass are transfer coefficient

$$
f=e^{K o A} \cdot\left(\frac{1}{Q_{p}}-\frac{1}{Q_{d}}\right)
$$

The plasma flow (Qp) in I/min is calculated as:

$$
Q_{p}=Q_{b} \cdot\left(1-\frac{H c t}{100}\right)
$$

where $\mathrm{Qb}$ is the average whole blood flow during the treatment in $1 / \mathrm{min}$ and the instantaneous hematocrit as volume percentage of red cells in the whole blood (Hct). This is of importance when estimating the diffusive mass transfer [MT(t) diffusive] in $\mathrm{mg}$ within the time interval between two consecutive time points and is calculated as follows

$$
M T(t)_{\text {diffusive }}=[K \cdot(D C-P W C(t))],(4)
$$


where, DC is the dialysate constituent concentration, $\mathrm{PWC}(\mathrm{t})$ is, in a rather simple approach, the average plasma water concentration between two measurements at time points of interest of the respective solute in $\mathrm{mg} / \mathrm{l}$ (serum concentration corrected for the void volume by the factor 0.93 ) during the time interval of the duration $t$ in minutes. The intradialytic diffusive glucose mass transfer, in $\mathrm{mg}$, can now be estimated. It is generally accepted to present equations in this way so that a positive mass transfer corresponds to a diffusive transfer from the dialysate to the patient.

The convective mass transfer in mg during the time interval between two consecutive time points can be calculated as follows

$$
\mathrm{MT}(\mathrm{t})_{\text {convective }}=-(\mathrm{UFV}(\mathrm{t}) \cdot \operatorname{PWC}(\mathrm{t})),(5)
$$

where $U F V(t)$ is the ultrafiltration volume removed, in $L$ during the time interval $t$, in minutes. This calculation is valid with the assumption that the concentration in the ultrafiltrate is equal to the plasma water concentration which is not strictly true. However, it is generally accepted as an approach to estimate convective solute removal. The total intradialytic, extracorporal mass transfer can thus be calculated as the sum of diffusive and convective mass transfer.

Diffusive glucose transfer has been estimated to be on average $-16.7 \mathrm{~g}$ per hour loss from the patient to the dialysate for glucose-free dialysate ${ }^{22}$ and up to a $20 \mathrm{~g}$ per hour gain with a dialysate glucose concentration of $200 \mathrm{mg} / \mathrm{dL}(11.1 \mathrm{mmol} / \mathrm{l})^{23}$.

For sodium the situation is more complex since sodium transfer between intracellular and extracellular, and intravascular and interstitial compartment are not yet entirely understood shifts (Figure 1.1). Further, sodium, as a charged particle, is dependent on the Gibbs-Donnan effect directed at electroneutrality at the membrane and is strongly dependent on negatively charged proteins on the blood side. This leads to the retention of positively charged sodium cations on the blood side (thus affecting the relationship between clearance and concentration gradient) ${ }^{24}$.

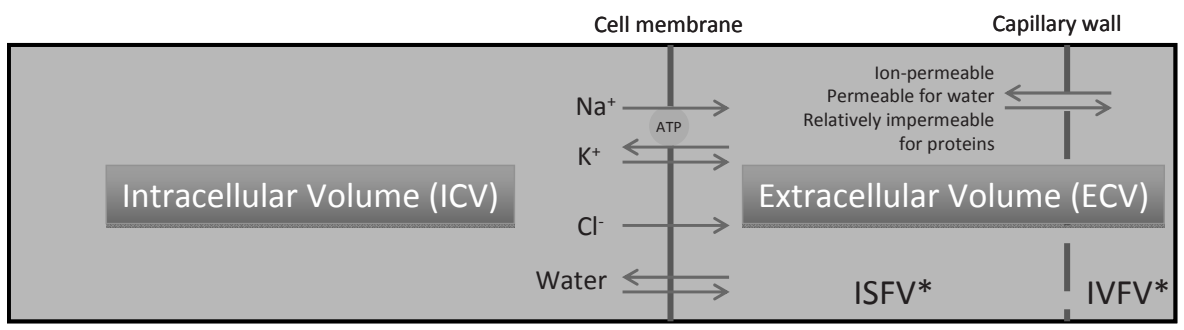

*interstitial fluid volume (ISFV); intravascular fluid volume (IVFV).

Figure 1.1 Sodium transfer. 
In addition it is not yet entirely understood how to account for the translocation of sodium and volume between compartments, in particular between interstitial and intravascular compartments. This thesis and the included analyses do not include nonosmotic storage of sodium in the interstitium by the reticulo-endothelial system in the skin as per the findings of Titze et al. ${ }^{25,26}$. Glucose concentrations in the blood also affect the concentration of sodium by causing volume shifts from the intracellular to the extracellular compartment.

Since recommendations of the National Kidney Foundation (NKF) - Kidney Disease Outcomes Quality Initiative (KDOQI) are for less or equal than $2.4 \mathrm{~g}$ of daily dietary sodium intake ${ }^{27}$, the need to avoid sodium loading by the dialysis treatment, which could exceed the daily recommended dietary sodium intake (in only 4 hours of time), appears obvious.

\section{Pathophysiologic and clinical aspects related to serum glucose and dialysate glucose prescription}

In the early days of dialysis, when ultrafiltration was not yet available, very high dialysate glucose concentrations were used to create an osmotic gradient which would remove water during the treatment similar to the dynamics used in aiding fluid removal in peritoneal dialysis. The concentrations used for HD were as high as $1600 \mathrm{mg} / \mathrm{dl}$ $(88.8 \mathrm{mmol} / \mathrm{I})$ and consequentially resulted in glucose loading during the treatment ${ }^{28}$. With the current universal use of hydraulic ultrafiltration and convective volume removal the glucose concentrations were lowered, which resulted in a reduction in plasma osmolality. This was even further accentuated by the very long treatment durations common before the 1980s.

The acute osmotic effects of urea had been deemed important in the special situation of the dialysis disequilibrium syndrome where the rapid reduction of azotemia (particularly urea, which is a non-effective osmolyte in steady state, but an effective osmolyte during acute changes) during dialysis resulted in the entry of fluid into the intracellular from the extracellular compartment ${ }^{29-31}$. In order to counteract the occurrence of this syndrome hypertonic dialysate solutions were commonly used. Dialysate glucose concentrations of $200 \mathrm{mg} / \mathrm{dl}$ (11.1 mmol/l) which are higher than the physiological level were routinely used in the US for decades. Also dialysate sodium $\left(\mathrm{DNa}^{+}\right.$) were often (substantially) greater than $140 \mathrm{mEq} / \mathrm{l}$ following this change in practice. Both of these prescriptions resulted in the loading of the patient with the respective substances due to rapid diffusion of glucose and sodium from the dialysate because of these solutes' low molecular mass. Consequentially it was repeatedly hypothesized that this would result in a full range of characteristic adverse consequences.

Generally, hyperglycemia and hypoglycemia are known to result in various serious short- and long-term consequences. Associations between high blood glucose and insulin resistance are well established and diabetes is a major risk factor for 
cardiovascular death risk in both the general population and also the HD population. Besides the formation of advanced glycosylation products (AGEs) and the subsequent deposition in vessel walls, causing inflammation and accelerating atherosclerosis, high blood glucose is also involved in the pathogenesis of diabetic nephropathy and neuropathy affecting the autonomic nervous system. In addition the literature reports effects of hyperinsulinism and hyperglycemia on heart rate variability (HRV) ${ }^{32,33}$, oxidative stress and inflammation ${ }^{34-36}$ and a randomized trial has suggested increased glucose concentrations as being predictive of mortality in patients suffering from acute coronary events ${ }^{37}$. In concert all these consequences emphasize the importance of tight glycemic control and the probable adverse effects of glucose loading.

For a remarkably long time there has been no consensus on what dialysate glucose concentrations should be. Currently the use of high dialysate glucose concentrations [greater than $100 \mathrm{mg} / \mathrm{dl}(5.5 \mathrm{mmol} / \mathrm{l})$ ] has been virtually abandoned worldwide. Despite the logical consequence of glucose loading caused by raising dialysate glucose levels above the physiological serum levels, the most commonly used dialysate glucose concentration in the US was $200 \mathrm{mg} / \mathrm{dl}(11.1 \mathrm{mmol} / \mathrm{l})$ for decades ${ }^{28}$. At the same time most other countries, including all countries in Europe and Canada, were using $100 \mathrm{mg} / \mathrm{dl}$ (5.5 mmol/l). Some countries mostly in Asia and South America have used glucose-free dialysate, mainly to reduce the risk of bacterial contamination of the dialysate.

As mentioned above dialysate glucose concentrations will have effects on serum glucose concentrations and serum insulin concentration by glucose removal or glucose loading following the kinetic principles at the dialyzer outlined above. Reports of hypoglycemic events in studies comparing glucose-containing versus glucose-free dialysates ${ }^{22}$ and other data also suggests differences in hemodynamic stability occurring between high and low dialysate glucose concentrations ${ }^{38,39}$. The latter was considered to be of particular interest for our analysis. There is evidence that rapid intravascular administration of glucose and other polysaccharides has effects on the circulating volume $^{40}$ and could prevent adverse consequences caused by ultrafiltration such as drops in blood pressure (BP), cramps, headache and nausea. These so-called intradialytic morbid events are commonly reported in HD patients and an occurrence in up to $27 \%$ of all treatments has been suggested ${ }^{41,42}$. The occurrence of hemodynamic instability, which potentially results in hypoperfusion of essential organs, has been significantly associated with an increased risk of hospitalization and mortality ${ }^{43}$.

Furthermore high insulin levels possibly reduce potassium and phosphorus removal due to their promoting effects on the uptake of these molecules by red blood cells ${ }^{23,44}$. This has sparked the hypothesis that different dialysate glucose concentrations may also account for the differences in the removal kinetics of potassium. It is emphasized that all the above hypotheses were formulated in the context of the topic but, at the time of writing of Chapter 2, 3 and 4, not yet been studied and compared in a randomized setting. The hypothetical differences on potassium kinetics focused interest on 
potential effects on cardiac rhythmicity. To evaluate this aspect we performed evaluations of the occurrence of cardiac arrhythmias of data from 24 hours Holter recordings in studied subjects.

In addition to cardiac rhythmicity we also performed analyses of HRV data based on the Holter recordings. Effects of the hypothesized differences in serum glucose and insulin concentrations appeared to be of possible interest for HRV analyses reported previously ${ }^{32,33,45}$. In addition to conventional HRV we also performed computations of non-linear HRV indices which are reflective of the entropy in the system and have been shown lately to associate to outcomes in dialysis patients ${ }^{46,47}$. For more details on HRV see Chapter 3.

Associations between the activation of the autonomic nervous system and fatigue ${ }^{48,49}$, and differences in post-dialysis fatigue with different dialysate sodium concentrations (utilizing the same concept as glucose affecting the post-dialysis osmolality) ${ }^{50-52}$ stimulated our interest in differences in self-reported fatigue following treatments with the studied dialysate glucose concentrations.

In summary theoretical disadvantages of high dialysate glucose concentrations on one hand, leading to high spiking glucose concentrations versus a possible risk of hypoglycemic events possibly compromising organ function with lower glucose or glucose-free dialysate on the other hand ${ }^{22,53,54}$ emphasize the need for clinical studies which shed more light on the preferable dialysate glucose prescription. To compare these two commonly prescribed dialysate glucose concentrations we have analyzed data from a randomized-crossover trial conducted in 14 diabetic and 15 non-diabetic HD patients. This thesis will report data from such a randomized as to how the choice of dialysate glucose concentration affects metabolic outcomes (Chapter 2), traditional and non-linear indices of HRV (Chapter 3) and the post-dialysis fatigue (Chapter 4) in diabetic and non-diabetic HD patients.

\section{Pathophysiologic and clinical aspects related to serum sodium and dialysate sodium prescription}

$\mathrm{DNa}^{+}$considerations add complexity to the glucose discussion. It needs to be noted that dialysate glucose concentrations and glucose-insulin metabolism may also play an important role in the choice of the appropriate $\mathrm{DNa}^{+}$due to the effect of extracellular glucose concentration on volume distribution between compartments and the consequent effects on the diffusive mass transfer between the dialysate and the blood. The effect of serum glucose on serum sodium $\left(\mathrm{SNa}^{+}\right)$is, as a rule of thumb, estimated to result in a lower $\mathrm{SNa}^{+}$by $1.6 \mathrm{mEq} / \mathrm{l}$ per $100 \mathrm{mg} / \mathrm{dl}(5.5 \mathrm{mmol} / \mathrm{l})$ increase in serum glucose. To further understand these dynamics we performed a retrospective analysis in 208 chronic HD patients receiving dialysis at clinics of the Renal Research Institute, included clinics were also those outside of the urban area of NY. We calculated a patient-specific slope to estimate the $\mathrm{SNa}^{+}$based on large changes of serum glucose concentration (Chapter 5). These dynamics are likely to also be of importance in the 
context of Chapter 6 which discusses the pathophysiologic and clinical effects of $\mathrm{SNa}^{+}$ and $\mathrm{DNa}^{+}$prescription.

Generally, body fluid volume increases as a result of an accumulation of sodium and water distributed mainly in the extracellular volume. This is in equilibrium with potassium, as the other major cation, which distributes largely in the intracellular space ${ }^{55}$. Sodium, as the cation of current interest, is gained from various sources, such as diet, or as in the special case of the dialysis patient, by a diffusive process during the dialysis treatment [in the presence of a positive sodium gradient $\left(\mathrm{GNa}^{+}\right)$]. Although not the focus of this thesis, saline administration to counteract intradialytic morbid events is another source of sodium.

As mentioned above the use of high $\mathrm{DNa}^{+}$was commonly used in the 1970s and 1980s in order to prevent the dialysis disequilibrium syndrome ${ }^{29}$, but also to preserve hemodynamic stability throughout the now shorter treatment times ${ }^{56}$. The potential to remove more accumulated fluid during shorter dialysis times was ascribed to the purported improvement in blood volume preservation because of a shift of water from the intra- to the extracellular, and subsequently from the interstitial to the intravascular compartment, following diffusion of sodium from the dialysate to the blood. These hypothesized benefits of the use of high dialysate sodium concentration had been already contradicted in the 1980s in reports of the advantageous effects of isonatric $H D^{57}$. A comparable approach aiming to allow shorter dialysis times and a lower frequency of intradialytic morbid events was the use of sodium profiling. The principle behind it was the use of high $\mathrm{DNa}^{+}$at the start of dialysis permitting higher ultrafiltration rates and fluid removal at this time in the treatment. This concentration would then be gradually lowered through the course of the treatment until at the end the $\mathrm{DNa}^{+}$would be lower than the $\mathrm{SNa}^{+,}$resulting in diffusive removal of the excess sodium from the blood. While this, appealing hypothetical approach, was suggested as a means to preserve circulating blood volume during ultrafiltration maintaining hemodynamic stability ${ }^{58}$ it remained somewhat controversial because of increased interdialytic weight gain (IDWG $)^{58,59}$ without substantially improving hemodynamic stability. The main theoretical problem is that the exact kinetics are difficult to anticipate with the lack of knowledge of the accurate magnitude of many variables needed (e.g. $\mathrm{SNa}^{+}$, distribution volume and intradialytic shifts between the compartments). The discussion of sodium profiling is however beyond the scope of this thesis.

Since the advent of the discussion about the optimal $\mathrm{DNa}^{+}$to use, it has been repeatedly shown that sodium loading during the course of dialysis is associated with adverse outcomes such as increased IDWG complicating the achievement of the target post dialysis weight and increased BP. The effects of sodium loading on hard outcomes such as left ventricular mass increase, hospitalizations and death are still not entirely clear and conflicting data has been published ${ }^{60-63}$. One of the problems for the analysis of the effect of the $\mathrm{DNa}^{+}$prescription is the fact that $\mathrm{SNa}^{+}$as well the $\mathrm{GNa}^{+}$(the 
difference between $\mathrm{DNa}^{+}$and $\mathrm{SNa}^{+}$) is, an operative vector relating to outcomes, are interrelated and both known to be associated with outcomes ${ }^{61,63,64}$. However, currently available evidence from prospective studies investigating the effects of reducing the $\mathrm{DNa}^{+}$show very clearly that it is beneficial in terms of at least outcomes such as IDWG and BP amongst others ${ }^{65-67}$.

Most data currently available derives from research projects which studied an 'across the board' change of $\mathrm{DNa}^{+65,66}$. Lately the use of lower $\mathrm{DNa}^{+}$was claimed to be not proven to be of benefit for all HD patients ${ }^{68}$. This call for needed research came from researchers currently conducting a large-scale and adequately powered trial comparing low versus high $\mathrm{DNa}^{+}$with left ventricular mass as the outcome ${ }^{69}$.

It is well established that the pre $\mathrm{HD} \mathrm{DNa}$ and the resulting $\mathrm{GNa}^{+}$(i.e. the difference between $\mathrm{DNa}^{+}$and $\mathrm{SNa}^{+}$) is linearly associated with change in $\mathrm{SNa}^{+}$during the treatment (i.e. the difference between pre and post $\left.\mathrm{SNa}^{+}\right)^{70-72}$. As a consequence the individualization of the $\mathrm{GNa}^{+}$allows the achievement of a desired diffusive intradialytic sodium balance. Despite some controversial publications in the literature which suggest a survival advantage for those at low $\mathrm{SNa}^{+}(<136 \mathrm{mEq} / \mathrm{l})$ dialyzed with high $\mathrm{DNa}^{+}$ $(>142 \mathrm{mEq} / \mathrm{l})^{73,74}$ the current belief suggests a neutral balance is to be desired. Dialysis should not result in diffusive sodium gain for the patient and should not alter $\mathrm{SNa}^{+}$ throughout the treatment. In this context $\mathrm{DNa}^{+}$to $\mathrm{SNa}^{+}$alignment appears to be of benefit for the patient.

The practical problem with alignment in busy dialysis clinics is that it is operationally impossible to measure pre dialytic $\mathrm{SNa}^{+}$before every treatment. The currently available data on alignment strategies are unfortunately from underpowered studies (thus not allowing elucidation of the effects on hard outcomes) ${ }^{57,75,76}$ and comprises only one randomized trial in 27 subjects only ${ }^{75}$. However, in the light of the currently published literature it appears likely that the use of sodium alignment results in positive outcomes in terms of reduction of IDWG, BP control, reduction of inflammation and intradialytic morbid events ${ }^{57,75,77}$. However, these studies are not sufficiently powered and hard evidence is required to draw solid conclusions. Therefore, preliminary data from the largest $\mathrm{DNa}^{+}$to $\mathrm{SNa}^{+}$alignment project to date which was conducted in dialysis clinics of the Renal Research Institute is presented in Chapter 6.

In healthy subjects serum sodium concentrations are between 135 and $145 \mathrm{mEq} / \mathrm{l}$ and the osmolality is between 280 to $295 \mathrm{mOsm} / \mathrm{kg}$. Both are tightly controlled and maintained by several regulatory mechanisms mainly comprising excretion and retention of sodium and water, thirst-triggered water intake promoted by stimulation of osmoreceptors in the brain, the effects of vasopressin and the renal response to vasopressin and other hormones ${ }^{78}$.

As mentioned above, in dialysis patients, sodium either from dialysis or from the diet will affect osmolality which again triggers thirst. Consequently volume expansion in dialysis patients following the increase of $\mathrm{SNa}^{+}$affects BP over a prolonged period of time and this effect disappears once the excess volume and salt is removed ${ }^{79-84}$. Fluid 
overload may cause irreversible and reversible damage to the cardiovascular system and compromise several other systems ${ }^{17,85}$.

In addition recent evidence suggests that there are also volume-independent relationships between $\mathrm{SNa}^{+}$and $\mathrm{BP}^{86}$. Partially these may be due to mechanisms and disturbances of the regulatory axes of electrolyte and water metabolism, such as the renin-angiotensin-aldosterone system (one of the main regulators of this system), which are still intact ${ }^{87,88}$. Due to the lack of kidney function (the actual effector) the mechanisms are not effective for their original purpose but rather result in adverse consequences. The most relevant consequences described in this thesis (Chapter 7) are vasoconstriction and remodeling of the vessel walls by aldosterone (in combination with sodium $)^{89}$. Mechanisms such as sympathetic activation and elevated levels of asymmetric di-methyl arginine (ADMA) may however also be involved in this vasoconstriction and the subsequent alteration of BP.

Sodium concentrations before a dialysis treatment [reflecting the dynamics during the interdialytic period $\left.{ }^{90}\right]$ and the concentrations during HD are positively associated with $\mathrm{BP}$ levels ${ }^{91}$. It is not yet known to what extent this is generalizable and if this is a finding independent of the magnitude of systolic, diastolic BP and the $\mathrm{SNa}^{+}$itself.

We are analyzing this in more detail in a large international cohort of incident HD patients from the Monitoring Dialysis Outcomes (MONDO) database ${ }^{92,93}$ and present the data in Chapter 7.

\section{The importance of longitudinal observations}

Generally there is currently a trend in the medical community to emphasize the need of longitudinal observation instead of only basing interpretations on cross-sectional analyses. Many retrospective analyses and many findings based on cross-sectional data have had important additions lately by longitudinal re-analyses. For example some recent evidence showed that clinical parameters (i.e. IDWG, systolic BP, albumin and C-reactive protein) prior to death showed characteristic non-linear dynamics which may be of great value for the development of prediction models aiding to identify patients at risk ${ }^{94}$. This reflects longitudinal analysis to clearly be a superior approach compared to cross-sectional analyses for the determination of risk factors. An example which sparked our interest in sodium and water metabolism were recent reports which suggested low $\mathrm{SNa}^{+}(<135 \mathrm{mEq} / \mathrm{l})$ to be a predictor of death in dialysis patients ${ }^{61,63,64}$. In combination with reports about trends in $\mathrm{SNa}^{+}$being a predictor of outcomes in patients with heart failure ${ }^{95}$, it appeared to be a valuable next step, to evaluate data in a longitudinal fashion. This may aid to either determine a novel prognostic marker for the treatment of dialysis patient or possibly even identify a new therapeutic target.

Despite not focusing on hard outcomes, Chapter 7 already reflects an example of the information gain achieved by analyzing longitudinal data. As outlined above, a dialysis patient generally will, due to the lack of kidney function and the resulting inability to excrete excess salt, ingest hypotonic fluids to return the osmolality (and the 
corresponding sodium levels) back to the initial value during the period between two dialyses. The resulting pre-HD SNa ${ }^{+}$has been termed the sodium setpoint ${ }^{70}$ and some stability can be seen in longitudinal evaluations ${ }^{96}$. There are many influences on this and the setpoint concept comprises an average standard deviation (SD) of monthly preHD serums sodium levels approximately $2.0 \mathrm{mEq} / \mathrm{l}$ with an average range of $7 \mathrm{mEq} / \mathrm{I}$ over the period of one year ${ }^{96}$. This variability includes seasonal changes in $\mathrm{SNa}^{+}$but also other potential factors such as osmotic gradients causing translocation of water between compartments, comorbidities or the occurrence of acute diseases which lower absolute levels for example as described in the symptom complex of the sick-cell syndrome ${ }^{97}$.

In summary the exact factors determining this variability and the knowledge how these relate to outcomes is currently unknown, however longitudinal observation of trends and variability could be of great prognostic importance possibly even represent a novel, yet not researched therapeutic target. This thesis aims to shed light on the factors determining variability and changes of $\mathrm{SNa}^{+}$and will also evaluate the relationship of these two indicators with mortality (Chapter 8).

As an additional focus in the context of the importance of longitudinal observations BP will be discussed in Chapter 9. Abundant data and publications report reference levels for BP in the general population, but for HD patients the situation is more complex, since the BP in a dialysis patient is strongly affected by accumulated salt and water which cannot be excreted. On the other hand a decreasing BP could also be a reflection of a rapidly deteriorating cardiac function.

The J-shaped curve of the mortality risk as a function of the BP reported in the general population, is also present in dialysis patients but at a somewhat higher level of $\mathrm{BP}^{98}$. The current paradigm is that BP levels below the lower threshold of $120 \mathrm{mmHg}$ may be indicative of reduced cardiac function and consequential hypoperfusion of organs ${ }^{98-100}$, whereas those levels above the higher threshold $(\geq 140 \mathrm{mmHg}$ prior to the HD treatment) are considered hypertension and potentially affecting the cardiovascular system. Both extremes are resulting in adverse outcomes but via different pathophysiological outcomes.

Additional evidence has emphasized the importance of longitudinal observations and the observance of dynamics of various parameters during this period as a predictor of death. For dialysis patients these analyses comprised indicators such as variability of $\mathrm{BP}^{101,102}$, trends in body temperature ${ }^{103}$ and the evolution of parameters before death $^{94,104}$. In Chapter 9 we analyze the relationship between trends in BP and mortality in a population of incident HD patients in the US. 


\section{Aim of the thesis}

In this thesis we aim to shed light on the question on what the effects of using different dialysate concentrations of sodium and glucose on affected parameters (such as BP, IDWG amongst others) are and how they associate with outcomes. The first part of the thesis focuses on dialysate glucose on the effects on metabolic aspects, HRV and fatigue of using a high dialysate glucose concentration in comparison to use a lower concentration (Chapter 2, Chapter 3 and Chapter 4). Since glucose is known to affect sodium concentrations by creating an osmotic disequilibrium between extra- and intracellular compartment we transition then to work we did on determining the means effects of serum glucose on $\mathrm{SNa}^{+}$. This is of importance for efforts to individualize $\mathrm{DNa}^{+}$ (Chapter 5). The individualization is then discussed in detail based on work done on $\mathrm{DNa}^{+}$to $\mathrm{SNa}^{+}$alignment. This section discusses the problem of operational feasibility of alignment, the implementation into clinical routine and presents preliminary data of the largest $\mathrm{DNa}^{+}$to $\mathrm{SNa}^{+}$alignment project to date (Chapter 6). Chapter 7 focuses on volume-independent effects of $\mathrm{SNa}^{+}$on $\mathrm{BP}$ emphasizing how important these possibly could be for clinical medicine. Dynamics of $\mathrm{SNa}^{+}$will be discussed in the following section reporting the relationship between $\mathrm{SNa}^{+}$trends and variability and outcomes (Chapter 8). Chapter 8 aims to provide further evidence that longitudinal observations are the only means informative enough to determine relationships between treatmentrelated and biological parameters, to outcomes. Chapter $\mathbf{9}$ aims to analyze the relationship between longitudinal dynamics of BP and its relationship to mortality over an observation period of one year. 


\section{References}

1. Graham T. The Bakerian lecture: Osmotic force. Philos Trans R Soc Lond 1854;144:117-28.

2. Abel JJ, Rowntree LG, Turner BB. On the removal of diffusible substances from the circulating blood of living animals by dialysis. J Pharmacol Exp Ther 1914;5:275-316.

3. Haas G. Versuche der Blutauswaschung am Lebenden mit Hilfe der Dialyse. Klin Wochenschrift 1925;4:13.

4. Kolff WJ, Berk HTJ, Welle M, et al. De kunstmatige nier. Een dialysator met groot oppervlak. Ned Tijdschr Geneeskd 1943;87:1684-8.

5. Scribner BH, Buri R, Caner JE, et al. The treatment of chronic uremia by means of intermittent hemodialysis: a preliminary report. Trans Am Soc Artif Intern Organs 1960;6:114-22.

6. Quinton W, Dillard D, Scribner BH. Cannulation of blood vessels for prolonged hemodialysis. Trans Am Soc Artif Intern Organs 1960;6:104-13.

7. Twardowski ZJ. History of hemodialyzers' designs. Hemodial Int 2008;12(2):173-210.

8. Lipps BJ, Stewart RD, Perkins HA, et al. The Hollow Fiber Artificial Kidney. ASAIO Journal 1967;13:200-7.

9. Gotch F, Lipps B, Weaver J, Jr., et al. Chronic hemodialysis with the hollow fiber artificial kidney (HFAK). Trans Am Soc Artif Intern Organs 1969;15:87-96.

10. Stewart RD, Cerny JC, Mahon HI. The Capillary "Kidney": Preliminary Report. Med Bull (Ann Arbor) 1964;30:116-8.

11. Nguyen MK, Kurtz I. Quantitative interrelationship between Gibbs-Donnan equilibrium, osmolality of body fluid compartments, and plasma water sodium concentration. J Appl Physiol 2006;100:1293-300.

12. Ing TS, Rahman MA, Kjellstrand CM. Dialysis : history, development and promise. New Jersey: World Scientific; 2012.

13. Cameron JS. A history of dialysis. Oxford: Oxford University Press; 2002.

14. Raimann JG, Kirisits W, Gebetsroither E, et al. Saliva urea dipstick test: application in chronic kidney disease. Clin Nephrol 2011;76:23-8.

15. Zdolsek JH, Lisander B, Hahn RG. Measuring the size of the extracellular fluid space using bromide, iohexol, and sodium dilution. Anesth Analg 2005;101:1770-7.

16. Raimann J, Liu L, Tyagi S, et al. A fresh look at dry weight. Hemodial Int 2008;12:395-405.

17. Raimann J, Liu L, Ulloa D, et al. Consequences of overhydration and the need for dry weight assessment. Contrib Nephrol 2008;161:99-107.

18. Raimann JG, Levin NW, Craig RG, et al. Is vitamin C intake too low in dialysis patients? Semin Dial 2013;26:1-5.

19. Michaels AS. Operating parameters and performance criteria for hemodialyzers and other membraneseparation devices. Trans Am Soc Artif Intern Organs 1966;12:387-92.

20. Gotch FA, Sargent JA, Keen ML, et al. Individualized, quantified dialysis therapy of uremia. Proc Clin Dial Transplant Forum 1974;4:27-35.

21. Gotch FA, Sargent JA. A mechanistic analysis of the National Cooperative Dialysis Study (NCDS). Kidney Int 1985;28:526-34.

22. Burmeister JE, Scapini A, da Rosa Miltersteiner D, et al. Glucose-added dialysis fluid prevents asymptomatic hypoglycaemia in regular haemodialysis. Nephrol Dial Transplant 2007;22:1184-9.

23. Ward RA, Wathen RL, Williams TE, et al. Hemodialysate composition and intradialytic metabolic, acidbase and potassium changes. Kidney Int 1987;32:129-35.

24. Gotch FA, Lam MA, Prowitt M, et al. Preliminary clinical results with sodium-volume modeling of hemodialysis therapy. Proc Clin Dial Transplant Forum 1980;10:12-7.

25. Kopp C, Linz P, Dahlmann A, et al. 23Na magnetic resonance imaging-determined tissue sodium in healthy subjects and hypertensive patients. Hypertension 2013;61:635-40.

26. Titze J, Dahlmann A, Lerchl K, et al. Spooky sodium balance. Kidney Int 2014; 85:759-67.

27. Clinical practice guidelines for hemodialysis adequacy, update 2006. Am J Kidney Dis 2006;48 Suppl 1:S2-90.

28. Sharma R, Rosner MH. Glucose in the dialysate: historical perspective and possible implications? Hemodial Int 2008;12:221-6. 
29. Port FK, Johnson WJ, Klass DW. Prevention of dialysis disequilibrium syndrome by use of high sodium concentration in the dialysate. Kidney Int 1973;3:327-33.

30. Wakim KG, Johnson WJ, Klass DW. Role of blood urea and serum sodium concentrations in the pathogenesis of the dialysis dysequilibrium syndrome. Trans Am Soc Artif Intern Organs 1968;14: 394-401.

31. Kennedy AC, Linton AL, Eaton JC. Urea levels in cerebrospinal fluid after haemodialysis. Lancet 1962;1:410-1.

32. Paolisso G, Manzella D, Rizzo MR, et al. Effects of glucose ingestion on cardiac autonomic nervous system in healthy centenarians: differences with aged subjects. Eur J Clin Invest 2000;30:277-84.

33. Paolisso G, Manzella D, Rizzo MR, et al. Effects of insulin on the cardiac autonomic nervous system in insulin-resistant states. Clin Sci (Lond) 2000;98:129-36.

34. Dandona $\mathrm{P}$, Chaudhuri $\mathrm{A}$, Ghanim $\mathrm{H}$, et al. Anti-Inflammatory Effects of Insulin and the ProInflammatory Effects of Glucose. Semin Thorac Cardiovasc Surg 2006;18:293-301.

35. Dandona P, Chaudhuri A, Ghanim H, et al. Insulin as an Anti-Inflammatory and Antiatherogenic Modulator. J Am Coll Cardiol 2009;53(5, Supplement 1):S14-S20.

36. Vos FE, Manning PJ, Sutherland WH, et al. Anti-inflammatory effect of an insulin infusion in patients on maintenance haemodialysis: A randomized controlled pilot study. Nephrology 2011;16:68-75.

37. Malmberg K, Norhammar A, Wedel H, et al. Glycometabolic state at admission: important risk marker of mortality in conventionally treated patients with diabetes mellitus and acute myocardial infarction: long-term results from the Diabetes and Insulin-Glucose Infusion in Acute Myocardial Infarction (DIGAMI) study. Circulation 1999;99:2626-32.

38. Sangill M, Pedersen EB. The effect of glucose added to the dialysis fluid on blood pressure, blood glucose, and quality of life in hemodialysis patients: a placebo-controlled crossover study. Am J Kidney Dis 2006;47:636-43.

39. Simic-Ogrizovic S, Backus G, Mayer A, et al. The influence of different glucose concentrations in haemodialysis solutions on metabolism and blood pressure stability in diabetic patients. Int J Artif Organs 2001;24:863-9.

40. Nette RW, Krepel HP, van den Meiracker AH, et al. Specific effect of the infusion of glucose on blood volume during haemodialysis. Nephrol Dial Transplant 2002;17:1275-80.

41. van der Sande FM, Kooman JP, Barendregt JN, et al. Effect of intravenous saline, albumin, or hydroxyethylstarch on blood volume during combined ultrafiltration and hemodialysis. J Am Soc Nephrol 1999;10:1303-8.

42. Kooman J, Basci A, Pizzarelli F, et al. EBPG guideline on haemodynamic instability. Nephrol Dial Transplant 2007;22 Suppl 2:ii22-44.

43. Sands JJ, Usvyat LA, Sullivan T, et al. Intradialytic hypotension: Frequency, sources of variation and correlation with clinical outcome. Hemodial Int 2014; 18:415-22.

44. Kemp GJ, Blumsohn A, Morris BW. Cellular phosphate shifts during oral glucose loading. Clin Chem 1992;38:2338-9.

45. Kanaley JA, Baynard T, Franklin RM, et al. The effects of a glucose load and sympathetic challenge on autonomic function in obese women with and without type 2 diabetes mellitus. Metabolism 2007;56:778-85.

46. Fukuta $\mathrm{H}$, Hayano J, Ishihara $\mathrm{S}$, et al. Prognostic value of heart rate variability in patients with end-stage renal disease on chronic haemodialysis. Nephrol Dial Transplant 2003;18:318-25.

47. Fukuta $\mathrm{H}$, Hayano J, Ishihara S, et al. Prognostic value of nonlinear heart rate dynamics in hemodialysis patients with coronary artery disease. Kidney Int 2003;64:641-8.

48. Pagani M, Lucini D. Chronic fatigue syndrome: a hypothesis focusing on the autonomic nervous system. Clin Sci (Lond) 1999;96:117-25.

49. Pagani M, Lucini D, Mela GS, et al. Sympathetic overactivity in subjects complaining of unexplained fatigue. Clin Sci (Lond) 1994;87:655-61.

50. Rayner HC, Zepel L, Fuller DS, et al. Recovery Time, Quality of Life, and Mortality in Hemodialysis Patients: The Dialysis Outcomes and Practice Patterns Study (DOPPS). Am J Kidney Dis 2014;64:86-94..

51. Sklar A, Newman N, Scott R, et al. Identification of factors responsible for postdialysis fatigue. Am J Kidney Dis 1999;34:464-70. 
52. Sklar AH, Beezhold DH, Newman $\mathrm{N}$, et al. Postdialysis fatigue: lack of effect of a biocompatible membrane. Am J Kidney Dis 1998;31:1007-10.

53. Jackson MA, Holland MR, Nicholas J, et al. Hemodialysis-induced hypoglycemia in diabetic patients. Clin Nephrol 2000;54:30-4.

54. Jackson MA, Holland MR, Nicholas J, et al. Occult hypoglycemia caused by hemodialysis. Clin Nephrol 1999;51:242-7.

55. Edelman IS, Leibman J, O'Meara MP, et al. Interrelations between serum sodium concentration, serum osmolarity and total exchangeable sodium, total exchangeable potassium and total body water. J Clin Invest 1958;37:1236-56.

56. Stewart WK, Fleming LW, Manuel MA. Benefits obtained by the use of high sodium dialysate during maintenance haemodialysis. Proc Eur Dial Transplant Assoc 1972;9:111-8.

57. Murisasco A, France G, Leblond G, et al. Sequential sodium therapy allows correction of sodium-volume balance and reduces morbidity. Clin Nephrol 1985;24:201-8.

58. Stiller S, Bonnie-Schorn E, Grassmann A, et al. A critical review of sodium profiling for hemodialysis. Semin Dial 2001;14:337-47.

59. Song JH, Park GH, Lee SY, et al. Effect of sodium balance and the combination of ultrafiltration profile during sodium profiling hemodialysis on the maintenance of the quality of dialysis and sodium and fluid balances. J Am Soc Nephrol 2005;16:237-46.

60. Hecking $\mathrm{M}$, Kainz $\mathrm{A}$, Horl $\mathrm{WH}$, et al. Sodium setpoint and sodium gradient: influence on plasma sodium change and weight gain. Am J Nephrol 2011;33:39-48.

61. Hecking M, Karaboyas A, Saran R, et al. Predialysis serum sodium level, dialysate sodium, and mortality in maintenance hemodialysis patients: the Dialysis Outcomes and Practice Patterns Study (DOPPS). Am J Kidney Dis 2011;59:238-48.

62. Munoz Mendoza J, Sun S, Chertow GM, et al. Dialysate sodium and sodium gradient in maintenance hemodialysis: a neglected sodium restriction approach? Nephrol Dial Transplant 2011;26:1281-7.

63. Mc Causland FR, Brunelli SM, Waikar SS. Dialysate sodium, serum sodium and mortality in maintenance hemodialysis. Nephrol Dial Transplant 2011;27:1613-8.

64. Waikar SS, Curhan GC, Brunelli SM. Mortality associated with low serum sodium concentration in maintenance hemodialysis. Am J Med 2011;124:77-84.

65. Munoz Mendoza J, Bayes LY, Sun S, et al. Effect of lowering dialysate sodium concentration on interdialytic weight gain and blood pressure in patients undergoing thrice-weekly in-center nocturnal hemodialysis: a quality improvement study. Am J Kidney Dis 2011;58:956-63.

66. Thein H, Haloob I, Marshall MR. Associations of a facility level decrease in dialysate sodium concentration with blood pressure and interdialytic weight gain. Nephrol Dial Transplant 2007;22: 2630-9.

67. Lacson EK, Rogus J, Kotanko P, et al. Lower Dialysate Na+ Impacts Weight Gain \& Fluid Overload Hospitalizations. J Am Soc Nephrol 2011;22(Abstract Supplement):93A.

68. Marshall MR, Dunlop JL. Are Dialysate Sodium Levels Too High? Semin Dial 2012; 25:431-2.

69. Dunlop JL, Vandal AC, de Zoysa JR, et al. Rationale and design of the Sodium Lowering In Dialysate (SoLID) trial: a randomised controlled trial of low versus standard dialysate sodium concentration during hemodialysis for regression of left ventricular mass. BMC Nephrol 2013;14:149.

70. Keen ML, Gotch FA. The association of the sodium "setpoint" to interdialytic weight gain and blood pressure in hemodialysis patients. Int J Artif Organs 2007;30:971-9.

71. Hecking $M$, Kainz $A$, Horl $W H$, et al. Sodium setpoint and sodium gradient: influence on plasma sodium change and weight gain. Am J Nephrol 2010;33:39-48.

72. Raimann JG, Gotch F, Keen ML, et al. Correlates of intradialytic change in Serum Sodium: The roles of pre-dialysis dialysate to serum sodium gradient and treatment time. (Abstract). Nephrol Dial Transplant 2013;28(Supplement 1):474-75.

73. Hecking $M$, Karaboyas A, Saran R, et al. Dialysate sodium concentration and the association with interdialytic weight gain, hospitalization, and mortality. Clin J Am Soc Nephrol 2012;7:92-100.

74. Mc Causland FR, Tilley BS, Waikar SS. Dialysate sodium and the milieu interieur. Clin J Am Soc Nephrol 2011;7:5-7.

75. de Paula FM, Peixoto AJ, Pinto LV, et al. Clinical consequences of an individualized dialysate sodium prescription in hemodialysis patients. Kidney Int 2004;66:1232-8. 
76. Elshahawy Y, Sany D, Shawky S. Outcome of individualized dialysate sodium concentration for hemodialysis patients. Saudi J Kidney Dis Transpl 2013;24:507-13.

77. Beduschi GC, Telini LS, Caramori JC, et al. Effect of Dialysate Sodium Reduction on Body Water Volume, Blood Pressure, and Inflammatory Markers in Hemodialysis Patients - A Prospective Randomized Controlled Study. Ren Fail 2013; 35: 742-7.

78. Mount DB. The brain in hyponatremia: both culprit and victim. Semin Nephrol 2009;29:196-215.

79. Thomson GE, Waterhouse K, McDonald HP, Jr., et al. Hemodialysis for chronic renal failure. Clinical observations. Arch Intern Med 1967;120:153-67.

80. Charra B. Fluid balance, dry weight, and blood pressure in dialysis. Hemodial Int 2007;11:21-31.

81. Charra B, Bergstrom J, Scribner BH. Blood pressure control in dialysis patients: importance of the lag phenomenon. Am J Kidney Dis 1998;32:720-4.

82. Charra B, Calemard M, Laurent G. Importance of treatment time and blood pressure control in achieving long-term survival on dialysis. Am J Nephrol 1996;16:35-44.

83. Charra B, Laurent G, Chazot C, et al. Clinical assessment of dry weight. Nephrol Dial Transplant 1996;11 Suppl 2:16-9.

84. Chazot C, Charra B, Vo Van C, et al. The Janus-faced aspect of 'dry weight'. Nephrol Dial Transplant 1999;14:121-4.

85. Raimann J., Liu L., Tyagi S., et al. A fresh look at dry weight. Hemodialysis International 2008;12: 395-405.

86. Oberleithner H. A physiological concept unmasking vascular salt sensitivity in man. Pflugers Arch 2012;464:287-93.

87. Volk MJ, Bomback AS, Klemmer PJ. Mineralocorticoid Receptor Blockade in Chronic Kidney Disease. Curr Hypertens Rep 2011; 13: 282-8.

88. Raimann JG, Liu L, Zhu F, et al. Serum aldosterone concentrations relate to fluid overload and serum potassium levels in hemodialysis patients. J Am Soc Nephrol 2012;23(Abstract Supplement):448A.

89. Joffe HV, Adler GK. Effect of aldosterone and mineralocorticoid receptor blockade on vascular inflammation. Heart Fail Rev 2005;10:31-7.

90. He FJ, Fan S, Macgregor GA, et al. Plasma sodium and blood pressure in individuals on haemodialysis. J Hum Hypertens 2013;27:85-9.

91. Suckling RJ, Swift PA, He FJ, et al. Altering plasma sodium concentration rapidly changes blood pressure during haemodialysis. Nephrol Dial Transplant 2013;28:2181-6.

92. Usvyat LA, Haviv YS, Etter M, et al. The MONitoring Dialysis Outcomes (MONDO) initiative. Blood Purif 2013;35:37-48.

93. von Gersdorff GD, Usvyat L, Marcelli D, et al. Monitoring Dialysis Outcomes across the World - The MONDO Global Database Consortium. Blood Purification 2013;36:165-72.

94. Usvyat LA, Barth C, Bayh I, et al. Interdialytic weight gain, systolic blood pressure, serum albumin, and C-reactive protein levels change in chronic dialysis patients prior to death. Kidney Int 2013;84:149-57.

95. Madan VD, Novak E, Rich MW. Impact of change in serum sodium concentration on mortality in patients hospitalized with heart failure and hyponatremia. Circ Heart Fail 2011;4:637-43.

96. Peixoto AJ, Gowda N, Parikh CR, et al. Long-term stability of serum sodium in hemodialysis patients. Blood Purif 2010;29:264-7.

97. Flear CT, Gill GV, Burn J. Hyponatraemia: mechanisms and management. Lancet 1981;2:26-31.

98. Zager PG, Nikolic J, Brown RH, et al. "U" curve association of blood pressure and mortality in hemodialysis patients. Medical Directors of Dialysis Clinic, Inc. Kidney Int 1998;54:561-9.

99. Cruickshank JM. Coronary flow reserve and the J curve relation between diastolic blood pressure and myocardial infarction. BMJ 1988;297:1227-30.

100. Cruickshank JM, Thorp JM, Zacharias FJ. Benefits and potential harm of lowering high blood pressure. Lancet 1987;1:581-4.

101. Mallamaci F, Minutolo R, Leonardis D, et al. Long-term visit-to-visit office blood pressure variability increases the risk of adverse cardiovascular outcomes in patients with chronic kidney disease. Kidney Int 2013;84:381-9.

102. Mallamaci F, Tripepi G. Blood pressure variability in chronic kidney disease patients. Blood Purif 2013;36:58-62. 
103. Usvyat LA, Raimann JG, Carter M, et al. Relation between trends in body temperature and outcome in incident hemodialysis patients. Nephrol Dial Transplant 2012;27:3255-63.

104. Kotanko P, Thijssen S, Usvyat L, et al. Temporal evolution of clinical parameters before death in dialysis patients: a new concept. Blood Purif 2009;27:38-47. 


\section{Chapter}

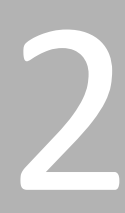

Metabolic effects of dialysate glucose in chronic hemodialysis: results from a prospective, randomized, cross-over trial

JG Raimann, A Kruse, S Thijssen, V Kuntsevich, P Dabel, M Bachar, JA Diaz-Buxo, NW Levin, P Kotanko Nephrol Dial Transplant 2012;27:1559-1568 


\section{Abstract}

\section{Background}

There is no agreement concerning dialysate glucose concentration in hemodialysis (HD) and 100 and $200 \mathrm{mg} / \mathrm{dl}(\mathrm{G} 100, \mathrm{G} 200)$ are frequently used. G200 may result in diffusive glucose flux into the patient, with consequent hyperglycemia and hyperinsulinism, and electrolyte alterations, in particular potassium (K) and phosphorus (P). This trial compared metabolic effects of $\mathrm{G} 100$ versus G200.

\section{Methods}

Chronic HD patients participated in this randomized, single masked, controlled crossover trial (www.clinicaltrials.gov: \#NCT00618033) consisting of two consecutive three-week segments with G100 and G200, respectively. Intradialytic serum glucose (SG) and insulin concentrations (SI) were measured at $0,30,60,120,180,240$ minutes, and immediately post-HD; P and $\mathrm{K}$ were measured at 0, 120, $180 \mathrm{~min}$, and post-HD. Hypoglycemia was defined as a SG $<70 \mathrm{mg} / \mathrm{dl}$. Mean SG and SI were computed as area under the curve divided by treatment time.

\section{Results}

Fourteen diabetic and 15 non-diabetic subjects were studied. SG was significantly higher with G200 as compared to G100, both in diabetic [G200: 192.8 \pm 48.1 ; G100: $154.0 \pm 27.3$; difference 38.8 (95\% Cl: 21.2 to 56.4$) \mathrm{mg} / \mathrm{dl} ; P<0.001$ ] and non-diabetic subjects [G200: $127.0 \pm 11.2 \mathrm{mg} / \mathrm{dl}$; G100 106.5 $\pm 10.8 \mathrm{mg} / \mathrm{dl}$; difference 20.6 (95\% Cl: 15.3 to 25.9 ) $\mathrm{mg} / \mathrm{dl} ; \quad P<0.001$ ]. SI was significantly higher with G200 in non-diabetic subjects. Frequency of hypoglycemia, P and K serum levels, interdialytic weight gain, and adverse intradialytic events did not differ significantly between $\mathrm{G} 100$ and $\mathrm{G} 200$.

\section{Conclusions}

G200 may exert unfavorable metabolic effects in chronic HD patients, in particular hyperglycemia and hyperinsulinism, the latter in non-diabetic subjects 


\section{Introduction}

Hemodialysis (HD) fluid can be considered a temporary extension of the patient's extracellular fluid because of the bi-directional transport processes when blood and dialysate are flowing through the dialyzer. Therefore, the composition of the dialysate is critical for the patient's electrolyte and metabolic homeostasis. Glucose is a main dialysate component, but there exists no general agreement on the optimal level. In the 1960s, prior to the general use of ultrafiltration in dialysis machines, the osmotic forces induced by glucose were used for fluid removal and dialysate glucose concentrations of up to $1600 \mathrm{mg} / \mathrm{dl}$ were used for this reason ${ }^{1}$. After ultrafiltration, which has been firstly incorporated in a dialysis machine by the Swedish scientist Nils Alwall, became a standard feature of dialysis machines, high dialysate glucose concentrations lost importance. The addition of dialysate glucose remained standard of most dialysis providers, due to concerns about hypoglycemia, but the optimal dialysate glucose concentration remained controversial. In the United States a dialysate glucose concentration of $200 \mathrm{mg} / \mathrm{dl}$ (11 mmol/l; G200) became standard until recently. In Europe, the most frequently used glucose concentration is $100 \mathrm{mg} / \mathrm{dl}(5.5 \mathrm{mmol} / \mathrm{l}$; $\mathrm{G} 100$ ), whereas in some countries glucose-free dialysate (G0) is used, mainly due to concerns about bacterial and fungal contamination, and economic considerations.

While several studies on G0 versus $G 200$ and G100, respectively, (1-6) have been reported, data comparing G100 and G200 are scarce ${ }^{1,6}$. In particular, G100 and G200 have never been compared in a randomized controlled trial (RCT).

Additionally, not much information has been reported in recent years on glucose kinetics during HD. There is evidence that glucose-containing dialysate to some degree prevents glucose losses from the patient and thus reduces the risk of intradialytic hypoglycemia ${ }^{2,7,8}$. Diabetic HD patients treated with oral anti-diabetic agents or insulin may be particularly prone to hypoglycemia, because eating during HD is discouraged due to adverse effects on hemodynamic stability ${ }^{9}$. On the other hand, G200 may result in overt intradialytic hyperglycemia and transient hyperinsulinism ${ }^{1,2,10}$.

Since insulin affects serum potassium levels by promoting cellular potassium (K) uptake, hyperinsulinism may thus reduce $\mathrm{K}$ removal by $\mathrm{HD}^{10}$. Hyperinsulinism may also reduce phosphorus $(P)$ removal during HD due to increased cellular $\mathrm{P}$ uptake ${ }^{11}$.

An additional theoretical consideration is the contribution of plasma glucose to plasma osmolality, although this effect may be deemed negligible ${ }^{5}$. However, it can not be entirely excluded that intradialytic hyperglycemia may result in increased thirst after dialysis and higher interdialytic weight gains (IDWG); on the other hand, hyperglycemia may promote fluid shifts from the intracellular to the extracellular compartment and thus stabilizes blood pressure during ultrafiltration.

In order to address the questions outlined above, we embarked on a RCT of G100 and G200 in chronic HD patients. The primary endpoint was mean intradialytic serum glucose level; secondary endpoints included adverse intradialytic events such as 
hypoglycemic or other events requiring intervention as per unit's policy, insulin levels, intradialytic glucose removal or gain, intradialytic $\mathrm{K}$ and $\mathrm{P}$ concentrations, systolic blood pressure (SBP), occurrence of cardiac arrhythmias and IDWG.

\section{Subjects and methods}

\section{Patient selection}

Maintenance HD patients dialyzed thrice weekly on a regular schedule at two dialysis centers of the Renal Research Institute in New York City were included in this singlemasked cross-over RCT (www.clinicaltrials.gov: \#NCT00618033). The study protocol was approved by the Institutional Review Board of Beth Israel Medical Center New York City, New York, USA. Patients signed informed consent prior to enrollment and the study was conducted in full accordance with the Declaration of Helsinki.

Patients were enrolled according to the in- and exclusion criteria (see below) regardless of gender, race and ethnicity. Inclusion criteria were age $\geq 18$ years and HD vintage $>30$ days. Patients receiving HD other than thrice weekly, those with a history of infection, antibiotic treatment or hospitalization during the preceding month were excluded. The enrollment target was 15 diabetic and 15 non-diabetic patients.

Diabetes mellitus was defined by either antidiabetic therapy (oral drugs or insulin), or a random blood glucose $>200 \mathrm{mg} / \mathrm{dl}$ in the preceding 12 months.

\section{Study design}

The study comprised two randomized consecutive 3-week treatment periods (9 HD treatments during each period) with $\mathrm{G} 100$ and G200, respectively (Figure 2.1). Randomization of the treatment sequence was done at the facility level to avoid potential influence of facility practices patterns. Study coordinators assured proper delivery of the allocated treatment regimen. Throughout the entire study patients were masked to dialysate glucose levels. Blinding of study coordinators, technicians, nurses and physicians was not feasible for safety reasons. In order to maintain the singlemasked design dialysate was administered via unlabelled taps or jugs, depending on the facility. Dialyzer type (Fresenius Optiflux F180NR), treatment time, blood and dialysate flow rates, target weights, and medications remained unchanged throughout the entire 6-week study period. No food was provided during the study treatments and subjects were asked to refrain from eating. 


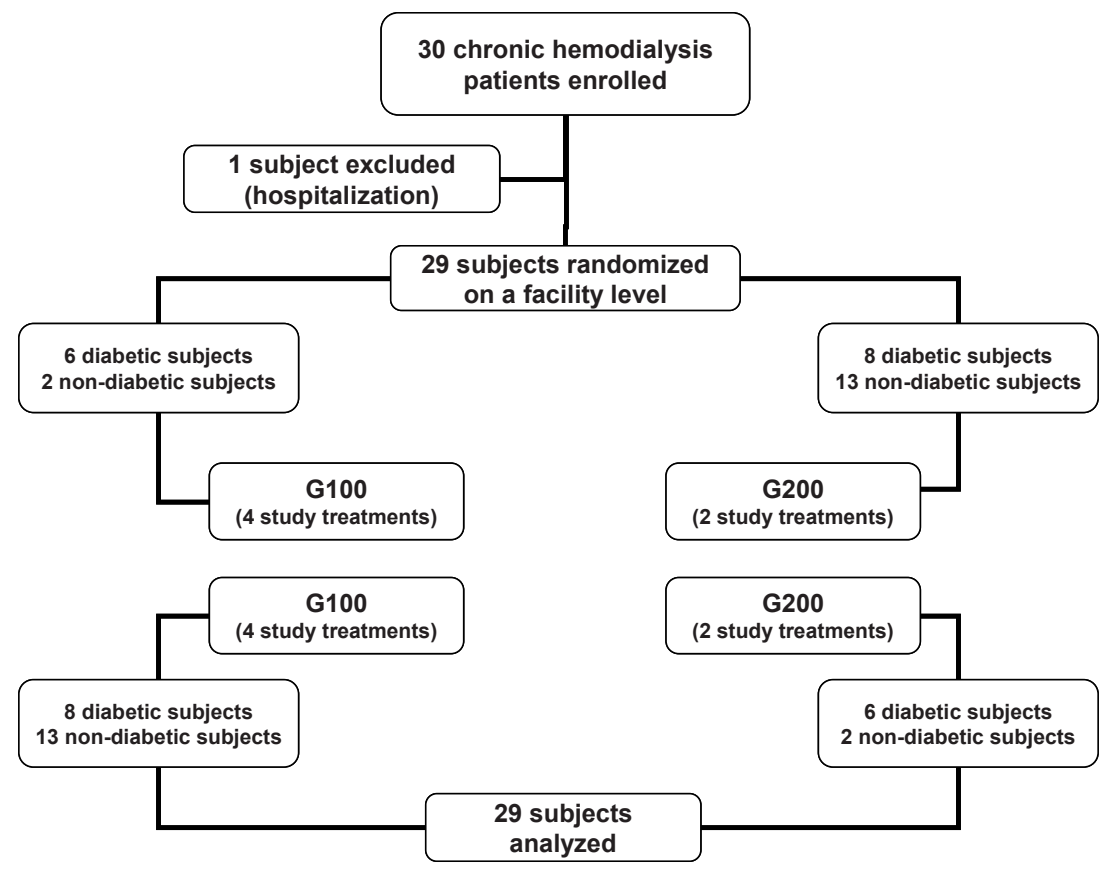

Figure 2.1 Study flow chart.

\section{Measurements}

In the units enrolled in the study no previous experience with G100 existed and G200 was the standard dialysate. Therefore, in order to address concerns about the safety of G100, twice as many study treatments with G100 were scheduled (4 with G100, 2 with G200). Study treatments where blood samples were obtained were scheduled after long and short interdialytic intervals in a 1:1 ratio.

\section{Biochemistry}

Serum glucose and insulin levels were measured at 0, 30, 60, 120, 180 minutes and at the end of HD. Serum potassium and phosphorus were measured at 0,120 minutes and at the end of HD. Glucose, phosphorus and potassium were measured with standard methods using the Olympus AU5400 analyzer (Olympus Diagnostics Systems, Center Valley, PA, USA). Insulin was measured with a chemiluminescent immunoassay implemented on the Advia Centaur (Siemens Healthcare Diagnostics, Deerfield, IL, USA). Hematocrit was estimated from clinical routine measurements of mean erythrocyte cell volume and red blood cell count. All measurements were performed at 
a certified laboratory (Spectra Laboratories; Rockleigh, NJ, USA). Data of serum glucose is reported in conventional units $(\mathrm{mg} / \mathrm{dl})$, for conversion to $\mathrm{SI}$ units $(\mathrm{mmol} / \mathrm{l})$ values have to be multiplied by 0.0555 .

\section{Glucose kinetics}

Mean intradialytic serum glucose and insulin concentrations ( $\mathrm{SG}_{\text {mean }}$; $\mathrm{SI}_{\text {mean }}$ ) were calculated by the respective areas under the curves divided by the duration of the treatment in minutes. The area under the curve was calculated employing a $3^{\text {rd }}$ order polynomial fit of all measured intradialytic serum glucose and insulin concentrations, respectively.

The glucose KoA of the dialyzer for the Fresenius Optiflux F180NR was determined to be $0.749 \mathrm{l} / \mathrm{min}$ as per in-vitro experiments using aqueous solutions and heparinized bovine blood (D. Schneditz, Medical University Graz, Austria, unpublished data). Glucose clearance was calculated as $^{12}$ :

$$
K=\frac{Q_{p} \cdot Q_{d} \cdot(1-f)}{Q_{p}-Q_{d} \cdot f}
$$

where $Q_{p}$ is the effective plasma flow in $1 / \min , Q_{d}$ the dialysate flow in $1 /$ min and

$$
f=e^{K o A} \cdot\left(\frac{1}{Q_{p}}-\frac{1}{Q_{d}}\right),
$$

The plasma flow $\left(Q_{p}\right)$ in $1 /$ min was calculated as:

$$
Q_{p}=Q_{b} \cdot\left(1-\frac{H c t}{100}\right),
$$

where $Q_{b}$ is the average blood flow during the treatment in $1 /$ min and Hct the hematocrit as volume percentage of whole blood.

Per definition, glucose flux into the patient was considered as positive, and out of the patient as negative.

The diffusive glucose mass transfer ( $\left.\mathrm{MT}(\mathrm{t})_{\text {diffusive }}\right)$ in $\mathrm{mg}$ within the time interval between two consecutive blood draws was calculated as follows

$$
\mathrm{MT}(\mathrm{t})_{\text {diffusive }}=\left[\mathrm{K} .\left(\mathrm{G}_{\text {dialysate }}-\mathrm{SG}(\mathrm{t})_{\text {average }}\right)\right] . \mathrm{t},
$$

where $\mathrm{SG}(\mathrm{t})_{\text {avg }}$ is the average plasma water glucose concentration in $\mathrm{mg} / \mathrm{l}$ (plasma concentration corrected for plasma void volume by the factor 0.93 ) during the time 
interval of the duration $t$ in minutes. A positive glucose mass transfer corresponds to a diffuse glucose transfer from the dialysate to the patient. The total intradialytic diffusive glucose mass transfer, MT(total) diffusive, in $\mathrm{mg}$, was calculated as the sum of individual glucose transfers over all time intervals.

The convective glucose mass transfer in mg during the time interval between two consecutive blood draws was calculated as follows

$$
\mathrm{MT}(\mathrm{t})_{\text {convective }}=-\left(\mathrm{UFV}(\mathrm{t}) \cdot \mathrm{SG}(\mathrm{t})_{\text {avg }}\right),
$$

where UFV is the ultrafiltration volume removed, in I, during the time interval $t$, in

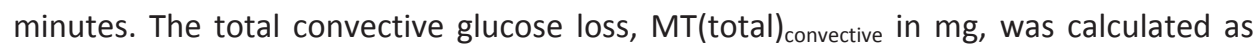
the sum of the individual convective glucose losses over all time intervals.

The total intradialytic, extracorporal glucose mass transfer was calculated as the sum of diffusive and convective mass transfer:

$$
M T=M T(\text { total })_{\text {diffusive }}+M T(\text { total })_{\text {convective }}
$$

\section{Insulin kinetics}

Dialyzer insulin clearance was estimated from insulin's molecular weight: a linear equation was generated (least squares regression) describing solute clearance as a function of the logarithm of the solute's molecular weight. The data used to fit this regression were the in vitro clearances of urea, sodium, creatinine, phosphorus, vitamin $\mathrm{B} 12$, and lysozyme at a solute diffusion volume flow rate of $0.3 \mathrm{l} / \mathrm{min}$ and a dialysate flow rate of $0.5 \mathrm{l} / \mathrm{min}$ (provided by the dialyzer manufacturer) and the logarithms of those solutes' molecular weights. Insulin clearance was estimated using this equation, based on its molecular weight. The insulin mass transfer area coefficient (KoA) was then calculated according to well-established relationships ${ }^{12}$ after correction for plasma void volume using the factor 0.93 .

\section{Other measures}

Intradialytic SBP was recorded at time points 0, 30, 60, 120, 180 and end of HD by an oscillometric method.

Holter recordings were performed after the long interdialytic interval, once each with HD100 and HD200, commencing about ten minutes before HD. ECGs were continuously recorded at a sampling rate of $250 \mathrm{~Hz}$ with a three-lead Holter device (clickholter, Cardioline, HealthFrontier Inc., Branchburg, NJ, USA) for 24 hours. The Holter recordings were analyzed by an ECG analyst blinded to the dialysate.

In diabetic subjects, hypoglycemia was defined as a serum glucose below $70 \mathrm{mg} / \mathrm{dl}^{13}$. 
Intradialytic adverse events and appropriate interventions (such as administration of saline in the event of intradialytic hypotension) were defined and treated as per unit's policy.

Interdialytic weight gain was defined as the difference between pre-HD weight and the preceding post-HD weight.

\section{Statistical analyses}

Normality of data was assessed by the Kolmogorov-Smirnoff Test. Student's T-Test, was employed to compare demographics, treatment characteristics, SBP, ultrafiltration volume, IDWG, mean glucose and insulin concentrations, diffusive and convective glucose mass transfer during HD using G100 and G200. Z-Test was used to test the statistical significance of insulin and glucose transfer. Mann Whitney $U$ Test was used to compare the difference of occurrence of cardiac arrhythmias between G100 and G200. McNemar Change Test was employed to compare the incidence of hypoglycemia and adverse intradialytic events with G100 and G200 on a patient level. In two sensitivity analyses a) diabetic subjects not on antidiabetic medication or insulin and b) treatments where food was ingested in the very beginning of the HD treatment, were excluded. A p-value $<0.05$ was considered statistically significant for all tests. All statistical analyses were done with SPSS 17.0 (SPSS Inc., Chicago, IL, USA).

\section{Results}

Thirty patients (15 diabetic and 15 non-diabetic subjects) were enrolled during the period from April to June 2008. One subject had to be withdrawn prior to randomization due to hospitalization (Figure 2.1). Twenty-nine subjects underwent 551 study treatments in total, 286 with $\mathrm{G} 200$ and 264 with G100, respectively. Demographics are shown in Table 2.1, dialysis treatment parameters in Table 2.2. 
Table 2.1 Demographics of study cohort. Data reported as mean \pm standard deviation. No statistically significant differences between G100 and G200 have been found.

\begin{tabular}{lccc}
\hline & $\begin{array}{c}\text { all } \\
\text { subjects }\end{array}$ & $\begin{array}{c}\text { diabetic } \\
\text { subjects }\end{array}$ & $\begin{array}{c}\text { non-diabetic } \\
\text { subjects }\end{array}$ \\
\hline $\mathrm{n}$ [count] & 29 & 14 & 15 \\
age [years] & $54 \pm 13$ & $59 \pm 12$ & $49 \pm 11$ \\
gender $(\mathrm{m} / \mathrm{f})$ & $15 / 14$ & $6 / 8$ & $9 / 6$ \\
race (black/non-black) & $16 / 13$ & $8 / 6$ & $6 / 9$ \\
dialysis vintage [years] & $5 \pm 4$ & $3 \pm 3$ & $6 \pm 5$ \\
height [cm] & $167 \pm 10$ & $164 \pm 11$ & $170 \pm 10$ \\
post HD weight $[\mathrm{kg}]$ & $81 \pm 19$ & $78 \pm 19$ & $84 \pm 20$ \\
post HD body mass index $\left[\mathrm{kg} / \mathrm{m}^{2}\right.$ ] & $28 \pm 7$ & $28 \pm 6$ & $28 \pm 7$ \\
beta blocker $\left(\beta_{1}\right.$-selective / $\alpha_{1}-\beta_{1}$ selective) & $6 / 8$ & $3 / 5$ & $3 / 3$ \\
antihypertensive drugs (ACE inhibitors/ ARB / CCB) & $4 / 4 / 13$ & $2 / 4 / 8$ & $2 / 0 / 5$ \\
type of diabetes (Type $1 / \mathrm{Type} 2$ ) & $1 / 13$ & $1 / 13$ & $\mathrm{n} . \mathrm{a}$. \\
diabetes-related medication (insulin/oral antidiabetic drugs) & $9 / 3$ & $9 / 3$ & n.a. \\
\hline
\end{tabular}

ACE (angiotensin converting enzyme); ARB (angiotensin receptor blocker); CCB (calcium channel blocker); n.s. (not significant); n.a. (not applicable).

Table 2.2 Hemodialysis (HD) treatment parameters. Data reported as mean \pm standard deviation. Values marked with * were only assessed on days where blood draws where conducted (G100: 104 treatments; G200: 56 treatments). No statistically significant differences between G100 and G200 have been found.

\begin{tabular}{|c|c|c|c|c|}
\hline & \multicolumn{2}{|c|}{$\begin{array}{c}\text { diabetic subjects } \\
(n=14)\end{array}$} & \multicolumn{2}{|c|}{$\begin{array}{l}\text { non-diabetic subjects } \\
\qquad(\mathrm{n}=15)\end{array}$} \\
\hline & G100 & G200 & G100 & G200 \\
\hline treatments [count] & 126 & 138 & 138 & 148 \\
\hline treatment time [min] & $207 \pm 31$ & $210 \pm 33$ & $213 \pm 25$ & $214 \pm 21$ \\
\hline dialysate $\mathrm{Na}^{+}$concentration $[\mathrm{mmol} / \mathrm{l}]$ & 138 & 138 & 138 & 138 \\
\hline dialysate $\mathrm{K}^{+}$concentration [mmol/l] [2 / 3] & $13 / 1$ & $13 / 1$ & $14 / 1$ & $14 / 1$ \\
\hline dialysate $\mathrm{Ca}^{++}$concentration $[\mathrm{mmol} /](1.125$ / 1.5) & $14 / 0$ & $14 / 0$ & $14 / 1$ & $14 / 1$ \\
\hline dialysate temperature $\left[{ }^{\circ} \mathrm{Celsius}\right]$ & 37 & 37 & 37 & 37 \\
\hline blood flow $[\mathrm{ml} / \mathrm{min}]^{*}$ & $401 \pm 13$ & $408 \pm 28$ & $396 \pm 32$ & $399 \pm 21$ \\
\hline Hematocrit [\%]* & $36 \pm 4$ & $35 \pm 3$ & $35 \pm 3$ & $36 \pm 4$ \\
\hline plasma flow $[\mathrm{ml} / \mathrm{min}] *$ & $259 \pm 21$ & $265 \pm 24$ & $257 \pm 23$ & $256 \pm 20$ \\
\hline urea kinetic volume [l] & $34 \pm 6$ & $34 \pm 6$ & $36 \pm 7$ & $36 \pm 7$ \\
\hline interdialytic weight gain [kg] & $2.3 \pm 0.9$ & $2.3 \pm 1.0$ & $2.3 \pm 1.3$ & $2.4 \pm 1.1$ \\
\hline Weight change during HD & $2.3 \pm 1.0$ & $2.3 \pm 1.2$ & $2.4 \pm 0.8$ & $2.9 \pm 2.1$ \\
\hline \multicolumn{5}{|l|}{ (pre HD weight - post HD weight) [kg] } \\
\hline intradialytic saline administration [count] & 21 & 24 & 25 & 26 \\
\hline $\begin{array}{l}\text { Reasons for saline administration (hypotension / } \\
\text { Cramps / access / reason not specified) }\end{array}$ & $6 / 7 / 2 / 6$ & $6 / 4 / 4 / 10$ & $5 / 1 / 7 / 9$ & $7 / 5 / 5 / 8$ \\
\hline Pre HD serum glucose $[\mathrm{mg} / \mathrm{d}]^{*}$ & $176.9 \pm 49.1$ & $189.7 \pm 114.0$ & $109.6 \pm 17.3$ & $112.7 \pm 24.7$ \\
\hline Pre HD serum insulin [mU/I]* & $45.6 \pm 24.6$ & $44.5 \pm 28.4$ & $35.4 \pm 27.2$ & $41.3 \pm 31.0$ \\
\hline
\end{tabular}

Data of serum glucose are reported in conventional units $(\mathrm{mg} / \mathrm{dl})$, for conversion to SI units (mmol/l) values have to be multiplied by 0.0555 . 


\section{Biochemistry}

\section{Serum glucose (SG) and insulin (SI)}

$\mathrm{SG}_{\text {mean }}$ was significantly higher with $\mathrm{G} 200(\mathrm{n}=56)$ compared to $\mathrm{G} 100(\mathrm{n}=104)$ (Table 2.3) in diabetic (G100: $154.0 \pm 27.3 \mathrm{mg} / \mathrm{dl} ; \mathrm{G} 200: 192.8 \pm 48.1 \mathrm{mg} / \mathrm{dl} ; \mathrm{P}<0.001$ ) and nondiabetic (G100: $106.5 \pm 10.8 \mathrm{mg} / \mathrm{dl} ; \mathrm{G} 200: 127.0 \pm 16.8 \mathrm{mg} / \mathrm{dl} ; P<0.001$ ) subjects. At the beginning of HD, SG did not differ between G100 and G200 in either group (Table 2.2). By 30 minutes, both diabetic and non-diabetic subjects showed significantly higher plasma glucose concentrations during dialyses using G200. This difference was significant throughout the whole treatment in both groups (Figure 2.2). $\mathrm{SI}_{\text {mean }}$ were significantly higher in non-diabetic subjects during G200 treatments (G100: $33.4 \pm 12.6 \mathrm{mU} / \mathrm{l} ; \mathrm{G} 200$ : $50.5 \pm 40.3 \mathrm{mU} / \mathrm{l} ; \quad P<0.05)$. Non-diabetic subjects showed significantly higher mean insulin levels at 30 minutes. In contrast diabetic subjects did not show significant differences of $\mathrm{SI}_{\text {mean }}$ between $\mathrm{G} 100$ and $\mathrm{G} 200$, a finding which was consistent throughout the entire treatment (Figure 2.3).

In subjects with diabetes, hypoglycemia was observed none of the treatments with $\mathrm{G} 200$, and in 4 treatments with $\mathrm{G} 100(P=0.13)$.

\section{Glucose mass transfer}

Diabetic subjects gained on average $1.4 \pm 27.1 \mathrm{~g}$ of glucose during HD using G200, and lost $34.8 \pm 16.0 \mathrm{~g}$ of glucose when using G100. In contrast non-diabetic subjects gained 24.8 $\pm 7.2 \mathrm{~g}$ using G200, and lost 7.9 $\pm 6.2 \mathrm{~g}$ using G100 (Table 2.3).

\section{Insulin mass transfer}

Based on information provided by the manufacturer the KoA of insulin was estimated to be $0.165 \mathrm{l} / \mathrm{min}$ in average, which translates into an insulin clearance between 0.103 and $0.122 \mathrm{l} / \mathrm{min}$, depending on the individual blood and dialysate flow rates. The estimated insulin clearances allowed us to calculate the intradialytic insulin removal in the 14 diabetic (G200: $0.9 \pm 0.4$ IU; G100: 0.9 \pm 0.4 IU per treatment, n.s.) and 15 nondiabetic subjects (G200: $1.5 \pm 0.9 \mathrm{IU}$; G100: $1.0 \pm 0.5 \mathrm{IU}$ per treatment, n.s.).

\section{Potassium/Phosphorus}

Mean serum potassium levels did not show substantial differences between G100 and G200 at any time point (Table 2.4). In diabetic subjects $P$ concentration at the end of HD was slightly lower with G100 (G100: 1.9 \pm 0.4 ; G200: $2.1 \pm 0.3 \mathrm{mg} / \mathrm{dl} ; P<0.05$ ) (Table 2.5). In non-diabetic subjects early decline in $P$ was more pronounced with $G 100$. 
Table 2.3 Diffusive and convective (MTdiff, MTconv), total mass transfer and mean serum glucose (SGmean) during hemodialyses using 100 (G100) and 200 (G200) mg/dl dialysate glucose concentrations (G100: 104 treatments; G200: 56 treatments). ${ }^{*} \mathrm{P}<0.05$.

\begin{tabular}{lcccc}
\hline & $\mathbf{S G}_{\text {mean }}[\mathrm{mg} / \mathrm{dl}\}$ & $\mathbf{M T}_{\text {diff }}$ [g] & $\mathbf{M T}_{\text {conv }}[\mathrm{g}]$ & $\begin{array}{c}\text { total mass } \\
\text { transfer [g] }\end{array}$ \\
\hline $\begin{array}{l}\text { Diabetic subjects } \\
\text { G100 }\end{array}$ & $154.0 \pm 27.3$ & $-30.1 \pm 14.7$ & $-4.7 \pm 1.7$ & $-34.8 \pm 16.0$ \\
G200 & $192.8 \pm 48.1$ & $-11.6 \pm 25.8$ & $-4.9 \pm 1.8$ & $1.4 \pm 27.1$ \\
Difference G100 - G200 (95\% Cl) & -38.8 & -25.2 & 1.9 & -23.2 \\
& $(-56.4 \text { to }-21.2)^{*}$ & $(-32.5 \text { to }-17.9)^{*}$ & $(1.0 \text { to } 2.9)^{*}$ & $(-31.2 \text { to }-15.2)^{*}$ \\
Non-diabetic subjects & $106.5 \pm 10.8$ & $-5.0 \pm 5.9$ & $-2.9 \pm 0.8$ & $-7.9 \pm 6.2$ \\
G100 & $127.0 \pm 11.2$ & $28.5 \pm 7.0$ & $-3.8 \pm 0.8$ & $24.8 \pm 7.2$ \\
G200 & -20.6 & -33.5 & 0.8 & -32.7 \\
Difference G100 - G200 (95\% Cl) & $(-25.9 \text { to }-15.3)^{*}$ & $(-37.6 \text { to }-28.2)^{*}$ & $(0.2 \text { to } 1.5)^{*}$ & $(-37.2 \text { to }-28.2)^{*}$ \\
\hline
\end{tabular}

Data of serum glucose are reported in conventional units $(\mathrm{mg} / \mathrm{dl})$, for conversion to SI units (mmol/l) values have to be multiplied by 0.0555 .

Table 2.4 Serum potassium $\left(\mathrm{K}^{+}\right)$concentrations in diabetic and non-diabetic patients at the beginning, after 120 minutes and at the end the end of hemodialysis (HD), and the temporal changes during the course of hemodialyses (HD) treatments using 100 (G100) and $200 \mathrm{mg} / \mathrm{dl}$ (G200) dialysate glucose (G100: 104 treatments; G200: 56 treatments). No statistically significant differences between $\mathrm{G} 100$ and $\mathrm{G} 200$ have been found.

\begin{tabular}{|c|c|c|c|}
\hline & pre HD K ${ }^{+}$ & $\mathrm{K}_{120 \min }^{+}$ & $\mathrm{K}^{+}$end $\mathrm{HD}$ \\
\hline \multicolumn{4}{|l|}{ Diabetic subjects } \\
\hline G100 & $4.8 \pm 0.4$ & $3.6 \pm 0.5$ & $3.5 \pm 0.2$ \\
\hline G200 & $5.2 \pm 0.9$ & $3.7 \pm 0.4$ & $3.5 \pm 0.2$ \\
\hline Difference G100 - G200 (95\% Cl) & $-0.4(-1.0$ to 0.2$)$ & $-0.1(-0.3$ to 0.1$)$ & $0(-0.1$ to 0.2$)$ \\
\hline \multicolumn{4}{|l|}{ Non-diabetic subjects } \\
\hline G100 & $4.9 \pm 0.5$ & $3.5 \pm 0.5$ & $3.6 \pm 0.3$ \\
\hline G200 & $4.8 \pm 0.4$ & $3.5 \pm 0.4$ & $3.3 \pm 0.4$ \\
\hline Difference G100 - G200 (95\% Cl) & $0.1(-0.1$ to 0.3$)$ & $0(-0.2$ to 0.2$)$ & $0.3(-0.1$ to 0.7$)$ \\
\hline
\end{tabular}

Table 2.5 Serum phosphorus (P) concentrations in diabetic and non-diabetic patients at the beginning, after 120 minutes and at the end and the temporal changes during the course of hemodialyses (HD) treatments using 100 (G100) and $200 \mathrm{mg} / \mathrm{dl}$ (G200) dialysate glucose concentrations (G100: 104 treatments; G200: 56 treatments). ${ }^{*} P<0.05$.

\begin{tabular}{lccc}
\hline & pre HD P & $\mathbf{P}_{\mathbf{1 2 0} \text { min }}$ & $\mathbf{P}_{\text {end HD }}$ \\
\hline Diabetic subjects & & & \\
G100 & $4.9 \pm 0.9$ & $2.3 \pm 0.3$ & $1.9 \pm 0.4$ \\
G200 & $5.2 \pm 0.8$ & $2.4 \pm 0.3$ & $2.1 \pm 0.3$ \\
$\quad$ Difference G100 - G200 (95\% Cl) & $-0.3(-0.9$ to 0.3$)$ & $-0.1(-0.3$ to 0$)$ & $-0.2(-0.3 \text { to }-0.1)^{*}$ \\
Non-diabetic subjects & & & \\
G100 & $5.9 \pm 0.8$ & $2.6 \pm 0.6$ & $2.5 \pm 0.4$ \\
G200 & $5.5 \pm 1.2$ & $2.6 \pm 0.4$ & $2.2 \pm 0.4$ \\
Difference G100 - G200 $(95 \% \mathrm{Cl})$ & $0.4(0.0$ to 0.7$)$ & $0(-0.2$ to 0.2$)$ & $0.4(0.0$ to 0.7$)$ \\
\hline
\end{tabular}


A

Diabetic subjects

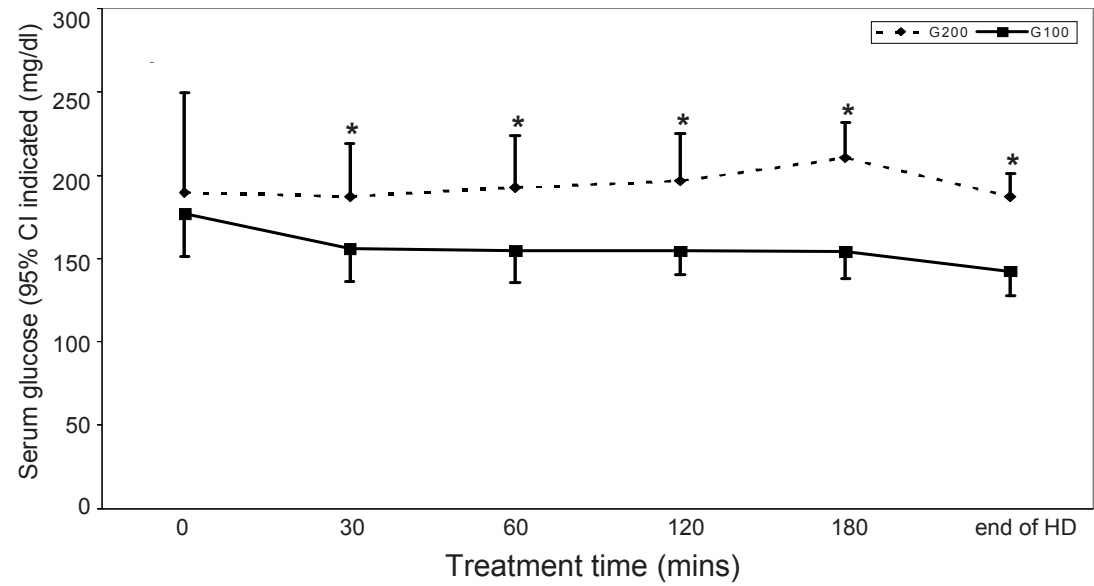

B

Non-diabetic subjects

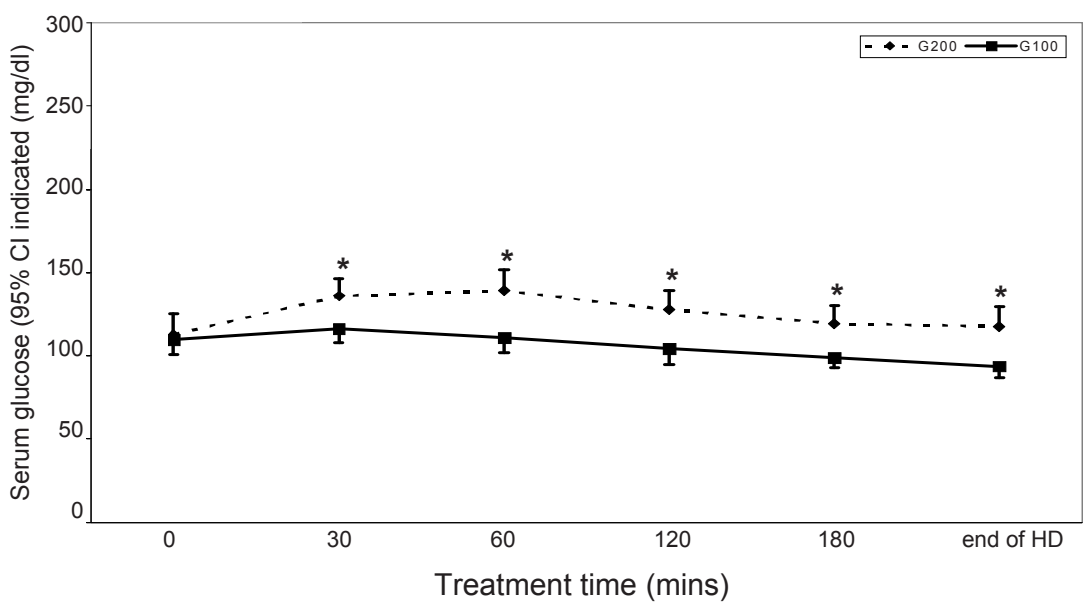

Figure 2.2 Serum glucose concentrations during hemodialyses using dialysate glucose concentrations of 100 (G100, depicted as circles connected with a full line) and $200 \mathrm{mg} / \mathrm{dl}$ (G200, depicted as rhomboids connected with a dashed line) in a) diabetic ( $n=14$, on the left) and b) non-diabetic subjects ( $n=15$, on the right). Data of serum glucose is reported in conventional units $(\mathrm{mg} / \mathrm{dl})$, for conversion to $\mathrm{SI}$ units $(\mathrm{mmol} / \mathrm{l})$ values have to be multiplied by 0.0555 . ${ }^{*} P<0.05$. 
A

Diabetic subjects

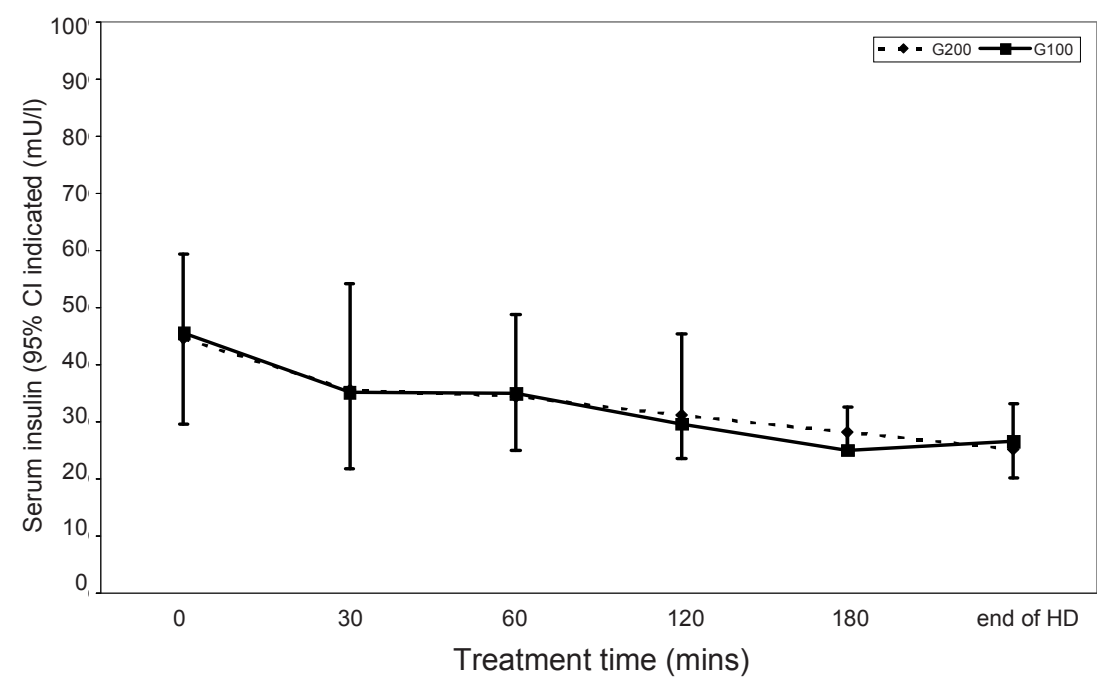

B

Non-diabetic subjects

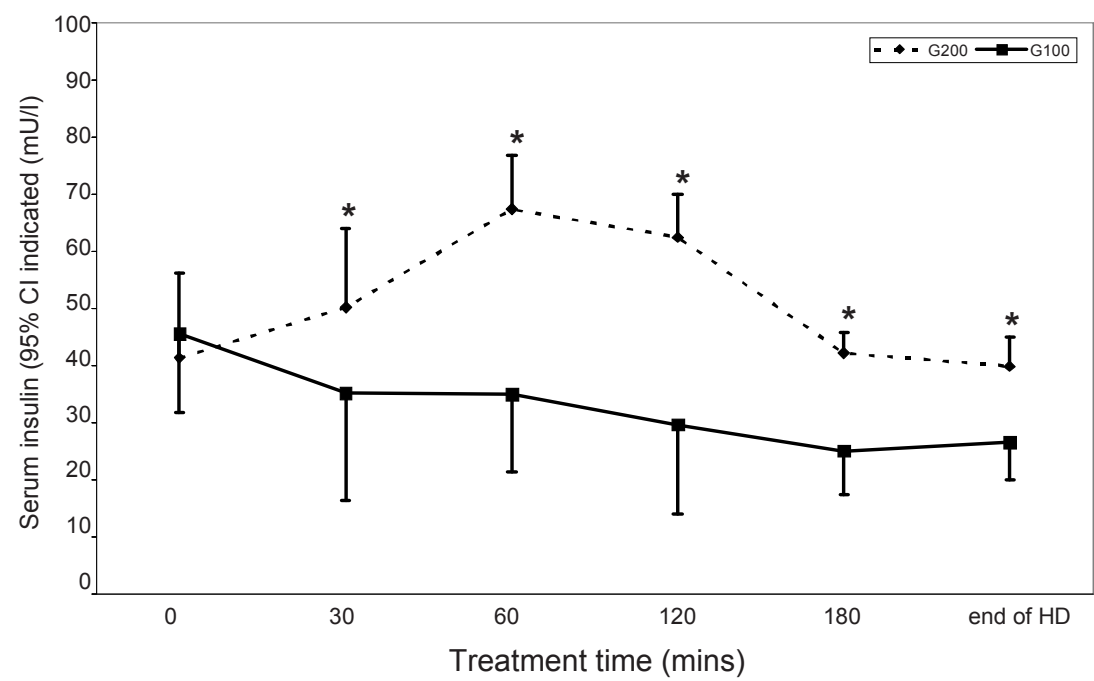

Figure 2.3 Serum insulin concentrations during hemodialyses using dialysate glucose concentrations of 100 (G100, depicted as circles connected with a full line) and $200 \mathrm{mg} / \mathrm{dl}$ (G200, depicted as rhomboids connected with a dashed line) in a) diabetic ( $n=14$, on the left) and b) non-diabetic subjects ( $\mathrm{n}=15$, on the right). ${ }^{*} P<0.05$. 
A

Diabetic subjects

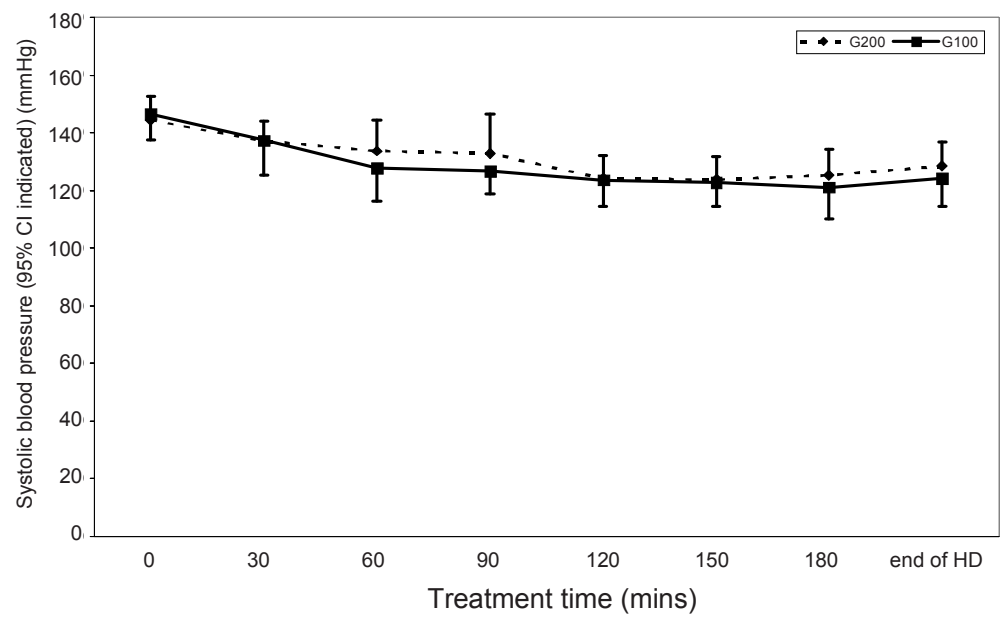

B

Non-diabetic subjects

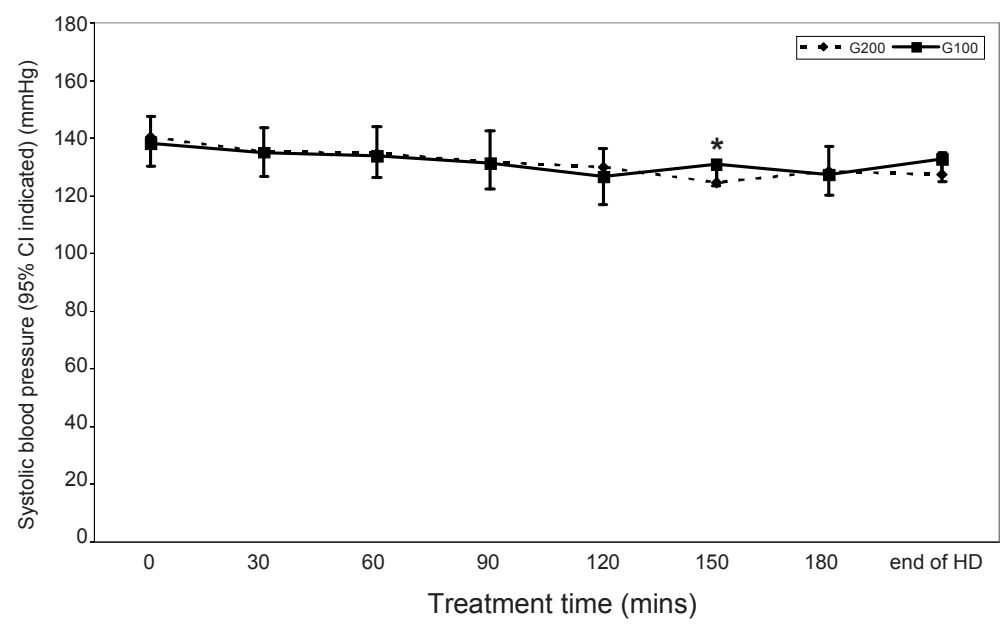

Figure 2.4 Systolic blood pressures (SBP) during hemodialyses using dialysate glucose concentrations of 100 (G100, depicted as rhomboids connected with a full line) and $200 \mathrm{mg} / \mathrm{dl}$ (G200, depicted as circles connected with a dashed line) in a) diabetic ( $n=14$, on the left side) and $b$ ) non-diabetic subjects ( $\mathrm{n}=15$, on the right side). ${ }^{*} P<0.05$.

\section{IDWG, SBP, Holter recordings and adverse events}

SBP (Figure 2.4; Table 2.6) and intradialytic adverse events did not differ significantly between G100 and G200 (Table 2.2). IDWG was not affected by dialysate glucose. Cardiac arrhythmias (supraventricular and ventricular tachycardia, ventricular extrasystolic beats) did not differ between G100 and G200. 
Table 2.6 Systolic blood pressures (SBP) in diabetic and non-diabetic subjects during the course of hemodialysis (HD) treatments where blood samples were obtained, using dialysate with 100 (G100) and $200 \mathrm{mg} / \mathrm{dl}$ (G200) of glucose (G100: 104 treatments; G200: 56 treatments). No statistically significant differences between $\mathrm{G} 100$ and $\mathrm{G} 200$ have been found.

\begin{tabular}{|c|c|c|c|c|c|c|}
\hline & SBP $_{\text {pre HD }}$ & $\mathrm{SBP}_{30 \mathrm{~min}}$ & $\mathrm{SBP}_{60 \mathrm{~min}}$ & $\mathrm{SBP}_{120 \mathrm{~min}}$ & $\mathrm{SBP}_{180 \mathrm{~min}}$ & $\mathrm{SBP}_{\text {end HD }}$ \\
\hline \multicolumn{7}{|l|}{ Diabetic subjects } \\
\hline G100 SBP(t) & $146 \pm 17$ & $137 \pm 23$ & $128 \pm 22$ & $124 \pm 17$ & $121 \pm 19$ & $124 \pm 19$ \\
\hline G200 SBP(t) & $144 \pm 16$ & $137 \pm 13$ & $134 \pm 20$ & $124 \pm 15$ & $125 \pm 17$ & $128 \pm 16$ \\
\hline $\begin{array}{l}\text { Difference } \\
\text { G100-G200 (95\% CI) }\end{array}$ & $2(-6$ to 10$)$ & $0(-8$ to 9$)$ & $-6(-17$ to 5$)$ & $0(-9$ to 8$)$ & $-3(-11$ to 5$)$ & $-4(-13$ to 5$)$ \\
\hline \multicolumn{7}{|l|}{ Non-diabetic subjects } \\
\hline G100 SBP(t) & $138 \pm 15$ & $135 \pm 16$ & $133 \pm 15$ & $126 \pm 19$ & $127 \pm 14$ & $132 \pm 15$ \\
\hline G200 SBP(t) & $140 \pm 14$ & $135 \pm 17$ & $135 \pm 18$ & $130 \pm 12$ & $129 \pm 15$ & $127 \pm 15$ \\
\hline $\begin{array}{l}\text { Difference } \\
\text { G100-G200 (95\% Cl) }\end{array}$ & $-2(-7$ to 3$)$ & $0(-7$ to 7$)$ & $-1(-7$ to 5$)$ & $-3(-11$ to 5$)$ & $-10(-31$ to 12$)$ & $8(-2$ to 19$)$ \\
\hline
\end{tabular}

\section{Sensitivity analysis}

Exclusion of a) patients not receiving insulin and/or antidiabetic medication $(n=2)$ and b) treatments where food was ingested in the very beginning of the HD treatment (G100: 23 treatments, G200: 14 treatments), did not alter the results materially (data not shown).

\section{Discussion}

To the best of our knowledge this is the first RCT to compare the metabolic effects of G200 and G100 during dialysis. The main findings are significantly lower glucose shifts from the dialysate to the subject's blood with the use of G100, and correspondingly lower SG and SI levels without effects on hemodynamic stability, and without the occurrence of symptomatic hypoglycemic events.

The interpretation of the intradialytic glucose and insulin levels has to consider the insulin removal via the dialyzer ${ }^{14,15}$ and also a large variability of SG and SI levels between the studied subjects. It has been proposed recently, that insulin removal is mainly due to adsorption and not due to dialysis ${ }^{16}$. If this is correct our insulin removal estimate may be to some extent inaccurate. Notwithstanding these considerations, insulin removal by the dialyzer is likely to result in an increased insulin secretion in nondiabetic subjects. The basal insulin secretion rate ranges from 15 to $18 \mathrm{mU} / \mathrm{min}$ in healthy subjects ${ }^{17}$, which translates to approximately 3.5 to $4.5 \mathrm{IU}$ over the course of a HD treatment. Insulin secretion can be increased up to a total of $1.4 \mathrm{IU}$ per $12.5 \mathrm{~g}$ of ingested glucose in healthy subjects ${ }^{17}$. Insulin removal via the dialyzer in tandem with failure to adequately increase insulin secretion despite the presence of hyperglycemia may contribute to the steady intradialytic decline of insulin levels observed in diabetic subjects (Figure 2.2 and Figure 2.3). The absence of significant differences in insulin 
concentrations between $\mathrm{G} 100$ and G200, despite significant differences in glucose concentrations, may indicate impaired insulin secretion. To what extent the uremic milieu affects insulin secretion and contributes to defective beta cell function, as suggested by several authors ${ }^{18,19}$, warrants future studies.

Average serum glucose levels over the course of HD were significantly higher with G200 as compared to $\mathrm{G} 100$ (Figure 2.2). This is readily explained by a larger glucose gradient between dialysate and blood, which results in a diffusive flux of glucose into the patient (Table 2.3). In diabetic subjects this resulted in a glucose mass transfer in the range of $159 \mathrm{~g}$ to $22 \mathrm{~g}$ [ -636 to 88 calories] with G200 and -158 to $-4 \mathrm{~g}$ [-632 to -16 calories] with G100. In non-diabetic subjects, glucose mass transfer ranged from 1 to $37 \mathrm{~g}$ [4 to 148 calories] with $\mathrm{G} 200$ and $-14 \mathrm{~g}$ to $10 \mathrm{~g}$ [-56 to 40 calories] with G100. Burmeister reported an average glucose removal of $16.7 \mathrm{~g}$ [66.8 calories] per hour with G0 and $5.2 \mathrm{~g}$ [20.8 calories] per hour with G90 in diabetic and non-diabetic patients. Ward et al. reported a total intradialytic glucose gain with G200 between 18.2 and $20.6 \mathrm{~g}$ [72.8 to 82.4 calories] in diabetic and non-diabetic patients. In contrast, total glucose removal with G0 was between 27.7 and $29.3 \mathrm{~g}$ [110.8 to 117.2 calories] in diabetic and nondiabetic patients ${ }^{2,10}$. These results show the importance of considering adequate dialysate glucose concentration to avoid either glucose loading or excessive losses. In addition it is important to note that this amount of glucose enters the circulation intravenously and may not adequately induce physiological reactions, such as insulin section stimulated by gastric and/or duodenal hormones (e.g. GLP-1), as compared to oral ingestion. As a consequence of blunted insulin secretion glucose remains at higher concentrations for a longer time in the circulation, which may result in more pronounced adverse effects.

Malnutrition is prevalent in a high percentage of chronic HD patients and it has been suggested that dialysate glucose could serve as a means to improve nutritional status ${ }^{20}$. It is conceivable that highly malnourished patients may have potential benefit from the intradialytic glucose influx with G200. Nevertheless, given the discouraging results with hypercaloric intradialytic parenteral nutrition ${ }^{21}$, we deem it unlikely that $\mathrm{G} 200$ would result in improved nutritional status and result in better outcomes.

Glucose mass transfer was estimated based on glucose KoA determined for the specific polysulfone high-flux dialyzer used in our study (Fresenius Optiflux F180NR).

For the calculation of glucose mass transfer, the glucose levels between two consecutive time points were interpolated by a linear function to calculate the mean glucose gradient in a given time interval. The glucose concentration between two measurements may not necessarily follow a linear function. For a more detailed understanding of intradialytic glucose and insulin kinetics, future studies may employ shorter sampling intervals and may also be validated by estimations by kinetic modeling by direct dialysis quantification (DDQ). 
Postdialytic potassium and phosphorus concentrations did not differ substantially between G100 and G200, irrespective of diabetes status (Table 2.4 and Table 2.5). This may be due to transient hyperinsulinism, which is known to cause shifts of potassium and phosphorus in the intracellular compartment. To refute the notion that G200 may result in reduced dialytic $\mathrm{K}$ and $\mathrm{P}$ removal future studies, adjusting concentrations and the resulting gradients for plasma void volume, are needed. The intradialytic change in phosphorus levels was slightly lower in diabetic subjects with G200, a finding of potential clinical significance requiring further research and validation by DDQ.

Hypoglycemia has been a major concern with the use of G100 instead of G200. Our study showed no significantly different frequency of hypoglycemia with G100. All hypoglycemic episodes were asymptomatic.

Differences in activation of the autonomic nervous system during dialysis using G100 and $\mathrm{G} 200$ have been recently reported ${ }^{22}$. This and theoretical considerations of differences in osmolality raised concern for more intradialytic events, in particular hypotension. Our clinical results indicate no difference in SBP, intradialytic adverse events, or saline use between G100 and G200 (Figure 2.4; Table 2.2 and Table 2.6). No difference in the occurrence of cardiac arrhythmias, which may have been caused by temporary shifts of $\mathrm{K}$ between the intra- and extracellular compartment, were found between both concentrations.

Hyperinsulinism as a result of G200 deserves consideration because it may induce proinflammatory cytokines and promote insulin resistance (e.g. via ras-related-associatedwith-diabetes-gene (RRAD), serum/glucocorticoid-regulated kinase (SGK)). Of note hyperinsulinism as short as 4 hours has been shown to induce these effects ${ }^{23}$. Other adverse effects of hyperglycemia are its associated cardiovascular risks ${ }^{24-26}$, and prothrombotic $^{27,28}$ and pro-inflammatory effects ${ }^{29,30}$. It may be noted at this point that other studies have shown anti-inflammatory effects of insulin infusions in hospital settings $^{31,32}$ and during the course of HD treatments ${ }^{33}$. However, this requires additional research and had not been subject of this investigation.

Limitations are the small sample size, which is of particular importance in the analysis of the few hypoglycemic events, and the short study duration. Furthermore, the exact doses and the timing of the intake of insulin and antidiabetic medication are unknown. However, since patients were blinded to the dialysate glucose concentration, it is unlikely that doses of insulin and oral antidiabetic drugs were changed systematically. In addition, sensitivity analysis showed no influence of antidiabetic therapy on the results. It also needs to be noted that this study was not designed and not powered to test for differences in hypoglycemia between $\mathrm{G} 100$ and G200, and future adequately powered studies, also investigating hard outcomes such as hospitalization and survival, are warranted, including adjustments of antidiabetic therapy with lower dialysate glucose levels, both in patients with oral antidiabetic drugs and insulin therapy. Trials, 
studying hard endpoints could also help to answer the important question of the optimal dialysate glucose concentration.

Measurements of triglycerides were not available in this study and may be considered in future projects. It may also be noted that it was not captured when the last meal prior to HD was ingested. However, in regard of subjects being blinded to dialysate they received, this is unlikely to be of significance when comparing both periods. Furthermore sensitivity analysis excluding treatments where patients ingested food in the very beginning of dialysis did also not alter the results of the study. Finally, the mean age of the study population ( $54 \pm 13$ years) was substantially lower than that of the general US HD population $(61.3 \pm 15 \text { years })^{34}$; in addition study subjects were only recruited in two different urban dialysis clinics in New York City, all of which may potentially affect the external validity of this study. However, these limitations are in part outweighed by the randomized cross-over design and the paired analysis. In particular the paired fashioned analysis and the comparison of two consecutive midterm study periods without intraindividual variability by virtually unchanged dialysis and medications prescriptions are major strengths of this study.

To our knowledge this is the first study comparing the metabolic effects of $\mathrm{G} 200$ versus G100 in a randomized, prospective cross-over trial. In this short-term study HD with G100 reveals a more favourable metabolic profile both in patients with and without diabetes mellitus as compared to G200. Adverse events (intradialytic hypotension and hypoglycemia) did not differ between the two dialysate glucose concentrations. Larger trials are necessary to further address the potential association of hypoglycemia and G100 and to investigate the effects on hard outcomes such as hospitalizations and survival. 


\section{References}

1. Sharma R and Rosner $\mathrm{MH}$ : Glucose in the dialysate: historical perspective and possible implications? Hemodial Int 2008;12:221-6.

2. Burmeister JE, Scapini A, da Rosa Miltersteiner D, da Costa MG and Campos BM: Glucose-added dialysis fluid prevents asymptomatic hypoglycaemia in regular haemodialysis. Nephrol Dial Transplant 2007;22: 1184-9.

3. Fischbach M, Terzic J, Bitoun Cohen C, et al.: Glucose-charged dialysate for children on hemodialysis: acute dialytic changes. Pediatr Nephrol 1998;12:60-2.

4. Gutierrez A, Bergstrom J and Alvestrand A: Hemodialysis-associated protein catabolism with and without glucose in the dialysis fluid. Kidney Int 1994;46:814-22.

5. Ramirez G, Bercaw BL, Butcher DE, Mathis HL, Brueggemeyer C and Newton JL: The role of glucose in hemodialysis: the effects of glucose-free dialysate. Am J Kidney Dis 1986;7:413-20.

6. Simic-Ogrizovic S, Backus G, Mayer A, Vienken J, Djukanovic L and Kleophas W: The influence of different glucose concentrations in haemodialysis solutions on metabolism and blood pressure stability in diabetic patients. Int J Artif Organs 2001;24:863-9.

7. Jackson MA, Holland MR, Nicholas J, Lodwick R, Forster D and Macdonald IA: Hemodialysis-induced hypoglycemia in diabetic patients. Clin Nephrol 2000;54:30-4.

8. Jackson MA, Holland MR, Nicholas J, et al.: Occult hypoglycemia caused by hemodialysis. Clin Nephrol 1999;51:242-7.

9. Kooman J, Basci A, Pizzarelli F, et al.: EBPG guideline on haemodynamic instability. Nephrol Dial Transplant 2007;22 Suppl 2:ii22-44.

10. Ward RA, Wathen RL, Williams TE and Harding GB: Hemodialysate composition and intradialytic metabolic, acid-base and potassium changes. Kidney Int 1987;32:129-35.

11. Kemp GJ, Land JM, Coppack SW and Frayn KN: Skeletal muscle phosphate uptake during euglycemichyperinsulinemic clamp. Clin Chem 1993;39:170-1.

12. Michaels AS: Operating parameters and performance criteria for hemodialyzers and other membraneseparation devices. Trans Am Soc Artif Intern Organs 1966;12:387-92.

13. Workgroup on Hypoglycemia, American Diabetes Association. Defining and reporting hypoglycemia in diabetes: a report from the American Diabetes Association Workgroup on Hypoglycemia. Diabetes Care 2005;28:1245-9.

14. Schneditz D, Hafner-Giessauf H, Thomaseth K, Bachler I, Obermayer-Pietsch B and Holzer H: Insulinogenic index in non-diabetics during haemodialysis. Nephrol Dial Transplant 2010;25:3365-72.

15. Abe M, Kikuchi F, Kaizu K and Matsumoto K: The influence of hemodialysis membranes on the plasma insulin level of diabetic patients on maintenance hemodialysis. Clin Nephrol 2008;69:354-60.

16. Abe M, Okada K, Ikeda K, Matsumoto S, Soma M and Matsumoto K: Characterization of insulin adsorption behavior of dialyzer membranes used in hemodialysis. Artif Organs 2011;35:398-403.

17. WaldhausI W, Bratusch-Marrain P, Gasic S, Korn A and Nowotny P: Insulin production rate following glucose ingestion estimated by splanchnic C-peptide output in normal man. Diabetologia 1979;17: 221-7.

18. Allegra V, Mengozzi G, Martimbianco L and Vasile A: Glucose-induced insulin secretion in uremia: effects of aminophylline infusion and glucose loads. Kidney Int 1990;38:1146-50.

19. DeFronzo RA and Alvestrand A: Glucose intolerance in uremia: site and mechanism. Am J Clin Nutr 1980;33:1438-45.

20. Wathen RL, Keshaviah P, Hommeyer P, Cadwell K and Comty CM: The metabolic effects of hemodialysis with and without glucose in the dialysate. Am J Clin Nutr 1978;31:1870-5.

21. Dukkipati R, Kalantar-Zadeh $\mathrm{K}$ and Kopple JD: Is there a role for intradialytic parenteral nutrition? A review of the evidence. Am J Kidney Dis 2010;55:352-64.

22. Ferrario M, Raimann JG, Thijssen S, et al.: Effects of Dialysate Glucose Concentration on Heart Rate Variability in Chronic Hemodialysis Patients: Results of a Prospective Randomized Trial. Kidney Blood Press Res 2011;34:334-43.

23. Coletta DK, Balas B, Chavez AO, et al.: Effect of acute physiological hyperinsulinemia on gene expression in human skeletal muscle in vivo. Am J Physiol Endocrinol Metab 2008;294:E910-7. 
24. Malmberg K, Ryden L, Efendic S, et al.: Randomized trial of insulin-glucose infusion followed by subcutaneous insulin treatment in diabetic patients with acute myocardial infarction (DIGAMI study): effects on mortality at 1 year. J Am Coll Cardiol 1995;26:57-65.

25. Malmberg K, Ryden L, Hamsten A, Herlitz J, Waldenstrom A and Wedel H: Mortality prediction in diabetic patients with myocardial infarction: experiences from the DIGAMI study. Cardiovasc Res 1997; 34:248-53.

26. Malmberg K, Norhammar A, Wedel H and Ryden L: Glycometabolic state at admission: important risk marker of mortality in conventionally treated patients with diabetes mellitus and acute myocardial infarction: long-term results from the Diabetes and Insulin-Glucose Infusion in Acute Myocardial Infarction (DIGAMI) study. Circulation 1999;99:2626-32.

27. Nordt TK, Klassen KJ, Schneider DJ and Sobel BE: Augmentation of synthesis of plasminogen activator inhibitor type-1 in arterial endothelial cells by glucose and its implications for local fibrinolysis. Arterioscler Thromb 1993;13:1822-8.

28. Meigs JB, Mittleman MA, Nathan DM, et al.: Hyperinsulinemia, hyperglycemia, and impaired hemostasis: the Framingham Offspring Study. JAMA 2000;283:221-8.

29. Esposito K, Nappo F, Marfella R, et al.: Inflammatory cytokine concentrations are acutely increased by hyperglycemia in humans: role of oxidative stress. Circulation 2002;106:2067-72.

30. van Oostrom AJ, Sijmonsma TP, Verseyden C, et al.: Postprandial recruitment of neutrophils may contribute to endothelial dysfunction. J Lipid Res 2003;44:576-83.

31. Dandona P, Chaudhuri A, Ghanim H and Mohanty P: Insulin as an Anti-Inflammatory and Antiatherogenic Modulator. J Am Coll Cardiol 2009;53:S14-S20.

32. Dandona P, Chaudhuri A, Ghanim H and Mohanty P: Anti-Inflammatory Effects of Insulin and the ProInflammatory Effects of Glucose. Semin Thorac Cardiovasc Surg 2006;18:293-301.

33. Vos FE, Manning PJ, Sutherland WH, Schollum JB and Walker RJ: Anti-inflammatory effect of an insulin infusion in patients on maintenance haemodialysis: A randomized controlled pilot study. Nephrology 2011;16:68-75.

34. US Renal Data System 2008 Annual Data Report: Atlas of Chronic Kidney Disease and End-Stage Renal Disease in the United States, National Institutes of Health, National Institute of Diabetes and Digestive and Kidney Diseases 


\section{Chapter}

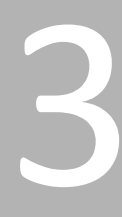

Effects of dialysate glucose concentration on heart rate variability in chronic hemodialysis patients: results of a prospective randomized trial

M Ferrario, JG Raimann, S Thijssen, MG Signorini, A Kruse, JA Diaz-Buxo, S Cerutti, NW Levin, P Kotanko

Kidney Blood Press Res. 2011;34:334-343 


\section{Abstract}

\section{Background}

Chronic hemodialysis (HD) patients suffer from an appallingly high cardiovascular mortality. During HD, patients are exposed to dialysate glucose, which may alter blood glucose levels and thus exert effects on the autonomic nervous system. Heart rate variability (HRV) is an established indicator of autonomic nervous system activity and a predictor of cardiovascular outcomes. This study investigated the effects of two commonly used dialysate glucose concentrations $(100 \mathrm{mg} / \mathrm{dl}$ (HD100), and $200 \mathrm{mg} / \mathrm{dl}$ (HD200)) on HRV in chronic HD patients.

\section{Methods}

In this prospective, randomized, controlled, single-masked, cross-over trial subjects were randomized to receive HD100 or HD200 for a period of three weeks followed by a cross-over to the respective other dialysate (www.clicaltrials.gov \#NCT00618033). Blood glucose and insulin levels were measured before and after HD. Intradialytic Holter electrocardiograms were recorded and HRV time domain, frequency domain, and complexity parameters analyzed.

\section{Results}

Twenty-three HD patients (age 56 \pm 12 years, 11 male, 14 black, 11 with diabetes) were studied. Diabetic subjects showed significantly higher serum glucose levels with HD200 as compared to HD100 (HD100: $146 \pm 48 \mathrm{mg} / \mathrm{dl}$; HD200: $192 \pm 57 \mathrm{mg} / \mathrm{dl} ; P<0.01$ ); this hyperglycemia was accompanied by an increase of the high frequency band of HRV $(P=0.019)$, a reflection of an increased parasympathetic activity. HRV did not change in non-diabetic subjects.

\section{Conclusion}

In diabetic subjects the use of HD200 increased vagal tone. Given the importance of sympathetic activation to counteract intradialytic hypotension, our findings support the use of HD100 in diabetic HD patients. 


\section{Introduction}

Hemodialysate glucose concentrations differ widely between units and countries, with $100 \mathrm{mg} / \mathrm{dl}$ (5.55 mmol/l; HD100) and $200 \mathrm{mg} / \mathrm{dl}$ (11.11 mmol/l; HD200) being used most frequently; nevertheless, glucose-free dialysate is used in some countries. Dialysate glucose exceeding serum concentrations results in a diffusive glucose flux shift into the patient and a rise of blood glucose levels with consecutive insulin secretion. In turn, insulin affects the cardiovascular system by reducing the vagal and increasing the sympathetic tone ${ }^{1,2}$. Data on the direct effects of blood glucose on the autonomic nervous system (ANS) are scarce. Kanaley et al. recently reported an increased parasympathetic activation following an oral glucose load ${ }^{3}$.

ANS activity can be studied non-invasively by heart rate variability (HRV) analysis. HRV refers to the variability of the length of R-R intervals in electrocardiogram. HRV is determined by the interactions of hemodynamic, electrophysiological and humoral factors and modulating ANS inputs ${ }^{4,5}$.

HRV can be quantified by descriptive statistics of R-R interval duration and its variation over time, e.g. minimum, maximum, average, standard deviation. This analysis is called time domain analysis, and decreased HRV as determined by time domain analysis has been linked to poor prognosis ${ }^{6}$. In frequency domain analysis R-R time series data are considered to be composed of individual sinus oscillations with different frequencies. The time series data are mathematically broken down into a spectrum of sinus waves, and it becomes possible to analyze the contribution of each frequency's amplitude to the original time series data (power spectral analysis). In power spectral analysis, by convention, frequencies are grouped together and categorized as very low frequency (VLF, 0.003 to $0.04 \mathrm{~Hz}$ ), low frequency (LF, 0.04 to $0.15 \mathrm{~Hz}$ ) and high frequency (HF, 0.15 to $0.4 \mathrm{~Hz})^{7}$. The LF and HF bands indicate sympathetic (LF) and parasympathetic (HF) activities. Accordingly, sympathetic activation increases the LF power, whereas parasympathetic activation (and to some extent respiration) increases of the HF power. The VLF band reflects slow regulatory mechanisms such as humoral, endocrine factors (e.g., endothelial factors, renin-angiotensin system) and the circadian rhythm ${ }^{5}$.

Cardiovascular autonomic neuropathy is highly prevalent in patients with diabetes mellitus (DM) and results in a general reduction of HRV. Autonomic tests have demonstrated significantly reduced sympathetic responses, as reflected by the LF band, to orthostatic challenges in patients with DM. This finding was also present in diabetic patients who had not yet been diagnosed clinically with autonomic neuropathy ${ }^{8,9}$. It is noteworthy that patients suffering from renal failure had markedly reduced total spectral power, as well as reduced power in the LF and HF band ${ }^{10,11}$.

Congestive heart failure and myocardial infarction are also associated with alterations of HRV. An inverse relationship between HRV and cardiovascular mortality in patients with cardiovascular disease was reported previously ${ }^{12-14}$. Chan et al. reported an association between left ventricular mass, HRV and physical performance in a large 
cohort of HD patients ${ }^{15}$. The prognostic value of HRV analysis to predict cardiovascular events was recently extended to HD patients ${ }^{16,17}$.

Since heart rate is determined by a complex interaction of networks of control mechanisms which quickly adapt the cardiac output to changing needs, nonlinear control characteristics arise. Goldberger and his co-workers recognized the presence of the long-term correlations in R-R intervals and its relationship to the concept of 'dynamic disease' ${ }^{18,19}$. To quantitatively describe these nonlinear characteristics, new measures of HRV were developed. The Approximate Entropy $\operatorname{ApEn}(m, r)$ quantifies the unpredictability of fluctuations in a time series, measuring the logarithmic probability that patterns of $m$ observations will repeat themselves within predetermined tolerance thresholds $r$ on the next incremental comparisons $(m+1)$. A time series containing many repetitive patterns has smaller entropy values than a time series which does not present such patterns. The Sample Entropy $\operatorname{SampEn}(m, r)$ is a measure closely related to approximate entropy ${ }^{20}$. For details see Appendix 3.1.

Another measure of complexity was developed by Lempel and Ziv and is used for the assessment of algorithmic complexity, which is defined as the minimum quantity of information needed to define a binary string ${ }^{21}$. In case of random strings, the algorithmic complexity is the length of the string itself. The Lempel Ziv complexity (LZC) reflects the rate of new pattern occurrences with time.

Compared to linear approaches, non-linear statistics are more powerful in predicting mortality. In addition, nonlinear methods showed superiority in stratification of populations according to different physiological and pathological states ${ }^{22}$.

Given the abysmal cardiovascular mortality in chronic HD patients all aspects of dialysis therapy related to their cardiovascular system call for rigorous scientific inquiry. The present study aimed to test the hypothesis that HRV of chronic hemodialysis patients is affected by dialysate glucose concentration.

\section{Methods}

\section{Study design and procedures}

This study was a two-center, prospective, randomized, controlled, single-masked, crossover clinical trial of HD100 versus HD200 (www.clinicaltrials.gov: \#NCT00618033). After enrolment, subjects were randomized to receive HD100 and HD200, respectively, for a period of three weeks ( 9 HD treatments). Thereafter subjects were switched for 3 weeks to the respective other dialysate glucose concentration. Subjects were blinded to the dialysate glucose concentration. In adherence to the ceteris paribus principle, neither dialysis prescription (including temperature, electrolyte composition and flow rates of the dialysate) or medications were changed in the course of the study. 
Holter recordings were performed after the long interdialytic interval, once each with HD100 and HD200, commencing about ten minutes before HD. ECGs were continuously recorded at a sampling rate of $250 \mathrm{~Hz}$ with a three-lead Holter device (clickholter, Cardioline, HealthFrontier Inc, NJ, USA) for 24 hours.

Holter recordings of subjects receiving HD100 and HD200 recordings were analyzed.

\section{Patient population}

Subjects were recruited from two urban dialysis facilities of the Renal Research Institute in New York City, NY. Inclusion criteria were age above 18 years and HD vintage of at least 30 days. Exclusion criteria were dialysis frequency other than thrice weekly, hospitalization or antibiotic treatments in the preceding 8 weeks, or persistent intradialytic arrhythmia. The study was approved by the Institutional Review Board of Beth Israel Medical Center, New York, and written informed consent was obtained from each subject before enrolment into the study. The enrollment target was 30 subjects, and recruitment was aimed to sample a 1:1 ratio between subjects with and without DM at each center. DM was defined as either requiring oral antidiabetic medication or insulin or having random blood glucose levels over $200 \mathrm{mg} / \mathrm{dl}$ at routine clinical measurements in the preceding 12 months. Both type I and type II DM patients were eligible for the study.

\section{Biochemical analysis}

Blood draws for pre-HD potassium, glucose and insulin (pre- and post-HD) were collected at the beginning and end of four HD100 and during two HD200 treatments, respectively. Serum concentrations were averaged for each timepoint (beginning and end of dialysis) and for each regimen. The Olympus AU5400 (Olympus Diagnostic Systems, Center Valley, PA) was used for the measurement of glucose with a colorimetric assay and an ion-selective electrode for potassium. Insulin was measured with a chemiluminescent immunoassay using the Advia Centaur (Siemens Healthcare Diagnostic, Deerlied, IL).

\section{Blood pressure measurements}

Systolic and diastolic Blood pressures (BP) were measured using an oscillometric method every 30 minutes during those treatments where Holter electrocardiograms were recorded.

\section{HRV analysis}

HRV was analyzed by an observer masked to dialysate glucose concentration. Beat-bybeat series of $R-R$ intervals and their annotations were obtained from the Holter recording with the software provided by the manufacturer. The entire recording was 
subdivided into 5-minute epochs and only sub-sequences with at least $85 \%$ of qualified sinus beats (NN intervals) were included in the analyses. The sub-sequences were corrected by means of an adaptive filtering procedure to remove artefacts or ventricular premature complexes ${ }^{23}$. After filtering, the series were re-sampled at $2 \mathrm{~Hz}^{7}$. In recognition of changing pathophysiological circumstances in the course of a HD session $^{24}$, HRV was analyzed during three distinct time periods, two during HD (the first $30 \mathrm{~min}$, the proto-dialytic period, $\mathrm{HD}_{\text {proto; }}$ and the last 30 minutes, telo-dialytic period, $\left.H D_{\text {telo }}\right)$, and one in the 60 minutes after the end of $H D\left(H D_{\text {post }}\right)$.

\section{A. Time domain analysis}

The following indices were computed every 5-minute epoch: 1. the mean NN interval (mean NNI), 2. the standard deviation of the NN intervals (SDNN), 3. the square root of the sum of the squares of differences between adjacent NN intervals (RMSSD), 4. the percentage of pairs of adjacent NN intervals differing by more than $50 \mathrm{~ms}$ in the sequence (pNN50\%).

\section{B. Frequency domain analysis}

Autoregressive (AR) spectral analysis was performed and power in the 1 . very low frequency $(V L F, 0.003<f \leq 0.04 \mathrm{~Hz})$, 2. the low frequency $(L F, 0.04<f \leq 0.15 \mathrm{~Hz}), 3$. the high frequency $(\mathrm{HF}, 0.15<\mathrm{f} \leq 0.4 \mathrm{~Hz}$ ) bands was computed, as well as 4 . the total power and 5 . the LF/HF ratio, in accordance with recommendations of the European Society of Cardiology and the North American Society of Pacing and Electrophysiology ${ }^{7}$.

\section{Entropy and complexity analysis}

For each 5-minute epoch, the regularity of the signals was estimated by computing the Approximate Entropy (ApEn) and the Sample entropy (SampEn). The parameters adopted for the computation of ApEn and SampEn were: $m=2$ and $r=0.15$.

For the estimation of the Lempel Ziv complexity (LZC), the RR time series was encoded into a string. Given a signal $\left\{x_{n}\right\}$, the encoding rule adopted for the binary alphabet was the following: assign 0 if $x_{n+1} \leq x_{n}+p \cdot x_{n}$, and 1 if $x_{n+1}>x_{n}+p \cdot x_{n}$. The rule for the ternary alphabet was assign 2 if $x_{n}-p \cdot x_{n} \leq x_{n+1} \leq x_{n}+p \cdot x_{n}, 0$ if $x_{n+1}<x_{n}-p \cdot x_{n}$ and 1 if $x_{n+1}>x_{n}+p \cdot x_{n}$. The factor $p$ is a fixed parameter; in these analyses, $P$ was 0.001 .

\section{Statistical analysis}

Treatment parameters were compared between HD100 and HD200 using paired Student's t-test. Fisher's Exact Test was used for categorical data. Patients were stratified by diabetes status.

HRV indices were compared between HD100 and HD200 in a paired fashion using the Wilcoxon signed rank test. $\mathrm{HRV}$ indices between $H D_{\text {proto, }} H D_{\text {telo }}$ and $H D_{\text {post }}$ were compared in a paired fashion. Glucose and insulin concentrations were compared using 
a paired Student's t-test. A $P$-value $<0.05$ (2-tailed) was considered statistically significant.

Signal processing and statistical analyses were performed with MATLAB (The MathWorks Inc., Natick, Mass., USA)

\section{Results}

A total of 30 patients were enrolled between April and June 2008. Seven subjects were excluded from HRV analysis because of hospitalization, intradialytic arrhythmia, technical reasons and missing matched pairs (Figure 3.1). Table 3.1 reports the demographic data of the included subjects. All subjects underwent HD using Optiflux F180NR Polysulphone dialyzer (Fresenius Medical Care North America). Table 3.2 shows the HD treatment parameters on the days of the Holter recordings.

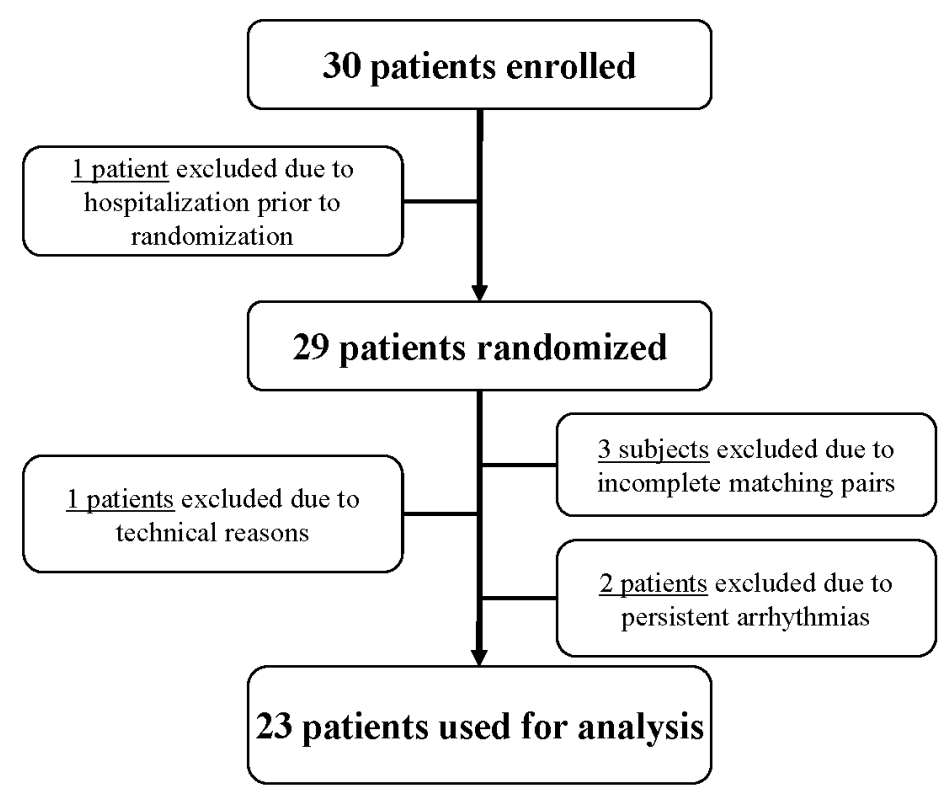

Figure 3.1 Study flow chart. 
Table 3.1 Demographics of study cohort. Data reported as mean \pm standard deviation.

\begin{tabular}{|c|c|c|c|}
\hline & all subjects & diabetic subjects & $\begin{array}{c}\text { non-diabetic } \\
\text { subjects }\end{array}$ \\
\hline $\mathrm{n}$ [count] & 23 & 11 & 12 \\
\hline age [years] & $56 \pm 12$ & $60 \pm 11$ & $51 \pm 12$ \\
\hline gender $(\mathrm{m} / \mathrm{f})$ & $11 / 12$ & $4 / 7$ & $7 / 5$ \\
\hline race (black/non-black) & $14 / 9$ & $7 / 4$ & $7 / 5$ \\
\hline dialysis vintage [years] & $5 \pm 4$ & $3 \pm 3$ & $7 \pm 5$ \\
\hline height $[\mathrm{cm}]$ & $168 \pm 11$ & $163 \pm 11$ & $172 \pm 8$ \\
\hline weight [kg] & $82 \pm 18$ & $79 \pm 20$ & $84 \pm 16$ \\
\hline body mass index $\left[\mathrm{kg} / \mathrm{m}^{2}\right]$ & $29 \pm 7$ & $30 \pm 8$ & $29 \pm 7$ \\
\hline \multicolumn{4}{|l|}{ access type } \\
\hline AV fistula/AV Graft & $7 / 16$ & $6 / 5$ & $1 / 11$ \\
\hline \multicolumn{4}{|l|}{ beta blocker } \\
\hline$\beta_{1}$-selective / $\alpha_{1}-\beta_{1}$ selective & $6 / 7$ & $3 / 4$ & $3 / 3$ \\
\hline \multicolumn{4}{|l|}{ antihypertensive drugs } \\
\hline ACE inhibitors/ ARB / CCB & $3 / 4 / 10$ & $2 / 4 / 6$ & $1 / 0 / 4$ \\
\hline \multicolumn{4}{|l|}{ type of diabetes } \\
\hline Type 1 / Type 2 & $1 / 10$ & $1 / 10$ & n. a. \\
\hline \multicolumn{4}{|l|}{ diabetes-related medication } \\
\hline insulin / oral antidiabetic drugs & $6 / 3$ & $6 / 3$ & n. a. \\
\hline
\end{tabular}

ACE (angiotensin converting enzyme); ARB (angiotensin receptor blocker); CCB (calcium channel blocker).

Table 3.2 Hemodialysis (HD) treatment parameters. Data reported as mean \pm standard deviation.

\begin{tabular}{|c|c|c|c|c|c|c|}
\hline & \multicolumn{3}{|c|}{$\begin{array}{c}\text { Diabetic subjects } \\
\qquad(n=11)\end{array}$} & \multicolumn{3}{|c|}{$\begin{array}{l}\text { Non-diabetic subjects } \\
\qquad(n=12)\end{array}$} \\
\hline & HD100 & HD200 & p-value & HD100 & HD200 & p-value \\
\hline $\mathrm{n}$ [count] & 11 & 11 & & 12 & 12 & \\
\hline treatment time [min] & $206 \pm 28$ & $213 \pm 30$ & n.s. & $206 \pm 31$ & $212 \pm 28$ & n.s. \\
\hline $\begin{array}{l}\text { dialysate } \mathrm{K}^{+} \text {concentration } \\
{[2 \mathrm{mmol} / \mathrm{l} / 3 \mathrm{mmol} / \mathrm{l}]} \\
\text { dialysate } \mathrm{Ca}^{++} \text {concentration }\end{array}$ & $10 / 1$ & $10 / 1$ & n.s. & 12 / 0 & 12 / 0 & n.s. \\
\hline$[1.125 / 1.5 \mathrm{mmol} / \mathrm{l}]$ & $11 / 0$ & $11 / 0$ & n.s. & 11 / 1 & $11 / 1$ & n.s \\
\hline interdialytic weight gain $[\mathrm{kg}]$ & $2.8 \pm 1.6$ & $2.7 \pm 1.1$ & n.s. & $2.7 \pm 1.1$ & $2.9 \pm 1.5$ & n.s. \\
\hline ultrafiltration volume [ml] & $2677 \pm 1109$ & $2901 \pm 869$ & n.s. & $2830 \pm 1001$ & $3215 \pm 1029$ & 0.03 \\
\hline pre HD serum potassium [mEq/l] & $4.8 \pm 0.5$ & $5.1 \pm 0.9$ & n.s. & $4.8 \pm 0.5$ & $4.8 \pm 0.5$ & n.s. \\
\hline $\begin{array}{l}\text { pre HD systolic blood pressure } \\
{[\mathrm{mm} / \mathrm{Hg}]}\end{array}$ & $146.6 \pm 27.8$ & $146.5 \pm 24.5$ & n.s. & $142.2 \pm 28.8$ & $149.2 \pm 37.8$ & n.s. \\
\hline $\begin{array}{l}\text { intradialytic saline administration } \\
\text { [number] }\end{array}$ & 2 & 2 & n.s. & 2 & 1 & n.s. \\
\hline $\begin{array}{l}\text { reasons for saline administration } \\
\text { cramps / hypotension / reason } \\
\text { not evaluable }\end{array}$ & $1 / 0 / 1$ & $1 / 0 / 1$ & n.a. & $0 / 1 / 1$ & $0 / 0 / 1$ & n.s. \\
\hline
\end{tabular}

n. s. (not significant). 


\section{Comparisons between HD100 and HD200.}

\section{Glucose and insulin levels}

Significantly higher glucose concentrations were observed in diabetic subjects at the end of HD200 compared to HD100; insulin levels showed no difference (Table 3.3). In contrast, non-diabetic subjects at the end of HD200 showed only marginally higher glucose concentrations. In non-diabetic subjects post-HD insulin concentrations were significantly higher compared to HD100. Noteworthy, during HD200 only 3 diabetic subjects (27\%) had higher insulin levels at the end of dialysis as compared to 6 subjects $(50 \%)$ in the non-diabetic group.

Table 3.3 Glucose and Insulin concentration at the beginning and the end dialysis using dialysate with a glucose concentration of 100 and 200 mg/dl (HD100, HD200), respectively.

\begin{tabular}{|c|c|c|c|c|c|}
\hline \multirow[b]{2}{*}{$\begin{array}{l}\text { Dialysate glucose } \\
\text { concentration } \\
{[\mathrm{mg} / \mathrm{dl}]}\end{array}$} & \multirow[b]{2}{*}{ Time point } & \multicolumn{2}{|c|}{ Diabetic subjects ( $n=11)$} & \multicolumn{2}{|c|}{ Non-diabetic subjects $(n=12)$} \\
\hline & & $\begin{array}{l}\text { Glucose } \\
\text { [mg/dl] }\end{array}$ & $\begin{array}{c}\text { Insulin } \\
{[\mu \mathrm{U} / \mathrm{I}]}\end{array}$ & $\begin{array}{l}\text { Glucose } \\
\text { [mg/dl] }\end{array}$ & $\begin{array}{c}\text { Insulin } \\
{[\mu \mathrm{U} / \mathrm{I}]}\end{array}$ \\
\hline \multirow[t]{3}{*}{100} & HD start & $176 \pm 111$ & $44 \pm 48$ & $106 \pm 20$ & $29 \pm 20$ \\
\hline & HD end & $146 \pm 48^{* *}$ & $23 \pm 16$ & $90 \pm 10^{* *}$ & $15 \pm 11^{*}$ \\
\hline & $\begin{array}{c}\text { HD start }-\mathrm{HD} \text { end } \\
(95 \% \mathrm{Cl})\end{array}$ & $-30(-84$ to 24$)$ & $-21(-47$ to 7$)$ & $-16(-4 \text { to }-28)^{\dagger}$ & $-14(-3$ to -24$) \dagger$ \\
\hline \multirow[t]{3}{*}{200} & HD start & $194 \pm 142$ & $38 \pm 28$ & $110 \pm 20$ & $34 \pm 29$ \\
\hline & HD end & $192 \pm 57^{* *}$ & $24 \pm 23$ & $114 \pm 17^{* *}$ & $36 \pm 41^{*}$ \\
\hline & $\begin{array}{c}\text { HD start }-\mathrm{HD} \text { end } \\
(95 \% \mathrm{Cl})\end{array}$ & $-2(-70$ to 67$)$ & $-14(-35$ to 8$)$ & $4(-10$ to 18$)$ & $2(-10$ to 14$)$ \\
\hline
\end{tabular}

Data reported as means \pm standard deviation, or mean $(95 \% \mathrm{Cl}$ in parentheses) and represent averaged values collected before and after treatments using HD100 ( $n=4$ per subjects) and HD200 ( $n=2$ per subject). Significant differences between HD100 and HD200 are indicated in bold. + indicates significant differences between the HD beginning and the HD end of treatment. ${ }^{*} P=0.05, * * P<0.01$.

\section{Blood Pressure}

Figure $3.2 \mathrm{a}$ and $3.2 \mathrm{~b}$ show blood pressures during the 46 dialysis treatments with valid Holter recordings. Blood pressure declined significantly during all HD treatments, without significant differences between HD100 and HD200. 

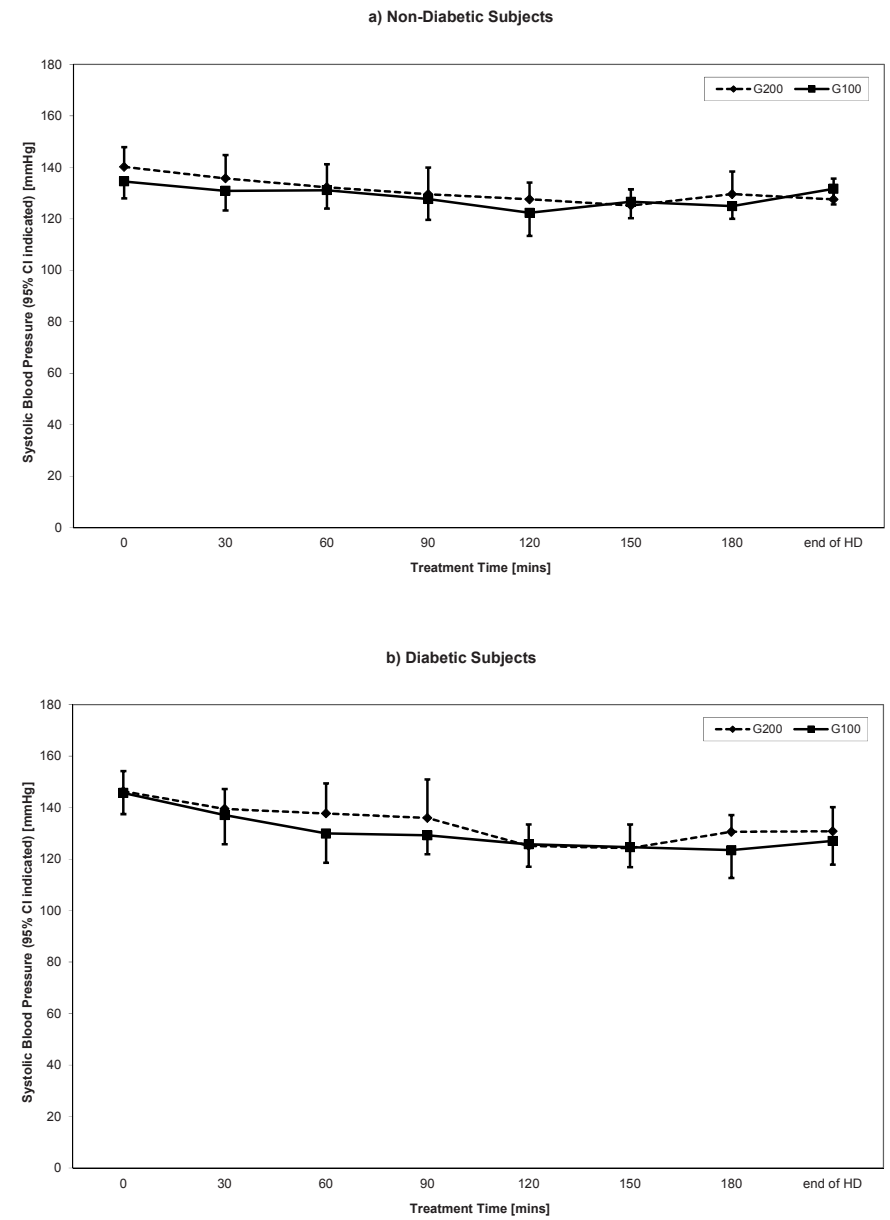

Figure 3.2 Systolic blood pressure during hemodialysis using dialysate glucose concentrations of 100 and $200 \mathrm{mg} / \mathrm{dl}$ in a) non-diabetic ( $\mathrm{n}=12)$ and b) diabetic subjects ( $\mathrm{n}=11)$. Mean and $95 \% \mathrm{Cl}$ indicated.

\section{HRV analysis}

As outlined in detail below and in Table 3.4, dialysate glucose significantly affected HRV.

\section{-Time domain parameters}

In diabetic subjects, mean NNI was higher at $\mathrm{HD}^{200}$ telo $(P=0.024)$ and $\mathrm{HD} 200_{\text {post }}$ $(P=0.054)$ as compared to HD100 (Figure 3.3). In addition, in these subjects SDNN was significantly higher at $\mathrm{HD} 200_{\text {post }}$ compared to $\mathrm{HD} 100_{\text {post }}$. No significant differences were found in non- diabetic subjects. 


\section{-Frequency domain parameters}

In diabetic subjects VLF, HF and total power was higher during $\mathrm{HD}_{200_{\text {post }}}$ compared to

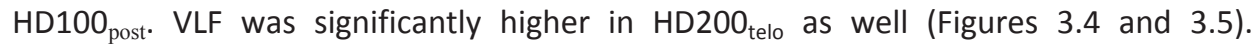
Subjects without DM did not show any significant differences.

\section{-Complexity parameters}

Significant differences were found in the complexity indices. Diabetic subjects showed significantly higher values of SampEn(2,0.15) during HD200 $0_{\text {telo }}$ compared to HD100 telo. On the contrary, $\operatorname{ApEn}(2,0.15)$ was significantly lower during HD200 ${ }_{\text {post }}$ when compared to $\mathrm{HD}_{100}$ post $($ Table 3.4).

In non-diabetic subjects, significantly higher values of $\operatorname{ApEn}(2,0.15)$ and $\operatorname{LZC}(3,0.001)$ were found at $\mathrm{HD} 200_{\text {proto }}$ and $\mathrm{HD}^{200_{\text {telo, }}}$ respectively, in comparison to the same periods during HD100 (Table 3.4). 


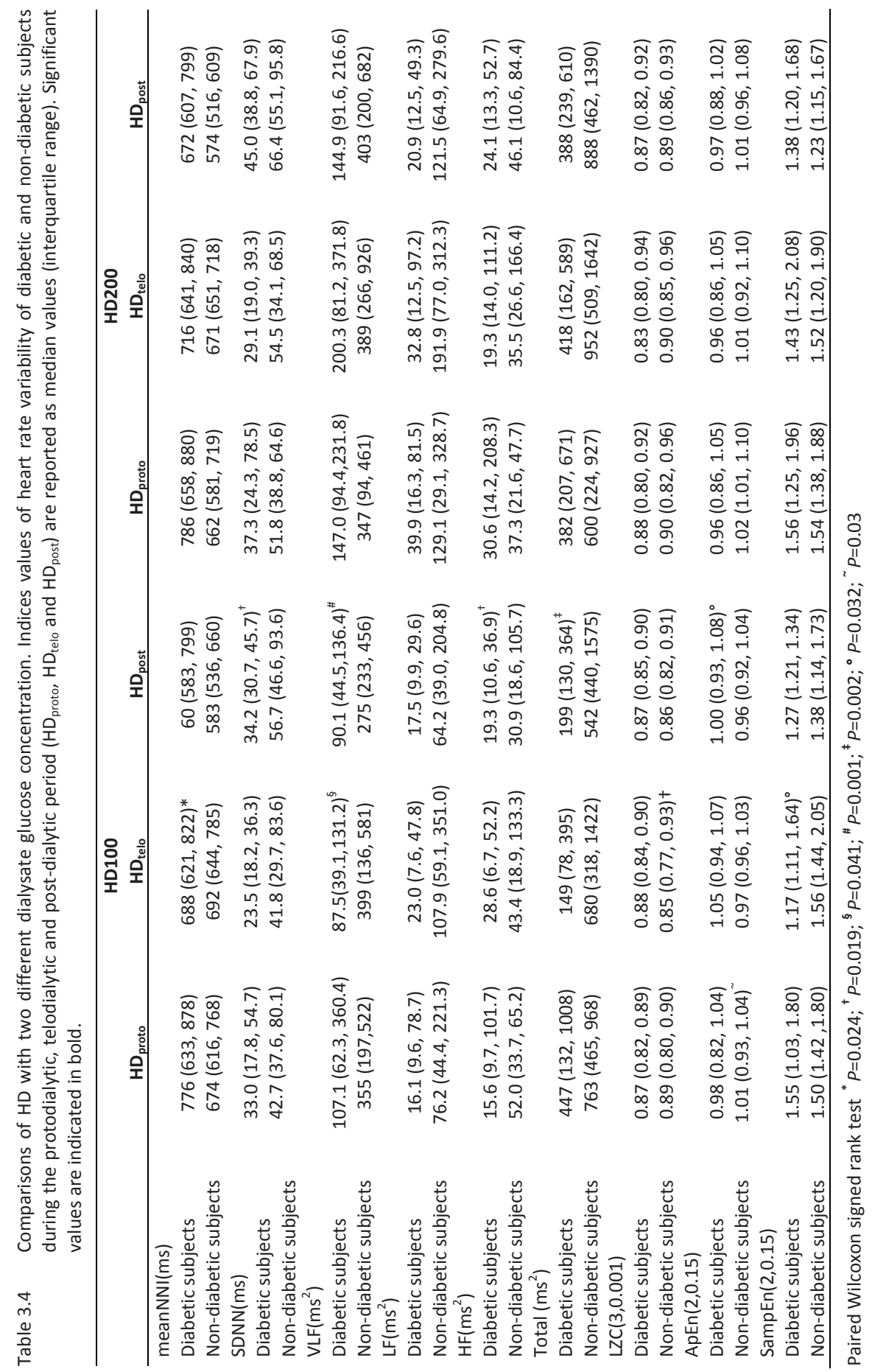




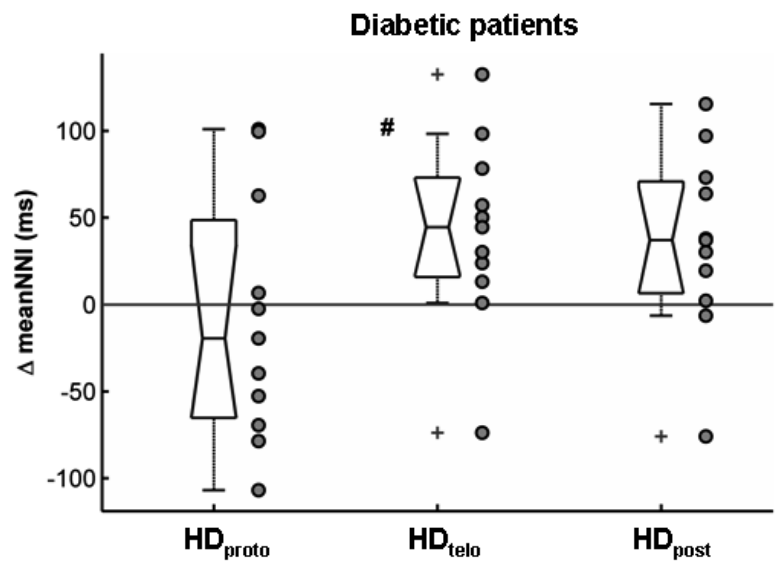

Figure 3.3 Differences of meanNNI (time interval between two qualified sinus heart beats) in diabetic subjects during the protodialytic, telodialytic and post-dialytic period ( $H D_{\text {proto }}, H D_{\text {telo }}$ and $\left.H D_{\text {post }}\right)$, using dialysate glucose concentrations of $200 \mathrm{mg} / \mathrm{dl}$ (HD200) and a glucose concentration of $100 \mathrm{mg} / \mathrm{dl}$ (HD100), respectively. The difference $\Delta$ was calculated as: $\Delta$ meanNNI= meanNNI(HD200) - meanNNI(HD100). The box and whisker plots show median, $10 \%, 25 \%, 75 \%$ and $90 \%$ percentiles; values outside the $10 \%$ and $90 \%$ percentile are marked as + . Individual data are shown as circles. \# indicates significance $(P$-value $<0.05)$.

\section{Diabetic patients}

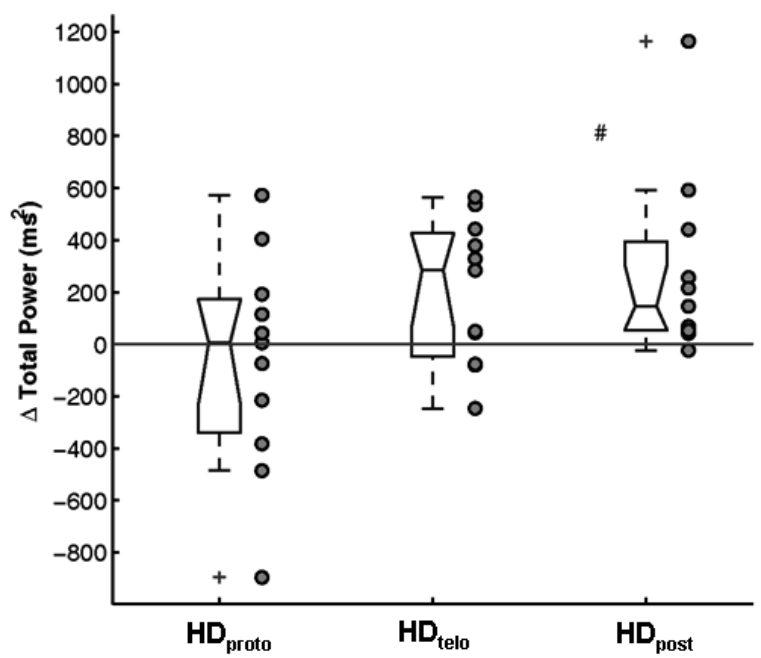

Figure 3.4 Differences of spectral total power $\left(\mathrm{ms}^{2}\right)$ in diabetic subjects during the protodialytic, telodialytic and post-dialytic period $\left(H D_{\text {proto, }} H D_{\text {telo }}\right.$ and $\left.H D_{\text {post }}\right)$ using hemodialysates with a glucose concentration of $200 \mathrm{mg} / \mathrm{dl}$ (HD200) and $100 \mathrm{mg} / \mathrm{dl}$ (HD100), respectively. The difference $\Delta$ was calculated as: $\Delta$ total power $=$ total power (HD200) - total power (HD100). The box and whisker plots show median, $10 \%, 25 \%, 75 \%$ and $90 \%$ percentiles; values outside the $10 \%$ and $90 \%$ percentile are marked as + . Individual data are shown as circles. \# indicates significance $(P$-value $<0.05)$. 


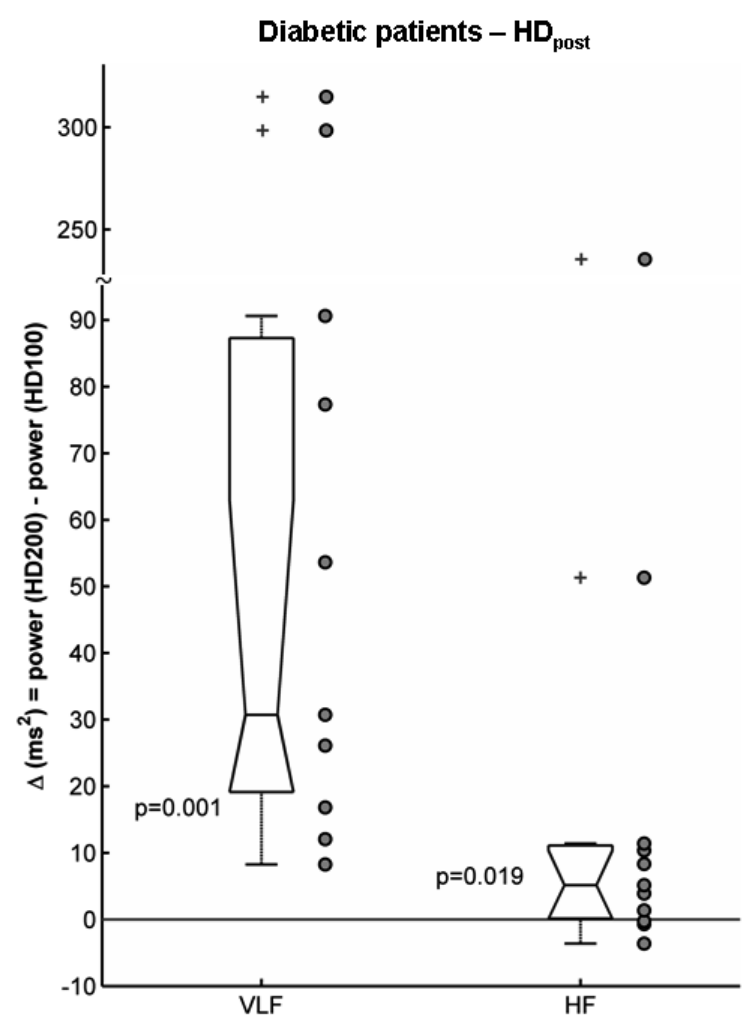

Figure 3.5 Differences of the spectral total power $\left(\mathrm{ms}^{2}\right)$ of very low frequency (VLF) and high frequency (HF) components during the first hour after hemodialysis $\left(H D_{\text {post }}\right)$ in diabetic subjects. The difference $\Delta$ was calculated as: $\Delta=$ power (HD200) - power (HD100). The box and whisker plots show median, $10 \%, 25 \%, 75 \%$ and $90 \%$ percentiles; values outside the $10 \%$ and $90 \%$ percentile are marked as + .

When comparing HRV indices between the first and the last 30 minutes of dialysis, no significant differences were found in non-diabetic subjects, irrespective of dialysate glucose level. In contrast, in diabetic subjects meanNNI, VLF power, total power and LZC $(3,0.001)$ differed significantly with HD100 ( $P<0.05)$ (Table 3.4).

\section{Discussion}

The key finding of the present study is that HD using a dialysate with $200 \mathrm{mg} / \mathrm{dl}$ glucose resulted in a significantly increased vagal activation in diabetic subjects. This predominantly vagal activation may adversely affect the hemodynamic response to ultrafiltration and thus facilitate intradialytic morbid events, such as hypotension. 
Cardiovascular disease is the leading cause of death in dialysis patients, and disturbances of the ANS, as analyzed by means of HRV analysis, have been shown to correlate with cardiovascular pathology and mortality risk in the general population ${ }^{13,14}$ and in HD patients ${ }^{15-17,25}$.

The present study in HD patients is the first randomized, controlled study to investigate the short-term effects of two commonly used dialysate glucose concentrations on autonomic function. To eliminate potential confounding factors, dialysis prescriptions and drugs remained unchanged throughout the study. The only intervention was a change in dialysate glucose concentration. Subjects were analyzed in a paired fashion therefore drugs which potentially influence HRV (e.g. beta blockers) are unlikely to bias the results. Intradialytic positive sodium balance and body temperature have the potential to affect HRV, although temperature has been previously shown not to exert influence on $\mathrm{HRV}^{26}$. Except for a slightly higher ultrafiltration volume in non-diabetic subjects treated with HD200 (Table 3.2), no significant differences of treatment time and rate of fluid removal were seen.

As mentioned earlier, the main finding of this study is a significant increase of the parasympathetic response (which is predominantly reflected by the power of the HF spectral component) in diabetic subjects using HD200. This is reflected by an increase in mean $\mathrm{NNI}^{27}$ and VLF. Taylor et al. ${ }^{28}$ demonstrated that the VLF component estimated on epochs of 20 minutes is highly dependent on parasympathetic tone, mainly because efferent vagal nerve traffic to the human heart can fluctuate over very low to high frequencies.

As expected, diabetic subjects showed a reduced sympathetic tone during and after dialysis. Diabetic subjects showed lower HRV in all indices, in particular a reduced power of their LF band (Table 3.4), a reflection of their inability to mount a sympathetic response to HD and fluid removal ${ }^{8}$. Although not specifically addressed in our study, this lack of adequate sympathetic response may contribute to the increased incidence of intradialytic hypotensive episodes in diabetic HD patients ${ }^{29}$. In view of the association between intradialytic hypotension and mortality ${ }^{30}$, we suspect that an increase in parasympathetic tone, as shown with HD200, is particularly adverse in this patient population.

To our knowledge, there are no data relating blood glucose level, following intravenous administration of glucose, to changes in HRV. Kanaley et al. reported vagal stimulation (as determined by the power of the HF band) and increased total power in patients undergoing oral glucose tolerance testing; interestingly, the vagal activation was apparent in supine but not in the upright position ${ }^{3}$.

The observation that a rise of blood glucose induces a parasympathetic response may be related to direct or indirect effects of glucose both on peripheral vagal sensory fibres 
and on central components of vagovagal reflexes ${ }^{3}$. The physiological insulin response to elevated blood glucose levels was seen in non-diabetic subjects only (Table 3.3). Noteworthy, non-diabetic subjects did not show any differences in HRV (time and frequency domain parameters) between HD100 and HD200. We propose that this is related to an adequate insulin response to the dialysate glucose load, resulting in a blunted blood glucose rise and mitigated parasympathetic activation. Under most circumstances HD activates the sympathetic system in response to ultrafiltration ${ }^{31,32}$. In addition to this "classical" stimulus, a rise in insulin levels may stimulate the sympathetic nervous system ${ }^{1}$. In order to dissect and quantify the relative effects of glucose and insulin on HRV, euglycemic and hyperinsulinemic clamp studies may be helpful. Given a larger patients number stratification by types of diabetes (insulin dependent; non-insulin dependent) and therapy (e.g. diet, insulin, and oral antidiabetic agents) may provide additional insights. Studies of HRV in a normoglycemic state would further help to better understand the relationship between metabolic changes and HRV, in particular in diabetic subjects, who presented in a state of hyperglycemia already prior to dialysis (Table 3.3). Notwithstanding, the strength of the current study is that patients were investigated under clinical "real life" circumstances, reflecting treatment conditions they are exposed to three time a week.

The complexity measures of HRV displayed a heterogeneous pattern. In non-diabetic subjects, there were generally no differences between HD100 and HD200. In diabetic subjects, SampEn was significantly higher during $\mathrm{HD}_{200_{\text {telo }}}$ compared to $\mathrm{HD} 100_{\text {telo, }}$, whereas ApEn was significantly lower HD200. These novel findings await physiological interpretation.

In conclusion, in maintenance HD patients with DM, HD200 results in pronounced hyperglycemia and parasympathetic activation without showing hemodynamic advantages compared to HD100. In the light of these findings and given the importance of sympathetic activation to counteract intradialytic hypotension the use of HD100 appears preferable, particularly in diabetic patients. 


\section{References}

1 Paolisso G, Manzella D, Rizzo MR, Barbieri M, Gambardella A, Varricchio M: Effects of glucose ingestion on cardiac autonomic nervous system in healthy centenarians: Differences with aged subjects. Eur J Clin Invest 2000;30:277-84.

2 Straznicky NE, Lambert GW, Masuo K, Dawood T, Eikelis N, Nestel PJ, McGrane MT, Mariani JA, Socratous F, Chopra R, Esler MD, Schlaich MP, Lambert EA: Blunted sympathetic neural response to oral glucose in obese subjects with the insulin-resistant metabolic syndrome. Am J Clin Nutr. 2009;89:27-36.

3 Kanaley JA, Baynard T, Franklin RM, Weinstock RS, Goulopoulou S, Carhart R, Jr., Ploutz-Snyder R, Figueroa A, Fernhall B: The effects of a glucose load and sympathetic challenge on autonomic function in obese women with and without type 2 diabetes mellitus. Metabolism 2007;56:778-85.

4 Akselrod S, Gordon D, Ubel FA, Shannon DC, Berger AC, Cohen RJ: Power spectrum analysis of heart rate fluctuation: A quantitative probe of beat-to-beat cardiovascular control. Science (New York, NY) 1981;213:220-2.

5 Pagani M, Lombardi F, Guzzetti S, Rimoldi O, Furlan R, Pizzinelli P, Sandrone G, Malfatto G, Dell'Orto S, Piccaluga E: Power spectral analysis of heart rate and arterial pressure variabilities as a marker of sympatho-vagal interaction in man and conscious dog. Circ Res. 1986;59:178-93.

6 Kleiger RE, Miller JP, Krone RJ, Bigger JT, Jr.: The independence of cycle length variability and exercise testing on predicting mortality of patients surviving acute myocardial infarction. The multicenter postinfarction research group. J Am Coll Cardiol 1990;65:408-11.

7 Heart rate variability: Standards of measurement, physiological interpretation and clinical use. Task Force of the European Society of Cardiology and the North American Society of Pacing and Electrophysiology. Circulation 1996;93:1043-65.

8 Bianchi A, Bontempi B, Cerutti S, Gianoglio P, Comi G, Natali Sora MG: Spectral analysis of heart rate variability signal and respiration in diabetic subjects. Med Biol Eng Comput 1990;28:205-11.

9 Cabezas-Cerrato J, Gonzalez-Quintela A, Perez-Rodriguez M, Calle A, Faure-Noguera E, Vazquez-Garcia JA, the neuropathy Spanish study group of the Spanish Diabetes S: Combination of cardiorespiratory reflex parameters and heart rate variability power spectrum analysis for early diagnosis of diabetic cardiac autonomic neuropathy. Diabetes Metab. 2009;35:305-11.

10 Chan CT, Hanly P, Gabor J, Picton P, Pierratos A, Floras JS: Impact of nocturnal hemodialysis on the variability of heart rate and duration of hypoxemia during sleep. Kidney Int 2004;65:661-5.

11 Ranpuria R, Hall M, Chan CT, Unruh M: Heart rate variability (hrv) in kidney failure: Measurement and consequences of reduced hrv. Nephrol Dial Transplant. 2008;23:444-9.

12 Copie X, Hnatkova K, Staunton A, Fei L, Camm AJ, Malik M: Predictive power of increased heart rate versus depressed left ventricular ejection fraction and heart rate variability for risk stratification after myocardial infarction. Results of a two-year follow-up study. J Am Coll Cardiol 1996;27:270-6.

13 La Rovere MT, Pinna GD, Maestri R, Mortara A, Capomolla S, Febo O, Ferrari R, Franchini M, Gnemmi M, Opasich C, Riccardi PG, Traversi E, Cobelli F: Short-term heart rate variability strongly predicts sudden cardiac death in chronic heart failure patients. Circulation 2003;107:565-70.

14 Lombardi F, Sandrone G, Pernpruner S, Sala R, Garimoldi M, Cerutti S, Baselli G, Pagani M, Malliani A: Heart rate variability as an index of sympathovagal interaction after acute myocardial infarction. J Am Coll Cardiol 1987;60:1239-45.

15 Chan CT, Levin NW, Chertow GM, Larive B, Schulman G, Kotanko P: Determinants of cardiac autonomic dysfunction in ESRD. Clin J Am Soc Nephrol 2010;5: 1821-7.

16 Fukuta H, Hayano J, Ishihara S, Sakata S, Mukai S, Ohte N, Ojika K, Yagi K, Matsumoto H, Sohmiya S, Kimura G: Prognostic value of heart rate variability in patients with end-stage renal disease on chronic haemodialysis. Nephrol Dial Transplant 2003;18:318-25.

17 Chan CT: Heart rate variability in patients with end-stage renal disease: An emerging predictive tool for sudden cardiac death? Nephrol Dial Transplant 2008;23:3061-2.

18 Goldberger AL, Bhargava V, West BJ, Mandell AJ: On a mechanism of cardiac electrical stability. The fractal hypothesis. Biophys J. 1985;48:525-8.

19 Mackey MC, Milton JG: Dynamical diseases. Ann N Y Acad Sci 1987;504:16-32. 
20 Richman JS, Moorman JR: Physiological time-series analysis using approximate entropy and sample entropy. Am J Physiol Heart Circ Physiol 2000;278:H2039-49.

21 Lempel A, Ziv J: On the complexity of finite sequences. Information Theory, IEEE Transactions on 1976;22:75-81.

22 Huikuri HV, Perkiomaki JS, Maestri R, Pinna GD: Clinical impact of evaluation of cardiovascular control by novel methods of heart rate dynamics. Phil. Trans. R. Soc. A 2009;367:1223-38.

23 Wessel N, Voss A, Malberg H, Ziehmann C, Voss H, Schirdewan A, Meyerfeldt U, Kurths J: Nonlinear analysis of complex phenomena in cardiological data. Herzschr. Elektrophys. 2000;11:159-73.

24 Kolb J, Kitzler TM, Tauber T, Morris N, Skrabal F, Kotanko P: Proto-dialytic cardiac function relates to intra-dialytic morbid events. Nephrol Dial Transplant 2011;26:1645-51

25 Fukuta H, Hayano J, Ishihara S, Sakata S, Ohte N, Takahashi H, Yokoya M, Toriyama T, Kawahara H, Yajima K, Kobayashi K, Kimura G: Prognostic value of nonlinear heart rate dynamics in hemodialysis patients with coronary artery disease. Kidney Int 2003;64:641-8.

26 van der Sande FM, Wystrychowski G, Kooman JP, Rosales L, Raimann J, Kotanko P, Carter M, Chan CT, Leunissen KM, Levin NW: Control of core temperature and blood pressure stability during hemodialysis. Clin J Am Soc Nephrol 2008;26:1645-51.

27 Van De Borne P, Hausberg M, Hoffman RP, Mark AL, Anderson EA: Hyperinsulinemia produces cardiac vagal withdrawal and nonuniform sympathetic activation in normal subjects. Am J Physiol 1999;276:R178-83.

28 Taylor JA, Carr DL, Myers CW, Eckberg DL: Mechanisms underlying very-low-frequency RR-interval oscillations in humans. Circulation 1998;98:547-55.

29 Davenport A, Cox C, Thuraisingham R: Blood pressure control and symptomatic intradialytic hypotension in diabetic haemodialysis patients: A cross-sectional survey. Nephron Clin Pract 2008;109:c65-71.

30 Shoji T, Tsubakihara Y, Fujii M, Imai E: Hemodialysis-associated hypotension as an independent risk factor for two-year mortality in hemodialysis patients. Kidney Int 2004;66:1212-20.

31 Koomans HA, Blankestijn PJ, Joles JA: Sympathetic hyperactivity in chronic renal failure: A wake-up call. J Am Soc Nephrol 2004;15:524-37.

32 Kotanko P: Cause and consequences of sympathetic hyperactivity in chronic kidney disease. Blood Purif 2006;24:95-9.

33 Pincus SM: Approximate entropy as a measure of system complexity. Proc Natl Acad Sci U S A. 1991;88:2297-2301. 


\section{Chapter 4}

Fatigue in hemodialysis patients with and without diabetes mellitus: Results from a randomized controlled trial of two glucose-containing dialysates

JG Raimann, A Kruse, S Thijssen, V Kuntsevich, JA. Diaz-Buxo, NW Levin, P Kotanko

Diabetes Care 2010;33:e121

(Letter to the Editor) 
In hemodialysis (HD) dialysate glucose concentrations differ worldwide between 0 and $200 \mathrm{mg} / \mathrm{dl}$ and can, if above the serum glucose levels, lead to diffusive glucose shifts into the patient ${ }^{1}$. The effects of glucose $e^{2}$ and insulin ${ }^{3}$ on the autonomic nervous system, as well as during HD with different glucose concentrations ${ }^{4}$ have been reported. However the effect of dialysate glucose on fatigue has not been studied. This study investigated fatigue in chronic HD subjects treated with $100 \mathrm{mg} / \mathrm{dl}$ versus $200 \mathrm{mg} / \mathrm{dl}$ dialysate glucose (G100; G200).

In this randomized, cross-over, multi-center study (www.clinicaltrials.gov: \#NCT00618033), diabetic and non-diabetic patients were enrolled in a 1:1 fashion. Diabetes mellitus (DM) was defined as either requiring oral antidiabetic medication or insulin or having random blood glucose levels above $200 \mathrm{mg} / \mathrm{dl}$ during the preceding 12 months. The study protocol was approved by the Beth Israel Medical Center Institutional Review Board and was conducted in full accordance to the Declaration of Helsinki.

Subjects were randomized to receive either G200 or G100 with a cross-over after 3 weeks. Dialysis regimen and medication remained unchanged during the study.

At the end of each period patient's perception of fatigue was assessed by the 9-items Fatigue Severity Scale (FSS) ${ }^{5}$. The FSS score ranges from 1 to 7 , with lower scores indicating less fatigue. The FSS comprises 9 items grouped in 6 domains: 1 ) motivation, 2) exercise, 3) physical functioning (2 items), 4) duties and responsibilities, 5) social life, and 6) subjective perception of fatigue (3 items). Internal test consistency was assessed by Cronbach's Alpha. Paired T-test was employed to compare FSS scores between G100 and G200, and unpaired T-test was used for comparison between diabetic and nondiabetic subjects. Data are displayed as mean \pm SD.

Thirty chronic HD patients (age $54 \pm 13$ years; 13 males; 13 blacks, 13 diabetic patients) were enrolled. One subject was withdrawn prior to any study intervention, two failed to complete both questionnaires. Internal consistency of the FSS was high (Cronbach's Alpha 0.9). FSS scores were significantly higher with G200 as compared to $G 100$ in

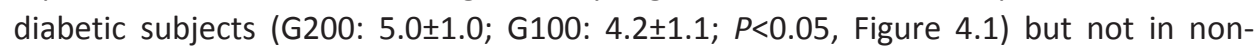
diabetic subjects (G200: 3.5 $\pm 1.9 ; \mathrm{G} 100: 3.0 \pm 1.6 ; P=0.234$, Figure 4.1 ). In cross-sectional analysis, FSS was higher in diabetic patients (G200: $+1.3 \pm 0.6, P<0.05 ; \mathrm{G} 100:+1.2 \pm 0.5$; $P<0.05$; Figure 4.1).

Post-dialytic fatigue is more pronounced in diabetic than in non-diabetic patients and is significantly increased with the use of G200. G100 decreased fatigue in diabetic patients to a level observed in healthy subjects ${ }^{5}$. Why diabetic subjects experience more post-dialytic fatigue remains to be determined; effects of glucose on the autonomic nervous system may be relevant ${ }^{4}$. Based on these results $\mathrm{G} 100$ offers advantages over $\mathrm{G} 200$ in diabetic HD patients. 


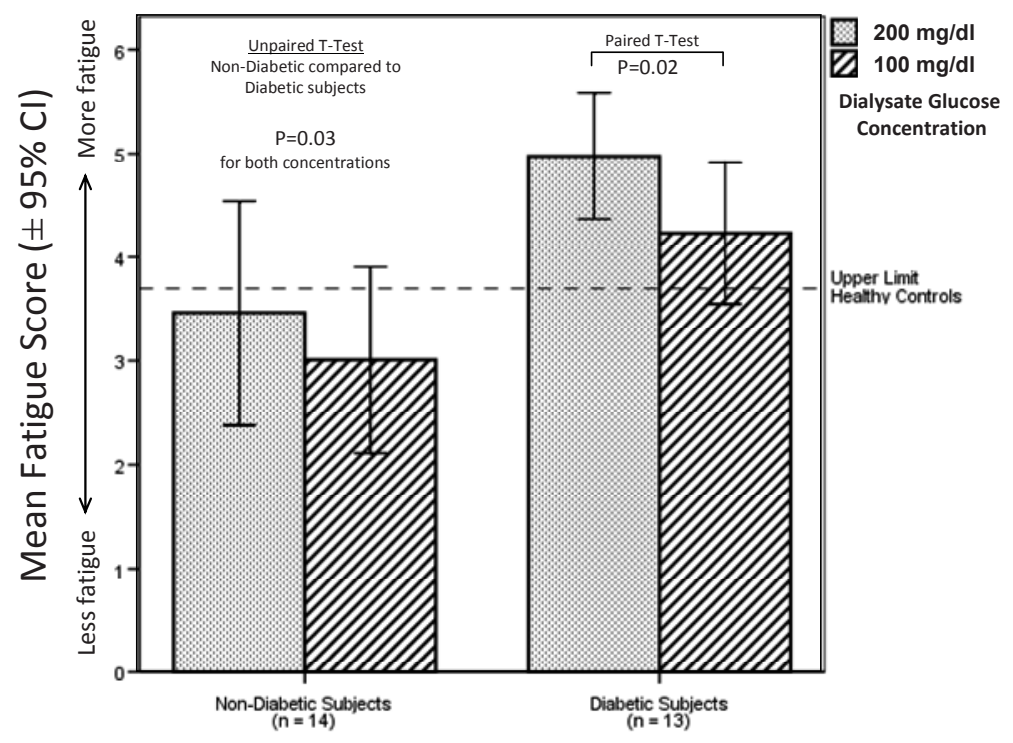

Figure 4.1 Fatigue Severity Scale (FSS) score in chronic hemodialysis patients with and without DM. Dialysates containing $200 \mathrm{mg} / \mathrm{dl}$ (dotted bars) and $100 \mathrm{mg} / \mathrm{dl}$ glucose (hatched bars), respectively, were used in a prospective and randomized fashion. The horizontal dashed line shows the upper limit of FSS score in healthy controls ([5]). Data represent means and 95\% confidence intervals. 


\section{References}

1. Schneditz D, Hafner-Giessauf $\mathrm{H}$, Holzer $\mathrm{H}$, et al. Intracorporeal glucose disposal during hemodialysis after a standardized glucose load. ASAIO J 2010;56:204-9.

2. Kanaley JA, Baynard T, Franklin RM, et al. The effects of a glucose load and sympathetic challenge on autonomic function in obese women with and without type 2 diabetes mellitus. Metabolism 2007; 56:778-85.

3. Paolisso G, Manzella D, Rizzo MR, et al. Effects of insulin on the cardiac autonomic nervous system in insulin-resistant states. Clin Sci (Lond) 2000;98:129-36.

4. Ferrario M, Raimann JG, Thijssen S, et al. Effects of Dialysate Glucose Concentration on Heart Rate Variability in Chronic Hemodialysis Patients: Results of a Prospective Randomized Trial. Kidney Blood Press Res 2011;34:334-43.

5. Krupp LB, LaRocca NG, Muir-Nash J, et al. The fatigue severity scale. Application to patients with multiple sclerosis and systemic lupus erythematosus. Arch Neurol 1989;46:1121-3. 


\section{Chapter}

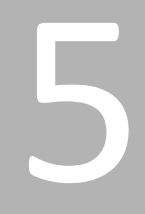

Correction of serum sodium for glucose concentration in hemodialysis patients with poor glucose control 
As a rule of thumb in clinical medicine, the serum sodium concentration decreases by $1.6 \mathrm{mEq} / \mathrm{l}$ for every $100 \mathrm{mg} / \mathrm{dl}$ increase in glucose concentration due to water shifts from the intracellular to the extracellular compartment ${ }^{1}$. This correction factor is based on theoretical considerations and has not been well validated. An experimental study in healthy subjects found significantly greater decreases in sodium concentration than expected when using the standard correction factor, especially when glucose concentrations were above $400 \mathrm{mg} / \mathrm{dl}^{2}$. It was suggested that a correction factor of $2.4 \mathrm{mEq} / \mathrm{l}$ per $100 \mathrm{mg} / \mathrm{dl}$ increase in glucose concentration might be a better overall estimate of the association between the serum sodium and glucose concentrations ${ }^{2}$.

Exact knowledge of this correction factor for hemodialysis (HD) patients is increasingly important in view of recent efforts to align the sodium concentration in the dialysis fluid with that of the serum during HD treatment ${ }^{3,4}$. A sodium concentration in the dialysis fluid higher than the serum sodium may lead to sodium loading and subsequent thirst, increased interdialytic weight gain, and hypertension. On the other hand, a sodium concentration in the dialysis fluid lower than the serum sodium may lead to a net sodium loss and has been associated with intradialytic symptoms such as hypotension and muscle cramps. Dialysis-related morbidity can be significantly reduced when the sodium concentration of the dialysis fluid is aligned with the serum sodium ${ }^{3}$. Although serum sodium measurements are stable over time, alignment of the dialysate sodium concentration in HD patients with highly variable glucose concentrations is challenging, and an adjustment may be needed ${ }^{5}$. Therefore, we recently evaluated the relation between serum sodium and glucose concentrations in HD patients with poor glucose control.

From a cohort of 4,532 prevalent patients receiving HD at one of our facilities between January and December 2009, we identified 208 patients with at least three available monthly serum sodium and glucose measurements and with a difference between the lowest and highest glucose value of more than $300 \mathrm{mg} / \mathrm{dl}$. The mean ( \pm SD) age of these patients was $55 \pm 13$ years, $52 \%$ were male and $55 \%$ were black. Glucose values ranged from 81 to $549 \mathrm{mg} / \mathrm{dl}$ (5th and 95th percentiles, respectively). We calculated the slope for the relation between serum sodium and glucose for each individual. The mean slope was $-1.47 \pm 0.82 \mathrm{mEq} / \mathrm{l}$ per $100 \mathrm{mg} / \mathrm{dl}$ increase in glucose level, which was significantly lower than the standard correction factor of $1.6(P=0.02)$. In other words, each increase in the glucose level by $68 \mathrm{mg} / \mathrm{dl}$ lowered the serum sodium concentration with $1 \mathrm{mEq} / \mathrm{l}$. The slope was independent of age, sex, and race. Although the interpretation of these data is limited due to their retrospective character, they do represent routine clinical practice.

We conclude that the reduction in sodium concentration of $1.5 \mathrm{mEq} / \mathrm{l}$ per $100 \mathrm{mg} / \mathrm{dl}$ increase in glucose concentration found in our study is slightly lower than $1.6 \mathrm{mEq} / \mathrm{l}$ generally used in clinical practice. However, for clinical purposes our data validate the established correction factor of $1.6 \mathrm{mEq} / \mathrm{l}$. 


\section{References}

1. Katz MA. Hyperglycemia-induced hyponatremia-calculation of expected serum sodium depression. $\mathrm{N}$ Engl J Med 1973;289:843-4.

2. Hillier TA, Abbott RD, Barrett EJ. Hyponatremia: evaluating the correction factorfor hyperglycemia. Am J Med 1999;106:399-403.

3. de Paula FM, Peixoto AJ, Pinto LV, Dorigo D, Patricio PJ, Santos SF. Clinical consequences of an individualized dialysate sodium prescription in hemodialysis patients. Kidney Int 2004;66:1232-38.

4. Raimann J, Usvyat L, Sergeyeva O, Thijssen S, Ulloa D, Ramos R, Tarallo M, Kotanko P, Levin NW. A novel algorithm for the prescription of dialysate $\mathrm{Na}^{+}$in chronic hemodialysis patients (Abstract). J Am Soc Nephrol 2009;20:446A.

5. Peixoto AJ, Gowda N, Parikh CR, Santos SF. Long-term stability of serum sodium in hemodialysis patients. Blood Purif 2010;29:264-7. 



\section{Chapter}

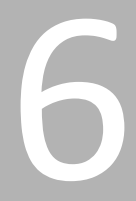

Sodium alignment in clinical practice implementation and implications

JG Raimann, S Thijssen, LA Usvyat, NW Levin, P Kotanko Semin Dial 2011;24:587-92 


\section{Abstract}

Numerous reports in the general and the dialysis population have shown associations of sodium $\left(\mathrm{Na}^{+}\right)$intake, blood pressure and survival. In addition to dietary $\mathrm{Na}^{+}$-intake, positive $\mathrm{Na}^{+}$-balance during dialysis also needs to be considered as a source of $\mathrm{Na}^{+}$. Dialysate $\mathrm{Na}^{+}\left(\mathrm{DNa}^{+}\right)$ concentrations above the serum sodium concentration $\left(\mathrm{SNa}^{+}\right)$result in diffusive $\mathrm{Na}^{+}$-flux from the dialysate into the patient which has recently been reported to be associated with increased interdialytic weight gain and mortality. Individualization of the $\mathrm{Na}^{+}$-prescription and $\mathrm{Na}^{+}-$ alignment ( $\mathrm{DNa}^{+}$equal to $\mathrm{SNa}^{+}$) prevents positive $\mathrm{Na}^{+}$balance and improves patient outcomes. Alignment requires the knowledge of patients' $\mathrm{SNa}^{+}$, which can be estimated from previous $\mathrm{SNa}^{+}$ in the monthly routine laboratory measurements. $\mathrm{Na}^{+}$alignment was recently implemented in a dialysis clinic of Renal Research Institute (RRI). Preliminary results of this initiative have shown a trend of predialysis weight and blood pressure reduction. Expansion of this initiative to all clinics of RRI is currently underway and as of April 2011 four additional clinics have been included.

Additional research on adequate $\mathrm{Na}^{+}$-alignment is needed to account for Gibbs-Donnan effects, differences in charges across the dialyzer membrane and variability in measurement methods. Regular calibration of $\mathrm{DNa}^{+}$-delivery by dialysis machines is necessary to ensure that the dialysis prescription is followed. How to provide dialysis to severely hyponatremic patients remains an open question. Finally, long term studies of the effects of $\mathrm{Na}^{+}$restriction on hospitalization and mortality are required to demonstrate the benefits of aligning $\mathrm{DNa}^{+}$with $\mathrm{SNa}^{+}$. 
Sodium $\left(\mathrm{Na}^{+}\right)$is an alkali metal with an atomic weight of 23 Daltons. It is the main solute of extracellular volume and the main determinant of serum osmolality. Body hydration is determined mainly as an accumulation of salt $(\mathrm{NaCl})$ and water. In healthy individuals, $\mathrm{Na}^{+}$and osmolality homeostasis is tightly controlled at an osmolality of 275 to $299 \mathrm{mOsm} / \mathrm{kg}$ by several regulatory mechanisms such as thirst-triggered water intake promoted by osmoreceptors in the brain, the effects of vasopressin and the renal response to vasopressin ${ }^{1}$. One of the consequences of decreasing kidney function is the decline of excretory capabilities of the kidney, which leads to accumulation of volume, and consequently fluid overload. The sequelae of fluid overload and the problems associated with the determination of "Dry Weight", which may be defined as the state of physiological hydration in dialysis patients, have been discussed in detail ${ }^{2}$. Fluid overload can only be prevented by effective body hydration management by means of ultrafiltration and the removal of the entire excess fluid during dialysis; this requires simultaneous restriction of salt and water intake.

Salt restriction, both dietary and during dialysis, is of high importance due to various pathophysiological implications. Many reports in the general population have shown that high dietary $\mathrm{Na}^{+}$-intake is associated with elevated blood pressure, cardiovascular events and death ${ }^{3-5}$, although this was recently challenged ${ }^{6}$. Beneficial effects of dietary salt restriction have also been shown in hemodialysis patients, where salt restriction and improved volume control led to regression of left ventricular hypertrophy ${ }^{7}$ and increased survival ${ }^{8}$.

$\mathrm{Na}^{+}$balance during dialysis as a potential source of $\mathrm{Na}^{+}$is an equally important concern. An increased dialysate to serum $\mathrm{Na}^{+}$gradient $\left(\mathrm{GNa}^{+}\right)$is defined as a positive difference between dialysate $\mathrm{Na}^{+}\left(\mathrm{DNa}^{+}\right)$and serum $\mathrm{Na}^{+}\left(\mathrm{SNa}^{+}\right)$:

$$
\mathrm{GNa}^{+}=\mathrm{DNa}^{+}-\mathrm{SNa}^{+}
$$

and is associated with increased thirst ${ }^{9}$, interdialytic weight gain ${ }^{9-11}$ and mortality ${ }^{11}$. Penne et al. showed an association between an increased occurrence of intradialytic morbidity and positive $\mathrm{GNa}^{+}$in a retrospective observational study ${ }^{12}$ and reported that a positive $\mathrm{GNa}^{+}$may be associated with an increased occurrence of intradialytic hypertension $^{13}$.

An effective strategy to avoid intradialytic $\mathrm{Na}^{+}$loading is choosing lower $\mathrm{DNa}^{+}$dialysate concentrations or to align $\mathrm{DNa}^{+}$to $\mathrm{SNa}^{+}$, which requires the knowledge of $\mathrm{SNa}^{+}$. Lowering $\mathrm{DNa}^{+}$has recently been shown to have positive effects on flow-mediated vasodilatation $^{14}$, which is a marker of endothelial dysfunction ${ }^{15}$. $\mathrm{Na}^{+}$-alignment was shown in the 1980 s to effectively reduce interdialytic weight gains ${ }^{16}$. In a patient population of 150 patients, choosing $\mathrm{DNa}^{+}$based on historic $\mathrm{SNa}^{+}$-measurements, 
which the authors named the equilibrium point, did result in a decrease of interdialytic hypertension, antihypertensive drug requirements and intradialytic morbidity ${ }^{16}$. In addition, another study showed that $\mathrm{Na}^{+}$-alignment results in decreased interdialytic weight gain, thirst, intradialytic morbidity and blood pressure in hypertensive patients $^{17}$.

\section{Algorithm for Sodium Alignment}

An operational roadblock to $\mathrm{Na}^{+}$alignment is the feasibility of measuring $\mathrm{SNa}^{+}$prior to every dialysis treatment, which is a requirement for on-site $\mathrm{Na}^{+}$-alignment. This is incompatible with the potential of daily routine in busy dialysis clinics and is also associated with additional costs. An alternative to a direct measurement of sodium may be the measurement of conductivity in serum and dialysate as a surrogate of $\mathrm{SNa}^{+}$and $\mathrm{DNa}^{+}$, however this also requires use of additional devices and results in additional costs. Furthermore the relation between $\mathrm{SNa}^{+}$and conductivity is influenced by many factors such as protein binding and complexation with anions such as sulfate and phosphate. These factors may potentially affect the accuracy of currently available methods.

A promising solution to avoid the problems of pre-dialysis measurements of $\mathrm{SNa}^{+}$and conductivity based surrogates is to use historic values. An association between increased interdialytic weight gain and mean arterial pressure with $\mathrm{DNa}^{+}$above patients' individual setpoint was reported in 58 hemodialysis patients ${ }^{18}$. The setpoint was computed from monthly routine labs over an observation period that ranged from 9 to 16 months for every patient ${ }^{18}$.

The setpoint hypothesis by Keen et al. is corroborated by a recent publication showing a coefficient of variation of only $1.6 \%$ of monthly $\mathrm{SNa}^{+}$in 100 patients over the period of 12 months ${ }^{19}$. An algorithm to estimate $\mathrm{SNa}^{+}$for a particular month by use of monthly $\mathrm{SNa}^{+}$measurements over the preceding 12 months was developed in a simulation applied to a population of 3248 chronic hemodialysis patients. This approach narrowed the distribution of $\mathrm{GNa}^{+}$and reduced the occurrence of extremely high $\mathrm{GNa}^{+} 20$. Additional analyses averaging four months' of $\mathrm{SNa}^{+}$measurements resulted in accurate prediction with low variability and reliable results (Figures 6.1 and 6.2). Inclusion of more than four months only offers marginal decreases of variability, as reflected by the slope of the function in Figure 6.1. 


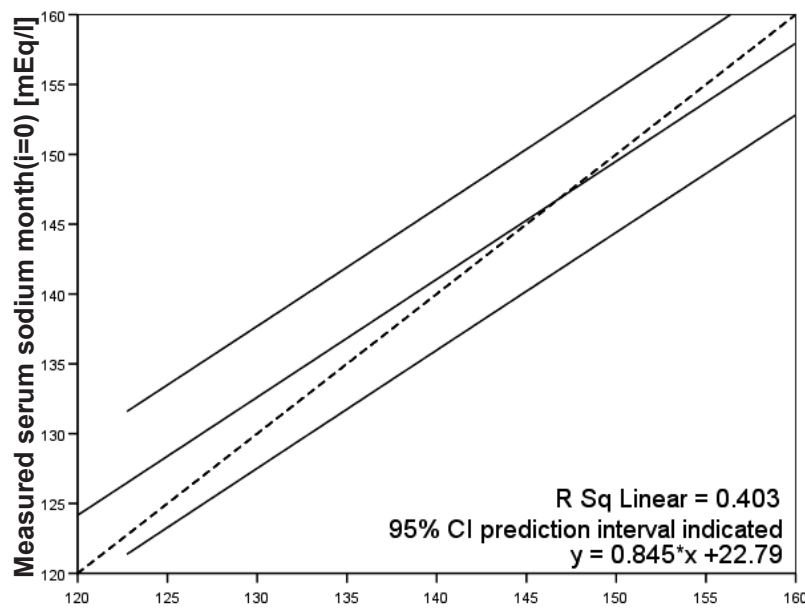

Average serum sodium month(i=0) to month(i=4) $[\mathrm{mEq} / \mathrm{l}]$

Figure 6.1 Regression analysis of measured serum sodium in the observed month 01/2009 versus the average of the preceding 4 months (09/2008 to 12/2008) in 3248 chronic hemodialysis patients.

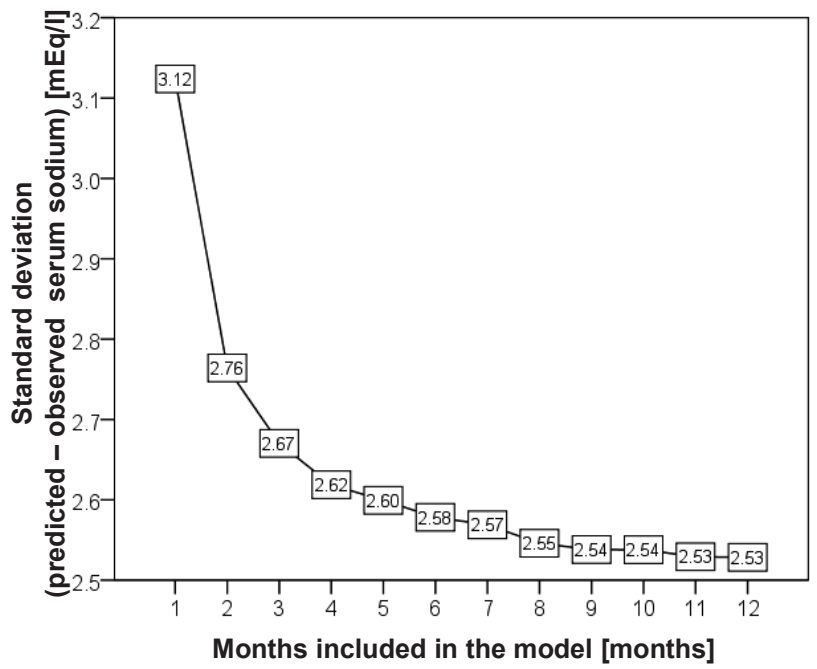

Figure 6.2 Standard deviation of the difference between the predicted serum sodium, computed as the average of monthly routine serum sodium measurements over a certain period of time, and the actual measured serum sodium concentration versus the number of months used for the calculation of the average serum sodium concentration. Observed month was $01 / 2009$ and the analysis contains data of 3114 chronic hemodialysis patients. 


\section{Implementation of $\mathrm{Na}^{+}$Alignment}

In April 2010, sodium alignment was implemented in the clinical routine of a Renal Research Institute dialysis clinic with 140 patients in Sanford, North Carolina, for the first time (Figure 6.3) $\mathrm{SNa}^{+}$measurements, using indirect potentiometry of the monthly routine blood draws, are transferred by Spectra Laboratories (Rockleigh, New Jersey) to the Data Warehouse. The Data Warehouse is an Oracle-based database that contains clinical, demographic, treatment and patient-related parameters. $\mathrm{SNa}^{+}$measurements are obtained from the database, the algorithm is applied to the last 4 measurements, the setpoint is determined and the information for every aligned patient is forwarded to the clinic. The nurse manager collects the data, forwards it to the treating physician, who decides the changes made to the prescription for this patient for the upcoming interval, until the next $\mathrm{SNa}^{+}$in the following month is available. The active $\mathrm{DNa}^{+}$ prescription is also entered into the Data Warehouse to centrally coordinate and ensure effective and adequate implementation of the algorithm.

The algorithm was only used for patients with a positive $\mathrm{GNa}^{+}$and for safety reasons it was implemented as follows: patients with a $\mathrm{DNa}^{+}$minus predicted $\mathrm{SNa}^{+}$of lower than $5 \mathrm{mEq} / \mathrm{I}$ received dialysis with a $\mathrm{DNa}^{+}$concentration equal to their predicted $\mathrm{SNa}^{+}$after the switch to $\mathrm{Na}^{+}$-alignment. Patients whose $\mathrm{DNa}^{+}$minus predicted $\mathrm{SNa}^{+}$was higher than $5 \mathrm{mEq} / \mathrm{l}$ received a $\mathrm{DNa}^{+}$concentration reduction of $5 \mathrm{mEq} / \mathrm{l}$ until the next month.

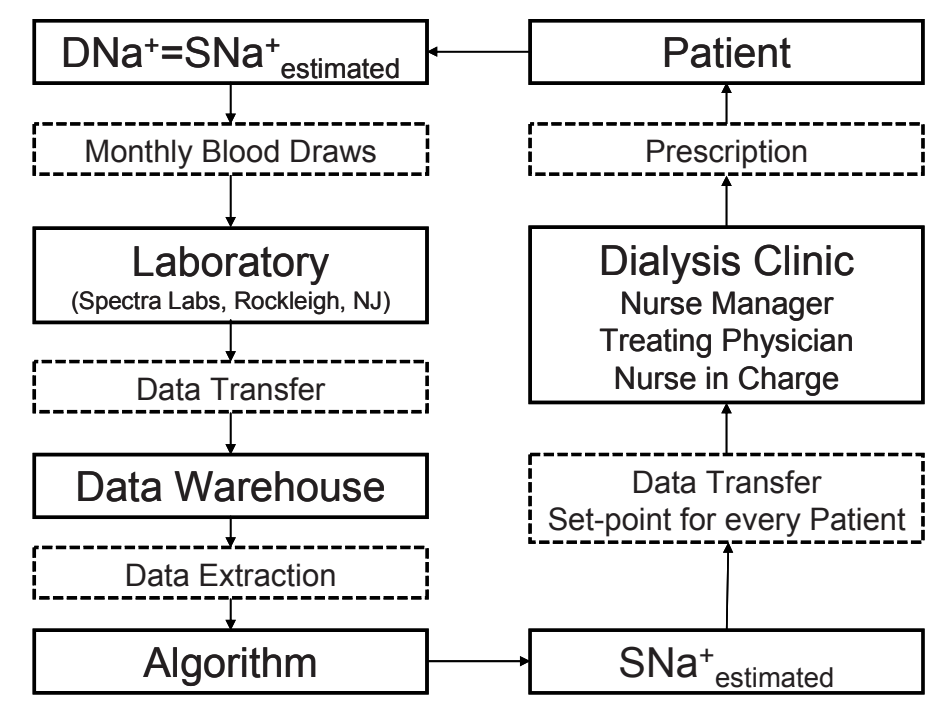

Figure 6.3 Process of clinical implication of statistical $\mathrm{Na}^{+}$alignment. Key personnel are the database analyst, the Head Nurse, and the attending physician. 


\section{Preliminary Results}

Data of aligned patients and those not subject to alignment were collected from January, to March,2010, prior to the switch to $\mathrm{Na}^{+}$alignment (May,2010). Data obtained from July to September 2010 were used for this interim-analysis and compared in a paired fashion for every individual patient and also between patients converted to alignment to those not subject to alignment. The number of aligned patients was rather small $(n=20)$ and the analysis underpowered, which may be one of the reasons that the results of this interim-analysis were not significant. A remarkable, yet non-significant trend of weight, as well as blood pressure decrease can be seen in the group with $\mathrm{Na}^{+}$-alignment (Tables 6.1 and 6.2) ${ }^{21}$. As of April 2011, four additional dialysis clinics in Connecticut, two clinics in New York State and one clinic in North Carolina were switched to $\mathrm{Na}^{+}$-alignment. Three more clinics in North Carolina will follow in May 2011 and subsequently all units operated by the Renal Research Institute will be switched to $\mathrm{Na}^{+}$-alignment using this method.

Table 6.1 Pre-dialysis body weight [kg] before and after implementation of a $\mathrm{Na}^{+}$alignment algorithm.

\begin{tabular}{lcccc}
\hline & $\begin{array}{c}\text { Before Alignment } \\
\text { Mean } \pm \text { SD }\end{array}$ & $\begin{array}{c}\text { After Alignment } \\
\text { Mean } \pm \text { SD }\end{array}$ & $\begin{array}{c}\text { Difference } \\
(\mathbf{9 5 \%} \mathrm{Cl})\end{array}$ & $\begin{array}{c}\text { Treatment effect } \\
\mathbf{( 9 5 \% ~ C l )}\end{array}$ \\
\hline $\begin{array}{l}\text { Alignment }(\mathrm{n}=20) \\
{[\mathrm{kg}]}\end{array}$ & $81.1 \pm 25.5$ & $78.8 \pm 24.5$ & $-2.2(-4.6$ to 0.08$)$ & $-1.6(-4.0$ to 0.8$)$ \\
$\begin{array}{l}\text { No Alignment }(\mathrm{n}=108) \\
{[\mathrm{kg}]}\end{array}$ & $82.7 \pm 25.0$ & $82.0 \pm 25.3$ & $-0.6(-1.3$ to 0.02$)$ & \\
\hline
\end{tabular}

No significant differences found.

Table 6.2 Pre-dialysis systolic blood pressure $[\mathrm{mmHg}]$ before and after implementation of a $\mathrm{Na}^{+}$alignment algorithm.

\begin{tabular}{|c|c|c|c|c|}
\hline & $\begin{array}{c}\text { Before Alignment } \\
\text { Mean } \pm S D\end{array}$ & $\begin{array}{c}\text { After Alignment } \\
\text { Mean } \pm S D\end{array}$ & Difference $(95 \% \mathrm{CI})$ & $\begin{array}{c}\text { Treatment effect } \\
(95 \% \mathrm{Cl}) \\
\end{array}$ \\
\hline $\begin{array}{l}\text { Alignment }(\mathrm{n}=20) \\
{[\mathrm{mmHg}]}\end{array}$ & $154.3 \pm 18.4$ & $146.7 \pm 20.7$ & $-7.6(-13.9 \text { to }-1.3)^{*}$ & $-4.8(-12.6$ to 2.9$)$ \\
\hline $\begin{array}{l}\text { No Alignment }(\mathrm{n}=108) \\
{[\mathrm{mmHg}]}\end{array}$ & $154.6 \pm 18.1$ & $151.8 \pm 19.6$ & $-2.8(-5.9$ to 0.4$)$ & \\
\hline
\end{tabular}

${ }^{*} \mathrm{P}<0.05$

\section{Additional Considerations}

Additional technical and physiological aspects are still to be considered and additional research is needed. 


\section{Technical Aspects}

\section{Further Adjustments of Sodium alignment}

Following the principle of diffusion, $\mathrm{Na}^{+}$fluxes from the compartment with the higher concentration to the one with the lower concentration aiming to establish equilibrium. The Gibbs Donnan effect ${ }^{22}$ aiming to establish electroneutrality, alters this diffusive flux of positively charged $\mathrm{Na}^{+}$ions because negatively charged plasma proteins are unable to pass through the membrane ${ }^{23}$. This effect, quantified by the Donnan coefficient $\alpha$, has been characterized as follows ${ }^{22}$ :

Donnan - coefficient $\alpha=1.007-0.009 \times$ TP ,

where TP is the total protein concentration in $\mathrm{g} / \mathrm{dl}$.

The other major aspect important to $\mathrm{Na}^{+}$-alignment is that osmotically active $\mathrm{Na}^{+}$ distributes in the plasma water only. Plasma contains approximately $94 \%$ water and $6 \%$ void volume consisting of proteins and lipids. Separation of plasma water from proteins and lipids is only possible by means of ultracentrifugation, which is not commonly used in clinical routine. For this reason, when using sodium alignment, it is crucial to know and understand the methods used for the determination of $\mathrm{SNa}^{+}$. Flame photometry, considered the gold standard for the measurement of $\mathrm{Na}^{+}$, measures total $\mathrm{Na}^{+}$in a defined volume. In contrast, direct potentiometry measures the electrically active $\mathrm{Na}^{+}$ concentration in plasma water. Resulting values will be higher according to the void volume in comparison to those measured with flame photometry ${ }^{24}$. Results obtained with direct potentiometry are adjusted and automatically integrated into the provision of results ${ }^{25}$. The most commonly used method in clinical routine is indirect potentiometry, which involves dilution (usually 1:20) of the sample. Dilution lowers the concentration of $\mathrm{Na}^{+}$and TP according to the dilution factor and adjustment for the void volume after dilution renders the void volume in the sample a negligible factor in the measurement. In a second step, the measured $\mathrm{Na}^{+}$concentration in the diluted sample is divided by the dilution factor, with results of $\mathrm{Na}^{+}$in plasma highly correlated with results obtained by flame photometry. Notably, both methods are flawed, though to markedly different degrees, because of some level of dependence on lipid and protein concentrations.

The measurement method is important for effective application of $\mathrm{Na}^{+}$-alignment. The sodium concentration that effectively builds the gradient with the dialysate sodium is the concentration in the plasma water. In order to know the required $\mathrm{DNa}^{+}$, the $\mathrm{SNa}^{+}$ needs to be adjusted to estimate the plasma water $\mathrm{Na}^{+}\left(\mathrm{PWNa}^{+}\right)$concentration. According to Gotch et al., this can be done with the following equation: 
$P W N a^{+}=\frac{S N a^{+}}{0.989-0.0047^{\prime} T P}$

In summary, when performing $\mathrm{Na}^{+}$-alignment calculations, the void volume and the Gibbs Donnan effect can be included. Arithmetically this is done as follows:

$$
S^{\prime} \mathrm{Na}^{+}=S \mathrm{Na}^{+} \cdot \frac{1.007-0.009^{\prime} \mathrm{TP}}{0.989-0.0047^{\prime} \mathrm{TP}} \text {. }
$$

It should be noted that the adjustment proposed by Gotch et al. does not consider lipid concentrations as part of the void volume. In the presence of hyperlipidemia the algorithm by Waugh et al. which incorporates TP and lipids may be more precise ${ }^{26}$.

\section{Calibration of Dialysis Machines}

Another important consideration in the prescription of dialysate $\mathrm{Na}$ is the calibration of the dialysis machines. The $\mathrm{DNa}^{+}$is available on a technical screen on the dialysis machine and is delivered as a mixture of the acid and the bicarbonate dialysis fluid flow. Adjustment changes the delivery of $\mathrm{DNa}^{+}$(and the mixture of acid and bicarbonate streams), which is controlled by monitoring the conductance of the dialysis fluid. This is a dynamic measurement and does not reflect the absolute value of delivered $\mathrm{DNa}^{+}$, which means that the measurement of conductance will keep delivery in a certain range $( \pm 0.1 \mathrm{mS})$. This implies that delivery of sodium will be within this range, but this does not mean the dialysis machine is delivering the correct level of $\mathrm{DNa}^{+}$, since the absolute value is determined by the flow and the ratio between acid and bicarbonate streams. For this reason, the quality of $\mathrm{DNa}^{+}$delivery must be assured by quality control programs such as regular $\mathrm{DNa}^{+}$measurements and machine calibration. A recently presented study found that the re-calibration of 71 dialysis machines in a dialysis clinic in London, United Kingdom resulted in significant decreases in delivered $\mathrm{DNa}^{+}$, the need of antihypertensive medication, interdialytic weight gain, (as reflected by ultrafiltration volume in the subsequent dialysis treatments), and a borderline significant decrease of blood pressure $(P=0.07)^{27}$.

\section{Physiological Aspects}

Some physiological aspects of $\mathrm{Na}^{+}$alignment warrant further studies. For example, it is unclear if alignment is beneficial for patients with $\mathrm{SNa}^{+}$higher than $\mathrm{DNa}^{+}$, particularly in regard to intradialytic morbid events. Even more challenging is the question if (and to what extent) severely hyponatremic patients should undergo $\mathrm{Na}^{+}$-alignment.

Analyses in 3248 chronic hemodialysis patients receiving dialysis in Renal Research Institute clinics showed that patients with a $\mathrm{SNa}^{+}$in the range from 130 to $136 \mathrm{mEq} / \mathrm{I}$ have the highest level of variation (Figure 6.4) making them a challenging subgroup for 
$\mathrm{Na}^{+}$alignment. These patients may represent a group with other illnesses in addition to kidney disease and are known to have lower survival rates compared to patients with higher $\mathrm{SNa}^{+}{ }^{28}$. When performing data analyses, patients' $\mathrm{SNa}^{+}$should be taken into account if the effects of $\mathrm{SNa}^{+}$and $\mathrm{GNa}^{+}$on survival are to be distinguished. However, the knowledge at this point is limited to retrospective, cross-sectional analyses, which are not conclusive about the possible reasons for hyponatremia, It may be argued that these patients may have more intradialytic morbid events as well as some elements of dialysis disequilibrium syndrome if dialyzed with a dialysate of low $\mathrm{Na}^{+}$concentration ${ }^{29}$. The treating physician should decide whether a patient receives $\mathrm{Na}^{+}$-alignment.

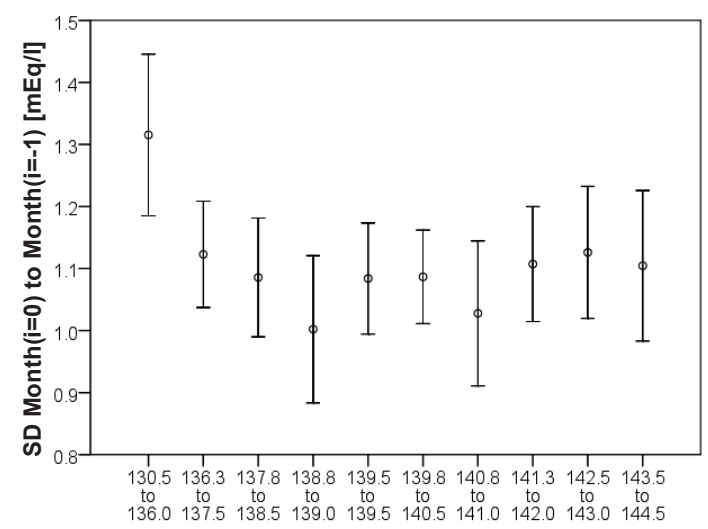

Average Month(i=0) to Month(i=-1) [mEq/l]

Figure 6.4 Predicted serum sodium, calculated as the average of all four serum sodium measurements in the Month $(i=0)$ to Month( $i=-3)$, subdivided in deciles versus the mean standard deviation (SD) and $95 \% \mathrm{Cl}$ of all four serum sodium measurements for every individual patient $(\mathrm{N}=3248)$. Patients with either a serum sodium above $145 \mathrm{mEq} / \mathrm{l}$ or below $130 \mathrm{mEq} / \mathrm{l}$ ( $\mathrm{n=31}$ ) were excluded for this analysis.

Another important aspect is $\mathrm{Na}^{+}$-alignment in diabetics, since glucose is osmotically active and hyperglycemia shifts water from the intracellular to the extracellular compartment ${ }^{30}$, which decreases $\mathrm{SNa}^{+}$because of dilution. This has been intensively researched, and correction factors have been proposed to estimate the actual $\mathrm{SNa}^{+}$. Katz and coworkers proposed a linear relation adding $1.6 \mathrm{mEq} / \mathrm{l}$ per every $100 \mathrm{mg} / \mathrm{dl}$ of glucose above $100 \mathrm{mg} / \mathrm{dl}^{31}$. Another study simulated a non-linear relation as the real relation of glucose increment and $\mathrm{SNa}^{+}$decrease ${ }^{32}$. A linear approach in chronic maintenance hemodialysis patients suggested a correction factor of $1.5 \mathrm{mEq} / \mathrm{l}$ decrease per $100 \mathrm{mg} / \mathrm{dl}$ increase of serum glucose ${ }^{33}$.

Other open questions such as how to align incident hemodialysis patients immediately after initiation of dialysis, the potential effects of seasonality, and the effects of comorbidities remain and require further research through retrospective and 
prospective studies. Whether the patient-specific $\mathrm{Na}^{+}$setpoint remains constant throughout the years or changes with alterations in extracellular fluid volume, comorbid conditions, age or therapy is not known. Therefore, it is imperative to use the running average of $\mathrm{SNa}^{+}$in determining $\mathrm{Na}^{+}$alignment for the time being.

In conclusion, $\mathrm{Na}^{+}$alignment by using this statistical approach is a simple and yet useful means to avoid intradialytic $\mathrm{Na}^{+}$-loading, and its sequelae. First steps of implementation in clinical routine have been done in dialysis clinics of the Renal Research Institute and expansion of this project is underway. The first promising results have been obtained. Long-term studies on hard outcomes such as mortality will show whether there is a real benefit of aligning $\mathrm{DNa}^{+}$with $\mathrm{SNa}^{+}$. 


\section{References}

1. Mount DB. The brain in hyponatremia: both culprit and victim. Semin Nephrol. 2009;29(3):196-215.

2. Raimann J, Liu L, Ulloa D, Kotanko P, Levin NW. Consequences of overhydration and the need for dry weight assessment. Contrib Nephrol. 2008;161:99-107.

3. Cook NR, Cutler JA, Obarzanek E, Buring JE, Rexrode KM, Kumanyika SK, Appel L, Whelton PK. Long term effects of dietary sodium reduction on cardiovascular disease outcomes: observational follow-up of the trials of hypertension prevention (TOHP). BMJ. 2007;334:885.

4. Sacks FM, Svetkey LP, Vollmer WM, Appel LJ, Bray GA, Harsha D, Obarzanek E, Conlin PR, Miller ER, 3rd, Simons-Morton DG, Karanja N, Lin PH. Effects on blood pressure of reduced dietary sodium and the Dietary Approaches to Stop Hypertension (DASH) diet. DASH-Sodium Collaborative Research Group. N Engl J Med. 2001;344:3-10.

5. Stamler J. The INTERSALT Study: background, methods, findings, and implications. Am J Clin Nutr. 1997;65(2 Suppl):626S-42S.

6. Stolarz-Skrzypek K, Kuznetsova T, Thijs L, Tikhonoff V, Seidlerova J, Richart T, Jin Y, Olszanecka A, Malyutina S, Casiglia E, Filipovsky J, Kawecka-Jaszcz K, Nikitin Y, Staessen JA. Fatal and nonfatal outcomes, incidence of hypertension, and blood pressure changes in relation to urinary sodium excretion. JAMA 2011;305:1777-85.

7. Ozkahya M, Ok E, Cirit M, Aydin S, Akcicek F, Basci A, Dorhout Mees EJ. Regression of left ventricular hypertrophy in haemodialysis patients by ultrafiltration and reduced salt intake without antihypertensive drugs. Nephrol Dial Transplant. 1998;13:1489-93.

8. Kayikcioglu M, Tumuklu M, Ozkahya M, Ozdogan O, Asci G, Duman S, Toz H, Can LH, Basci A, Ok E. The benefit of salt restriction in the treatment of end-stage renal disease by haemodialysis. Nephrol Dial Transplant. 2009;24:956-62.

9. Munoz Mendoza J, Sun S, Chertow GM, Moran J, Doss S, Schiller B. Dialysate sodium and sodium gradient in maintenance hemodialysis: a neglected sodium restriction approach? Nephrol Dial Transplant. 2011;26:1281-7.

10. Hecking $M$, Kainz A, Horl WH, Herkner H, Sunder-Plassmann G. Sodium setpoint and sodium gradient: influence on plasma sodium change and weight gain. Am J Nephrol. 2010;33:39-48.

11. Sergeveya O, Usvyat L, Kotanko P, Levin NW. Positive Intradialytic Sodium Gradients Relate to Reduced Survival in Chronic Hemodialysis Patients. J Am Soc Nephrol. 2008;19 (Abstract Supplement):71A-2A.

12. Penne EL, Usvyat LA, Raimann JG, Thijssen S, Sergeyeva O, Levin NW, Kotanko P. Intradialytic Sodium Gradient is a potential modifiable risk factor for intradialytic morbid events in chronic hemodialysis. NDT Plus. 2010;3:iii145.

13. Penne EL, Usvyat LA, Abbas SR, Sergeyeva O, Raimann JG, Thijssen S, Levin NW, Kotanko P. Relation between Intradialytic Changes in Systolic Blood Pressure and Sodium Gradient in Chronic Hemodialysis Patients. J Am Soc Nephrol. 2010;21 (Abstract Supplement):224A.

14. Aybal Kutlugun A, Erdem Y, Okutucu S, Yorgun H, Atalar E, Arici M. Effects of lowering dialysate sodium on flow-mediated dilatation in patients with chronic kidney disease. Nephrol Dial Transplant. 2011;26: 3678-82.

15. Corretti MC, Anderson TJ, Benjamin EJ, Celermajer D, Charbonneau F, Creager MA, Deanfield J, Drexler H, Gerhard-Herman M, Herrington D, Vallance P, Vita J, Vogel R. Guidelines for the ultrasound assessment of endothelial-dependent flow-mediated vasodilation of the brachial artery: a report of the International Brachial Artery Reactivity Task Force. J Am Coll Cardiol. 2002;39:257-65.

16. Murisasco A, France G, Leblond G, Durand C, el Mehdi M, Crevat A, Elsen R, Boobes Y, Baz M. Sequential sodium therapy allows correction of sodium-volume balance and reduces morbidity. Clin Nephrol. 1985;24:201-8.

17. de Paula FM, Peixoto AJ, Pinto LV, Dorigo D, Patricio PJ, Santos SF. Clinical consequences of an individualized dialysate sodium prescription in hemodialysis patients. Kidney Int. 2004;66:1232-8.

18. Keen ML, Gotch FA. The association of the sodium "setpoint" to interdialytic weight gain and blood pressure in hemodialysis patients. Int J Artif Organs. 2007;30:971-9.

19. Peixoto AJ, Gowda N, Parikh CR, Santos SF. Long-term stability of serum sodium in hemodialysis patients. Blood Purif. 2010;29:264-7. 
20. Raimann JG, Usvyat L, Sergeyeva O, Thijssen S, Ulloa D, Ramos R, Tarallo M, Kotanko P, Levin NW. A novel algorithm for prescription of dialysate sodium in chronic hemodialysis patients. J Am Soc Nephrol. 2009;20 (Abstract supplement):446A.

21. Thijssen S, Moore S, Usvyat LA, Balter P, Levin NW, Kotanko P. Effect of sodium alignment on blood pressure and body weight in hemodialysis patients. World Congress of Nephrology 2011 (abstract). 2011.

22. Gotch FA, Lam MA, Prowitt M, Keen M. Preliminary clinical results with sodium-volume modeling of hemodialysis therapy. Proc Clin Dial Transplant Forum. 1980;10:12-7.

23. Rugheimer L, Hansell $P$, Wolgast $M$. Determination of the charge of the plasma proteins and consequent Donnan equilibrium across the capillary barriers in the rat microvasculature. Acta Physiol (Oxf). 2008;194:335-9.

24. Preusse CJ, Fuchs C. [Comparison of ion-selective electrodes and flame photometry for the determination of serum $\mathrm{Na}+$ and $\mathrm{K}+$ for clinical purposes (author's transl)]. J Clin Chem Clin Biochem. 1979;17:639-45.

25. Burnett RW, Covington AK, Fogh-Andersen N, Kulpmann WR, Lewenstam A, Maas AH, Muller-Plathe O, Sachs C, Siggaard-Andersen O, VanKessel AL, Zijlstra WG. Recommendations for measurement of and conventions for reporting sodium and potassium by ion-selective electrodes in undiluted serum, plasma or whole blood. International Federation of Clinical Chemistry and Laboratory Medicine (IFCC). IFCC Scientific Division Working Group on Selective Electrodes. Clin Chem Lab Med. 2000;38:1065-71.

26. Waugh WH. Utility of expressing serum sodium per unit of water in assessing hyponatremia. Metabolism. 1969;18:706-12.

27. Edwards C, Singh S, Griffiths M, Cairns T, Taube D, Duncan N. Correct Calibration of Delivered Sodium Dialysate Concentration Results in Improved Blood Pressure Control. J Am Soc Nephrol. 2009;20 (Abstract Supplement):204A.

28. Waikar SS, Curhan GC, Brunelli SM. Mortality associated with low serum sodium concentration in maintenance hemodialysis. Am J Med. 2011;124:77-84.

29. Port FK, Johnson WJ, Klass DW. Prevention of dialysis disequilibrium syndrome by use of high sodium concentration in the dialysate. Kidney Int. 1973;3:327-33.

30. Seldin DW, Tarail R. Effect of hypertonic solutions on metabolism and excretion of electrolytes. Am J Physiol. 1949;159:160-74.

31 Katz MA: Hyperglycemia-induced hyponatremia-calculation of expected serum sodium depression. N Engl J Med 1973;289:843-4.

32. Robin AP, Ing TS, Lancaster GA, Soung LS, Sparagana M, Geis WP, Hano JE. Hyperglycemia-induced hyponatremia: a fresh look. Clin Chem. 1979;25:496-7.

33. Penne EL, Thijssen S, Raimann JG, Levin NW, Kotanko P. Correction of serum sodium for glucose concentration in hemodialysis patients with poor glucose control. Diabetes Care 2010;33:e91. 



\section{Chapter 7}

Relationship between pre hemodialysis serum sodium concentration and blood pressure: Results from a retrospective analysis from the international Monitoring Dialysis Outcomes (MONDO) initiative

JG Raimann, B Canaud, M Etter, JP Kooman, NW Levin, D Marcelli, C Marelli, A Power, FM van der Sande, S Thijssen, X Xu, LA Usvyat, Y Wang, P Kotanko and the MONDO Initiative 


\section{Abstract}

\section{Background}

A recent study from the UK indicates a relationship between pre-hemodialysis (HD) serum sodium ( $\mathrm{SNa}$ ) and systolic and diastolic blood pressure (SBP and DBP) in chronic HD patients. We extend this analysis to an international cohort of incident HD patients.

\section{Methods}

The Monitoring Dialysis Outcomes (MONDO) initiative encompasses patients from 26 countries. Over 2 years monthly pre-HD SNa ${ }^{+}$levels were used as predictors of pre-HD SBP and DBP in a linear mixed model (LMM) adjusted for age, gender, interdialytic weight gain, diabetes, serum albumin and calcium. Similar models were constructed with DBP as outcome. Analyses were carried out stratified by continent (North and South America; Europe and Asia). LMMs were also constructed for the entire observation period of 2 years, and separately the first and the second year after $\mathrm{HD}$ initiation.

\section{Results}

We studied 16,993 incident patients and found $\mathrm{SNa}^{+}$to have a significant slope estimate in the LMM predicting pre-HD SBP and DBP [ranging from 0.22 to 0.28 and 0.10 to $0.21 \mathrm{mmHg}$ per $\mathrm{mEq} / \mathrm{l}$, respectively, between the continents]. The findings were similar in subsets of SBP and $\mathrm{SNa}^{+}$tertiles, and separately analysed for the first and second year.

\section{Discussion and conclusion}

Our analysis shows an independent association between $\mathrm{SNa}^{+}$and $\mathrm{BP}$ in a large intercontinental database, indicating that this relation is a profound biological phenomenon in incident and prevalent HD patients, generalizable to an international level and independent of SBP and $\mathrm{SNa}^{+}$ magnitude. 


\section{Introduction}

"Hence if too much salt is used in food, the pulse hardens, tears make their appearance and the complexion changes." is written in the "Huangdi Neijing" (The Yellow Emperor's Classics of Internal Medicine), considered to be one of the first medical books which was firstly mentioned in $111 \mathrm{AD}$. Often quoted since by researchers in the field of sodium research, this mentioning reflects how well established the relationship between sodium intake and blood pressure (BP) is. In current days this relationship has been confirmed in various epidemiologic studies in the general population ${ }^{1-3}$ and the pathophysiologic mechanisms of these relationships are better understood. The classical theorem by Guyton suggests that short-term control of arterial BP is primarily a nervous function, whereas the long-term arterial pressure is principally a function of the fluid balance system ${ }^{4}$. While this is in principle true, sodium has also been determined to affect the cardiovascular system in a fluid-independent manner. Not only does sodium intake [and subsequently higher serum sodium concentrations $\left.\left(\mathrm{SNa}^{+}\right)\right]$increase arterial stiffness and wall thickness, it also increases blood and pulse pressure $^{5}$ over a short observation period ${ }^{6}$, but also over a longer period of time ${ }^{7,8}$.

On an epidemiologic level a recent publication by $\mathrm{He}$ et al. showed that $\mathrm{SNa}^{+}$in 651 chronic HD patients was a significant predictor of systolic and diastolic BP (SBP, DBP), which remained true even after adjustment for several relevant parameters with possible effect on the levels of $\mathrm{BP}^{9}$.

In the current analysis we extend the findings of He et al. ${ }^{9}$ to incident and prevalent HD patients in an international database and hypothesize that $\mathrm{SNa}^{+}$will be a predictor of both SBP and DBP in incident and prevalent HD patients on an international level.

\section{Methods}

The Monitoring Dialysis Outcomes (MONDO) initiative encompasses HD patients from 26 countries who started HD between 2000 and $2010^{10}$. Baseline characteristics of the included subjects have been published recently ${ }^{11}$. For this analysis data of incident patients who started HD between $1 / 1 / 2001$ and $7 / 30 / 2008$, in three databases from different continents (Renal Research Institute for North America, Fresenius Europe, Fresenius Asia-Pacific and Fresenius South America) were included and followed for an observation period of 12 months and a follow-up period of 6 further months. Database development and all subsequent analyses were conducted in compliance with local rules and regulations to protect data privacy and patients' rights. 


\section{Subset analyses}

Analyses were carried out in the whole data set and after stratification by continent (North America; South America, Europe and Asia-Pacific). Furthermore analyses for all included regions were carried out for the entire observation period, the first year, and the second year to analyze the relationship for incident and prevalent patients separately.

To confirm our results the analyses were repeated in subsets of $\mathrm{SNa}^{+}$concentration tertiles of $\mathrm{SNa}^{+}$(Tertile 1: $\leq 136.8 \mathrm{mEq} / \mathrm{l}$, Tertile 2: 136.8 to $139.0 \mathrm{mEq} / \mathrm{l}$ and Tertile 3: $\geq 139.2 \mathrm{mEq} / \mathrm{l}$ ), of SBP (Tertile 1: $\leq 133.2 \mathrm{mmHg}$, Tertile 2: 133.2 to $149.4 \mathrm{mmHg}$ and Tertile 3: $\geq 149.4 \mathrm{mmHg}$ ) and of DBP (Tertile 1: $\leq 70.0 \mathrm{mmHg}$, Tertile 2: 70.0 to 79.0 $\mathrm{mmHg}$ and Tertile 3: $\geq 79 \mathrm{mmHg}$ ). To exclude effects on the relationship by diabetes, more specifically from blood glucose levels and the antidiabetic treatment, we performed analyses in diabetic and non-diabetic subjects only.

\section{Statistical analysis}

Continuous data are reported as mean $\pm S D$ and categorical data as fractions of the analyzed population. Monthly pre-HD SNa ${ }^{+}$levels were used as fixed effects of pre-HD SBP and DBP prediction in a linear mixed model (LMM) with either random intercepts or random intercepts and random slopes, as determined by Likelihood Ratio Test (LRT) with two degrees of freedom for LMM comparison. According to the parameters included in the analyses of He et al. ${ }^{9}$ all LMMs were constructed including age, gender, interdialytic weight gain (IDWG; in \% of post-HD body weight), diabetes, serum albumin, potassium and calcium as fixed effects. Similar models were constructed with DBP as the outcome. All analyses were repeated in the subsets outlined above. A pvalue below 0.05 was considered significant. Analyses were conducted with $\mathrm{R}$ version 3.0.1 $1^{12}$ ("Good Sport"; R Foundation for Statistical Computing; Vienna, Austria) additionally using the packages nlme, multcomp and plyr.

\section{Results}

\section{Patient Population}

For the current analysis 216,554 HD treatments with available $\mathrm{SNa}^{+}$measurements of 16,993 incident HD patients were included, with 4,106 from the Renal Research Institute database, 1,456 from Asia, 9,705 from Europe and 1,726 from South America (Table 7.1). It is of note that there were differences in the reported parameters between the continents in terms of age, gender, IDWG and fraction of diabetic subjects in the population (Table 7.1). Histograms of SBP, DBP and $\mathrm{SNa}^{+}$are shown in 
Supplemental Figure S7.1 and Supplemental Figure S7.2. Figure 7.1 shows SBP, DBP, SNa and IDWG over the course of the observation period.

Table 7.1 Demographics in all studied patients and stratified by continents at hemodialysis (HD) initiation.

\begin{tabular}{lccccc}
\hline & All subjects & North America & Asia & Europe & South America \\
\hline Subjects [count] & 16993 & 4106 & 1456 & 9705 & 1726 \\
Treatments [count] & 216554 & 74680 & 23002 & 115445 & 3427 \\
Age [years] & $62.1+/-14.7$ & $60.3+/-14.9$ & $58.4+/-13.3$ & $64.1+/-14.4$ & $57.7+/-16.5$ \\
Male [yes/no] & 56.9 & 55.2 & 53.4 & 58.7 & 57.3 \\
IDWG [\% body weight] & $2.8+/-1.3$ & $3.2+/-1$ & $4.2+/-1.7$ & $2.5+/-1.2$ & $3+/-2$ \\
Serum potassium [mEq/I] & $4.8+/-0.7$ & $4.6+/-0.6$ & $4.8+/-0.8$ & $4.9+/-0.7$ & $4.7+/-0.8$ \\
Serum albumin [g/dl] & $3.8+/-0.4$ & $3.7+/-0.4$ & $3.9+/-0.3$ & $3.7+/-0.5$ & $3.8+/-0.5$ \\
Diabetes [yes/no] & $41.9+/-1$ & $56+/-1$ & $33.9+/-1$ & $34.8+/-1$ & $23.9+/-1$ \\
Serum calcium [mg/dl] & $8.8+/-0.7$ & $8.9+/-0.6$ & $9.2+/-0.8$ & $8.7+/-0.7$ & $8.8+/-0.7$ \\
Serum Sodium [mEq/l] & $137.8+/-2.8$ & $138.3+/-2.4$ & $137.8+/-2.6$ & $137.6+/-2.9$ & $136.4+/-3.6$ \\
pre HD SBP [mmHg] & $142+/-18.8$ & $151.2+/-18$ & $141+/-17.6$ & $138.4+/-17.6$ & $132.2+/-19.6$ \\
pre HD DBP [mmHg] & $74.5+/-10.9$ & $79.1+/-10.8$ & $78.5+/-8.6$ & $72.1+/-10.4$ & $72.6+/-11$ \\
\hline
\end{tabular}

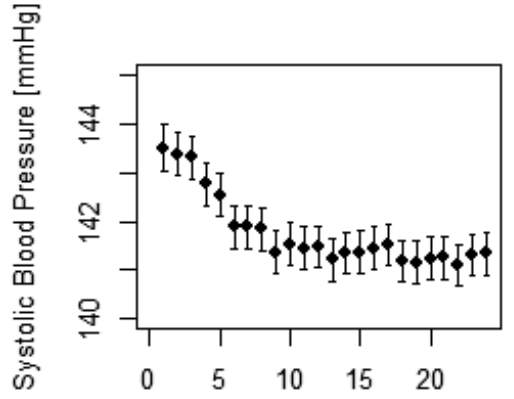

Months since HD initiation [months]

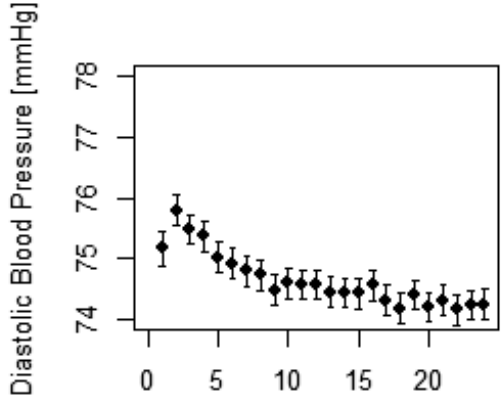

Months since HD initiation [months]

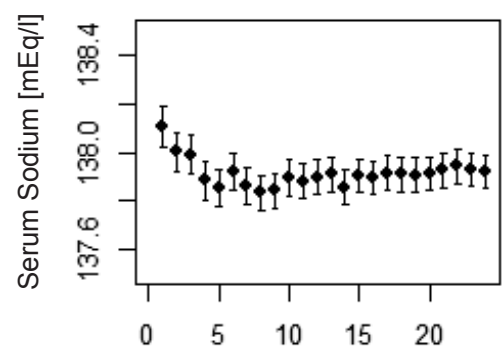

Months since HD initiation [months]

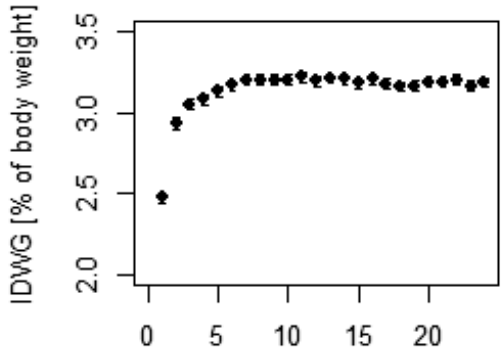

Months since HD initiation [months]

Figure 7.1 Average values ( $95 \% \mathrm{Cl}$ indicated) of a) systolic and b) diastolic blood pressure, c) serum sodium and $\mathrm{d}$ ) interdialytic weight gain for every month during the course of the observation period of 24 months. 


\section{Serum sodium concentration as a predictor of blood pressure}

Comparison of LMM with a) random intercept and b) with random intercept and slope using a likelihood ratio test showed the random slope to be significant and was thus included in the models. Based on the results of the developed models it appears that there is a significant increase of pre HD SBP and DBP with increasing $\mathrm{SNa}^{+}$based on the data of the entire 24 months observation after period The estimates of the $\mathrm{SNa}^{+}$slopes in the LMM predicting SBP and DBP are shown in Table 7.2. The estimate of the slope in the entire population implies that for example in North America with every $\mathrm{mEq} / \mathrm{I} \mathrm{SNa}{ }^{+}$ increase there was an increase of $0.22 \mathrm{mmHg}$ for SBP and $0.10 \mathrm{mmHg}$ for DBP. Slope estimates of $\mathrm{SNa}^{+}$for the other analyzed continents are shown in Table 7.2. The relationship between $\mathrm{SNa}^{+}$and $\mathrm{BP}$ remained consistent for the $\mathrm{LMM}$ developed with DBP as the dependent variable. Full models are shown in Supplemental Table S7.2.

Table 7.2 Slope estimate of serum sodium in a Linear Mixed Effects Model predicting pre hemodialysis (HD) a) systolic and b) diastolic blood pressure (SBP, DBP) over the entire observation period (24 months), based on sodium concentrations and other parameters of relevance. Additional fixed effects in the model were: interdialytic weight gain, age at hemodialysis initiation, male gender, serum potassium, serum albumin, diabetes serum calcium and hemodialysis vintage.

\begin{tabular}{lcc}
\hline Continent & $\begin{array}{c}\mathrm{SNa}^{+} \text {slope estimate for Pre HD SBP } \\
\text { [mmHg change per mEq/l change] }\end{array}$ & $\begin{array}{c}\mathrm{SNa}^{+} \text {slope estimate for Pre HD DBP } \\
\text { [mmHg change per mEq/I change] }\end{array}$ \\
\hline North America & $0.22(0.17$ to 0.28$)$ & $0.10(0.07$ to 0.13$)$ \\
Asia & $0.28(0.16$ to 0.40$)$ & $0.14(0.08$ to 0.21$)$ \\
Europe & $0.19(0.15$ to 0.22$)$ & $0.14(0.08$ to 0.21$)$ \\
South America* & $0.25(0.05$ to 0.45$)$ & $0.21(0.11$ to 0.32$)$ \\
\hline
\end{tabular}

*Estimates of a linear model constructed based on cross-sectional data.

\section{Subset analyses}

Analysis in tertiles of pre HD SBP and DBP, respectively, showed a comparable magnitude of the slope estimates for $\mathrm{SNa}^{+}$included as fixed effects in the model in all three tertiles of SBP and DBP, respectively (Figure 7.2; Supplemental Table S7.3). Repetition of the analysis in tertiles of pre $\mathrm{HD} \mathrm{SNa}^{+}$and IDWG also showed comparable slope estimates for pre HD SNa ${ }^{+}$included as a fixed effect in the prediction of pre HD SBP (Figure 7.3 and Figure 7.4) and DBP (data not shown), both of which increased with an increasing range of $\mathrm{SNa}^{+}$. The estimation of the slope for $\mathrm{SNa}^{+}$showed an increasing trend with an increasing range of $\mathrm{SNa}^{+}$for the prediction of SBP and DBP (Figure 7.3). Repetition of the analysis in subsets of diabetic and non-diabetic subjects only, showed comparable slope estimates for the estimate of SBP and DBP in diabetic [0.19 (0.15 to 0.24 ) and 0.07 (0.05 to 0.10$) \mathrm{mmHg}$ per $\mathrm{mEq} / \mathrm{l}$, respectively] and non-diabetic subjects [0.25 (0.21 to 0.29$)$ and 0.11 (0.09 to 0.13$) \mathrm{mmHg}$ per $\mathrm{mEq} / \mathrm{l}$, respectively]. 
Furthermore analyses of the study population stratified into incident and prevalent HD patients in Year 1 and Year 2, respectively, showed virtually identical results (Supplemental Table S7.2a and Supplemental Table S7.2b).
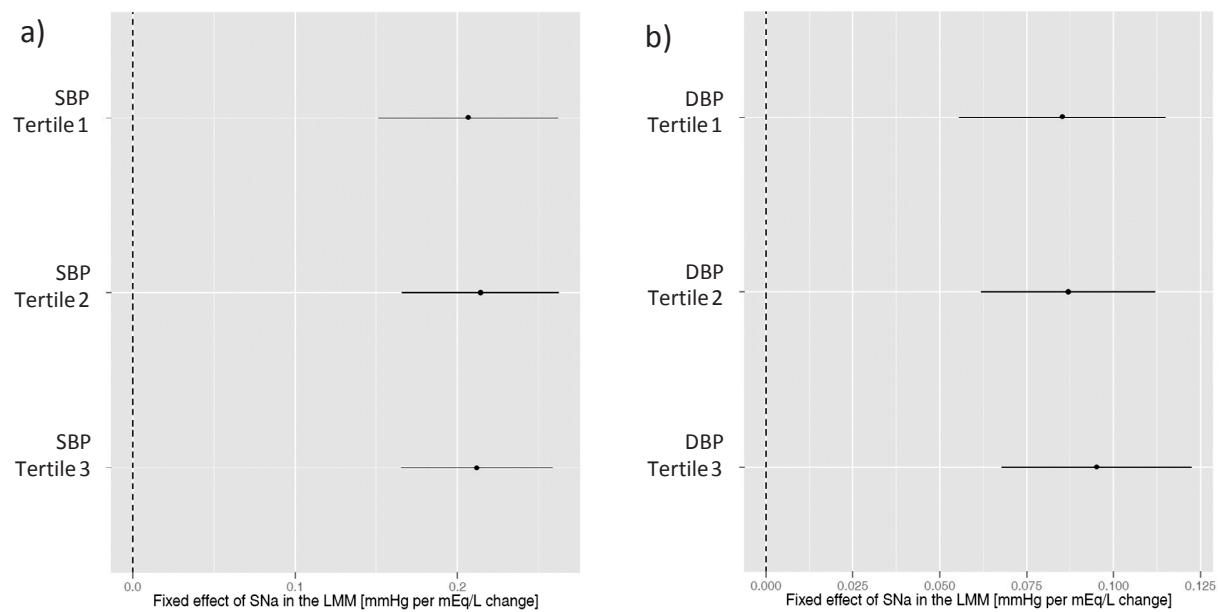

Figure 7.2 Forest Plot of the slope estimate of serum sodium $\left(\mathrm{SNa}^{+}\right)$in a Linear Mixed Model predicting pre hemodialysis (HD) systolic blood pressure (SBP) after stratification into tertiles of a) SBP and b) DBP. Additional fixed effects in the model were: interdialytic weight gain, age at hemodialysis initiation, male gender, serum potassium, serum albumin, diabetes, serum calcium and hemodialysis vintage.
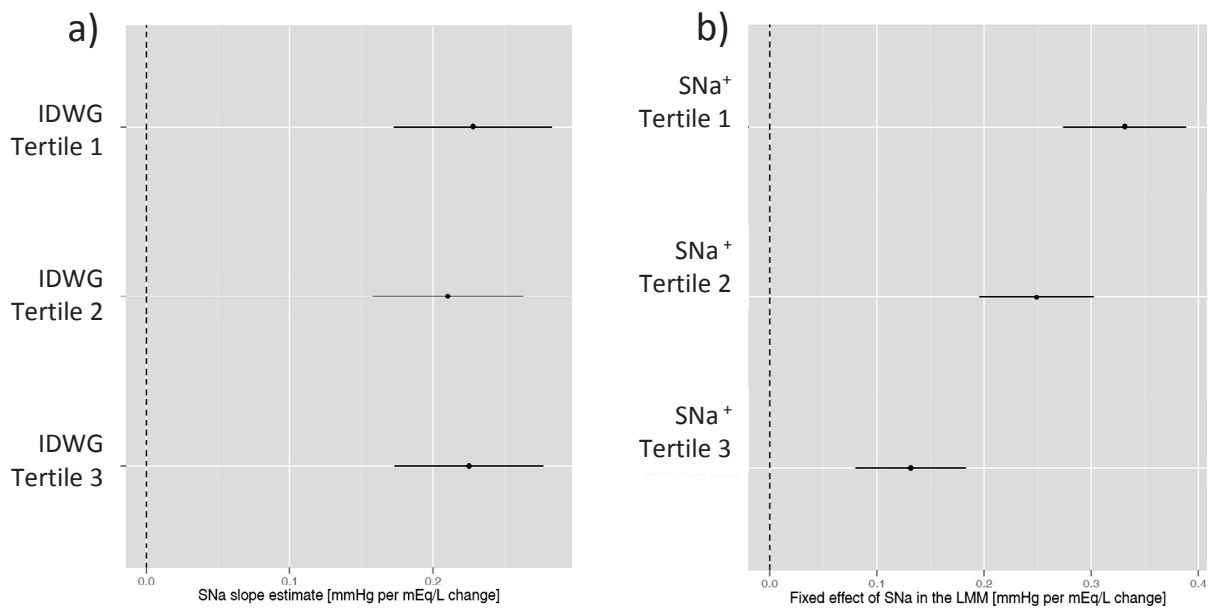

Figure 7.3 Forest Plot of the slope estimate of serum sodium $\left(\mathrm{SNa}^{+}\right)$in a Linear Mixed Model predicting pre hemodialysis (HD) systolic blood pressure (SBP) after stratification into tertiles of a) IDWG and b) $\mathrm{SNa}^{+}$. Additional fixed effects in the model were: interdialytic weight gain, age at hemodialysis initiation, male gender, serum potassium, serum albumin, diabetes, serum calcium and hemodialysis vintage. 


\section{Discussion}

\section{Statement of principal findings}

Based on the current data there exist a relationship between plasma Na and SBP prior to HD treatments. These relationships were found to be independent of relevant covariates (age, gender, IDWG, diabetes, serum albumin, potassium and calcium). In addition we confirmed the relationship in analyses conducted in different continents, which, in our opinion, renders this relationship a pathophysiologic finding somewhat independent of race, ethnicity, laboratory techniques or treatment practices in the respective continents. Furthermore the analyses were repeated for the periods from HD initiation to Month 12 and for the period from Month 13 to 24, which is consistent with analyses in incident and prevalent patients. Subset analyses in tertiles of SBP and DBP confirmed the analyses independent of the magnitude of these potentially relevant parameters. Presence of diabetes and the antidiabetic treatment did also not affect the relationship as per the subset analyses in these two subpopulations. The analysis in tertiles of $\mathrm{SNa}^{+}$showed a clearly increasing slope estimate at higher $\mathrm{SNa}^{+}$ levels.

\section{Comparison to other studies}

Compared to previous data reported by He et al. we found a smaller effect size, but a nevertheless consistent relationship in a substantially larger sample size as compared to He's double-center study in the United Kingdom (651 prevalent HD patients over 7445 observations) ${ }^{9}$. The current data carries these previous findings a step further by choosing incident and prevalent patients as subsets. To allow this analysis, patients' data was stratified into months 0 to 12 (incident patients) and months 13 to 24 (prevalent patients) and the results showed a consistent relationship between $\mathrm{SNa}^{+}$and $\mathrm{BP}$ independent of HD vintage. Furthermore we extended the findings to several continents and were able to establish this relationship in four different continents. We also conducted subset analyses in tertiles of SNa, SBP and DBP which confirms that the magnitude of these parameters, which may be considered to have potential influences on the relationship between $\mathrm{SNa}^{+}$and $\mathrm{BP}$. Despite a slightly increasing trend in the magnitude of the $\mathrm{SNa}^{+}$slope estimate at larger $\mathrm{SNa}^{+}$tertile, an effect size comparable between continents and all analyzed subsets was found in the constructed models. Also stratification into diabetic and non-diabetic subjects did not materially alter the relationship between $\mathrm{SNa}^{+}$and $\mathrm{BP}$.

A difference in the effect size between the model constructed by He et al. $[0.65(95 \% \mathrm{Cl}$ 0.46 to 0.84$) \mathrm{mmHg}$ SBP and $0.36(95 \% \mathrm{Cl} 0.25$ to 0.46$) \mathrm{mmHg} \mathrm{DBP}$, respectively, per $\mathrm{mEq} / \mathrm{I} \mathrm{SNa}^{+}$] may be noted in comparison to our models (Table 7.2). The reasons for these differences are not clear and remain speculative at this point. However, in summary it is remarkable that the presence and direction of this relationship remained 
consistent across all continents (Table 7.2a and Table 7.2b), equally for incident and prevalent patients (Supplementary Table 1) and also in the subset analyses (Figure 7.2; Supplemental Table S7.2 and Supplemental Table S7.3).

The exact reasons for these dynamics may only be speculated, however, work by Oberleithner et al. suggested direct effects of plasma sodium on endothelial cells in the presence of aldosterone ${ }^{13}$, which triggers the expression of $\mathrm{ENaC}$ by the endothelial cell which in turn promotes cell swelling ${ }^{14}$ and cell stiffening ${ }^{15}$, plasma sodium appears to strongly affect the deformability and elasticity of endothelial cells ${ }^{13}$. Furthermore it is important to note that the elasticity of endothelial cells is a prerequisite of normal endothelial function by control of the stress-induced release of nitric oxide ${ }^{16}$. In addition recent publication reported data suggesting a relationship between plasma nitric oxide and blood pressure during salt loading and restriction, respectively, and furthermore an increase in asymmetric dimethyl-arginine with higher salt intake ${ }^{17}$.

\section{Implications of this research}

The relationship is of pathophysiologic importance, as it sheds further light on the complex relation between sodium, fluid overload and BP in dialysis patients. It also shows, for the first time, this relation at a global level in a large-scale database.

Whether the results of this study are of importance for clinical practice, given the possible intervention possibilities by the HD treatment, such as the dialysate prescription, as well of antihypertensive agents which might influence this relationship, should be addressed in future studies. Particularly in regard of analyses conducted by He et al. in subsets with and without a prescription of antihypertensive drugs ${ }^{9}$.

Furthermore the estimate of the effect size in the longitudinal analysis conducted by the authors was comparable between both groups, thus the effects of sodium may possibly be of importance in BP management. It is regrettable we were not able to conduct any analyses using data of antihypertensive medication from our data. However, confirming the relationship suggested by He et al. in our data does confirm a generalizability of the relationship, which renders this of general importance for BP management.

Furthermore it needs to be emphasized that a close observation of $\mathrm{SNa}^{+}$is also of importance, given the direct effects of $\mathrm{SNa}^{+}$on cardiovascular structures. Previously published findings of left atrial enlargement associated with $\mathrm{SNa}^{+}$levels independent of BP levels in chronic kidney disease patients were explained by the pro-fibrotic effects of sodium and a proliferative effect on myocardial tissue ${ }^{18}$. The well-established relationship (independent of $\mathrm{BP}$ ) between left ventricular mass, salt intake and urinary sodium excretion, respectively, in the general but also in the chronic kidney disease population, has been proposed to be caused by direct effects on cardiomyocytes, modulation of the neurohumoral system (with vasopressin being the mabut) also effects on the intravascular volume state ${ }^{19,20}$. 


\section{Strengths and weaknesses}

A great strength of the current analysis is the large sample size, the considerably long observation period of 24 months for each patient and, due to high number of patients from international HD populations, the resulting high level of generalizability. Particularly the long observation period, allowing separate analyses in incident and prevalent patients and the separate confirmation of findings in explicit analyses of data from different continents strengthen the conclusions drawn from our data. Limitations mainly comprise as all retrospective analyses, a possible lack of documentation for some parameters and the unavoidable probability of documentation errors. Particularly the lack of data on existing BP treatment and race and ethnicity for all continents limits the comparability of the current study to the previous work ${ }^{9}$. Information on comorbidities, residual renal function and volume status may also be of additional interest, but have also not been available for the current analysis. It may also be argued that in the formerly analyzed ethnic group, BP treatment was found to be significant estimated fixed effects only at a level between 1 to $5 \%$ for SBP and not significant for DBP at all ${ }^{9}$. In this context it may be argued that the effects the inclusion of these parameters would have had, is rather marginal. It can however not be excluded to be a possible reason for the differences found between the estimated effect sizes.

\section{Conclusions}

In summary our data (in concert with previous data) suggests that many factors such as $\mathrm{SNa}^{+}$affect BP. In summary the data of this study suggest that the longitudinal observation of $\mathrm{SNa}^{+}$and its dynamics over time do provide information gain and may be helpful to aid diagnosis, treatment and determination of the risk of an adverse outcome. Future research on the exact pathophysiologic mechanisms is needed whether this relationship could also be a therapeutic target. 


\section{Supplemental figures}

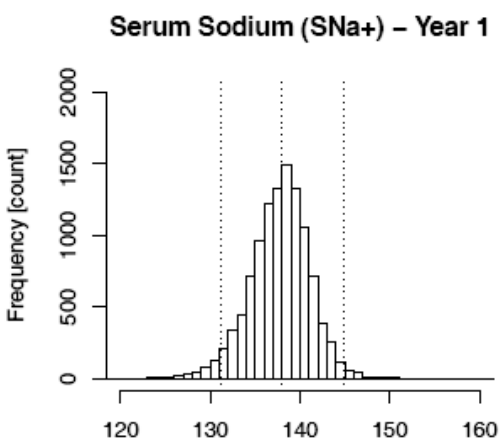

$\mathrm{SNa}+$ over the first 3 months [mEq/L]
Serum Sodium (SNa+) - Year 2

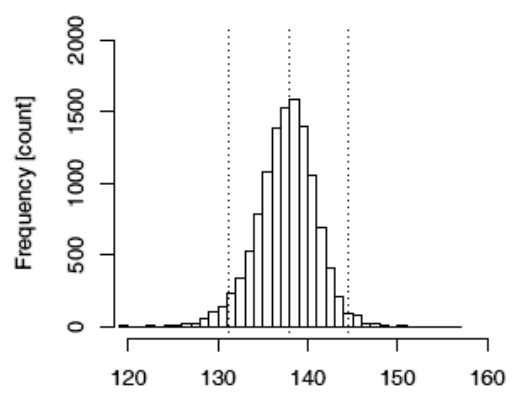

Average SNa+ over the first 3 months [mEq/L]

Figure S7.1 Distribution of serum sodium $\left(\mathrm{SNa}^{+}\right)$in all patients included in the analysis.

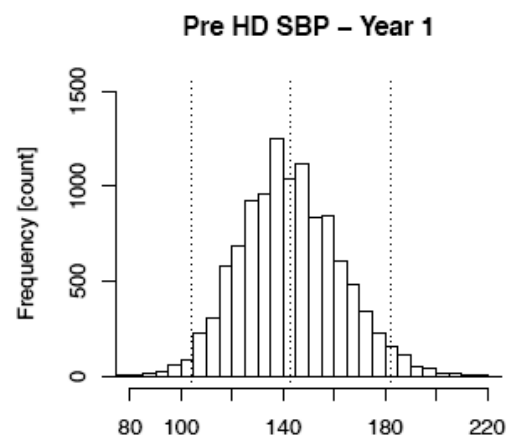

Pre HD SBP - Month 1 to $3[\mathrm{mmHg}]$

Pre HD SBP - Year 2

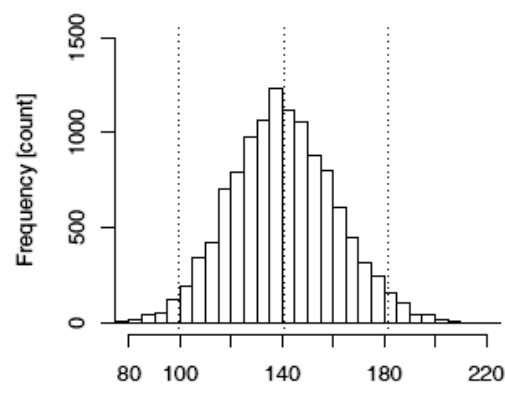

Pre HD SBP - Month 1 to $3[\mathrm{mmHg}]$
Pre HD DBP - Year 1

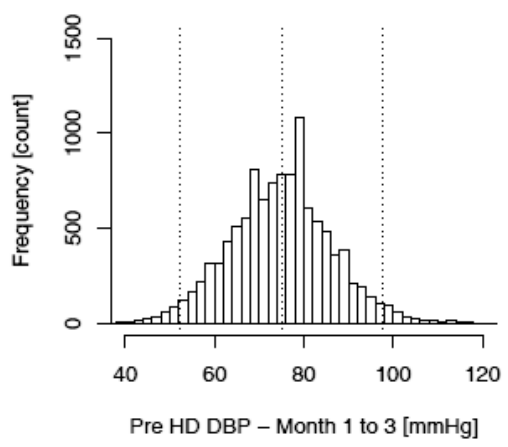

Pre HD DBP - Year 2

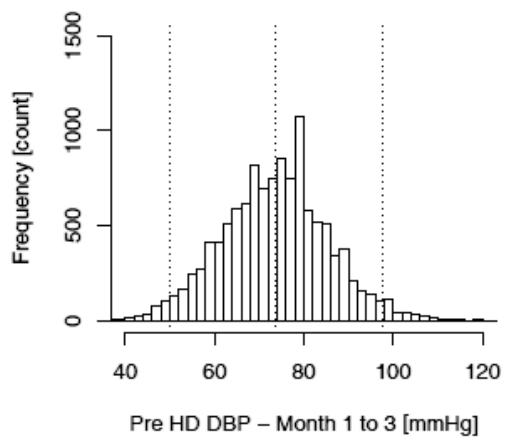

Figure S7.2 Distribution of systolic and diastolic blood pressure (SBP, DBP) in all patients included in the analysis for the first 6 months of Year 1 and Year 2. 


\section{References}

1. Intersalt: an international study of electrolyte excretion and blood pressure. Results for 24 hour urinary sodium and potassium excretion. Intersalt Cooperative Research Group. BMJ 1988;297:319-28.

2. Appel LJ, Moore TJ, Obarzanek E, et al. A clinical trial of the effects of dietary patterns on blood pressure. DASH Collaborative Research Group. N Engl J Med 1997;336:1117-24.

3. Sacks FM, Svetkey LP, Vollmer WM, et al. Effects on blood pressure of reduced dietary sodium and the Dietary Approaches to Stop Hypertension (DASH) diet. DASH-Sodium Collaborative Research Group. N Engl J Med 2001;344:3-10.

4. Guyton AC, Hall JE. Textbook of medical physiology, 11th edn. Elsevier Saunders: Philadelphia, 2006.

5. du Cailar G, Mimran A, Fesler P, et al. Dietary sodium and pulse pressure in normotensive and essential hypertensive subjects. J Hypertens 2004;22:697-703.

6. Suckling RJ, He FJ, Markandu ND, et al. Dietary salt influences postprandial plasma sodium concentration and systolic blood pressure. Kidney Int 2012;81:407-11.

7. Komiya I, Yamada T, Takasu N, et al. An abnormal sodium metabolism in Japanese patients with essential hypertension, judged by serum sodium distribution, renal function and the renin-aldosterone system. J Hypertens 1997;15:65-72.

8. Wannamethee G, Whincup PH, Shaper AG, et al. Serum sodium concentration and risk of stroke in middle-aged males. J Hypertens 1994;12:971-9.

9. He FJ, Fan S, Macgregor GA, et al. Plasma sodium and blood pressure in individuals on haemodialysis. J Hum Hypertens 2013;27:85-9.

10. Usvyat LA, Haviv YS, Etter M, et al. The MONitoring Dialysis Outcomes (MONDO) initiative. Blood Purif 2013;35:37-48.

11. von Gersdorff GD, Usvyat L, Marcelli D, et al. Monitoring Dialysis Outcomes across the World - The MONDO Global Database Consortium. Blood Purif 2013;36:165-72.

12. R Development Core Team: R: A language and environment for statistical computing. In, Vienna, Austria, R Foundation for Statistical Computing, 2010

13. Oberleithner H, Riethmüller C, Schillers H, MacGregor GA, de Wardener HE, Hausberg M. Plasma sodium stiffens vascular endothelium and reduces nitric oxide release. Proc Natl Acad Sci U S A. 2007;104:16281-6.

14. Chen W, Valamanesh F, Mirshahi T, et al. Aldosterone signaling modifies capillary formation by human bone marrow endothelial cells. Vascul Pharmacol 2004;40:269-77.

15. Duffy SJ, Biegelsen ES, Eberhardt RT, et al. Low-renin hypertension with relative aldosterone excess is associated with impaired NO-mediated vasodilation. Hypertension 2005;46:707-13.

16. Fleming I, Busse R. Molecular mechanisms involved in the regulation of the endothelial nitric oxide synthase. Am J Physiol Regul Integr Comp Physiol 2003;284:R1-12.

17. Fujiwara N, Osanai T, Kamada $\mathrm{T}$, et al. Study on the relationship between plasma nitrite and nitrate level and salt sensitivity in human hypertension : modulation of nitric oxide synthesis by salt intake. Circulation 2000;101:856-61.

18. Yee-Moon Wang A, Lu Y, Cheung S, et al. Plasma sodium and subclinical left atrial enlargement in chronic kidney disease. Nephrol Dial Transplant 2013;28:2319-28.

19. Du Cailar G, Ribstein J, Daures JP, et al. Sodium and left ventricular mass in untreated hypertensive and normotensive subjects. Am J Physiol 1992;263:H177-81.

20. Kupari M, Koskinen P, Virolainen J. Correlates of left ventricular mass in a population sample aged 36 to 37 years. Focus on lifestyle and salt intake. Circulation 1994;89:1041-50. 


\section{Chapter 8}

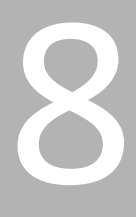

Variability of pre-dialysis serum sodium and its association with survival in incident hemodialysis patients: Results from a retrospective analysis from the international Monitoring Dialysis Outcomes (MONDO) initiative

JG Raimann, J Reyes-Bahamonde, B Canaud, M Etter, JP Kooman, NW Levin, D Marcelli, C Marelli, A Power, FM van der Sande, S Thijssen, X Xu, LA Usvyat, Y Wang, P Kotanko and the MONDO Initiative 


\section{Abstract}

\section{Background}

Pre-hemodialysis (pre-HD) serum sodium $\left(\mathrm{SNa}^{+}\right)$has been assumed to show low variability. Recent reports suggest that stability of various parameters confers improved survival. We investigated the relationship between the rate of change of $\mathrm{SNa}^{+}$(slope of $\mathrm{SNa}^{+}$over time) and $\mathrm{SNa}^{+}$variability (standard deviation, $\mathrm{SD}$ ), respectively, with $\mathrm{SNa}^{+}$, and risk of all-cause death in incident HD patients.

\section{Methods}

Incident patients from the global MONDO initiative with available data were included in this retrospective analysis. The first 12 months of HD were defined as baseline, patient outcomes were noted in months 13 to 24 (follow-up period). We applied smoothing spline ANOVA logistic regression models to investigate the joint effect of (a) $\mathrm{SNa}^{+}$and $\mathrm{SNa}^{+}$slope, and (b) $\mathrm{SNa}^{+}$and $\mathrm{SNa}^{+}$ $\mathrm{SD}$ on the risk of death in the follow-up period. The models were adjusted for age, gender, diabetes, interdialytic weight gain, serum albumin, $\mathrm{nPCR}$, dialysate sodium concentration and body mass index.

\section{Results}

We studied 16,420 incident HD patients ( $63.1 \pm 14.9$ years, $59 \%$ males, $36 \%$ diabetics) from Europe $(n=11,057)$ and North America $(n=5,363)$. The risk of death appears to be higher in patients with $\mathrm{SNa}^{+}$below $137 \mathrm{mEq} / \mathrm{l}$ and $\mathrm{SNa}^{+}$greater than $143 \mathrm{mEq} / \mathrm{l}$. Increased risk of death with higher $\mathrm{SNa}^{+}$ variability and changes of $\mathrm{SNa}^{+}$appears to be present at all levels of $\mathrm{SNa}^{+}$, but the increase is most pronounced at higher $\mathrm{SNa}^{+}$.

\section{Conclusion}

$\mathrm{SNa}^{+}$stability and levels greater than $137 \mathrm{mEq} / \mathrm{l}$ are associated with better survival in $\mathrm{HD}$ patients. This may be an important novel prognostic indicator. 


\section{Introduction}

Serum sodium $\left(\mathrm{SNa}^{+}\right)$is a main determinant of plasma osmolality, which is important for a host of cell functions. Swings in $\mathrm{SNa}^{+}$may lead to fluid shifts between the extracellular and intracellular spaces and cell volume changes. Rapid changes in $\mathrm{SNa}^{+}$ are associated with neurological disturbances and increased mortality ${ }^{1}$. The distribution of $\mathrm{SNa}^{+}$on a population level and within a given individual is substantially narrower in healthy subjects compared to hemodialysis (HD) patients, yet the existence of a patient-specific sodium set-point has been postulated in this patient population ${ }^{2-4}$. Nonetheless the yearly average standard deviation (SD) of monthly pre-HD SNa ${ }^{+}$levels is approximately $2.0 \mathrm{mEq} / \mathrm{l}$ with an mean range of $7 \mathrm{mEq} / \mathrm{I}^{4}$. Lower levels of pre-HD $\mathrm{SNa}^{+}$have been associated with increased mortality which has been suggested to reflect current comorbidities that affect clinical outcomes ${ }^{5}$.

Recent evidence has shown that, next to single measurements, variability of blood pressure and key laboratory parameters such as hemoglobin are also associated with important outcomes such as survival in HD patients ${ }^{6-8}$. Despite its pivotal physiological role, the relationship between $\mathrm{SNa}^{+}$variability and hard outcomes such as mortality has not been assessed. In patients with congestive heart failure who are not on dialysis a low $\mathrm{SNa}^{+}$and a decline in $\mathrm{SNa}^{+}$has been associated with poor outcomes ${ }^{9}$. While in congestive heart failure patients with preserved renal function non-osmotic vasopressin release and reduced free water clearance are key determinants of hyponatremia, the situation is less clear in HD patients without residual renal function. Earlier reports suggested the existence of the "sick-cell syndrome", a status of increased cell membrane permeability, leaking of intracellular osmolytes into the extracellular space causing fluid and water shifts resulting in hyponatremia ${ }^{10-12}$. The syndrome manifests as an osmolal gap ${ }^{13,14}$ and associates with several comorbidities such as inflammation, myocardial infarction amongst others. The primary goal of the present study was to explore the relationship between $\mathrm{SNa}^{+}$levels and their variability and mortality in a large international cohort of incident hemodialysis patients.

\section{Concise Methods}

\section{Study design}

The Monitoring Dialysis Outcomes (MONDO) initiative encompasses HD patients from 41 countries who started HD between 2000 and $2010^{15}$. Baseline characteristics of the cohort have been published already ${ }^{16}$. For this analysis data of incident patients who started HD between 1/1/2001 and 7/30/2008 in the United States and Europe were used. While the United States patients were treated in facilities of the Renal Research Institute, the European patients resided in 17 countries and were dialyzed in Fresenius 
Medical Care Europe clinics. The first 12 months on HD defined the baseline and months 13 to 24 the follow-up period. Only patients with three or more baseline $\mathrm{SNa}^{+}$ measurements were included. The study was conducted in compliance with local rules and regulations to protect data privacy and patients' rights and approved by the institutional review board at the Beth Israel Medical Center, New York.

\section{Measures of $\mathrm{SNa}^{+}$variability}

We employed two related yet different indicators of baseline $\mathrm{SNa}^{+}$variability, namely (a) the SD of pre-HD SNa ${ }^{+}$levels, and (b) the rate of change of $\mathrm{SNa}^{+}$. The latter measure was computed by simple linear regression of $\mathrm{SNa}^{+}$over time rate during baseline and expressed as the slope of the resultant regression line in $\mathrm{mEq} / \mathrm{l} /$ year.

Patients were stratified in tertiles of baseline $\mathrm{SNa}^{+} \mathrm{SD}$ (tertile 1: $<2.0 \mathrm{mEq} / \mathrm{l}$; tertile 2: 2.0 to 2.7 ; tertile 3 : $>2.7 \mathrm{mEq} / \mathrm{l}$ ), and $\mathrm{SNa}^{+}$slopes (decreasing: <-1.72; stable: -1.72 to 1.33; increasing: $>1.33 \mathrm{mEq} / \mathrm{l} /$ year).

\section{Statistical analysis}

Data are presented as mean \pm SD for descriptive analysis and point estimates with $95 \%$ confidence intervals, as appropriate.

\section{Survival analysis}

Crude mortality rates were computed for the three $\mathrm{SNa}^{+} \mathrm{SD}$ tertiles and slope categories, respectively. Kaplan-Meier analysis, log rank test and Cox regression were used to analyze the relationship between $\mathrm{SNa}^{+}, \mathrm{SNa}^{+}$slope and $\mathrm{SNa}^{+} \mathrm{SD}$ at baseline and all-cause mortality during follow-up. The Cox regression model was adjusted for age, gender, diabetes, interdialytic weight gain (IDWG in \% of body weight), serum albumin, normalized protein catabolic rate ( $\mathrm{nPCR}$ ), $\mathrm{DNa}^{+}$, and $\mathrm{BMI}$. The respective $\mathrm{SNa}^{+} \mathrm{SD}$ and slope group with the lowest mortality rate in the univariate analyses was used as reference group.

Because of the recently described relationship between $\mathrm{SNa}^{+}$and outcomes, we explored the joint effect of $\mathrm{SNa}^{+}, \mathrm{SNa}^{+} \mathrm{SD}$, and $\mathrm{SNa}^{+}$slope, respectively, on survival, without discretizing these variables. For this analysis we considered a semi-parametric logistic regression model. Specifically we applied smoothing spline ANOVA logistic regression model ${ }^{17,18}$ adjusted for the same covariates as the Cox regression analysis. The smoothing spline ANOVA (also called tensor product smoothing spline) method allows us to model the joint effect of two or more independent variables (e.g. SNa ${ }^{ \pm}$and $\left.\mathrm{SNa}^{+} \mathrm{SD}\right)$ without assuming a specific parametric form. Parametric effects were assumed for other covariates (age, gender, diabetes, $\mathrm{DNa}^{+}, \mathrm{IDWG}$, serum albumin, $\mathrm{nPCR}$ and $\mathrm{BMI})$. We used posterior standard deviation to delineate a region that 
contains sufficient data on the contour plot and the estimate is deemed reliable ${ }^{19}$. Estimates of the joint effects are shown for this region only.

\section{Evaluation of statistical predictors}

As a secondary outcome we aimed to determine what affects the stability of $\mathrm{SNa}^{+}$and $\mathrm{SNa}^{+}$change over time. To assess other factors predicting variability and trends, we developed multivariable linear regression models with $\mathrm{SNa}^{+} \mathrm{SD}$ [in $\left.\mathrm{mEq} / \mathrm{l}\right]$ and $\mathrm{SNa}^{+}$ slope [in $\mathrm{mEq} / \mathrm{l} /$ year] as the respective dependent variables. The analysis with $\mathrm{SNa}^{+}$ slope as the dependent variable was repeated after stratification into subjects with increasing and decreasing $\mathrm{SNa}^{+}$. The determined independent predictors found in regression analysis were used for the adjustment of the survival analysis. A two-sided $P$-value below 0.05 was considered statistically significant. Analyses were done in $\mathrm{R}$ version 3.0.2 ("Frisbee Sailing"; R Foundation for Statistical Computing; Vienna, Austria) $)^{20}$.

\section{Results}

\section{Patient population}

Data from 16,420 incident HD patients were analyzed. Table 8.1 shows demographics of the pooled population stratified by region. Regional differences were most pronounced with respect to age, diabetes prevalence, interdialytic weight gain (IDWG) and pre-HD systolic blood pressure (SBP) which is (to the comparable extent) fairly consistent with other reports ${ }^{21}$. Supplemental Figure 58.1 shows the distribution of baseline $\mathrm{SNa}^{+}, \mathrm{SNa}^{+}$slope, and $\mathrm{SNa}{ }^{+} \mathrm{SD}$. Table 8.2a and Table 8.2b show the tertiles of $\mathrm{SNa}^{+} \mathrm{SD}$ and groups of $\mathrm{SNa}^{+}$slopes, respectively. Comparison of these groups only showed slight differences in the various analyzed parameters.

\section{Survival analyses}

Both lower $\mathrm{SNa}^{+} \mathrm{SD}(<2 \mathrm{mEq} / \mathrm{l})$ and stable $\mathrm{SNa}^{+}$(slope -1.72 to $1.33 \mathrm{mEq} / \mathrm{l} /$ year) at baseline were associated with better survival during follow-up (92.4 deaths per 1000 patient-years in SNa ${ }^{+}$SD tertile 1 versus 111.3 and 140.7, respectively in tertile 2 and 3; Supplemental Table S8.1). Kaplan Meier analysis and log-rank test also demonstrated increased mortality in strata of higher $\mathrm{SNa}^{+} \mathrm{SD}$ ( $\geq 2 \mathrm{mEq} / \mathrm{l}$; Supplemental Figure S8.2). 
Table 8.1 Patient demographics stratified as per analyzed region.

\begin{tabular}{|c|c|c|c|c|}
\hline & All & Europe & North America & $\begin{array}{c}\text { Difference Europe - } \\
\text { North America }(95 \% \mathrm{Cl})\end{array}$ \\
\hline $\mathrm{n}$ [count] & 16420 & 11057 & 5363 & 5694 \\
\hline Age [years\} & $63.1+/-14.9$ & $64.1+/-14.6$ & $61.2+/-15.2$ & $2.9(2.4$ to 3.3$)$ \\
\hline Male gender [\%] & 58.5 & 59.6 & 56.1 & $3.5^{*}$ \\
\hline Diabetes [\%] & 35.9 & 26.4 & 55.5 & $-29.1^{*}$ \\
\hline IDWG [\% of body weight (BW)] & $3.02+/-1.00$ & $2.84+/-0.98$ & $3.38+/-0.94$ & $-0.53(-0.56$ to -0.50$)$ \\
\hline $\mathrm{nPCR}[\mathrm{g} / \mathrm{dl} / \mathrm{day} / \mathrm{kg}$ BW] & $0.98+/-0.15$ & $1.03+/-0.10$ & $0.87+/-0.19$ & 0.15 (0.15 to 0.16$)$ \\
\hline Pre HD SBP [mmHg] & $140.95+/-17.99$ & $136.23+/-16.39$ & $150.69+/-17.23$ & $-14.46(-15.01$ to -13.9$)$ \\
\hline Albumin $[\mathrm{g} / \mathrm{dl}]$ & $3.81+/-0.39$ & $3.83+/-0.40$ & $3.78+/-0.36$ & $0.04(-15.01$ to -13.90$)$ \\
\hline $\mathrm{DNa}^{+}[\mathrm{mEq} / \mathrm{l}]$ & $139.22+/-1.55$ & $138.91+/-1.51$ & $139.86+/-1.44$ & $-0.95(-1.00$ to -0.90$)$ \\
\hline $\mathrm{SNa}^{+}[\mathrm{mEq} / \mathrm{I}]$ & $138.03+/-2.56$ & $137.87+/-2.63$ & $138.35+/-2.37$ & $-0.47(-0.55$ to -0.39$)$ \\
\hline $\mathrm{SNa}^{+}$variability $(\mathrm{SD})[\mathrm{mEq} / \mathrm{l}]$ & $2.51+/-1.06$ & $2.58+/-1.15$ & $2.38+/-0.85$ & $0.20(0.17$ to 0.23$)$ \\
\hline $\mathrm{SNa}^{+}$slope $[\mathrm{mEq} / \mathrm{l} /$ year] & $-0.17+/-4.03$ & $-0.10+/-4.17$ & $-0.32+/-3.73$ & 0.22 (0.09 to 0.34$)$ \\
\hline Phosphorus [mg/dl] & $4.89+/-1.09$ & $4.72+/-1.05$ & $5.25+/-1.10$ & $-0.53(-0.56$ to -0.49$)$ \\
\hline Potassium $[\mathrm{mEq} / \mathrm{l}]$ & $4.84+/-0.58$ & $4.94+/-0.59$ & $4.64+/-0.50$ & $0.29(-0.56$ to -0.49$)$ \\
\hline Neutrophil/lymphocyte ratio (NLR) & $3.38+/-2.53$ & $3.16+/-2.03$ & $3.92+/-3.42$ & $-0.76(-0.88$ to -0.64$)$ \\
\hline Body Mass Index $\left[\mathrm{kg} / \mathrm{m}^{2}\right]$ & $26.72+/-6.27$ & $26.20+/-5.24$ & $27.81+/-7.87$ & $-1.61(-1.84$ to -1.38$)$ \\
\hline
\end{tabular}

Interdialytic weight gain (IDWG), body weight (BW), normalized protein catabolic rate (nPCR), hemodialysis $(\mathrm{HD})$, systolic blood pressure (SBP), dialysate sodium concentration $\left(\mathrm{DNa}^{+}\right)$, serum sodium concentration $\left(\mathrm{SNa}^{+}\right)$. *indicates $P<0.05$ in Chi-squared test.

This finding was corroborated in the adjusted Cox regression analysis (Supplemental Table S8.2), which showed higher risk of death with higher $\mathrm{SNa}^{+} \mathrm{SD}$ as compared to $\mathrm{SNa}^{+}$SD tertile 1 [SNa ${ }^{+}$SD Tertile 2: 1.1 (0.99 to 1.22$)$ and $\mathrm{SNa}^{+}$SD tertile 3: 1.3 (1.17 to 1.44)]. A contour plot based on logistic regression analysis showed that the lowest risk of death was present in a region delineated by a SNa ${ }^{+}$between 137 and $143 \mathrm{mEq} / \mathrm{I}$ and a $\mathrm{SNa}^{+} \mathrm{SD}<3 \mathrm{mEq} / \mathrm{l}$ and generally appears to be lower for higher $\mathrm{SNa}^{+}$. The probability of death was higher with increased $\mathrm{SNa}^{+} \mathrm{SD}$ [ranging from areas in Figure 8.1 showing a risk of less than $14 \%$ (light yellow) to a risk are of greater the $38 \%$ (dark red)], irrespective of $\mathrm{SNa}^{+}$(Figure 8.2). Mortality risk increased significantly with increasing magnitude of $\mathrm{SNa}^{+} \mathrm{SD}$ at different set $\mathrm{SNa}^{+}$levels (Figure 8.2). Furthermore we also observed an increasing probability of death with decreasing $\mathrm{SNa}^{+}$at different set $\mathrm{SNa}^{+}$ SD levels (Figure 8.1). 
Table 8.2 Patient demographics stratified according to tertiles of serum sodium concentration (SNa $\left.{ }^{+}\right)$and in second instance as per tertiles of a) $\mathrm{SNa}^{+}$variability (expressed as coefficient of variation) and b) $\mathrm{SNa}^{+}$monthly slopes, over the course of one year following hemodialysis (HD) initiation.

\begin{tabular}{|c|c|c|c|}
\hline a) Variability & SD Tertile 1 & SD Tertile 2 & SD Tertile 3 \\
\hline $\mathrm{n}$ & 5473 & 5474 & 5473 \\
\hline Age [years] & $62.2+/-15.2$ & $63.6+/-14.7$ & $63.6+/-14.6$ \\
\hline Male gender [\%] & 59.6 & 57.9 & 57.9 \\
\hline Diabetes [\%] & 30.8 & 36.9 & 40.1 \\
\hline IDWG [\% of body weight (BW)] & $2.92+/-0.99$ & $3.01+/-0.99$ & $3.13+/-1.01$ \\
\hline $\mathrm{nPCR}[\mathrm{g} / \mathrm{dl} / \mathrm{day} / \mathrm{kg}$ BW] & $0.98+/-0.16$ & $0.97+/-0.15$ & $0.98+/-0.15$ \\
\hline Pre HD SBP [mmHg] & $141.17+/-17.41$ & $141.04+/-18.00$ & $140.63+/-18.55$ \\
\hline Albumin [g/dl] & $3.86+/-0.37$ & $3.81+/-0.40$ & $3.76+/-0.40$ \\
\hline $\mathrm{DNa}^{+}[\mathrm{mEq} / \mathrm{l}]$ & $140+/-1.56$ & $139.24+/-1.53$ & $139.13+/-1.56$ \\
\hline $\mathrm{SNa}^{+}[\mathrm{mEq} / \mathrm{l}]$ & $138.32+/-2.27$ & $138.13+/-2.45$ & $137.64+/-2.88$ \\
\hline $\mathrm{SNa}^{+}$variability $(\mathrm{SD})[\mathrm{mEq} / \mathrm{l}]$ & $1.6+/-0.29$ & $2.33+/-0.20$ & $3.61+/-1.10$ \\
\hline $\mathrm{SNa}^{+}$slope $[\mathrm{mEq} / \mathrm{l} /$ year $]$ & $-0.15+/-2.24$ & $-0.14+/-3.35$ & $-0.22+/-5.70$ \\
\hline Phosphorus [mg/dl] & $4.92+/-1.09$ & $4.90+/-1.08$ & $4.85+/-1.11$ \\
\hline Potassium $[\mathrm{mEq} / \mathrm{l}]$ & $4.81+/-0.57$ & $4.85+/-0.58$ & $4.86+/-0.58$ \\
\hline Neutrophil/lymphocyte ratio (NLR) & $3.26+/-2.56$ & $3.40+/-2.79$ & $3.48+/-2.21$ \\
\hline Body Mass Index $\left[\mathrm{kg} / \mathrm{m}^{2}\right]$ & $27.07+/-6.21$ & $26.77+/-6.11$ & $26.32+/-6.46$ \\
\hline Region [count] North America & 1930 & 1881 & 1552 \\
\hline Europe & 3543 & 3593 & 3921 \\
\hline b) slope & Decreasing SNa ${ }^{+}$ & Stable SNa ${ }^{+}$ & Increasing $\mathrm{SNa}^{+}$ \\
\hline $\mathrm{N}$ & 5474 & 5472 & 5474 \\
\hline Age [years] & $62.9+/-15.2$ & $62.9+/-14.9$ & $63.5+/-14.5$ \\
\hline Male gender [\%] & 58.0 & 58.4 & 59.1 \\
\hline Diabetes [\%] & 35.2 & 35.6 & 36.9 \\
\hline IDWG [\% of body weight] & $3.05+/-1.01$ & $2.98+/-0.99$ & $3.02+/-10.00$ \\
\hline $\mathrm{nPCR}[\mathrm{g} / \mathrm{dl} / \mathrm{day} / \mathrm{kg}]$ & $0.97+/-0.15$ & $0.97+/-0.15$ & $0.98+/-0.15$ \\
\hline Pre HD SBP [mmHg] & $140.98+/-18.15$ & $141.47+/-17.97$ & $140.4+/-17.85$ \\
\hline Albumin $[\mathrm{g} / \mathrm{dl}]$ & $3.80+/-0.40$ & $3.83+/-0.38$ & $3.81+/-0.39$ \\
\hline $\mathrm{DNa}^{+}[\mathrm{mEq} / \mathrm{l}]$ & $139.70+/-1.56$ & $139.23+/-1.54$ & $139.24+/-1.54$ \\
\hline $\mathrm{SNa}^{+}[\mathrm{mEq} / \mathrm{l}]$ & $137.93+/-2.63$ & $138.19+/-2.4$ & $137.97+/-2.63$ \\
\hline $\mathrm{SNa}^{+}$variability $(\mathrm{SD})[\mathrm{mEq} / \mathrm{l}]$ & $2.72+/-1.15$ & $2.13+/-0.82$ & $2.69+/-1.09$ \\
\hline $\mathrm{SNa}^{+}$slope $[\mathrm{mEq} / \mathrm{l} /$ year $]$ & $-4.38+/-2.52$ & $-0.17+/-0.88$ & $4.04+/-2.49$ \\
\hline Phosphorus [mg/dl] & $4.92+/-1.13$ & $4.9+/-1.08$ & $4.85+/-1.07$ \\
\hline Potassium $[\mathrm{mEq} / \mathrm{l}]$ & $4.85+/-0.59$ & $4.83+/-0.57$ & $4.85+/-0.58$ \\
\hline Neutrophil/lymphocyte ratio (NLR) & $3.42+/-2.91$ & $3.33+/-2.40$ & $3.39+/-2.24$ \\
\hline Body Mass Index $\left[\mathrm{kg} / \mathrm{m}^{2}\right]$ & $26.78+/-6.57$ & $26.89+/-6.35$ & $26.5+/-5.86$ \\
\hline Region [count] North America & 1759 & 1947 & 1657 \\
\hline Europe & 3715 & 3525 & 3817 \\
\hline
\end{tabular}

Interdialytic weight gain (IDWG), body weight (BW), normalized protein catabolic rate (nPCR), hemodialysis $(\mathrm{HD})$, systolic blood pressure (SBP), dialysate sodium concentration $\left(\mathrm{DNa}^{+}\right)$, serum sodium concentration $\left(\mathrm{SNa}^{+}\right)$. Serum sodium concentration $\left(\mathrm{SNa}^{+}\right)$decrease: slope <-1.72 $\mathrm{mEq} / \mathrm{l}$, Stable $\mathrm{SNa}{ }^{+}$: slope -1.72 to $1.33 \mathrm{mEq} / \mathrm{l} ; \mathrm{SNa}^{+}$increase: slope $>1.33 \mathrm{mEq} / \mathrm{l}$; standard deviation (SD) tertile $1:<2.0 \mathrm{mEq} / \mathrm{l}, \mathrm{SNa}^{+}$SD tertile 2 : 2.0 to $2.7 \mathrm{mEq} / \mathrm{l} ; \mathrm{SNa}^{+} \mathrm{SD}$ tertile $3:>2.7 \mathrm{mEq} / \mathrm{l}$. 


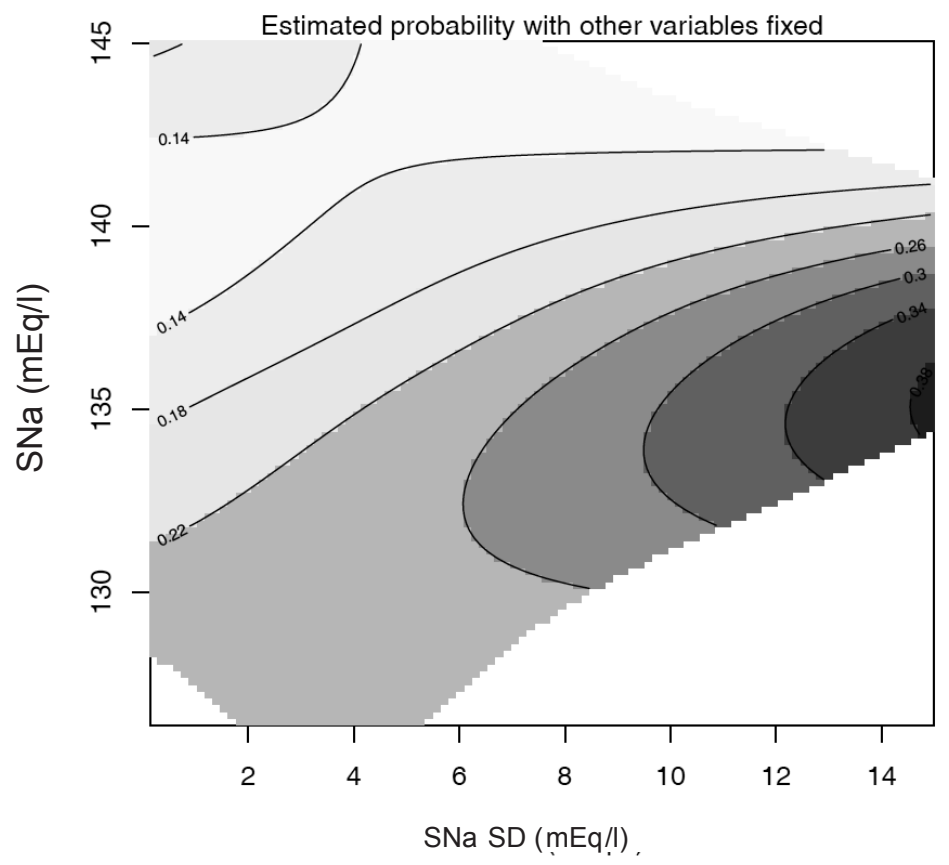

Figure 8.1 Contour plot depicting probability of death in Year 2 as a function of serum sodium concentration ( $\mathrm{SNa}$ ) and serum sodium variability (SNa SD) during Year 1. Probability of death was computed using a multivariate semi-parametric logistic regression model. Parameters included in the model were fixed at median values (continuous variables) and at reference conditions (categorical variables).

A stable $\mathrm{SNa}^{+}$was associated with a lower probability of death (106.6 deaths per 1000 patient-years in those with stable $\mathrm{SNa}^{+}$versus 126.0 and 111.5 , respectively, in those with decreasing and increasing $\mathrm{SNa}^{+}$; Supplemental Table S8.1). In contrast to an increasing $\mathrm{SNa}^{+}$, which was not significantly associated with an increased death risk as per log-rank test, a decreasing $\mathrm{SNa}^{+}$was significantly associated with a higher probability (Supplemental Figure S8.3). This was found confirmed in adjusted multivariable Cox regression analysis by a significantly increased hazard ratio of death in Year 2 (in reference to those with a stable $\mathrm{SNa}^{+}$) in those with a decreasing $\mathrm{SNa}^{+}[1.14$ (1.03 to 1.26 ) but not for those with an increasing SNa ${ }^{+}$(Supplemental Table S8.2). In the joint analysis the region with the lowest probability of death in Year 2 [ranging from 13 to $17 \%$ (yellow) with some areas of a risk even less than $13 \%$ (light yellow)] is defined by a SNa ${ }^{+}$between 137 and $143 \mathrm{mEq} / \mathrm{l}$, and a SNa ${ }^{+}$slope between -7 and 12 $\mathrm{mEq} / \mathrm{l} /$ year (Figure 8.3). Analysis of the associations between decreasing $\mathrm{SNa}^{+}$at fixed $\mathrm{SNa}^{+}$values confirmed a clear trend of increasing probability of death for a decrease in $\mathrm{SNa}^{+}$, except for higher levels of $\mathrm{SNa}^{+}$as shown for example for $141 \mathrm{mEq} / \mathrm{l}$ (Figure 8.4d). Increases of $\mathrm{SNa}^{+}$did not show significant associations with probability of death, except for increases at higher levels of $\mathrm{SNa}^{+}$[i.e. 139.2 and $141 \mathrm{mEq} / \mathrm{l}$ (Figure 8.4c and 8.4d)] 
where a non-significant but marked increase of the probability occurs with increasing $\mathrm{SNa}^{+}$. This is in contrast to the lower $\mathrm{SNa}^{+}$(shown for 133.7 and $137.2 \mathrm{mEq} / \mathrm{l}$ in Figure $8.4 \mathrm{a}$ and $8.4 \mathrm{~b})$.
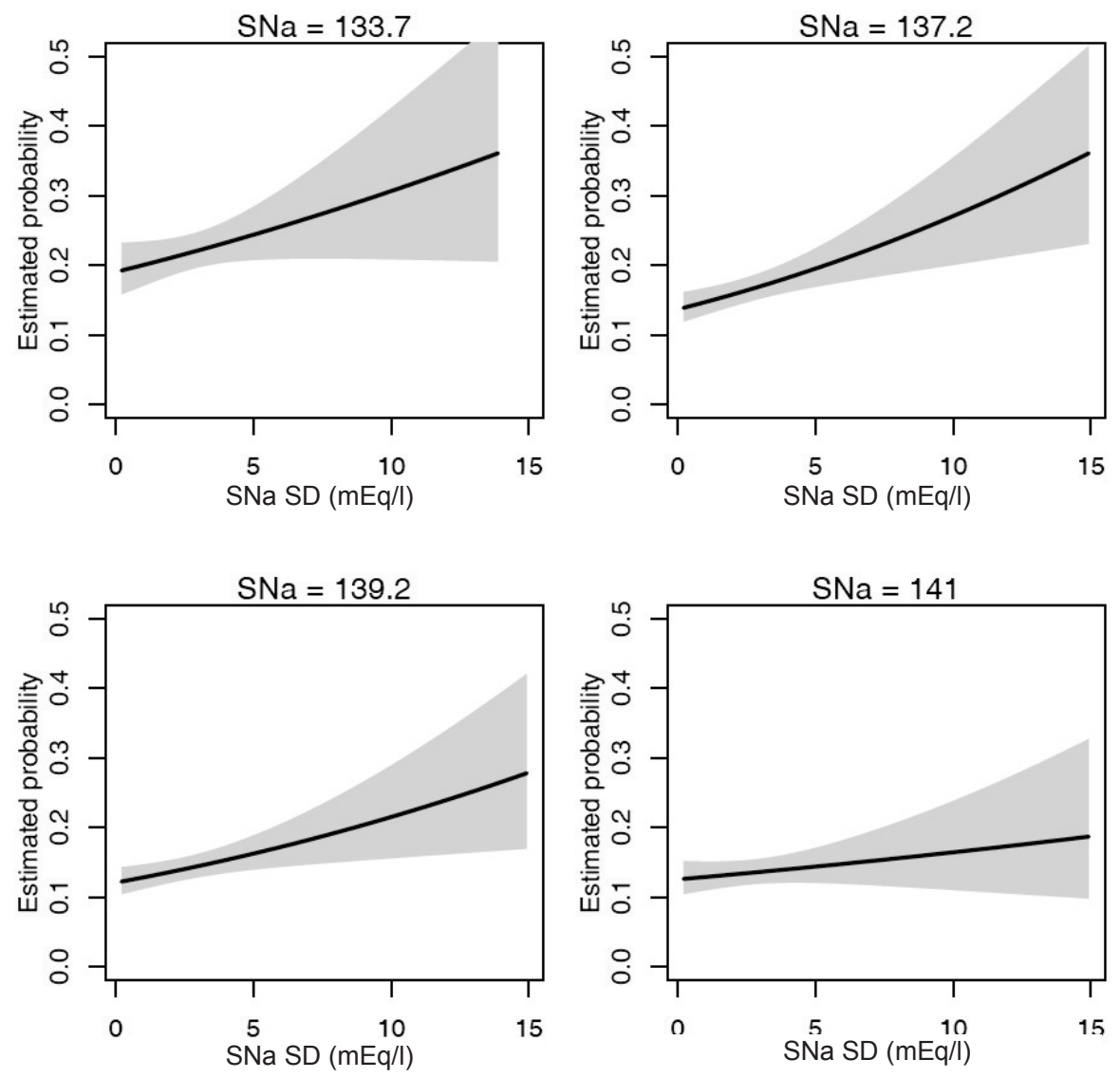

Figure 8.2 Spline analysis of the probability of death during Year 2 using a multivariate logistic regression model at 4 different magnitudes of serum sodium concentration $\left(\mathrm{SNa}^{+}\right)$over a range of available $\mathrm{SNa}^{+}$variability [as per standard deviation (SD)] data. Other parameters included in the model were fixed at median values (continuous variables) and at reference conditions (categorical variables). 


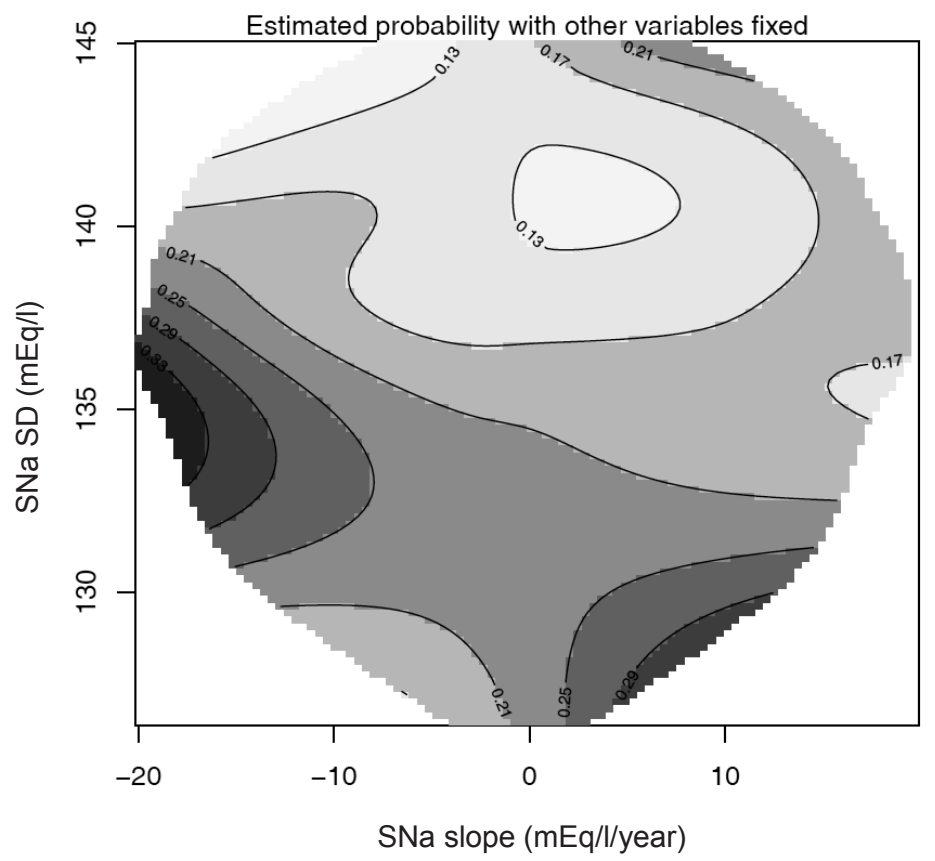

Figure 8.3 Contour plot depicting probability of death in Year 2 color-coded as a function of serum sodium concentration $\left(\mathrm{SNa}^{+}\right)$and serum sodium slope during Year 1. Probability of death was computed using a multivariate semi-parametric logistic regression model. Parameters included in the model were fixed at median values (continuous variables) and at reference condition (categorical variables).

\section{Statistical predictors of serum sodium slopes and variability}

Table 8.3a and Table 8.3b show the multiple regression models with $\mathrm{SNa}^{+}$variability and slopes as dependent variables. Statistically significant predictors of $\mathrm{SNa}^{+}$variability with a positive relationship were $\mathrm{SNa}^{+}$slope, age, diabetes, and IDWG, and those with an inverse relationship were male gender, serum albumin, body mass index (BMI) and dialysate sodium concentration $\left(\mathrm{DNa}^{+}\right)$. In contrast only diabetes, $\mathrm{nPCR}$ and $\mathrm{DNa}^{+}$were associated positively with $\mathrm{SNa}^{+}$slope. IDWG associated inversely with the magnitude of the $\mathrm{SNa}^{+}$slope. Repetition of the determinative analysis for $\mathrm{SNa}^{+}$variability in those with increasing and decreasing $\mathrm{SNa}^{+}$showed comparable results; some additional effects of $\mathrm{SNa}^{+}$, serum albumin and $\mathrm{DNa}^{+}$may be noted (Table 8.3b). 

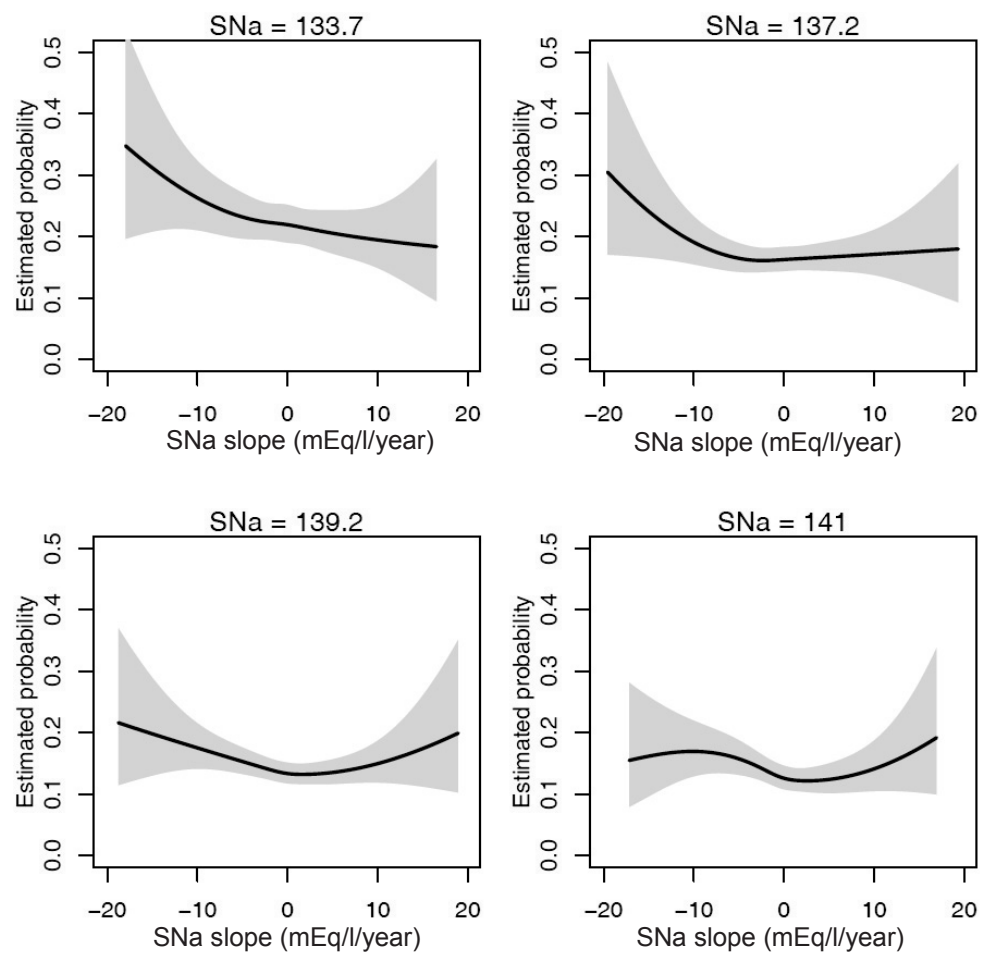

Figure 8.4 Spline analysis of the probability of death during Year 2 using a logistic regression model at 4 different magnitudes of serum sodium concentration $\left(\mathrm{SNa}^{+}\right)$over a range of available $\mathrm{SNa}^{+}$slope data. Other parameters included in the model were fixed at median values (continuous variables) and at reference conditions (categorical variables).

Table 8.3a Statistical predictors of serum sodium $\left(\mathrm{SNa}^{+}\right)$variability.

\begin{tabular}{|c|c|}
\hline $\mathrm{SNa}^{+}$variability & Estimate $(95 \% \mathrm{Cl})[\mathrm{mEq} / \mathrm{l}$ per unit] \\
\hline (Intercept) & $8.95(7.19$ to 10.71$)$ \\
\hline $\mathrm{SNa}^{+}[\mathrm{mEq} / \mathrm{l}]$ & $-0.011(-0.018$ to -0.004$)$ \\
\hline Age [years] & 0.002 (0.001 to 0.003$)$ \\
\hline Male gender & $-0.07(-0.1$ to -0.03$)$ \\
\hline Diabetes & $0.14(0.11$ to 0.18$)$ \\
\hline IDWG [\% of body weight] & $0.11(0.09$ to 0.13$)$ \\
\hline Albumin $[\mathrm{g} / \mathrm{dl}]$ & $-0.22(-0.27$ to -0.18$)$ \\
\hline $\mathrm{nPCR}[\mathrm{g} / \mathrm{kg} / \mathrm{d}]$ & $-0.23(-0.35$ to -0.11$)$ \\
\hline Serum potassium [mEq/l] & $-0.01(-0.04$ to 0.02$)$ \\
\hline Body Mass Index $\left[\mathrm{kg} / \mathrm{m}^{2}\right]$ & $-0.0031(-0.0059$ to -0.0004$)$ \\
\hline $\mathrm{DNa}^{+}[\mathrm{mEq} / \mathrm{l}]$ & $-0.03(-0.04$ to -0.02$)$ \\
\hline Region North America [Reference Europe] & $-0.31(-0.35$ to -0.26$)$ \\
\hline
\end{tabular}

Serum sodium concentration $\left(\mathrm{SNa}^{+}\right)$, interdialytic weight gain (IDWG), normalized protein catabolic rate (nPCR), hemodialysis (HD), systolic blood pressure (SBP), dialysate sodium concentration ( $\mathrm{DNa}^{+}$). 
Table 8.3b Statistical predictors of slopes in $\mathrm{SNa}^{+}$in multiple linear regression analysis.

\begin{tabular}{|c|c|c|c|}
\hline $\mathrm{SNa}^{+}$slope & $\begin{array}{c}\text { Estimate for all } \mathrm{SNa}^{+} \\
\text {slope }(95 \% \mathrm{Cl}) \\
{[\mathrm{mEq} / \mathrm{l} \text { per unit] }} \\
\end{array}$ & $\begin{array}{c}\text { Estimate in those with } \\
\text { decreasing } \mathrm{SNa}^{+}(95 \% \mathrm{Cl}) \\
{[\mathrm{mEq} / \mathrm{l} \text { per unit] }}\end{array}$ & $\begin{array}{c}\text { Estimate in those with } \\
\text { increasing } \mathrm{SNa}^{+}(95 \% \mathrm{Cl}) \\
{[\mathrm{mEq} / \mathrm{l} \text { per unit] }}\end{array}$ \\
\hline (Intercept) & $-9.21(-16.02$ to -2.40$)$ & $-21.69(-28.94$ to -14.45$)$ & $16.29(9.18$ to 23.4$)$ \\
\hline $\mathrm{SNa}^{+}[\mathrm{mEq} / \mathrm{I}]$ & $0.01(-0.02$ to 0.03$)$ & 0.05 (0.03 to 0.08$)$ & $-0.06(-0.09$ to -0.03$)$ \\
\hline Age [years] & $0.003(-0.001$ to 0.008$)$ & $-0.002(-0.007$ to 0.003$)$ & $0.0044(-0.0004$ to 0.0092$)$ \\
\hline Male gender [yes/no] & $0.04(-0.09$ to 0.17$)$ & $0.04(-0.09$ to 0.18$)$ & $-0.15(-0.29$ to -0.01$)$ \\
\hline Diabetes [yes/no] & 0.15 (0.01 to 0.29$)$ & $-0.15(-0.30$ to 0.01$)$ & $0.02(-0.13$ to 0.16$)$ \\
\hline IDWG [\% of body weight] & $-0.10(-0.17$ to -0.03$)$ & $-0.19(-0.27$ to -0.12$)$ & $0.08(0.01$ to 0.16$)$ \\
\hline Albumin $[\mathrm{g} / \mathrm{dl}]$ & $0.13(-0.04$ to 0.3$)$ & $0.23(0.06$ to 0.41$)$ & $-0.09(-0.26$ to 0.09$)$ \\
\hline $\mathrm{nPCR} g / \mathrm{kg} / \mathrm{d}]$ & $0.87(0.40$ to 1.34$)$ & $0.44(-0.08$ to 0.97$)$ & $-0.53(-1.03$ to -0.04$)$ \\
\hline Serum potassium [mEq/I] & $-0.03(-0.15$ to 0.08$)$ & $0.09(-0.03$ to 0.21$)$ & $-0.16(-0.28$ to -0.04$)$ \\
\hline Body Mass Index $\left[\mathrm{kg} / \mathrm{m}^{2}\right]$ & $-0.01(-0.03$ to 0$)$ & $-0.002(-0.013$ to 0.009$)$ & $-0.007(-0.019$ to 0.005$)$ \\
\hline $\mathrm{DNa}^{+}[\mathrm{mEq} / \mathrm{l}]$ & $0.05(0.01$ to 0.10$)$ & $0.06(0.02$ to 0.11$)$ & $-0.02(-0.06$ to 0.03$)$ \\
\hline $\begin{array}{l}\text { Region North America } \\
\text { [Reference Europe] }\end{array}$ & $-0.10(-0.27$ to 0.07$)$ & $0.35(0.16$ to 0.54$)$ & $-0.59(-0.77$ to -0.41$)$ \\
\hline
\end{tabular}

Serum sodium concentration $\left(\mathrm{SNa}^{+}\right)$, interdialytic weight gain (IDWG), body weight (BW), normalized protein catabolic rate (nPCR), hemodialysis (HD), systolic blood pressure (SBP), dialysate sodium concentration $\left(\mathrm{DNa}^{+}\right)$.

\section{Discussion}

\section{Main findings and Interpretation}

In this observational study pre-HD SNa ${ }^{+}$variability (as determined by SD), decreasing $\mathrm{SNa}^{+}$at lower levels of $\mathrm{SNa}^{+}$(approximately lower than a cut-off of $137 \mathrm{mEq} / \mathrm{l}$ ) and increasing $\mathrm{SNa}^{+}$at higher levels of $\mathrm{SNa}^{+}$(approximately when $\mathrm{SNa}^{+}$is greater than $143 \mathrm{mEq} / \mathrm{l}$ ) are predictors of all-cause mortality in the second year of dialysis in incident $\mathrm{HD}$ patients. To the best of our knowledge the predictive value of pre-HD SNa variability to mortality represents a novel finding. The increased mortality risk associated with pre-HD $\mathrm{SNa}^{+}$variability remained significant after adjustment for multiple potential confounders (age, gender, diabetes, IDWG, albumin, potassium, $\mathrm{nPCR}, \mathrm{DNa}^{+}$and $\left.\mathrm{BMI}\right)$.

\section{Discussion of findings}

A lower pre-HD SNa ${ }^{+}$(approximately lower than a cut-off of $137 \mathrm{mEq} / \mathrm{I}$ ) was associated with increased mortality (independent of variability and trends) in our study (Figure 8.1 and Figure 8.3). This finding has been reported on numerous occasions in the literature and was hypothesized to be a reflection of a 'frail phenotype' for these patients ${ }^{22-24}$. For this reason the analysis of dynamic changes in $\mathrm{SNa}^{+}$and $\mathrm{SNa}^{+}$variability and their impact on survival in addition to the effect of the absolute pre- $\mathrm{HD} \mathrm{SNa}^{+}$is of additional interest. Supporting evidence for the strong prognostic value of changes in $\mathrm{SNa}^{+}$levels 
has been reported in patients with heart failure ${ }^{9}$ who found a similar decrease in mortality in patients with increasing $\mathrm{SNa}^{+}$and an increase in those with a decreasing $\mathrm{SNa}^{+}$at the lower levels of $\mathrm{SNa}^{+9}$.

In the light of our data it becomes clear that whereas low $\mathrm{SNa}^{+}$has an effect on mortality, an unstable $\mathrm{SNa}^{+}$set-point (i.e. larger variability and/or slope) is also intimately associated with reduced survival over and above the pre- $\mathrm{HD} \mathrm{SNa}{ }^{+}$value (Figure 8.1 and Figure 8.3). We found that the lowest risk of death occurred at $\mathrm{SNa}^{+}$ levels between 137 and $143 \mathrm{mEq} / \mathrm{l}$ regardless of slope or variability, a range which may be hypothesized to be an optimal level of pre-HD SNa ${ }^{+}$in the dialysis patient.

The relationship between increased $\mathrm{SNa}^{+}$variability and outcome persisted after adjustment for relevant parameters related to outcome (age, gender, diabetes, IDWG, serum albumin, potassium, $\mathrm{nPCR}, \mathrm{DNa}^{+}$and $\mathrm{BMI}$ ). These parameters were also determinants of pre-HD SNa ${ }^{+}$variability and slope in multiple regression analysis. Our findings are corroborated by the consistency between the analysis of probability of death during Year 2 (as a binary outcome) in logistic regression analysis, and the time to event analysis as per Cox regression analysis.

An unanswered question is whether changes in $\mathrm{SNa}^{+}$are causally related to mortality by causing osmotic disequilibrium, or whether $\mathrm{SNa}^{+}$variability is reflective of underlying illness, which is not fully captured by the covariates included in the analysis, and as such related to outcome. Therefore, it may be hypothesized that variability and changes in $\mathrm{SNa}^{+}$may be a reflection of a "frail phenotype" and unaccounted comorbidities, as suggested by the DOPPS authors for patients with low $\mathrm{SNa}^{+}$levels ${ }^{5}$, but could also be consequence of an acute event such as myocardial infarction amongst others $^{11,12,25}$.

Changes in the neurohormonal responses mediating thirst and salt appetite in dialysis patients (e.g. vasopressin, adrenomedullin ${ }^{26}$ and copeptin) may also have contributed to our findings. Copeptin (a glycopeptide co-secreted with vasopressin) is associated with impaired ventricular function ${ }^{27}$ and is a predictor of adverse outcome both in patients with heart failure as well as in $\mathrm{CKD}^{28-30}$. To what extent changes in these vasoactive compounds explains sodium variability as well as the relationship between variability, trends and death, is not yet clear and represents an exciting area of future research.

Increases of $\mathrm{SNa}^{+}$can occur with age ${ }^{31}$, or may reflect dehydration. This may occur prior to death as recently reported ${ }^{32}$ and could possibly be associated with an increased occurrence of intradialytic morbid events that are themselves independently related to increased mortality ${ }^{33}$. Furthermore malnutrition and in particularly reduced protein intake is associated with increased mortality ${ }^{34}$. For this reason we included nPCR in the models since it is associated with nutrition but also is a predictor of death ${ }^{35-37}$. Indeed, $\mathrm{nPCR}$ was also inversely related to $\mathrm{SNa}^{+}$variability.

The seasonality of electrolyte concentrations ${ }^{38,39}$ and its relationship between seasons to mortality ${ }^{40}$ was also accounted for by defining a 12 months observation period which 
includes equally all seasons. Furthermore the analysis includes various regions on both continents with varying climates with (and without) seasonal differences.

Finally plasma glucose variability of different magnitudes may be expected in diabetic subjects (possibly as a result of anti-diabetic therapy or dietary intake) and may possibly impact on measured $\mathrm{SNa}^{+}$and $\mathrm{SNa}^{+}$variability ${ }^{41-44}$. Although diabetes is known to be associated with increased mortality and so was included as an adjustment factor in our models we were unable to account for variations in plasma glucose levels over time.

These and other factors result in higher variability (Table 8.3). However, this is not the only possible reason for higher variability, but which could also due to a higher level of randomness in an unstable and uncontrolled system possibly resulting from a loss of control and regulatory mechanisms which are in turn possibly associated with comorbidities $^{45}$.

In this analysis we focused on increased $\mathrm{SNa}^{+}$variability per se, and on the direction of changes in $\mathrm{SNa}^{+}$over time (slopes). Further decreases in $\mathrm{SNa}^{+}$in patients with already low $\mathrm{SNa}^{+}$levels were related to mortality, whereas increased variability related to mortality over a wide range of $\mathrm{SNa}^{+}$levels (Figure 8.1 and Figure 8.3). From these observations it may be hypothesized that decreasing $\mathrm{SNa}^{+}$at low $\mathrm{SNa}^{+}$levels may indicate patients at elevated risk of death.

Despite inclusion of the factors associated with $\mathrm{SNa}^{+}$variability and those established to relate to mortality in our analytic models the effect of $\mathrm{SNa}^{+}$variability on mortality remained significant even after full adjustment and thus may be considered to also have an independent effect.

\section{Limitations}

A limitation of the current analysis is the observational nature of our data, which does not allow for definite conclusions of causality between changes in $\mathrm{SNa}^{+}$and mortality, or whether these changes reflect a further loss of homeostasis in dialysis patients. Due to the multidimensional character of disease pathogenesis and progression the lack of complete data on comorbidities is an enduring limitation. Although we were not able to include data from all continents generalizability (which would allow to confirm these relationships in an Asian population or in those of Hispanic ethnicity explicitly), can still be considered sufficient given the large sample size and the origin of the patients from two different continents.

To a certain extent the current analysis is at variance with the concept of the existence of a stable sodium set-point in HD patients (at least in some subgroups), however, if our hypothesis of randomness due to an unstable and uncontrolled system with impaired or lost control and regulatory mechanisms, is correct, in those HD patients suffering only from a limited number of comorbidities the set-point may still be considerably stable $^{2,4}$. Finally the mean changes and SD of certain clinical parameters in our large 
dataset were in general relatively small and therefore might go undetected in daily clinical practice.

\section{Implications and conclusions}

The concept of longitudinal observation of variability and slopes in relation to outcome is quite novel, and expands our knowledge on mortality risk factors. The prognostic value of slopes to predict outcomes based on the variability and trends of various physiological and laboratory parameters might also be of relevance for future prognostic risk scores. These may facilitate the identification of patients at risk of death in the earlier stages of their illness which might currently remain clinically undetected.

The knowledge of the relationship between $\mathrm{SNa}^{+}$variability and death, may, next to pathophysiologic interest, also be of importance for the development of dynamic risk models. These may permit the development of alert systems in this vulnerable group of patients. Given the current paucity of data on the relation between dynamic changes in clinical and laboratory parameters in dialysis patients and outcome, we believe that our observations are not only of interest for the development for safety and alert algorithms but also are of significant pathophysiologic interest and may spark additional research to evaluate why patients with certain characteristic dynamics show an increased risk of mortality. 


\section{Supplemental tables and figures}

Table S8.1 Mortality rates in a) Serum Sodium Concentration $\left(\mathrm{SNa}^{+}\right)$standard deviation (SD) and b) $\mathrm{SNa}{ }^{+}$ slope tertiles.

\begin{tabular}{|c|c|c|c|}
\hline $\mathrm{SNa}^{+}$variability & SNa ${ }^{+}$SD tertile 1 & $\mathrm{SNa}^{+} \mathrm{SD}$ tertile 2 & $\mathrm{SNa}^{+} \mathrm{SD}$ tertile 3 \\
\hline Sample size [count] & 5473 & 5474 & 5473 \\
\hline Deaths [count] & 651 & 763 & 971 \\
\hline Exposure days [days] & 2572990 & 2504409 & 2521121 \\
\hline Death rate [death per 1000 patient years] & 92.41 & 111.28 & 140.67 \\
\hline
\end{tabular}

Serum Sodium Concentration $\left(\mathrm{SNa}^{+}\right)$standard deviation (SD) tertile $1:<2.0 \mathrm{mEq} / \mathrm{l}, \mathrm{SNa}^{+} \mathrm{SD}$ tertile $2: 2.0$ to $2.7 \mathrm{mEq} / \mathrm{l} ; \mathrm{SNa}^{+} \mathrm{SD}$ tertile $3:>2.7 \mathrm{mEq} / \mathrm{l}$.

\begin{tabular}{lccc}
\hline SNa & & & \\
\hline slope & $\mathrm{SNa}^{+}$decrease & Stable SNa & SNa $^{+}$increase \\
Sample size [count] & 5474 & 5472 & 5474 \\
Deaths [count] & 857 & 728 & 800 \\
Exposure days [days] & 2483435 & 2493474 & 2621611 \\
Death rate [death per 1000 patient years] & 126.04 & 106.64 & 111.46 \\
\hline
\end{tabular}

Serum Sodium Concentration $\left(\mathrm{SNa}^{+}\right)$decrease: slope <-1.72 $\mathrm{mEq} / \mathrm{l}$, Stable $\mathrm{SNa}^{+}$: slope -1.72 to1.33 mEq/l; $\mathrm{SNa}^{+}$increase: slope $>1.33 \mathrm{mEq} / \mathrm{l}$.

Table S8.2 Cox regression analysis of time to death in Year 2 including tertiles of a) variability and b) slope.

\begin{tabular}{|c|c|}
\hline Variability & Estimate $(95 \% \mathrm{Cl})$ \\
\hline $\mathrm{SNa}^{+} \mathrm{SD}$ tertile 1 [mEq/I] & Reference group \\
\hline $\mathrm{SNa}^{+} \mathrm{SD}$ tertile $2[\mathrm{mEq} / \mathrm{l}]$ & $1.10(0.99$ to 1.22$)$ \\
\hline $\mathrm{SNa}^{+} \mathrm{SD}$ tertile 3 [mEq/I] & 1.30 (1.17 to 1.44$)$ \\
\hline $\mathrm{DNa}^{+}[\mathrm{mEq} / \mathrm{l}]$ & 0.94 (0.92 to 0.97$)$ \\
\hline $\mathrm{SNa}^{+}[\mathrm{mEq} / \mathrm{I}]$ & 0.95 (0.93 to 0.96$)$ \\
\hline Age at HD initiation [years] & 1.04 (1.03 to 1.04$)$ \\
\hline Male gender & 1.13 (1.04 to 1.23$)$ \\
\hline Diabetes & 1.12 (1.03 to 1.23 ) \\
\hline IDWG [\% of body weight] & 1.06 (1.01 to 1.12$)$ \\
\hline $\mathrm{nPCR}[\mathrm{g} / \mathrm{kg} / \mathrm{d}]$ & 0.35 (0.25 to 0.49$)$ \\
\hline Serum potassium [mEq/l] & 0.92 (0.86 to 0.99$)$ \\
\hline Body mass index $\left[\mathrm{kg} / \mathrm{m}^{2}\right]$ & 0.98 (0.97 to 0.98$)$ \\
\hline Region North America & 1.01 (0.88 to 1.16$)$ \\
\hline
\end{tabular}

Serum sodium concentration $\left(\mathrm{SNa}^{+}\right)$, standard deviation (SD), interdialytic weight gain (IDWG), body weight (BW), normalized protein catabolic rate (nPCR), hemodialysis (HD), systolic blood pressure (SBP), dialysate sodium concentration ( $\mathrm{DNa}^{+}$). 


\begin{tabular}{lc}
\hline Slopes & Estimate $(95 \% \mathrm{Cl})$ \\
\hline decreasing SNa ${ }^{+}[\mathrm{mEq} / \mathrm{l} /$ year] & $\mathbf{1 . 1 4}(\mathbf{1 . 0 3}$ to 1.26$)$ \\
stable $\mathrm{SNa}^{+}[\mathrm{mEq} / \mathrm{l} /$ year] & Reference group \\
Increasing SNa $^{+}[\mathrm{mEq} / \mathrm{l} /$ year] & $1.00(0.91$ to 1.11$)$ \\
$\mathrm{DNa}^{+}[\mathrm{mEq} / \mathrm{l}]$ & $0.94(0.92$ to 0.97$)$ \\
$\mathrm{SNa}^{+}[\mathrm{mEq} / \mathrm{l}]$ & $0.95(0.93$ to 0.96$)$ \\
$\mathrm{Age}$ at $\mathrm{HD}$ initiation [years] & $1.04(1.03$ to 1.04$)$ \\
Male gender & $1.12(1.03$ to 1.22$)$ \\
Diabetes & $1.14(1.04$ to 1.24$)$ \\
IDWG $[\%$ of body weight] & $1.07(1.02$ to 1.12$)$ \\
$\mathrm{nPCR}[\mathrm{g} / \mathrm{kg} / \mathrm{d}]$ & $0.35(0.25$ to 0.50$)$ \\
Serum potassium $[\mathrm{mEq} / \mathrm{l}]$ & $0.92(0.86$ to 0.99$)$ \\
Body mass index $\left[\mathrm{kg} / \mathrm{m}^{2}\right]$ & $0.97(0.97$ to 0.98$)$ \\
Region North America & $0.99(0.86$ to 1.14$)$ \\
\hline
\end{tabular}

Serum sodium concentration $\left(\mathrm{SNa}^{+}\right)$, interdialytic weight gain (IDWG), body weight (BW), normalized protein catabolic rate (nPCR), hemodialysis (HD), systolic blood pressure (SBP), dialysate sodium concentration $\left(\mathrm{DNa}^{+}\right)$.

a) Serum Sodium ( $\mathrm{SNa}+)$

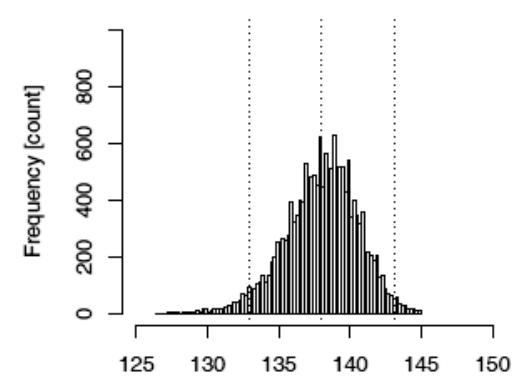

average $\mathrm{SNa}+$ over 12 months[mEq/L]

\section{c) $\mathrm{SNa}+$ variability}

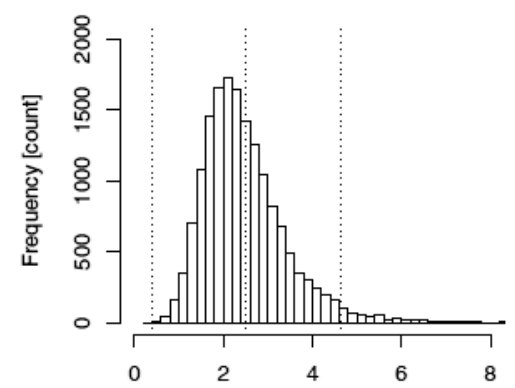

b) $\mathrm{SNa}+$ slope

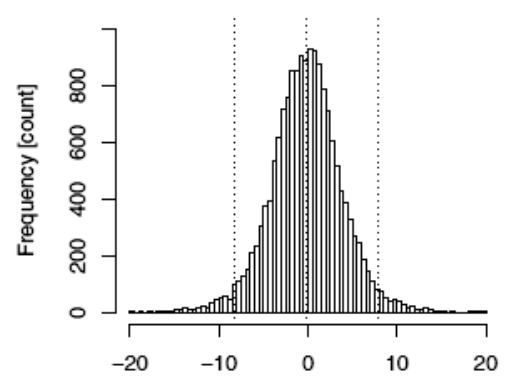

$\mathrm{SNa}+$ slope over 12 months [mEq/Lyear]

$\mathrm{SNa}+$ standard deviation over 12 months [ $\mathrm{mEq} / \mathrm{L}]$

Figure S8.1 : Distribution of serum sodium concentration $\left(\mathrm{SNa}^{+}\right), \mathrm{SNa}^{+}$change (as $\mathrm{mEq} / \mathrm{l} /$ year) and $\mathrm{SNa}^{+}$ variability (defined as SD over the period of the first year after HD initiation). 


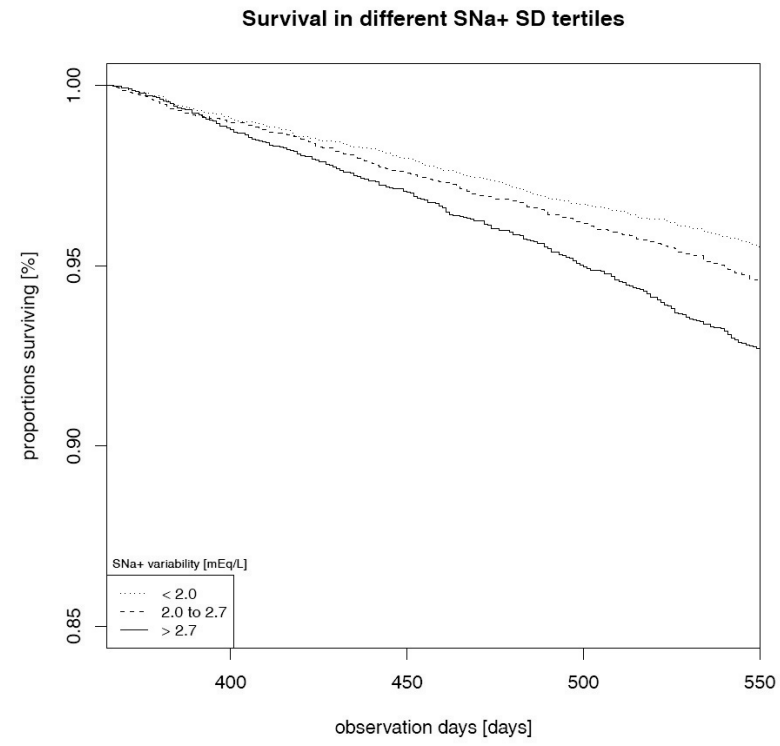

Figure S8.2 Kaplan Meier curve analysis of patients' survival during Year 2 stratified as per tertiles of serum sodium $\left(\mathrm{SNa}^{+}\right)$variability [as per standard deviation (SD)] during Year 1.

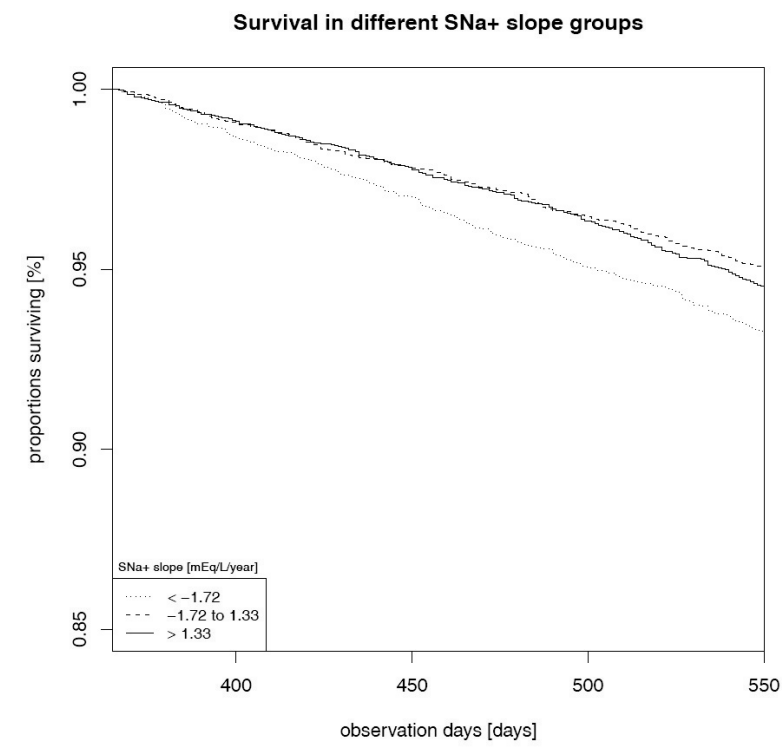

Figure S8.3 Kaplan Meier curve analysis of patients' survival during Year 2 stratified as per tertiles of SNa ${ }^{+}$ slope during Year 1. 


\section{References}

1. Lee JW. Fluid and electrolyte disturbances in critically ill patients. Electrolyte Blood Press 2010;8:72-81.

2. Keen ML, Gotch FA. The association of the sodium "setpoint" to interdialytic weight gain and blood pressure in hemodialysis patients. Int J Artif Organs 2007;30:971-9.

3. Raimann JG, Thijssen S, Usvyat LA, Levin NW, Kotanko P. Sodium alignment in clinical practice-implementation and implications. Semin Dial 2011;24:587-92.

4. Peixoto AJ, Gowda N, Parikh CR, Santos SF. Long-term stability of serum sodium in hemodialysis patients. Blood Purif 2010;29:264-7.

5. Hecking M, Karaboyas A, Saran R, Sen A, Horl WH, Pisoni RL, Robinson BM, Sunder-Plassmann G, Port FK. Predialysis Serum Sodium Level, Dialysate Sodium, and Mortality in Maintenance Hemodialysis Patients: The Dialysis Outcomes and Practice Patterns Study (DOPPS). Am J Kidney Dis 2011;59: 238-48.

6. Brunelli SM, Lynch KE, Ankers ED, Joffe MM, Yang W, Thadhani RI, Feldman HI. Association of hemoglobin variability and mortality among contemporary incident hemodialysis patients. Clin J Am Soc Nephrol 2008;3:1733-40.

7. Mallamaci F, Tripepi G. Blood pressure variability in chronic kidney disease patients. Blood Purif 2013;36:58-62.

8. Raimann JG, Usvyat LA, Thijssen S, Kotanko P, Rogus J, Lacson E Jr, Levin NW. Blood pressure stability in hemodialysis patients confers a survival advantage: results from a large retrospective cohort study. Kidney lint 2012;81:548-58.

9. Madan VD, Novak E, Rich MW. Impact of change in serum sodium concentration on mortality in patients hospitalized with heart failure and hyponatremia. Circ Heart Fail 2011;4:637-43.

10. Flear CT, Florence I, Williams JA. Water, sodium, potassium, and chloride content of skeletal muscle in fit and ill subjucts. J Clin Pathol 1968;21:555-63.

11. Flear CT, Hilton P. Hyponatraemia and severity and outcome of myocardial infarction. BMJ 1979;1: 1242-6.

12. Flear CT, Singh CM. Hyponatraemia and sick cells. Br J Anaesth 1973;45:976-94.

13. Guglielminotti J, Pernet P, Maury E, Alzieu M, Vaubourdolle M, Guidet B, Offenstadt G. Osmolar gap hyponatremia in critically ill patients: evidence for the sick cell syndrome? Crit Care Med 2002;30: 1051-5.

14. Flea, CT, Gill GV, Burn J. Hyponatraemia: mechanisms and management. Lancet 1981;2:26-31.

15. Usvyat LA, Haviv YS, Etter M, Kooman J, Marcelli D, Marelli C, Power A, Toffelmire T, Wang Y, Kotanko P. The MONitoring Dialysis Outcomes (MONDO) initiative. Blood Purif 2013;35:37-48.

16. von Gersdorff GD, Usvyat L, Marcelli D, Grassmann A, Marelli C, Etter M, Kooman JP, Power A, Toffelmire T, Haviv YS, Guinsburg A, Barth C, Schaller M, Bayh I, Scatizzi L, Tashman A, Thijssen S, Levin NW, van der Sande FM, Pusey C, Wang Y, Kotanko P. Monitoring Dialysis Outcomes across the World The MONDO Global Database Consortium. Blood Purif 2013;36:165-72.

17. Wang Y. Smoothing Splines: Methods and Applications Chapman \& Hall 2011.

18. Gu C: Smoothing Spline ANOVA Models, Springer, 2002.

19. Wahba G, Wang Y, Gu C, Klein R, Klein B. Smoothing Spline Anova for Exponential Families, with Application to the Wisconsin Epidemiological Study of Diabetic Retinopathy. Ann Stat 1995;23: 1865-95.

20. R Development Core Team: R. A language and environment for statistical computing. Vienna, Austria, R Foundation for Statistical Computing, 2010.

21. Dialysis and Practice Pattern Outcomes Study (DOPPS). 2012 Annual Report of the Dialysis Outcomes and Practice Patterns Study: Hemodialysis Data 1997-2011. Ann Arbor, MI., USA, Arbor Research Collaborative for Health, 2012.

22. Hecking M, Karaboyas A, Saran R, Sen A, Horl WH, Pisoni RL, Robinson BM, Sunder-Plassmann G, Port FK. Predialysis serum sodium level, dialysate sodium, and mortality in maintenance hemodialysis patients: The dialysis outcomes and practice patterns study (DOPPS). Am J Kidney Dis 2012;59:238-48.

23. Mc Causland FR, Brunelli SM, Waikar SS. Dialysate sodium, serum sodium and mortality in maintenance hemodialysis. Nephrol Dial Transplant 2012;27:1613-8.

24. Waikar SS, Curhan GC, Brunelli SM. Mortality associated with low serum sodium concentration in maintenance hemodialysis. Am J Med 2011;124:77-84. 
25. Flear $\mathrm{CT}$, Singh $\mathrm{CM}$. The sick cell concept and hyponatremia in congestive heart failure and liver disease. Lancet 1982;2:101-2.

26. White MM, Samson WK. A possible relationship between brain-derived adrenomedullin and oxytocin in the regulation of sodium balance. J Endocrinol 2009;203:253-62.

27. Bay M, Kirk V, Parner J, Hassager C, Nielsen H, Krogsgaard K, Trawinski J, Boesgaard S, Aldershvile J. NTproBNP: a new diagnostic screening tool to differentiate between patients with normal and reduced left ventricular systolic function. Heart 2003;89:150-4.

28. Artunc F, Nowak A, Mueller C, Breidthardt T, Twerenbold R, Wagner R, Peter A, Haering HU, Ebmeyer S, Friedrich B. Plasma concentrations of the vasoactive Peptide fragments mid-regional proadrenomedullin, C-terminal pro-endothelin 1 and copeptin in hemodialysis patients: associated factors and prediction of mortality. PloS One, 2014;9:e86148.

29. Przybylowski P, Malyszko J, Malyszko JS. Copeptin in heart transplant recipients depends on kidney function and intraventricular septal thickness. Transplant Proc 2010;42:1808-11.

30. Fenske W, Wanner C, Allolio B, Drechsler C, Blouin K, Lilienthal J, Krane V, German Diabetes DSI. Copeptin levels associate with cardiovascular events in patients with ESRD and type 2 diabetes mellitus. J Am Soc Nephrol 2011;22:782-90.

31. Thomson BK, Dixon SN, Huang SH, Leitch RE, Suri RS, Chan CT, Lindsay RM. Modifiable variables affecting interdialytic weight gain include dialysis time, frequency, and dialysate sodium. Hemodialysis international International Symposium on Home Hemodial Int. 2013;17:576-85.

32. Kotanko P, Thijssen S, Usvyat L, Tashman A, Kruse A, Huber C, Levin NW. Temporal evolution of clinical parameters before death in dialysis patients: a new concept. Blood Purif 2009;27:38-47.

33. Shoji T, Tsubakihara Y, Fujii M, Imai E. Hemodialysis-associated hypotension as an independent risk factor for two-year mortality in hemodialysis patients. Kidney Int 2004;66:1212-20.

34. Shinaberger CS, Kilpatrick RD, Regidor DL, McAllister, CJ, Greenland S, Kopple JD, Kalantar-Zadeh K. Longitudinal associations between dietary protein intake and survival in hemodialysis patients. Am J Kidney Dis 2006;48:37-49.

35. Block GA, Hulbert-Shearon TE, Levin NW, Port FK. Association of serum phosphorus and calcium $x$ phosphate product with mortality risk in chronic hemodialysis patients: a national study. Am J Kidney Dis 1998;31:607-17.

36. Kestenbaum B, Sampson JN, Rudser KD, Patterson DJ, Seliger SL, Young B, Sherrard DJ, Andress DL. Serum phosphate levels and mortality risk among people with chronic kidney disease. J Am Soc Nephrol 2005;16:520-8.

37. Lynch KE, Lynch R, Curhan GC, Brunelli SM. Prescribed Dietary Phosphate Restriction and Survival among Hemodialysis Patients. Clin J Am Soc Nephrol 2011;6:620-9.

38. Cheung AK, Yan G, Greene T, Daugirdas JT, Dwyer JT, Levin NW, Ornt DB, Schulman G, Eknoyan G. Seasonal variations in clinical and laboratory variables among chronic hemodialysis patients. J Am Soc Nephrol 2002;13:2345-52.

39. Morimoto T, Shiraki K, Inoue T, Yoshimura H. Seasonal variation of water and electrolyte in serum with respect to homeostasis. Jpn J Physiol 1969;19:801-13.

40. Usvyat LA, Carter M, Thijssen S, Kooman JP, van der Sande, FM, Zabetakis P, Balter P, Levin NW, Kotanko P. Seasonal variations in mortality, clinical, and laboratory parameters in hemodialysis patients: a 5-year cohort study. Clin J Am Soc Nephrol 2012;7:108-15.

41. Penne EL, Thijssen S, Raimann JG, Levin NW, Kotanko P. Correction of serum sodium for glucose concentration in hemodialysis patients with poor glucose control. Diabetes Care 2010;33:e91.

42. Katz MA. Hyperglycemia-induced hyponatremia--calculation of expected serum sodium depression. $\mathrm{N}$ Engl J Med 1973;289:843-4.

43. Robin AP, Ing TS, Lancaster GA, Soung LS, Sparagana M, Geis WP, Hano JE. Hyperglycemia-induced hyponatremia: a fresh look. Clin Chem 1979;25:496-7.

44. Tzamaloukas AH, Ing TS, Siamopoulos KC, Rohrscheib M, Elisaf MS, Raj DS, Murata GH. Body fluid abnormalities in severe hyperglycemia in patients on chronic dialysis: review of published reports. J Diabetes Complications 2008;22: 29-37.

45. Vaillancourt DE, Newell KM. Changing complexity in human behavior and physiology through aging and disease. Neurobiol Aging, 2002;23: 1-11. 


\section{Chapter}

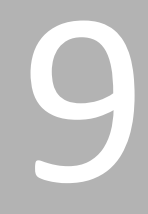

Relationship between levels and trends of blood pressure and survival: results of an observational cohort study in incident hemodialysis patients 


\section{Abstract}

This retrospective study (www.clinicaltrials.gov: \#NCT01330004) investigates the association between changes in SBP, DBP, and use of cardioprotective drugs (CPD) on survival in incident HD patients.

Pre HD SBP and DBP were averaged over the first month of HD. Slopes, reflecting temporal changes, were computed by linear regression of SBP. Patients were stratified into 4 SBP groups (1. below $120,2.120$ to $150,3.151$ to 180 , and 4. above $180 \mathrm{mmHg}$ ) and subdivided into groups with stable (+1 to $-1 \mathrm{mmHg} / \mathrm{month})$, increasing $(>1 \mathrm{mmHg}$ ) and decreasing $(<1 \mathrm{mmHg}$ ) slopes during year 1. Cox regression was used for survival analyses. Analyses were repeated for patients who were treated for $\geq 1$ month in Year 2 .

In 10245 patients (age $62 \pm 16$ years, 57\% males, 54\% whites, 59\% prescribed CPD) increases and decreases in all ranges of BP were associated with worse outcomes. Stable BP has a survival advantage as compared to increasing and declining BP at all levels of SBP and DBP. Use of CPD attenuated increases and declines and improved survival. Validation and sensitivity analyses confirmed the primary findings.

Increases and declines in BP associate with poor outcomes in HD patients at all BP ranges. Previous temporal trends need to be considered in patient care. Use of CPD is associated with enhanced survival in all blood pressure groups. 


\section{Introduction}

In the general population a strong association exists between elevated systolic and diastolic blood pressure (SBP, DBP) and mortality ${ }^{1}$. A recent meta-analysis showed that lower SBP and DBP are associated with a lower risk for stroke and ischemic heart disease at all ages ${ }^{2}$.

In the majority of hemodialysis patients predialysis BP measurements are above normal ranges $^{3,4}$. The Kidney Disease: Improving Global Outcomes (KDIGO) recently reviewed current views, concluded hypertension to be ubiquitous in this population and suggested the general use of cardioprotective drugs (CPD) ${ }^{5}$. Kidney Disease Outcomes Quality Initiative recommends, without evidence from randomized controlled trials, BP goals below 140/90 before hemodialysis and 130/80 mmHg after hemodialysis ${ }^{6}$.

Like in the general population ${ }^{7-15}$, in hemodialysis patients the relationship between BP and mortality is $U$-shaped in hemodialysis patients ${ }^{16-18}$. Deviations of BP levels associated with favorable outcomes in hemodialysis patients as compared to those in the general population have not been satisfactorily explained. It is remarkable that most studies consider the patients' average BP level as the key prognosticator, ignoring temporal trends and the potential impact of changes in BP.

This observational cohort study (www.clinicaltrials.gov: \#NCT01330004) examines the evolution and temporal changes in SBP and DBP of incident patients over the first year of dialysis and repeated the analysis in the subsequent year for survivors to test the hypothesis that both increases and decreases in BPs associate with higher mortality. The secondary aim of the study was to test the hypothesis that use of CPD influences BP changes and also associates with better survival.

\section{Methods}

\section{Patient Population}

All patients starting in-center hemodialysis between January $1^{\text {st }}, 2000$ and December $31^{\text {st }}, 2008$ in 51 facilities (see Appendix) operated by Renal Research Institute (RRI) and New York Dialysis Services were included in this analysis (www.clinicaltrials.gov: \#NCT01330004). Patients with complete demographic data (date of birth, gender, race, ethnicity, diabetic status, and height), at least one routine laboratory measurement, at least 13 treatments in the first year of dialysis, and the last treatment occurring within 30 days prior to discharge date or the end of year 1 , were included. Patients were monitored during Year 1; for patients who survived Year 1 the observation time was extended to the end of Year 2. Patients who were transferred to other clinics, switched modality, and received a transplant were censored for survival analysis. This 
observational study was approved by the Institutional Review Board of Beth Israel Medical Center, New York.

\section{Cohorts of systolic and diastolic blood pressure (SBP, DBP)}

SBP and DBP were measured prior to hemodialysis in a sitting position after a five minutes rest period with an oscillometric method by healthcare professionals in the clinics. Average SBP and DBP were individually computed from all treatments during the first 30 days after dialysis initiation. Slopes of SBP and DBP change were determined by univariable linear regression (LR) using all BP measurements available in Year 1 until censoring or death.

Patients were stratified into four groups according to mean predialysis SBP during the first month as follows: 1) below 120, 2) between 120 and 150, 3) between 151 and 180, and 4) above $180 \mathrm{mmHg}$. They were further stratified based on the slope of SBP as stable (SBP slope between +1 and $-1 \mathrm{mmHg}$ per month), decreasing (less than $-1 \mathrm{mmHg}$ per month) or increasing (more than $+1 \mathrm{mmHg}$ per month). This four-by-three grouping strategy resulted in 12 analytical cohorts.

In a second analysis, patients were stratified according to mean pre dialysis DBP in the first 30 days into: 1) below 65, 2) between 65 and 75, 3) between 76 and 85, and 4) above $85 \mathrm{mmHg}$. DBP categorization according to slope was done in the same manner as for SBP.

\section{Clinical parameters}

Pre and post dialysis weight and interdialytic weight gain (IDWG), were averaged from all available treatments during Year 1. Albumin was measured using the bromocresol green method, performed by a certified laboratory (Spectra Laboratories, Rockleigh, NJ, USA).

Comorbid illnesses were classified according to the International Classification of Diseases $(I C D)^{19}$.

\section{Evaluation of Cardioprotective Drugs}

Angiotensin converting enzyme inhibitors, angiotensin receptor blockers and betaadrenergic blockers were identified as cardioprotective drugs $(C P D)^{5,20,21}$. Therapy with CPD was binary coded and based on whether a patient was prescribed either of these drugs at start or during Year 1 of dialysis, regardless of dose and frequency.

\section{Sensitivity analyses}

Three sensitivity analyses were conducted to exclude confounding influences. A first sensitivity analysis defined a slope between 0.03 and $-0.03 \mathrm{mmHg}$ as stable and included patients with increasing and declining slopes only when showing a $P$-value 
below 0.05 for the slope in univariable LR. Others were entirely excluded. A second sensitivity analysis excluded first and last six SBP measurements per patient. This approach aimed to exclude confounding of slope computation by outliers at the beginning and the end of the observation period. A third sensitivity analysis excluded the lowest and highest quartiles of increasing and decreasing SBP, respectively. This aimed to exclude the possibility that the results were driven by a small number of patients with large changes in SBP. A fourth sensitivity analysis defined the categories of SBP change as follows: patients with increasing SBP were only those whose a lower $95 \%$ confidence interval limit was larger than $1 \mathrm{mmHg}$, and patients with decreasing SBP were only those with an upper 95\% confidence interval limit below $-1 \mathrm{mmHg}$. Patients with stable SBP were only those with upper $95 \%$ confidence interval limits lower than $1 \mathrm{mmHg}$ and lower $95 \%$ confidence interval limit larger than $-1 \mathrm{mmHg}$. This analysis aimed to test the statistical validity of our approach.

\section{Validation analyses}

In 2007 RRI instituted a quality initiative recommending physicians to prescribe CPD to most patients. To support the analysis of potential impact of CPD on SBP and DBP slope and to minimize 'treatment by indication' bias, analyses of BP levels and slope were compared between the subset of patients who: 1) initiated dialysis prior to 2006 and were not on CPD, and 2) Patients who started dialysis after the quality initiative in 2007 and were on CPD. The effect of this quality initiative on survival was analysed in the two subsets with Kaplan Meier Analysis to compare death rates between patients with and without CPD therapy.

To exclude influences of seasonality, the survival analysis was repeated with adjustment for season of death (Spring, Summer, Autumn and Winter) for patients who died and season of end of Year 1 for patients who survived.

To validate findings in Year 1, all analyses were repeated in patients who survived more than one month with more than 13 treatments in Year 2. Clinical parameters were determined anew at the beginning of Year 2 .

To validate these findings are related to the changes in SBP and not by other causes of death, the analysis of the relation of temporal changes of SBP at all levels of SBP to hazard ratio was repeated for cardiovascular mortality only.

\section{Statistical analysis}

Slopes of SBP and DBP were computed using univariable LR. Multivariable LR Models for patients with increasing and decreasing SBP slopes as dependent variables were constructed to estimate the effect of CPD on SBP change. Cox Proportional Hazards Models were developed to determine the relation of SBP and DBP slope to survival. A $P$-value below 0.05 was considered significant. Analyses were conducted in SPSS 18.0 (IBM, Somers, NY) and SAS 9.2 (SAS Institute, Cary, NC). 


\section{Results}

\section{Demographics}

The study population included 12695 incident hemodialysis patients, with 10245 patients who underwent an average of $94 \pm 37$ treatments in Year 1 meeting inclusion criteria (Figure 9.1). Demographics are shown in Table 9.1.

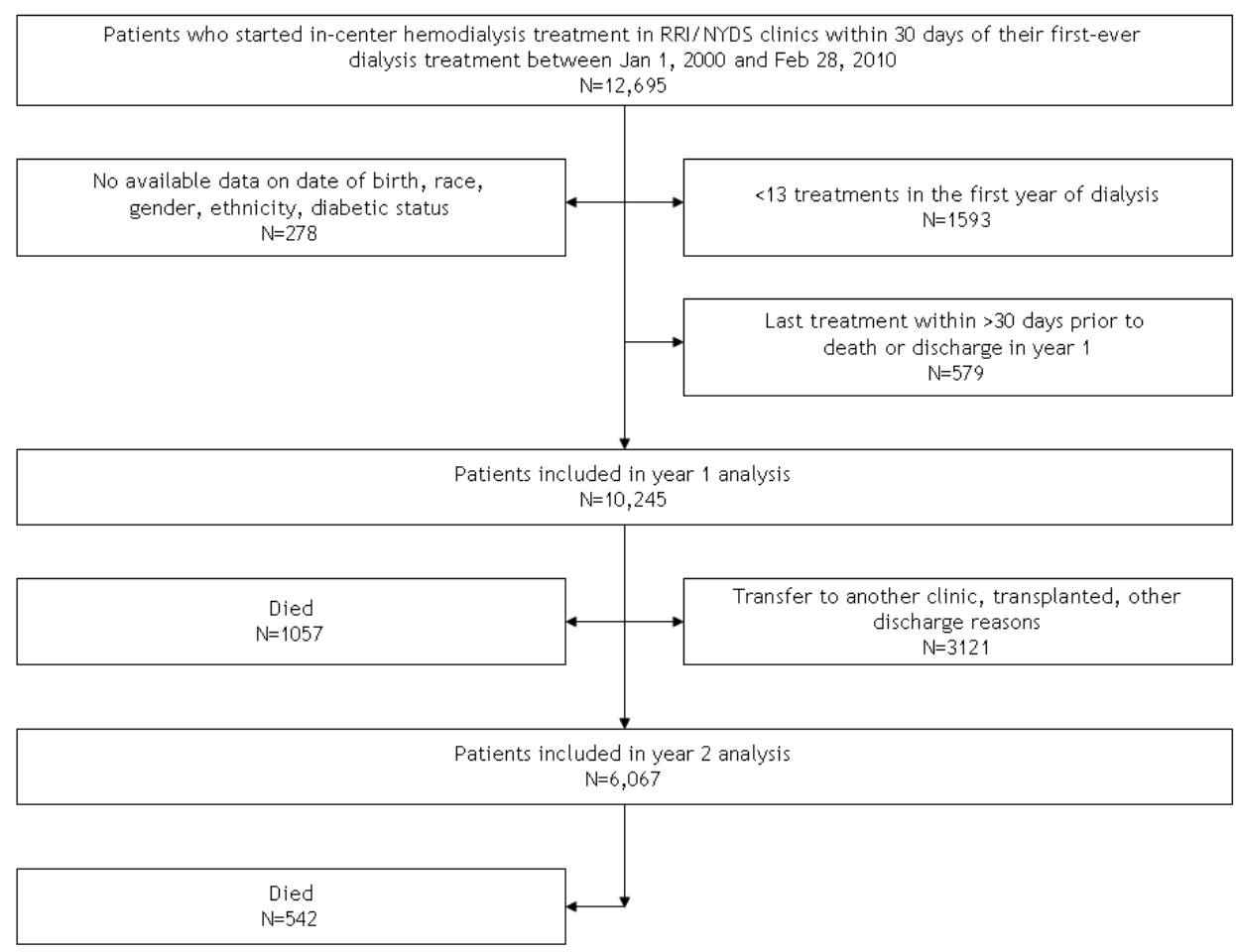

Figure 9.1 Study flowchart.

\section{Blood pressure}

Table 9.2 shows SBP and DBP during the first 30 days and the respective slopes of patients with stable, declining and increasing SBP after initiation of dialysis (see Figure 9.2 for the distribution of SBP in the studied cohort). With CPD prescription, both declines and increases in SBP were attenuated (Figure 9.3) and multivariable LR with SBP slope as the dependent variable showed that use of CPD had impact on the slope in patients with increasing (Beta $-0.06, P<0.01$ ) and decreasing (Beta 0.03, $P<0.01$ ) slope (data not shown). 


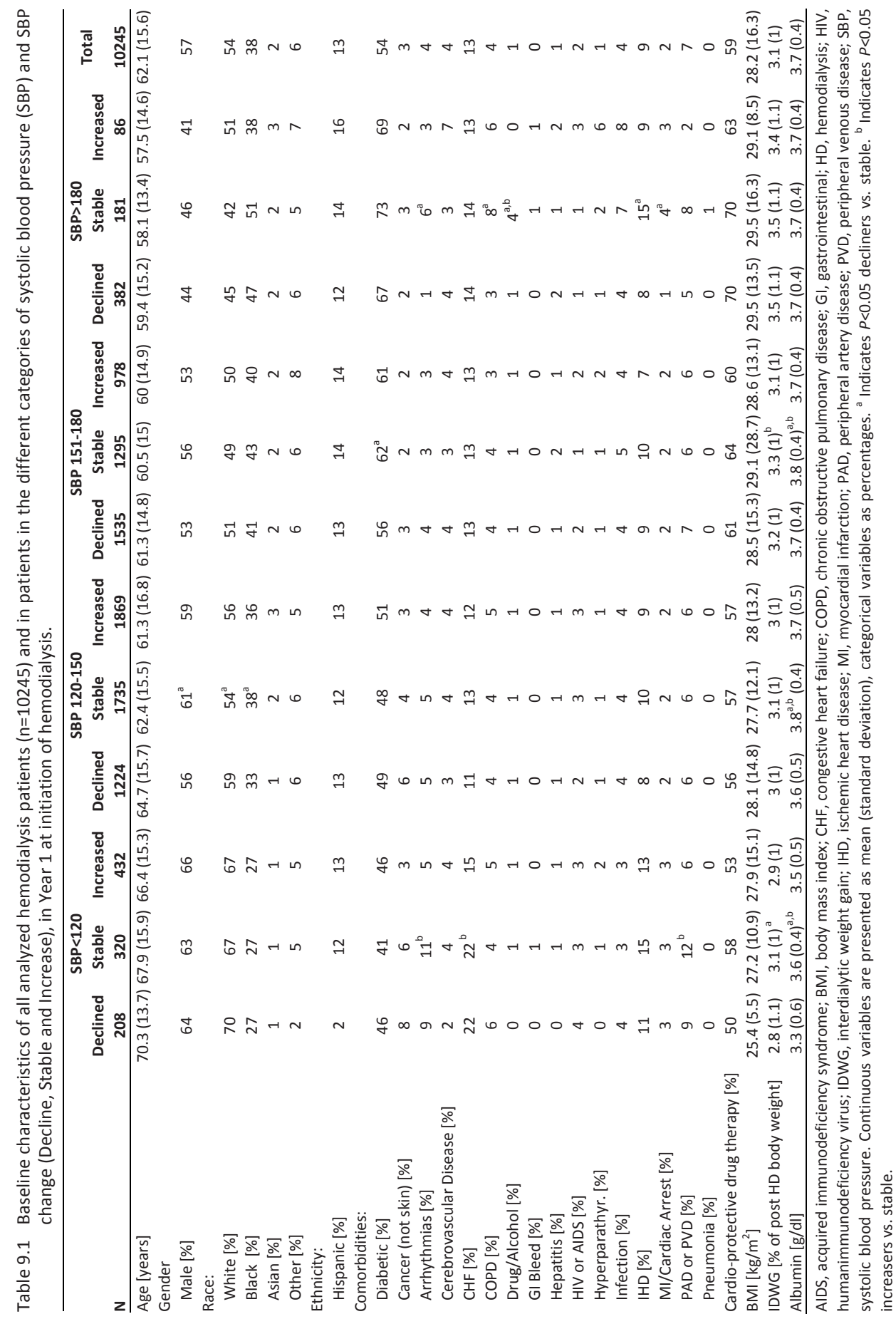




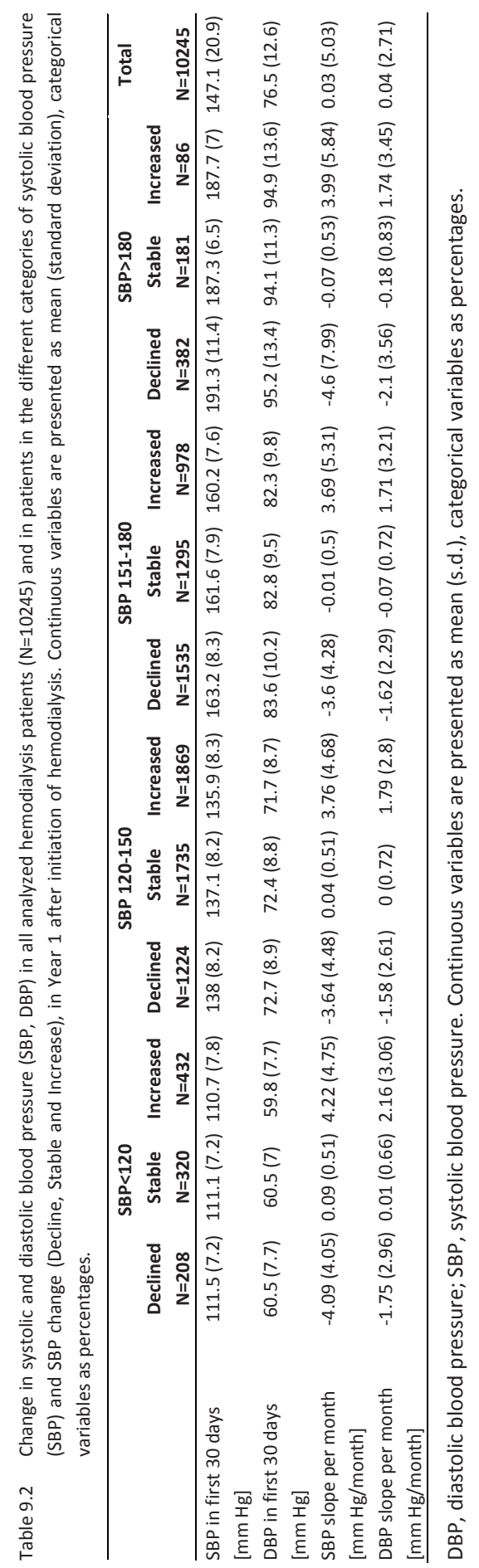




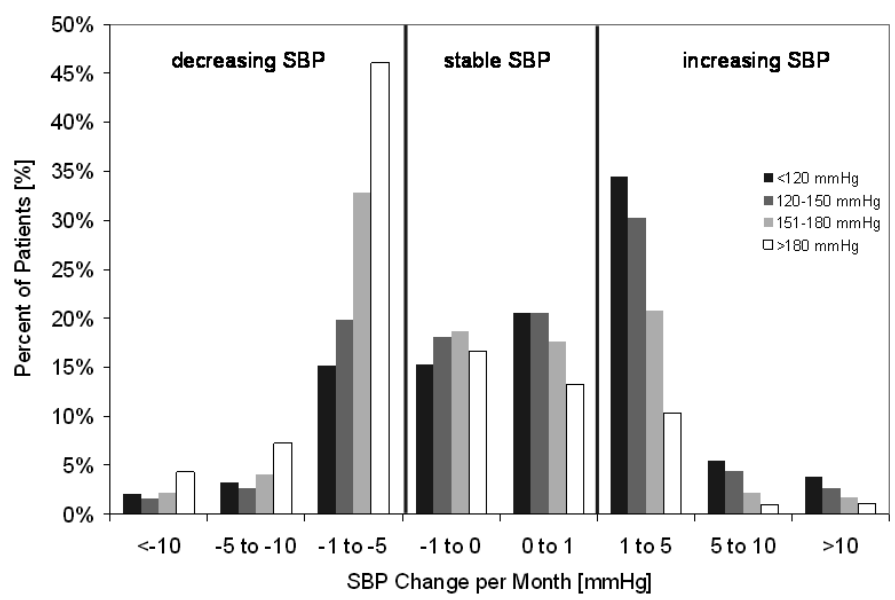

Figure 9.2 Histogram of change of systolic blood pressure (SBP) change per month of patients in all ranges of SBP.
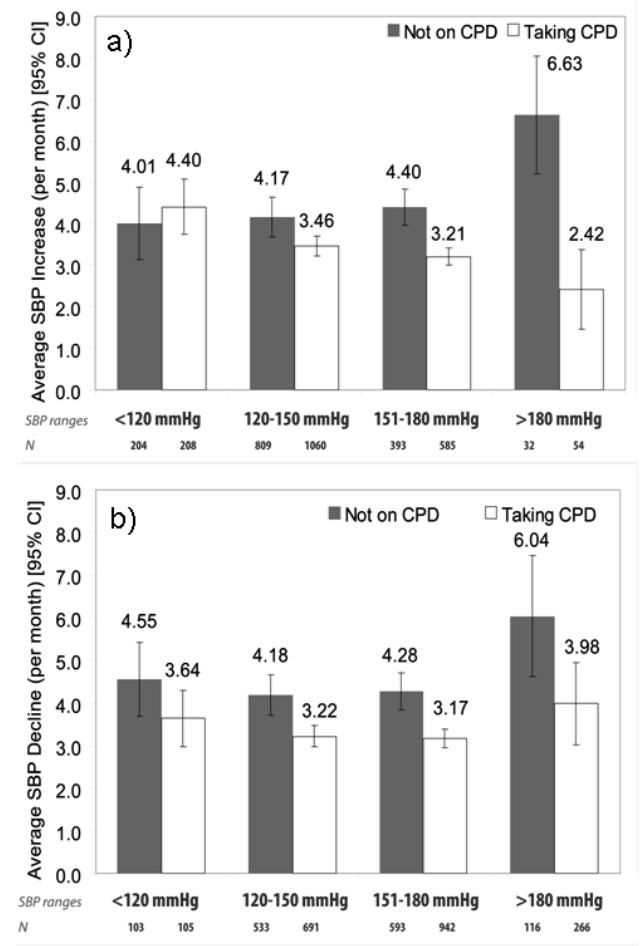

Figure 9.3 Cardioprotective drugs (CPD) and a) increases and b) declines of systolic blood pressure (SBP). $\mathrm{Cl}$, confidence interval. 
Stratification of patients into categories of 1 . stable SBP and 2. increase ( $>5 \mathrm{mmHg}$ per month) and 3. decrease (<-5 mmHg per month), indicated that patients with stable SBP were more likely to be on CPD (Table 9.3), consistent with the initial findings. Effects of CPD on DBP were similar but less pronounced.

Table 9.3 Change of Systolic Blood Pressure (SBP) in patients with active prescription of cardioprotective drugs (CPD) and without, after stratification in patients with 1 . stable SBP and 2. increase (>5 mmHg per month) and 3. decrease (<-5 mmHg per month) of SBP.

\begin{tabular}{lcc}
\hline SBP (Change per Month) & Not on CPD & On CPD \\
\hline Declined (<-5) [\%] & 13.8 & 9.8 \\
Stable (-1 to 1) [\%] & 72.0 & 79.9 \\
Increased (>5) [\%] & 14.1 & 10.3 \\
\hline
\end{tabular}

CPD, cardioprotective drug; SBP, systolic blood pressure.

\section{Survival analysis}

Crude mortality and normalized mortality rates (per 1000 patient-years) after initiation of hemodialysis differed between the groups (Table 9.4). Cox Proportional Hazard analysis (Table 9.5) demonstrated that within baseline BP categories, patients with a SBP below $120 \mathrm{~mm} \mathrm{Hg}$ had the worst, and patients with SBP in the range of 151 to 180 (reference group) the best survival (Figure 9.4). However, longitudinally, survival was highest in patients with stable SBP independent of SBP level. Patients with decreasing SBP exhibited the worst survival, which was most pronounced in the lowest SBP range. Survival was also poor in patients with SBP increase (Figure 9.4). Similar findings were obtained in the analysis of DBP (Figure 9.5). Use of CPD had a favorable impact on survival (Table 9.5).

\section{Sensitivity Analyses}

For the first sensitivity analysis only data of patients with slopes showing $P$-values below 0.05 , were included $(n=8395)$. The result of this survival analysis was consistent with the original analyses, thus the analysis did not appear to be confounded by the certainty of the slope computation.

For the second sensitivity analysis, first and last six SBP measurements were excluded, with the results remaining consistent with the original analyses. Slope computation did not appear to be confounded by outliers at the beginning or the end of the observation period.

For the third sensitivity analysis patients with the largest changes in SBP were excluded. The relation of changes in SBP and mortality remained the same in this analysis.

The fourth sensitivity analysis defined patients with stable, increasing and decreasing SBP according to the upper and lower, respectively, limits of their $95 \%$ confidence interval, with results similar to the primary analysis. 
Table 9.4 Number of deaths and mortality rates in all patients $(n=10245)$ and in patients in the different categories of systolic blood pressure (SBP) and SBP change (decline, stable and increase).

\begin{tabular}{llccc}
\hline & SBP change & $\begin{array}{c}\text { Deaths } \\
\text { [count] }\end{array}$ & $\begin{array}{c}\text { Exposure Time } \\
\text { [days] }\end{array}$ & $\begin{array}{c}\text { mortality rate [n/1000 } \\
\text { patient years] }\end{array}$ \\
\hline \multirow{4}{*}{ SBP<120 mmHg } & Decline $(n=208)$ & 94 & 39011 & 880.10 \\
& Stable $(n=320)$ & 28 & 99421 & 102.87 \\
& Increase $(n=432)$ & 79 & 104945 & 274.95 \\
& All Patients $(n=960)$ & 201 & 243377 & 301.65 \\
& Decline $(n=1224)$ & 226 & 316199 & 261.06 \\
SBP 120-150 mmHg & Stable $(n=1735)$ & 86 & 569950 & 55.11 \\
& Increase $(n=1869)$ & 202 & 505238 & 146.03 \\
& All Patients $(n=4828)$ & 514 & 1391387 & 134.93 \\
SBP 151-180 mmHg & Decline $(n=1535)$ & 159 & 433736 & 133.89 \\
& Stable $(n=1295)$ & 47 & 427963 & 40.11 \\
& Increase $(n=978)$ & 76 & 261933 & 105.98 \\
& All Patients $(n=3808)$ & 282 & 1123632 & 91.67 \\
SBP>180 mmHg & Decline $(n=382)$ & 46 & 112594 & 149.22 \\
& Stable $(n=181)$ & 7 & 60411 & 42.32 \\
All Patients $(n=10245)$ & Increase $(n=86)$ & 7 & 22184 & 115.25 \\
\hline
\end{tabular}

SBP, systolic blood pressure.

Table 9.5 Cox Proportional Hazards model for survival analysis in Year 1.

\begin{tabular}{|c|c|c|}
\hline & Hazard Ratio (95 \% Cl) & P-value \\
\hline SBP $<120 \mathrm{mmHg}$, Declined & 8.375 (5.805 to 12.084$)$ & $<0.0001$ \\
\hline SBP $<120 \mathrm{mmHg}$, Stable & $1.344(0.835$ to 2.164$)$ & 0.223 \\
\hline $\mathrm{SBP}<120 \mathrm{mmHg}$, Increased & 3.594 (2.483 to 5.202$)$ & $<0.0001$ \\
\hline SBP 120 to $150 \mathrm{mmHg}$, Declined & $3.731(2.700$ to 5.156$)$ & $<0.0001$ \\
\hline SBP 120 to $150 \mathrm{mmHg}$, Stable & 1.099 (0.766 to 1.578$)$ & 0.607 \\
\hline SBP 120 to $150 \mathrm{mmHg}$, Increased & $2.678(1.937$ to 3.702$)$ & $<0.0001$ \\
\hline SBP 151 to $180 \mathrm{mmHg}$, Declined & 2.634 (1.893 to 3.665$)$ & $<0.0001$ \\
\hline SBP 151 to $180 \mathrm{mmHg}$, Stable & \multicolumn{2}{|c|}{ Reference Group } \\
\hline SBP 151 to $180 \mathrm{mmHg}$, Increased & 2.516 (1.743 to 3.632$)$ & $<0.0001$ \\
\hline SBP $>180 \mathrm{mmHg}$, Declined & $3.344(2.213$ to 5.053$)$ & $<0.0001$ \\
\hline SBP $>180 \mathrm{mmHg}$, Stable & 1.125 (0.507 to 2.497$)$ & 0.773 \\
\hline SBP $>180 \mathrm{mmHg}$, Increased & 2.995 (1.349 to 6.650$)$ & 0.007 \\
\hline Age [years] & $1.028(1.023$ to 1.033$)$ & $<0.0001$ \\
\hline Male [yes/no] & $1.146(1.009$ to 1.301$)$ & 0.036 \\
\hline Race=White $[y e s / n o]$ & 1.260 (1.090 to 1.458$)$ & 0.002 \\
\hline Ethnicity=Hispanic [yes/no] & $0.713(0.564$ to 0.900$)$ & 0.004 \\
\hline COPD [yes/no] & 0.576 (0.391 to 0.848$)$ & 0.005 \\
\hline Drug/Alcohol [yes/no] & 0.552 (0.244 to 1.249$)$ & 0.154 \\
\hline Hepatitis [yes/no] & $1.970(0.812$ to 4.778$)$ & 0.134 \\
\hline Hyperparathyroidism [yes/no] & $0.588(0.277$ to 1.246$)$ & 0.166 \\
\hline Infection [yes/no] & $0.456(0.262$ to 0.796$)$ & 0.006 \\
\hline CPD therapy [yes/no] & 0.717 (0.630 to 0.815$)$ & $<0.0001$ \\
\hline Albumin $[\mathrm{g} / \mathrm{dl}]$ & $0.162(0.145$ to 0.181$)$ & $<0.0001$ \\
\hline IDWG [\%post HD body weight] & $0.926(0.866$ to 0.990$)$ & 0.023 \\
\hline
\end{tabular}

$\mathrm{Cl}$, confidence interval; COPD, chronic obstructive pulmonary disease; CPD, cardioprotective drug; HD, hemodialysis; IDWG, interdialytic weight gain; SBP, systolic blood pressure. Covariables (not related to blood pressure) with $P$-value in the model larger than 0.2 are not shown (Asian race, diabetes, pre-existing anemia, cancer, arrhythmias, cerebrovascular disease, congestive heart failure, gastrointestinal bleed, human immunodeficiency virus or acquired immunodeficiency syndrome, ischemic heart disease, myocardial infarction or cardiac arrest, peripheral arterial or venous disease, pneumonia, and body mass index). 


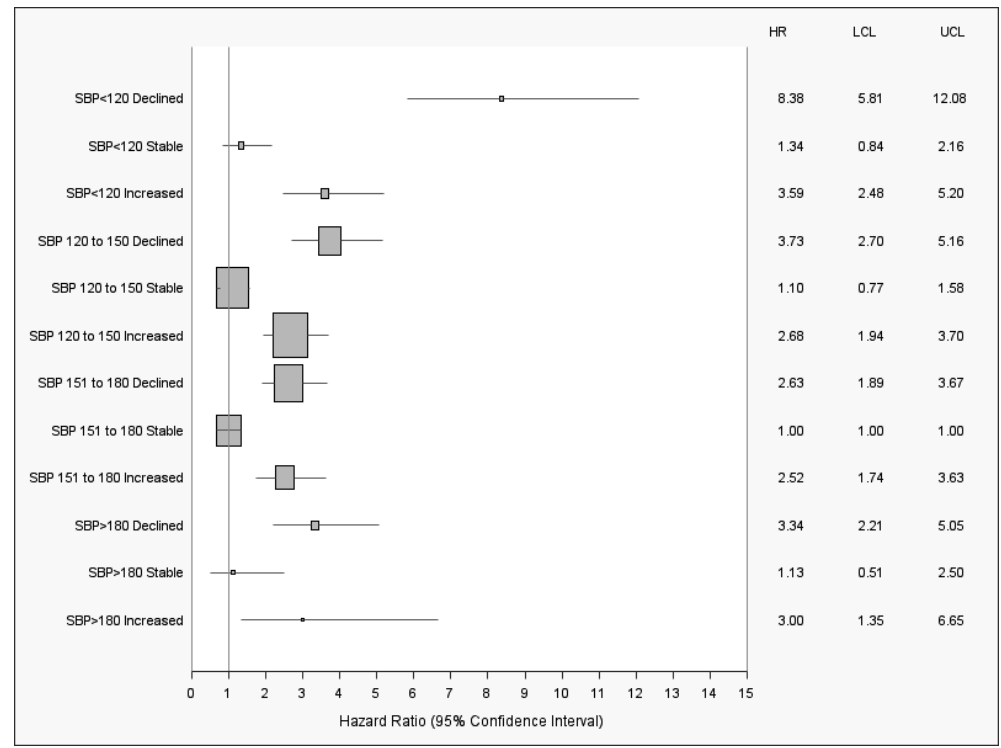

Figure 9.4 Forest plot of levels of systolic blood pressure (SBP) and temporal changes (reflected by changes in slope), and its relationship with hazard ratio for death in all 12 groups. Data are presented as hazard ratio (HR) and 95\% confidence interval (lower confidence limit (LCL) to upper confidence limit (UCL)).

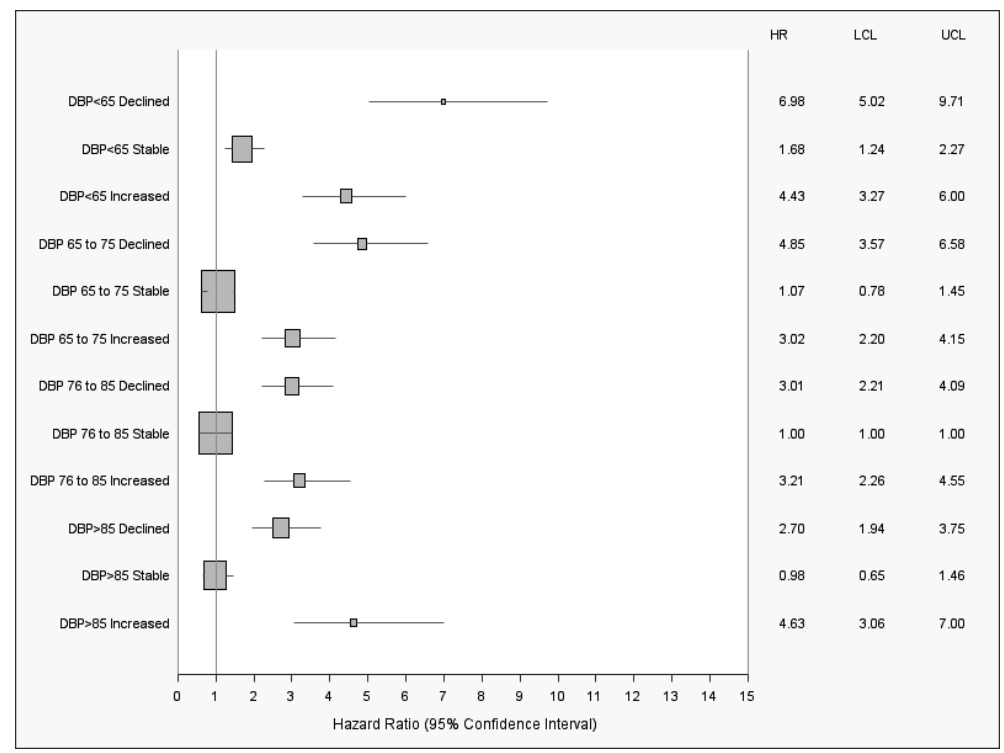

Figure 9.5 Forest plot of levels of diastolic blood pressure (DBP) and temporal changes (reflected by changes in slope) and its relation to hazard ratio for death in all 12 analyzed groups. Data is presented as Hazard Ratio (HR) and $[95 \% \mathrm{Cl}$ : Lower Confidence Limit (LCL) to Upper Confidence Limit (UCL)]. 


\section{Validation of survival analysis}

In a subset validation analysis (Figure 9.6) changes of SBP in patients with CPD therapy (initiating hemodialysis after 2008) and those in whom CPD was not being prescribed (initiating hemodialysis before 2006), showed, consistent with the initial findings, that patients on CPD were more likely to have stable BP and thus better outcome. The positive effect of the quality initiative on patients' survival is also illustrated in a Kaplan Meier survival analysis (Figure 9.7). Repetition of survival analysis with seasonality as an adjustment factor did not materially change the results as compared to the main analysis (Figure 9.8). 6067 (at this point prevalent) hemodialysis patients were included in the analysis in Year 2. Results of survival analysis according to SBP categories and temporal changes in Year 2 (Figure 9.9) were consistent with the results in Year 1 (Figure 9.4). Similar analysis of the relationship of temporal changes in SBP relative to all levels of SBP (producing hazard ratios for cardiovascular mortality), reflected findings similar to the primary analysis (Figure 9.10).

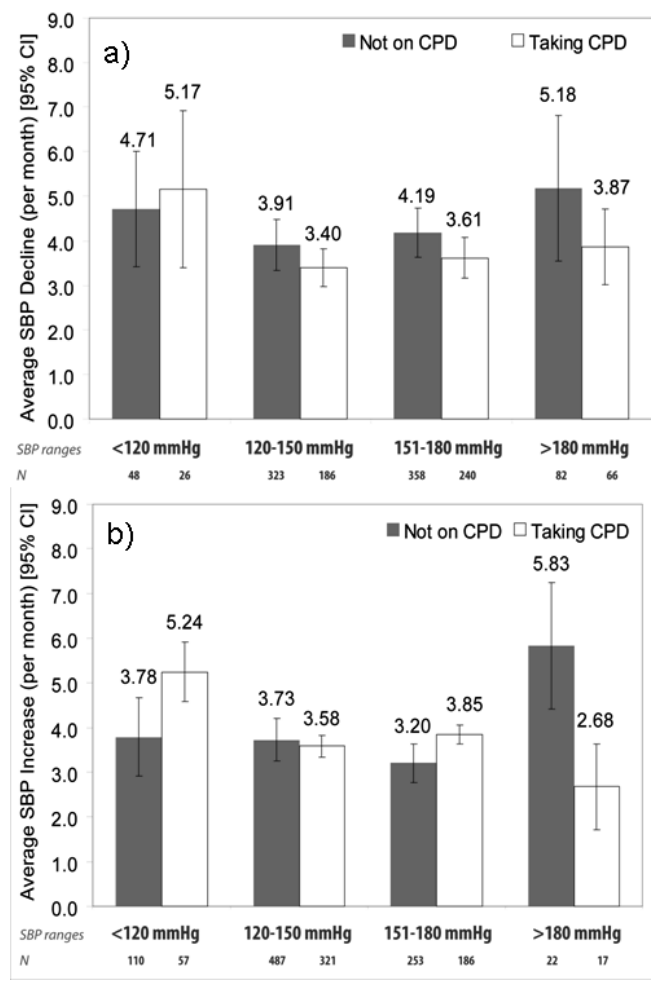

Figure 9.6 Subset validation analysis to validate the relationship between therapy with cardioprotective drugs (CPDs) and (a) decreases and (b) increases in systolic blood pressure (SBP). Patients included in the subset were those initiating dialysis before 2006 and were not on CPD, and patients who started dialysis after a CPD quality initiative in 2007 and who had an active CPD prescription. $\mathrm{Cl}$, confidence interval. 


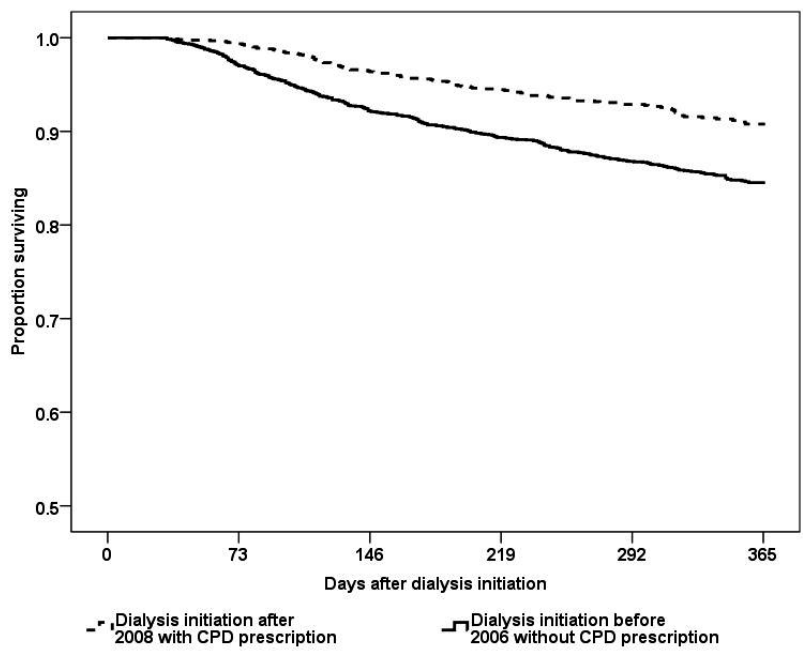

Figure 9.7 Kaplan-Meier survival curves in two subsets of patients: (1) those who initiated hemodialysis before 2006 and were not on cardioprotective drugs (CPDs), and (2) those who started hemodialysis after a quality initiative (suggesting use of CPD in all patients regardless of blood pressure) in 2007 and were on CPD.

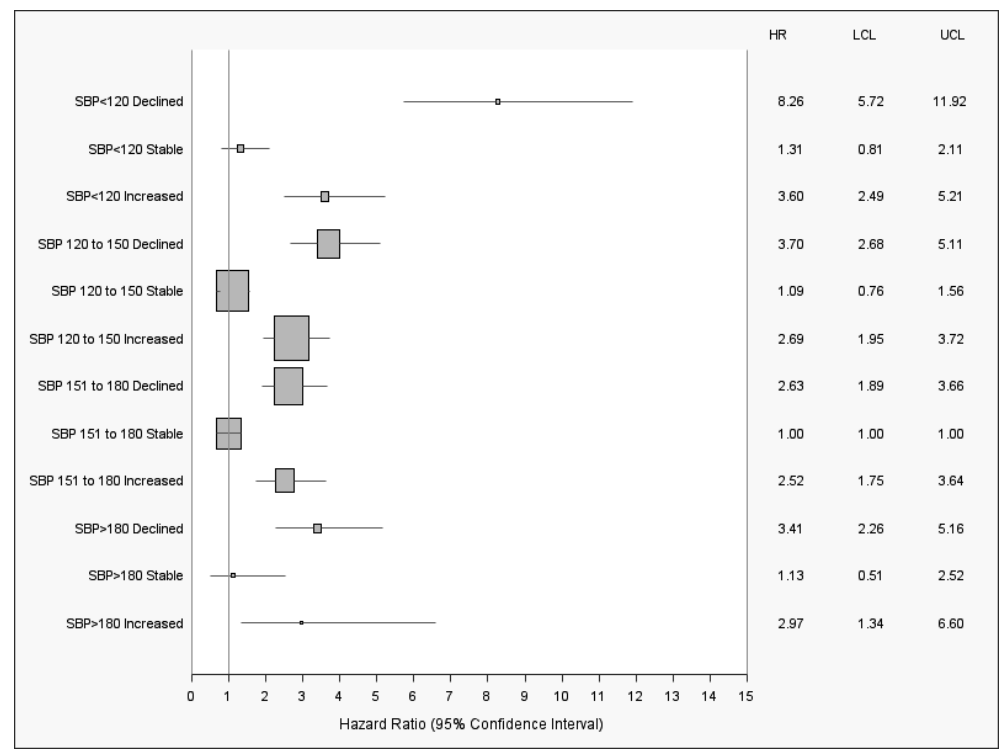

Figure 9.8 Validation analysis: Forest plot of levels of systolic blood pressure (SBP) and temporal changes (reflected by changes in slope), and its relationship with hazard ratio (HR) for death in all 12 groups after adjustment for season of death or season of end of Year 1 in survivors (spring, summer, autumn, and winter). Data are presented as HR and $95 \%$ confidence interval (lower confidence limit ( $(\mathrm{CL})$ to upper confidence limit $(\mathrm{UCL})$ ). 


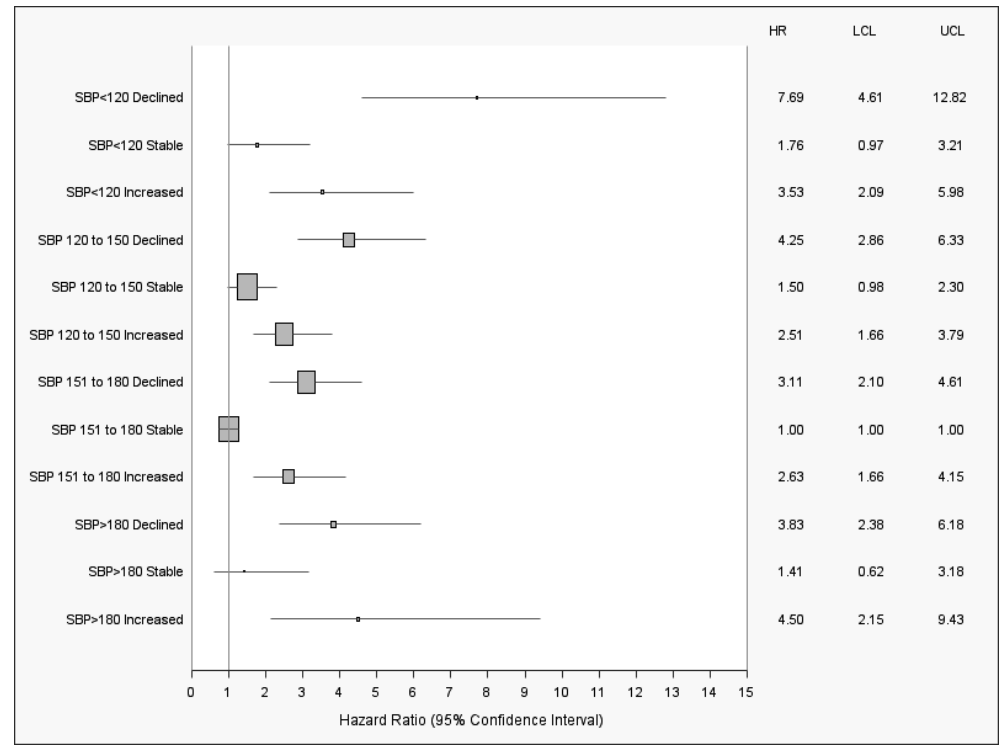

Figure 9.9 Validation analysis: Forest plot of levels of systolic blood pressure (SBP) and temporal changes (reflected by changes in slope) in Year 2, and its relationsip with hazard ratio (HR) for death in all 12 groups. Data are presented as HR and 95\% confidence interval (lower confidence limit (LCL) to upper confidence limit (UCL)).

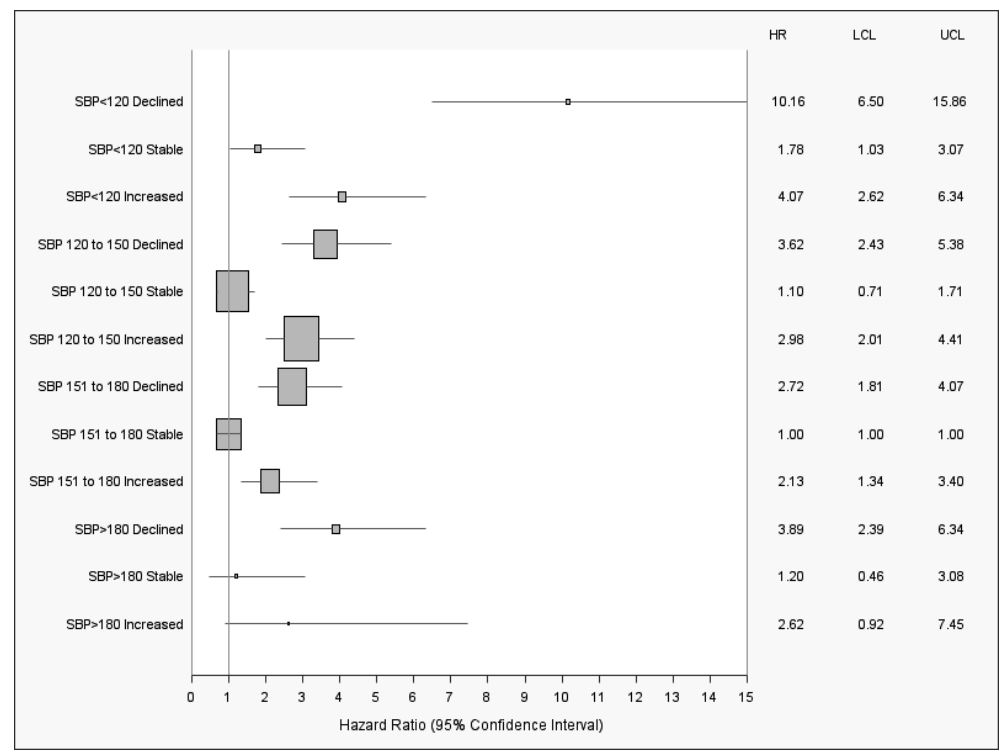

Figure 9.10 Validation analysis: Forest plot of levels of systolic blood pressure (SBP) and temporal changes (reflected by changes in slope), and its relationship with hazard ratio (HR) for cardiovascular death in all 12 analyzed groups. Data are presented as HR and 95\% confidence interval (lower confidence limit (LCL) to upper confidence limit (UCL)). 


\section{Discussion}

To the best of our knowledge this is the first observational cohort study in a large group of incident hemodialysis patients which evaluates the association of absolute SBP and DBP levels and subsequent temporal BP changes to mortality over one year. The main findings indicated that mortality in the first year on HD was greater in patients with both, declines or increases in BP relative to stable BP, independent of absolute BP levels (Figure 9.4, Figure 9.5); this result remained consistent in Year 2 (compare Figure 9.4 and Figure 9.9).

Temporal changes in both SBP and DBP rather than the BP category, had greater impact on survival (Figure 9.4). Furthermore our findings suggest a potential beneficial effect of using CPDs in potentially stabilizing temporal BP changes over time and improving survival.

The explanation of these findings may reflect two different operative vectors: One, the declining BP due to failure of ventricular function and thus a marked increase in mortality, and the second is increasing $\mathrm{BP}$, for reasons which remain to be fully determined, but likely includes salt and fluid overload, with a lesser effect on mortality than in those with declining blood pressure. In addition it is noteworthy that many comorbidities and laboratory parameters lost significance in the Cox Proportional Hazard Model, after inclusion of both, temporal changes of SBP and also with use of CPD. It is well known that cardiovascular disease is the leading cause of death in this population, but the extent to which temporal changes of SBP appear to influence survival in this analysis is quite remarkable (Table 9.5, Figure 9.4).

The favorable effect of CPD in improving mortality both in patients with declining and increasing in BP was unexpected, although it is consistent with reported cardioprotective effects of CPD demonstrated in the few long-term randomized trials performed in hemodialysis patients. Extensive meta-analyses have shown that reduced mortality risk was observed in patients on CPD without substantial BP change ${ }^{20}$. In this analysis calcium channel blockers were not included, although their use has been reported to reduce mortality ${ }^{22}$. However, due to the lack of data from RCTs on the cardioprotective effect of this drug class in dialysis patients, it was elected to not be included in this analysis.

Relative to other BP categories, CPD use is associated with a smaller decrease in BP in patients with baseline levels of below $120 \mathrm{~mm} \mathrm{Hg}$. This could be the result of medication effects counteracting the adverse consequences of progressive cardiomyopathy. In patients with increase in BP the subsequent reduction in BP by CPD is compatible with antihypertensive effects of CPD.

All Year 2 analyses of survival were consistent with Year 1 (compare Figure 9.4 and Figure 9.9). This confirmatory test of our basic argument also affirms the continued 
favorable effect of CPD in all patients at risk. This is further supported by the results of the quality initiative (Figure 9.7).

A major strength of this analysis is the large sample size and the balanced distribution of patients in all analyzed patient groups (Table 9.1). Patients of 51 different dialysis clinics in different states and geographical regions were included in this observational cohort study. With this widespread patient population and the large sample size improves generalizability to the United States hemodialysis population. Selection of incident patients allowed the study of the evolution of BP virtually with considerably little effect of hemodialysis treatment at study baseline (defined as the first month after the first hemodialysis treatment) and after initiation of hemodialysis, with its effects on the cardiovascular system.

The repetition of the survival analysis in Year $2(n=6067)$ diminishes survival bias often encountered in analyses of prevalent chronic hemodialysis patient cohorts. In addition this observational study allowed analysis of a prevalent patient population with exactly the same hemodialysis vintage (compare Figure 9.4 and Figure 9.9). Similar relations between cardiovascular mortality and temporal evolution of SBP (Figure 9.10) confirm the reliability of our findings. The sensitivity analysis with exclusion of patients in the highest quartiles of BP change indicated that the results were not driven by a few patients with extreme changes of SBP.

The sensitivity analysis utilizing univariable LR to estimate the slope for every individual patient was further validated by narrowing the criteria for defining patients as stable, and including only patients whose SBP slope increased and decreased significantly. The latter method confirmed that outlier measurements did not influence the results. The second sensitivity analysis, which excluded the first and last six SBP measurements in the observation period also indicated that the findings were not confounded by outliers. The third and the fourth sensitivity analyses confirmed the statistical validity of our approach and supported the hypothesized biological phenomena. Further, survival analyses with adjustment for season (Spring, Summer, Autumn and Winter) of death (or end of year 1 for survivors), excluded potential confounding by seasonal differences of mortality (Figure 9.8).

Limitations of the analysis included the absence of information on SBP prior to initiation of hemodialysis, which would have been of interest when investigating the temporal evolution subsequent to hemodialysis initiation. Lack of information of the degree of hydration status was another limitation, albeit difficult to overcome with current technologies $^{23}$. Knowledge of cardiac function and structure by cMRI or echocardiography would have provided information on cardiac structure and function that could confirm postulated reasons for the decline or increase in SBP. The use of different BP measurements methods, such as home or ambulatory methods, may have been preferable, but even these methods are to a degree difficult to interpret in a hemodialysis population because of the increase in volume and BP which occurs progressively during the interdialytic interval. While the measurements of pre- and 
post-dialysis BP are imprecise ${ }^{24}$, their frequent measurement and the relationship between levels and outcomes provide reassurance. Another consideration may be that the analysis of CPD could be confounded by treatment by indication biases, although this was minimized by 1 . the large sample size included in this analysis and 2 . the subset validation analysis comparing patients initiating dialysis prior to 2004 as compared to those starting dialysis after 2007 (Figure 9.6 and Figure 9.7). An additional concern is a potential bias induced by varying duration of CPD prescription, since this parameter was not captured in this analysis. Several limitations also exist on the documentation of comorbidities and CPD. The latter, in particular, includes: 1) the lack of knowledge on dose and frequency of CPD, 2) the dependence on the accuracy of the administrative staff on the documentation of drugs prescriptions, and 3) the possibility of erratic patient adherence. However, with the methods of analysis used, none of these issues are likely to cause any systematic error or bias (compare Figure 9.3 and Figure 9.6).

Future analyses are needed to elucidate the relationships between BP level, temporal changes of BP and CPD use on survival in patients prior to initiation of dialysis. Another further major research question remains: 'To what extent should BP increases and decreases be managed by sodium restriction and ultrafiltration or by use of CPD at different degrees of cardiac status and function'. This question can only be answered by an adequately powered RCT.

In conclusion, we found that blood pressure readings are best interpreted using prior temporal trends and should not be taken in isolation. The clinical problem posed by these data is that an apparently normal BP may be misinterpreted as being satisfactory. If absolute BP values are in the normal range due to cardiac decompensation, consideration of only BP values may provide a false sense of security when a declining particularly or increasing trend is not appreciated. Evaluation of cardiac and fluid status is essential in interpreting blood pressure levels. The favorable effect observed with the use of CPD and the mechanism of action requires further evaluation in prospective clinical trials of this patient population. 


\section{Appendix}

Patients were dialyzed at: Albany Dialysis Center (NY); Albany Regional Dialysis Center (NY); Amsterdam Dialysis Center (NY); Atlantic Hemodialysis (NY); Bayside Dialysis (NY); Branford Dialysis Center (CT); Bronx Center for Nursing \& Rehabilitation (NY); Brookdale Physicians Dialysis Associates (NY); Brooklyn Kidney Center (NY); Capital District Dialysis Center (NY); Carolina Dialysis - Carrboro (NC); Carolina Dialysis - Pittsboro (NC); Carolina Dialysis - Sanford (NC); Carolina Dialysis - Siler City (NC); Central Suffolk Artificial Kidney Center (NY); Champaign-Urbana Dialysis Center (IL); City Dialysis Center (NY); Cobble Hill Nursing Home (NY); Dutchess Dialysis Center; Harlem Dialysis Center; Irving Place Dialysis Center; Michigan Dialysis - Ann Arbor (MI); Michigan Dialysis Livonia (MI); Middletown Dialysis Center (NY); Milford Dialysis Center (CT); Montefiore Dialysis Center I (NY); Montefiore Dialysis Center II (NY); Montefiore Dialysis Center III (NY); Montefiore Dialysis Center IV (NY); Nephro Care Inc. (NY); Nephro Care West (NY); Newport Beach Dialysis Center (CA); Newport Mesa (CA); North Haven (CT); Queens Artificial Kidney Center (NY); Sound Shore Dialysis Center (NY); South Queens Dialysis Center (NY); Southern Manhattan Hemodialysis Center (NY); Southern Westchester Hemodialysis Center (NY); St. Alban's Dialysis (NY); St. Raphael's Dialysis (NY); Clinton Crossing Unit (NY)*; Finger Lakes Unit (NY)*; Highland Self Care Unit (NY)*; Living Center Unit (NY)*; Strong Memorial Hemo Program (NY)*; Upper Manhattan Dialysis Center (NY); Western New York Artificial Kidney Center - Buffalo (NY); Western New York Artificial Kidney Center - Kenmore (NY); Western New York Artificial Kidney Center - Niagara Falls (NY); Yorkville Dialysis Center (NY). Dialysis facilities indicated with an Asterisk are part of Strong Health Dialysis. 


\section{References}

1. Vasan RS, Larson MG, Leip EP, Evans JC, et al. Impact of high-normal blood pressure on the risk of cardiovascular disease. N Engl J Med 2001;345:1291-7.

2. Lewington S, Clarke R, Qizilbash N, Peto R, et al. Age-specific relevance of usual blood pressure to vascular mortality: a meta-analysis of individual data for one million adults in 61 prospective studies. Lancet 2002;360:1903-13.

3. Agarwal R, Nissenson AR, Batlle D, Coyne DW, et al. Prevalence, treatment, and control of hypertension in chronic hemodialysis patients in the United States. Am J Med 2003;115:291-7.

4. Rocco MV, Yan G, Heyka RJ, Benz R, et al. Risk factors for hypertension in chronic hemodialysis patients: baseline data from the HEMO study. Am J Nephrol 2001;21:280-8.

5. Levin NW, Kotanko P, Eckardt KU, Kasiske BL, et al. Blood pressure in chronic kidney disease stage 5Dreport from a Kidney Disease: Improving Global Outcomes controversies conference. Kidney Int 2009; 77:273-84.

6. Clinical practice guidelines for hemodialysis adequacy, update 2006. Am J Kidney Dis 2006;48 Suppl 1: S2-90.

7. Fletcher AE, Beevers DG, Bulpitt CJ, Butler A, et al. The relationship between a low treated blood pressure and IHD mortality: a report from the DHSS Hypertension Care Computing Project (DHCCP). J Hum Hypertens 1988;2:11-5.

8. Waller PC, Isles CG, Lever AF, Murray GD, et al. Does therapeutic reduction of diastolic blood pressure cause death from coronary heart disease? J Hum Hypertens 1988;2:7-10.

9. Protogerou $A D$, Safar ME, laria $P$, Safar $H$, et al. Diastolic blood pressure and mortality in the elderly with cardiovascular disease. Hypertension 2007;50:172-80.

10. Messerli FH, Mancia G, Conti CR, Hewkin AC, et al. Dogma disputed: can aggressively lowering blood pressure in hypertensive patients with coronary artery disease be dangerous? Ann Intern Med 2006; 144:884-93.

11. Samuelsson O, Wilhelmsen L, Andersson OK, Pennert K, et al. Cardiovascular morbidity in relation to change in blood pressure and serum cholesterol levels in treated hypertension. Results from the primary prevention trial in Goteborg, Sweden. JAMA 1987;258:1768-76.

12. Alderman $\mathrm{MH}$, Ooi $\mathrm{WL}$, Madhavan S, Cohen $\mathrm{H}$. Treatment-induced blood pressure reduction and the risk of myocardial infarction. JAMA 1989;262:920-4.

13. Cooper SP, Hardy RJ, Labarthe DR, Hawkins CM, et al. The relation between degree of blood pressure reduction and mortality among hypertensives in the Hypertension Detection and Follow-Up Program. Am J Epidemiol 1988;127:387-403.

14. Cruickshank JM, Thorp JM, Zacharias FJ. Benefits and potential harm of lowering high blood pressure. Lancet 1987;1:581-4.

15. Bangalore S, Messerli FH, Wun CC, Zuckerman AL, et al. J-curve revisited: an analysis of blood pressure and cardiovascular events in the Treating to New Targets (TNT) trial. Eur Heart J 2010 ;31:2897-2908.

16. Li Z, Lacson E, Jr., Lowrie EG, Ofsthun NJ, et al. The epidemiology of systolic blood pressure and death risk in hemodialysis patients. Am J Kidney Dis 2006;48:606-15.

17. Myers OB, Adams C, Rohrscheib MR, Servilla KS, et al. Age, race, diabetes, blood pressure, and mortality among hemodialysis patients. J Am Soc Nephrol 2010;21:1970-8.

18. Zager PG, Nikolic J, Brown RH, Campbell MA, et al. "U" curve association of blood pressure and mortality in hemodialysis patients. Medical Directors of Dialysis Clinic, Inc. Kidney Int 1998;54:561-9.

19. C enters for Disease Control and Prevention (U.S.), Centers for Medicare \& Medicaid Services (U.S.): ICD-9-CM international classification of diseases, ninth revision, clinical modification, sixth edition. In, Official ed, U.S. Dept. of Health and Human Services and the Centers for Medicare and Medicaid Services, 2008:1 CD-ROM

20. Agarwal R, Sinha AD. Cardiovascular protection with antihypertensive drugs in dialysis patients. systematic review and meta-analysis. Hypertension 2009;53:860-6.

21. Heerspink HJ, Ninomiya T, Zoungas S, de Zeeuw D, et al. Effect of lowering blood pressure on cardiovascular events and mortality in patients on dialysis: a systematic review and meta-analysis of randomised controlled trials. Lancet 2009;373:1009-15. 
22. Tepel M, Giet MV, Park A, Zidek W. Association of calcium channel blockers and mortality in haemodialysis patients. Clin Sci (Lond) 2002;103:511-5.

23. Raimann J., Li L., Tyagi S., Levin NW., et al. A fresh look at dry weight. Hemodial Int 2008; 12:395-405.

24. Agarwal R, Peixoto AJ, Santos SF, Zoccali C. Pre- and postdialysis blood pressures are imprecise estimates of interdialytic ambulatory blood pressure. Clin J Am Soc Nephrol 2006;1:389-98. 



\section{Chapter 10}

General discussion and summary 
Chapter 10 


\section{General discussion}

The aim of this thesis is to evaluate the importance of the dialysate prescription with particular focus on glucose and sodium concentrations, analyse the clinical effects of these serum constituents and emphasize that outcome studies should be based on longitudinal observations in preference to cross-sectional data only.

Despite much literature corroborating this notion, not all aspects of the relationships between dialysate and serum concentration and outcomes are well understood. Due to operational difficulty and a probable increase in effort, individualization of the dialysate prescription rarely occurs as the standard of care in dialysis patients. This thesis in Part A focuses mainly on the importance of differences in dialysate glucose concentration and its consequences. Part $B$ focuses on the dialysate sodium concentration $\left(\mathrm{DNa}^{+}\right)$and particularly on its individualization and the relationship between its concentration and pre HD systolic blood pressure (BP) and serum sodium concentration $\left(\mathrm{SNa}^{+}\right)$, which could be of importance for BP management. Part $C$ examines the need for longitudinal observations and uses the assessment of the relationships of its dynamics to mortality as an example to contrast with the lack of information provided by cross-sectional assessments only. Part $C$ in addition contains an analysis of the dynamics of BP and $\mathrm{SNa}^{+}$

\section{Part A: Glucose}

This part consists of three sub-chapters discussing the metabolic and cardiovascular effects of the use of different dialysate glucose concentrations, based on data from 29 hemodialysis (HD) patients participating in a multi-center randomized controlled crossover trial conducted in both diabetic and non-diabetic subjects in dialysis clinics of the Renal Research Institute, New York, USA in 2008 (clinicaltrials.gov: NCT00618033). The last chapter of Part $A$ discusses the relationship between $\mathrm{SNa}^{+}$and serum glucose in a retrospective analysis of 208 chronic HD patients.

Chapter 2 discusses the metabolic effects in both diabetic and non-diabetic subjects which are associated with the use of a dialysate glucose concentration of $200 \mathrm{mg} / \mathrm{dl}$ (11.1 mmol/l) compared to a concentration of $100 \mathrm{mg} / \mathrm{dl}(5.5 \mathrm{mmol} / \mathrm{l})$. Several aspects are considered and the pre-existing notions, discussed in detail in the Introduction which argued for the use of higher dialysate glucose concentrations are addressed. Higher serum glucose and insulin concentration were observed the higher dialysate glucose concentration and glucose mass transfer was estimated. The intradialytic mass transfer ranged in our data from $-159 \mathrm{~g}$ to $22 \mathrm{~g}$ and from -158 to $-4 \mathrm{~g}$ at the lower concentration. These mass transfer values are consistent with previously reported data by Ward et al. who reported an intradialytic glucose gain with a dialysate glucose concentration of $200 \mathrm{mg} / \mathrm{dl}(11.1 \mathrm{mmol} / \mathrm{l})$ of between 18.2 and $20.6 \mathrm{~g}^{1}$.

In regard to glucose: the avoidance of high dialysate glucose concentrations is likely to reduce the oxidative effects of glucose ${ }^{2,3}$. Arguments of glucose transfer being of 
benefit to nutritional status are doubtful in the light of discouraging results with hypercaloric intradialytic parenteral nutrition ${ }^{4}$.

Arguments for improved hemodynamic stability with use of high glucose concentrations of $200 \mathrm{mg} / \mathrm{dl}(11.1 \mathrm{mmol} / \mathrm{l})$ due to augmentation of refilling and thus maintenance of intravascular volume are presented. Earlier work had suggested improved BP stability during treatments using a dialysate glucose concentration of 200 $\mathrm{mg} / \mathrm{dl}(11.1 \mathrm{mmol} / \mathrm{l})$ as compared to the lower concentration of $100 \mathrm{mg} / \mathrm{dl}$ $(5.5 \mathrm{mmol} / \mathrm{l})^{5}$. This was not evident in our data in neither diabetic or non-diabetic subjects. We also did not find any evidence of increased occurrence of asymptomatic hypoglycaemia (as defined by the guidelines of the American Diabetes Association ${ }^{6}$ ) when using lower concentrations, which had been another concern regarding the use of lower concentrations. Lower dialysate glucose concentrations appear to be noninferior in terms of adverse events and beneficial in terms of not causing high serum glucose and insulin concentrations. Benefits of using lower dialysate glucose concentrations were hypothesized in terms of better phosphorus and potassium removal during HD. Since higher serum insulin concentrations induce a significant translocation of potassium and phosphorus from the extra- to the intracellular compartment and this mass may hypothetically not be available for clearance by the dialyzer, potassium and phosphorus levels were of interest in our research ${ }^{1,7}$. However, our data did not confirm that any differences in solute uptake triggered by different levels of insulin caused any difference in their intradialytic concentration. However, we have not performed any direct assessment of mass balance such as fractional direct dialysis quantification ${ }^{8}$ (or similar techniques) and thus only are able to negate effects on actual serum concentrations without being able to quantify effects of dialysate glucose concentrations on the mass balance, which may have differed regardless.

These hypothesized effects caused by the differences in potassium concentrations, the effects of potassium on cardiac muscle repolarization and possibly on the occurrence of cardiac arrhythmia was not reflected in the 24-hour Holter recordings. Overall, beneficial outcomes with the use of lower dialysate glucose concentrations in both diabetic and non-diabetic subjects without consequent disadvantageous effects on metabolism or on the cardiovascular system were found.

Chapter 3 presents additional aspects of the analysis of Holter recordings during dialyses using two different dialysate glucose concentrations analysing their relationship to heart rate variability. From this analysis it was evident that diabetic subjects generally had reduced power in all indices regardless of the dialysate used, in keeping with all previous analyses of this kind. Reduced power was particularly noted in the lower frequency band of heart rate variability, which is reflective of sympathetic activation. This was indicative of progression of diabetic neuropathy affecting the 
autonomic nervous system and hypothesized to be a contributing factor to the increased incidence of intradialytic morbid events in diabetic subjects ${ }^{9}$.

Increased parasympathetic activation was found with higher dialysate glucose concentrations but without any effects on systolic and diastolic BP. This finding is in line with the work by Kanaley et al. who reports comparable findings of increased parasympathetic activation following a glucose load in the general population ${ }^{10}$.

The response to high glucose levels could be to induce a neurogenic insulin response from the pancreas and, as a side effect, affect heart rate variability. This is purely speculative, but could be an interesting field of future research. Non-linear HRV indices reflecting entropy in the HRV of the studied subjects did not differ between regimens. Overall Chapter $\mathbf{3}$ confirms the lack of effect on hemodynamic stability by the glucose level intervention this however does not entirely negate an, the increased risk of adverse effects in patients prone to intradialytic morbid events by the aforementioned parasympathetic activation caused by glucose loading.

Chapter $\mathbf{2}$ and Chapter $\mathbf{3}$ establish the metabolic and cardiovascular effects of the use of different dialysate glucose concentrations. Chapter 4 evaluates the effects of the aforementioned glucose mass transfer from and to the patient during the treatment on fatigue. Fatigue was assessed using the Fatigue Severity Scale ${ }^{11}$, which quantifies on a scale from 1 to 7 (with 7 reflecting the highest degree of fatigue). This survey showed in addition to increased parasympathetic activation that diabetic subjects are more fatigued than non-diabetic subjects at both studied dialysate glucose concentrations studied. As an additional finding diabetic subjects were more fatigued when receiving HD with a higher dialysate glucose concentration due to reasons which remain speculative. Notably diabetic subjects did also report levels consistently higher than in healthy subjects ${ }^{11}$. However, as causal factors the differences in autonomic activation per se and possible influences of greater insulin concentrations on potassium levels cannot be excluded with sufficient certainty.

Serum glucose concentrations also affect electrolyte concentrations so that at increased glucose concentrations $\mathrm{SNa}^{+}$may need to be adjusted. This is necessary because of translocation of intracellular fluid to the extracellular compartment due to the osmotic activity of glucose. This phenomenon is discussed in more detail in Chapter 5, where analyzed data from our database was used to estimate the effect of high glucose concentrations on pre dialysis $\mathrm{SNa}^{+}$in poorly controlled diabetic HD patients.

Even when $\mathrm{DNa}^{+}$is aligned to the $\mathrm{SNa}^{+}$, aiming to produce neutral intradialytic diffusive sodium balance (Chapter 6 ), the effects of glucose and diabetic management on $\mathrm{SNa}^{+}$ are of importance, because intradialytic fluid shifts between compartments follow osmotic gradients almost immediately and may lower $\mathrm{SNa}^{+}$quickly. In addition the choice of dialysate glucose concentration may determine the increase or decrease of 
serum glucose and insulin, as reported in Chapter 2, and may separately effect changes in $\mathrm{SNa}^{+}$during the treatment. In summary: If the treatment has the potential in those with high serum glucose levels to lower the serum concentration prior to the treatment, a $\mathrm{DNa}^{+}$chosen based on the pre $\mathrm{HD} \mathrm{SNa}^{+}$may be too low and could result in a negative $\mathrm{GNa}^{+}$with possible adverse consequences. This remains subject to future research but is of importance in regard to the magnitude of the effects reported. The clinical rule of thumb is that an increase of $100 \mathrm{mg} / \mathrm{dl}$ serum glucose lowers the $\mathrm{SNa}^{+}$by $1.6 \mathrm{mEq} / \mathrm{l}$ as long as the osmotic gradient between the intra- and extra-cellular compartment persists. A comparable correction factor of $1.5 \mathrm{mEq} / \mathrm{l}$ per $100 \mathrm{mg} / \mathrm{dl}$ holds true for dialysis patients prior to HD treatment (Chapter 5). The knowledge of these relationships are possibly of great importance for $\mathrm{DNa}^{+}$to $\mathrm{SNa}^{+}$alignment, the subject of Chapter 6, which is an approach aiming to reduce intradialytic mass transfer,

\section{Part B: Sodium}

The largest $\mathrm{DNa}^{+}$to $\mathrm{SNa}^{+}$alignment project to this date, aimed at providing neutral diffusive sodium balance during dialysis, was conducted in dialysis clinics in Connecticut, USA, previously using a routine $\mathrm{DNa}^{+}$of $137 \mathrm{mEq} / \mathrm{l}$. Patients presenting with a SNa${ }^{+}$below $137 \mathrm{mEq} / \mathrm{l}$, were subject to $\mathrm{DNa}^{+}$to $\mathrm{SNa}^{+}$alignment. Chapter 6 outlines the importance of sodium alignment and describes an approach of centrally administering $\mathrm{DNa}^{+}$to $\mathrm{SNa}^{+}$alignment routinely in the clinic of a dialysis provider network in the US.

The approach makes alignment operationally feasible since it relies on historic data of $\mathrm{SNa}^{+}$which is considered to be relatively stable over time allowing the estimation of the actual current $\mathrm{SNa}^{+}$based on the average of the preceding 4 months. In essence, alignment should result in a reduction of intradialytic mass transfer and consequently a reduction in interdialytic weight gain (IDWG) and BP.

The approach used for this project includes the influences of seasonal change by utilizing preceding 4 months of a year to predict the coming month with relatively little information gain by the inclusion of additional months' data (Chapter 6). Based on data obtained from this quality initiative which we analyzed designed as a retrospective matched cohort study (clinicaltrials.gov \#NCT01825590), we found beneficial effects of alignment in terms of pre dialysis weight reduction [-2.2 (95\% $\mathrm{Cl}-4.6$ to 0.08$) \mathrm{kg}$ ] and $\mathrm{BP}$ reduction [-7.6 $(95 \% \mathrm{Cl}-13.9$ to 1.3$) \mathrm{mmHg}$ ] in those who were aligned. This suggests that alignment facilitates BP control and may aid to lower post HD target weights, possibly without causing increases in the occurrence of intradialytic hypotension dePaula et al. ${ }^{12}$. The possible advantage of alignment as opposed to general lowering of dialysate sodium concentrations, which has also been suggested to be beneficial ${ }^{13,14}$, is a intradialytic mass balance close to zero. When $\mathrm{DNa}^{+}$is lowered across the board without alignment, many patients will also receive HD with strongly negative gradients and subsequently will have sodium removed. Despite reports that a lowering of $\mathrm{DNa}^{+}$ 
only results in beneficial effects without causing an increased occurrence of adverse events ${ }^{13}$, there is nevertheless a lack of evidence that these findings are generalizable to the overall HD population. The data presented in Chapter 6 is data from the currently largest project analyzing the effects of alignment and currently additional analyses in larger study populations are underway.

The relative stability of pre dialysis $\mathrm{SNa}^{+}$is the fundamental base of the algorithm as shown in Chapter $6^{15}$. However, data in Chapter 8 suggests this not to be necessarily true and also determines factors causing $\mathrm{SNa}^{+}$variability are being identified. Furthermore in the same context it is important to note that the absolute $\mathrm{SNa}^{+}$level also has direct effects on systolic and diastolic BP (Chapter 7), which adds an additional complication to BP management.

Chapter 7 focuses on the relationship between $\mathrm{SNa}^{+}$and $\mathrm{BP}$. A relationship between sodium and BP was shown in the results of in-vitro experiments ${ }^{16,17}$, during $\mathrm{HD}^{18}$ and for the pre-HD assessments ${ }^{19}$. He et al. reported a significant slope estimate of $\mathrm{SNa}^{+}$in a linear mixed model estimating systolic and diastolic BP $\{0.65$ and $0.36 \mathrm{mmHg}$, respectively [BP per $\mathrm{mmol} / \mathrm{l}$ of $\mathrm{SNa}^{+}$change] $\}$in data from patients in two urban units in the United Kingdom ${ }^{19}$. As the most exciting aspect He et al. report this relationship to be independent of IDWG and fluid volume expansion, which is, according to Guyton's theorem, the operative vector of pre HD systolic BP in dialysis patients. The exact reasons for these dynamics are speculative. Oberleithner et al. showed direct effects of serum sodium on endothelial cells in the presence of aldosterone ${ }^{17}$, which triggered the expression of epithelial sodium channel $(\mathrm{ENaC})$ by the endothelial cell which in turn promotes swelling and stiffening ${ }^{20,21}$. Serum sodium appears to strongly affect the deformability and elasticity of endothelial cells ${ }^{17}$. Further, the elasticity of endothelial cells is a prerequisite of normal endothelial function by control of the stress-induced release of nitric oxide ${ }^{22}$. In addition a recent publication suggested a relationship between serum nitric oxide and BP during salt loading and restriction, and an increase of the nitric oxide inhibitor asymmetric dimethyl-arginine (ADMA) with higher salt intake ${ }^{23}$.

His findings sparked interest since the pre HD sodium concentration is at equilibrium (without effects from the dialysis treatment) and serves clinical-decision making. This was the first publication in this thesis based on data from the MONDO Initiative ${ }^{24}$, which encompasses data from incident HD patients commencing treatment in 41 countries from four continents ${ }^{25}$ and allows the analysis of many outcomes.

Based on data from the MONDO database we studied 16,993 incident HD patients commencing treatment in North America, Europe, Asia and South America how the pre-HD SNa ${ }^{+}$relates to pre-HD systolic and diastolic BP. We followed patients longitudinally for an observation period of 24 months using linear mixed effects models with random slope and intercept and the slopes of $\mathrm{SNa}^{+}$, IDWG, age, gender, potassium, albumin, calcium, diabetes and dialysis vintage included as fixed effects. The relationship between $\mathrm{SNa}^{+}$and $\mathrm{BP}$ appears to be a phenomenon independent of all 
included covariates, including country and continent of origin, $\mathrm{BP}$ levels, $\mathrm{SNa}^{+}$levels and to a certain extent independent of medical practice patterns. Due to a lack of available data we were not able to confirm our analyses stratified as per antihypertensive therapy in a comparable fashion to the work of He et al. Notably, the slope estimate was substantially smaller as compared to the data by He et al. (ranging from 0.19 to 0.28 and 0.10 to $0.21 \mathrm{mmHg}$, respectively, for systolic and diastolic BP per $\mathrm{mmol} / \mathrm{I}$ of $\mathrm{SNa}^{+}$change). The reasons for this cannot be found based on the data available but remain speculative. The lack of information on antihypertensive medication may possibly, at least in part, be a contributing factor.

This is a substantial gain in knowledge on this interesting relationship between $\mathrm{SNa}^{+}$ and $\mathrm{BP}$ and we believe this warrants additional research in order to increase our understanding on the determinants of BP and BP dynamics. This is particularly of importance for those where traditional measures of BP management are not sufficiently effective. It furthermore emphasizes the need to reduce sodium loading from all sources, either on during dialysis or from a diet level or both. Chapter 7 discusses this in great detail.

\section{Part C: The importance of longitudinal observations.}

Cross-sectional observations have been used as a reference to predict outcomes for a long time in medical research. Recently there is a trend to focus on longitudinal observation rather than only cross-sectional analyses.

Recent evidence showed the dynamics of relevant clinical parameters such as IDWG, SBP and body temperature, as well as laboratory parameters such as serum albumin and CRP to be predictive of death and hospitalization. Furthermore it was shown that the dynamics before death are also an early indicator of those being at high risk of death. In this context parameter dynamics were repeatedly suggested to serve the development of safety and alert algorithms allowing the identification and immediate attention of those at increased risk of adverse outcomes such as hospitalizations or death $^{26-29}$.

These studies however, did not yet focus on $\mathrm{SNa}^{+}$, despite the effect that this is a highly relevant factor in human pathophysiology. However, cross sectional studies have shown that low $\mathrm{SNa}^{+}$is predictive of an elevated risk of death, which is hypothesized to be a reflection of longstanding comorbidities which lower levels over an extended period of time ${ }^{30-32}$. However, these reports only cover a fraction of the actual information due to their cross-sectional nature. For this reason Chapter $\mathbf{8}$ analyzed the dynamics [i.e. variability (quantified as the standard deviation of all measurements during the observation period) and systematic changes (quantified as the slope estimate from a fitted linear model through all available measurements during the observation period)] of $\mathrm{SNa}^{+}$over a one year observation period following $\mathrm{HD}$ initiation in an international cohort of HD patients. The chapter further aimed to identify the main determinants of these dynamics and the relationship to outcomes. Statistically 
significant predictors of $\mathrm{SNa}^{+}$variability with a positive relationship were: $\mathrm{SNa}+$, male gender, serum albumin, nPCR, serum potassium, body mass index, DNa+ and North America as a region. In contrast only diabetes, normalized protein catabolic rate and $\mathrm{DNa}^{+}$were associated positively with $\mathrm{SNa}^{+}$slope. IDWG in turn has an inverse effect on the $\mathrm{SNa}^{+}$slope. Based on these data we were further able to find that variability (defined as the standard deviation of $\mathrm{SNa}^{+}$measurements over the period of 12 months) and the trend over time (change in $\mathrm{SNa}^{+}$over the period of 12 months) associated significantly to death in a study population of 16420 incident HD patients from North America and Europe. To illustrate these relationships we used a novel approach proposed and developed by Yuedong Wang, which allowed plotting of the risk of death in a bivariate fashion as a function of $\mathrm{SNa}^{+}$concentration and $\mathrm{SNa}^{+}$ variability, respectively and slope ${ }^{33-35}$. Increased variability and decreasing $\mathrm{SNa}^{+}$was associated with an increased risk of mortality (the latter particularly at lower levels of $\mathrm{SNa}^{+}$), whereas increasing $\mathrm{SNa}^{+}$from low levels of $\mathrm{SNa}^{+}$are associated with improved survival. Despite a significant relationship between systematic trends and variability, variability may be an independent predictor of death and may be speculated to be reflective of failing regulatory systems due to comorbidities. More research is required on the determining factors of $\mathrm{SNa}^{+}$variability and trends in order to find out how to alter the dynamics of $\mathrm{SNa}^{+}$and subsequently improve outcomes.

Chapter 9 focuses on systolic and diastolic BP, its dynamics and its determinants. BP itself is possibly the best described and studied predictor of death in the general population and HD patients. The strength of the relationship has long been known to be of utmost importance ${ }^{36}$.

Recently published reports showed relationships to longitudinal observations and in particular the variability of BP to be associated with death in patients suffering from chronic kidney disease and those treated with $\mathrm{HD}^{37-39}$. In Chapter 9 we discuss the dynamics of pre HD BP and their relationship to death. High BP has adverse sequelae such as increased left ventricular mass consequentially leading to an increased risk of death. Conversely, a low BP may not only be a reflection of successful BP management but also the result of continued deteriorating cardiac function and therefore a sign of an adverse pathophysiologic dynamic. A U- or J-shaped curve of the relationship between SBP, DBP and risk of death has been reported for the general population ${ }^{40}$ but and for HD patients ${ }^{36}$. HD patients visit dialysis centers thrice-weekly in most cases so that a greater number of measurements are available. This puts the dialysis provider in a unique position to identify those at risk of death with statistical tools. In Chapter 9 we identified patients at a higher risk of death with increasing and decreasing trends of systolic and diastolic BP regardless of the baseline BP level. This renders longitudinal observation and the consideration of parameter dynamics of great importance for clinical decision making. However, further research is required to evaluate determining factors and, more importantly to identify those which are modifiable to improve survival. 


\section{Conclusion}

In summary this thesis outlines the importance of the dialysis prescription and shows that the concentrations of both glucose and sodium in the dialysate are important and affecting both soft outcomes and hard outcomes such as death.. This thesis aimed to outline the possible benefits of individualization of sodium concentration in the dialysate and the avoidance of glucose and sodium loading of HD patients. To outline the importance of the metabolism of glucose and sodium the interrelationship between serum glucose and $\mathrm{SNa}^{+}$, and between $\mathrm{SNa}^{+}$and $\mathrm{BP}$ was discussed. Additional research is required as to other constituents of the dialysate such as bicarbonate, potassium, phosphorus, and others affect outcomes and how the balance of these solutes could be controlled in the dialysis clinic.

Further this thesis showed that longitudinal observations, at least in HD patients, where regular and high-frequently collected data are available, to be of great information gain when aiming to identify patients at risk of death. It could aid the development of safety and alert algorithms, and predictive models and their implementation. Models may enable the prediction of risk on an individual level and may aid the improvement of outcomes in the HD population, a population at a very high risk of hospitalizations and death. Understanding the dynamics reflected in longitudinal analyses will facilitate the understanding of all relevant relationships between parameters of interest and their association to death. For this purpose the extent as to which each parameter contributes to the information gain using these algorithms needs to be evaluated.

The findings reported in Part A of this thesis need to be confirmed in large international databases such as the MONDO database, in order to confirm the generalizability of these results to an international level. $\mathrm{DNa}^{+}$to $\mathrm{SNa}^{+}$alignment needs to be studied in adequately powered and randomized research settings.

Meeting the objectives of individualizing the dialysis treatment for every patient and to be able to identify patients at risk of adverse outcomes will only be possible by a close collaboration between governments, dialysis providers, researchers, physicians of many specialties, caregivers and - of course - the patients themselves. 


\section{References}

1. Ward RA, Wathen RL, Williams TE, et al. Hemodialysate composition and intradialytic metabolic, acidbase and potassium changes. Kidney Int 1987;32:129-35.

2. Esposito K, Nappo F, Marfella R, et al. Inflammatory cytokine concentrations are acutely increased by hyperglycemia in humans: role of oxidative stress. Circulation 2002;106:2067-72.

3. van Oostrom AJ, Sijmonsma TP, Verseyden C, et al. Postprandial recruitment of neutrophils may contribute to endothelial dysfunction. J Lipid Res 2003;44:576-83.

4. Dukkipati R, Kalantar-Zadeh K, Kopple JD. Is there a role for intradialytic parenteral nutrition? A review of the evidence. Am J Kidney Dis 2010;55:352-64.

5. Simic-Ogrizovic S, Backus G, Mayer A, et al. The influence of different glucose concentrations in haemodialysis solutions on metabolism and blood pressure stability in diabetic patients. Int J Artif Organs 2001;24:863-9.

6. Defining and reporting hypoglycemia in diabetes: a report from the American Diabetes Association Workgroup on Hypoglycemia. Diabetes Care 2005;28:1245-9.

7. Kemp GJ, Land JM, Coppack SW, et al. Skeletal muscle phosphate uptake during euglycemichyperinsulinemic clamp. Clin Chem 1993;39:170-1.

8. Charytan C, Gupta B, Meindel N, et al. Fractional direct dialysis quantification: a new approach for prescription and monitoring hemodialysis therapy. Kidney Int 1996;50:1845-9.

9. Davenport A, Cox C, Thuraisingham R. Blood pressure control and symptomatic intradialytic hypotension in diabetic haemodialysis patients: a cross-sectional survey. Nephron Clinical practice 2008;109:c65-71.

10. Kanaley JA, Baynard T, Franklin RM, et al. The effects of a glucose load and sympathetic challenge on autonomic function in obese women with and without type 2 diabetes mellitus. Metabolism 2007;56:778-85.

11. Krupp LB, LaRocca NG, Muir-Nash J, et al. The fatigue severity scale. Application to patients with multiple sclerosis and systemic lupus erythematosus. Arch Neurol 1989;46:1121-3.

12. de Paula FM, Peixoto AJ, Pinto LV, et al. Clinical consequences of an individualized dialysate sodium prescription in hemodialysis patients. Kidney Int 2004;66:1232-8.

13. Munoz Mendoza J, Bayes LY, Sun S, et al. Effect of lowering dialysate sodium concentration on interdialytic weight gain and blood pressure in patients undergoing thrice-weekly in-center nocturnal hemodialysis: a quality improvement study. Am J Kidney Dis 2011;58:956-63.

14. Thein H, Haloob I, Marshall MR. Associations of a facility level decrease in dialysate sodium concentration with blood pressure and interdialytic weight gain. Nephrol Dial Transplant 2007;22: 2630-9.

15. Peixoto AJ, Gowda N, Parikh CR, et al. Long-term stability of serum sodium in hemodialysis patients. Blood Purif 2010;29:264-7.

16. Oberleithner H. A physiological concept unmasking vascular salt sensitivity in man. Pflugers Arch 2012;464:287-93.

17. Oberleithner $\mathrm{H}$, Riethmuller $\mathrm{C}$, Schillers $\mathrm{H}$, et al. Plasma sodium stiffens vascular endothelium and reduces nitric oxide release. Proc Natl Acad Sci U S A 2007;104:16281-6.

18. Suckling RJ, Swift PA, He FJ, et al. Altering plasma sodium concentration rapidly changes blood pressure during haemodialysis. Nephrol Dial Transplant 2013;28:2181-6.

19. He FJ, Fan S, Macgregor GA, et al. Plasma sodium and blood pressure in individuals on haemodialysis. J Hum Hypertens 2013;27:85-9.

20. Chen W, Valamanesh F, Mirshahi T, et al. Aldosterone signaling modifies capillary formation by human bone marrow endothelial cells. Vascul Pharmacol 2004;40:269-77.

21. Duffy SJ, Biegelsen ES, Eberhardt RT, et al. Low-renin hypertension with relative aldosterone excess is associated with impaired NO-mediated vasodilation. Hypertension 2005;46:707-13.

22. Fleming I, Busse R. Molecular mechanisms involved in the regulation of the endothelial nitric oxide synthase. Am J Physiol Regul Integr Comp Physiol 2003;284:R1-12. 
23. Fujiwara $\mathrm{N}$, Osanai $\mathrm{T}$, Kamada $\mathrm{T}$, et al. Study on the relationship between plasma nitrite and nitrate level and salt sensitivity in human hypertension : modulation of nitric oxide synthesis by salt intake. Circulation 2000;101:856-61.

24. Usvyat LA, Haviv YS, Etter M, et al. The MONitoring Dialysis Outcomes (MONDO) initiative. Blood Purif 2013;35:37-48.

25. von Gersdorff GD, Usvyat L, Marcelli D, et al. Monitoring Dialysis Outcomes across the World - The MONDO Global Database Consortium. Blood Purification 2013;36:165-72.

26. Usvyat LA, Barth C, Bayh I, et al. Interdialytic weight gain, systolic blood pressure, serum albumin, and C-reactive protein levels change in chronic dialysis patients prior to death. Kidney Int 2013;84:149-57.

27. Usvyat LA, Carter M, Thijssen S, et al. Seasonal variations in mortality, clinical, and laboratory parameters in hemodialysis patients: a 5-year cohort study. Clin J Am Soc Nephrol 2012;7:108-15.

28. Usvyat LA, Kooman JP, van der Sande FM, et al. Dynamics of hospitalizations in hemodialysis patients: results from a large US provider. Nephrol Dial Transplant 2014;29:442-8.

29. Usvyat LA, Raimann JG, Carter M, et al. Relation between trends in body temperature and outcome in incident hemodialysis patients. Nephrol Dial Transplant 2012;27:3255-63.

30. Hecking M, Karaboyas A, Saran R, et al. Predialysis serum sodium level, dialysate sodium, and mortality in maintenance hemodialysis patients: the Dialysis Outcomes and Practice Patterns Study (DOPPS). Am J Kidney Dis 2011;59:238-48.

31. Mc Causland FR, Brunelli SM, Waikar SS. Dialysate sodium, serum sodium and mortality in maintenance hemodialysis. Nephrol Dial Transplant 2011;27:1613-8.

32. Waikar SS, Curhan GC, Brunelli SM. Mortality associated with low serum sodium concentration in maintenance hemodialysis. Am J Med 2011;124:77-84.

33. Wang Y. Smoothing Splines: Methods and Applications Chapman \& Hall 2011.

34. Gu C. Smoothing Spline ANOVA Models: Springer; 2002.

35. Wahba G, Wang Y, Gu C, et al. Smoothing Spline Anova for Exponential Families, with Application to the Wisconsin Epidemiological Study of Diabetic Retinopathy. The Annals of Statistics 1995;23:1865-95.

36. Zager PG, Nikolic J, Brown RH, et al. "U" curve association of blood pressure and mortality in hemodialysis patients. Medical Directors of Dialysis Clinic, Inc. Kidney Int 1998;54:561-9.

37. Mallamaci F, Minutolo R, Leonardis D, et al. Long-term visit-to-visit office blood pressure variability increases the risk of adverse cardiovascular outcomes in patients with chronic kidney disease. Kidney Int 2013;84:381-9.

38. Mallamaci F, Tripepi G. Blood pressure variability in chronic kidney disease patients. Blood Purif 2013;36:58-62.

39. Di lorio B, Di Micco L, Torraca S, et al. Variability of blood pressure in dialysis patients: a new marker of cardiovascular risk. J Nephrol 2013;26:173-82.

40. Cruickshank JM. Coronary flow reserve and the J curve relation between diastolic blood pressure and myocardial infarction. BMJ 1988;297:1227-30. 


\section{Valorization}




\section{Valorization}

\section{Social (and/or economic) relevance of our research results (i.e. in addition to the scientific relevance)?}

Since the first attempts to purify blood of a human patient suffering from renal failure in the 1920s by Georg Haas in Germany and then in the 1940s in the Netherlands by Willem Kolff, to the first attempt to treat a patient with chronic renal failure over an extended period of time by Belding Scribner in Seattle, USA, large technological progress was made. The treatment of the first maintenance dialysis patient Clyde Shields, in the light of limited resources brought along problems of ethical nature for all future patients with chronic renal failure: "Who would receive the life-saving treatment and who would be doomed to the fatal course of nature?" These ethical problems were solved in those days by the highly criticized and so-called "Death committees". Following these early days more and more resources were made available, governments stepped in to provide funding and dialysis is now to a large extent being provided by large dialysis provider networks. This changed the ethical and research questions to be elucidated, but raised different questions. How can a government afford to provide dialysis to everybody requiring dialysis but at the same time provide the best treatment options available. The question if private co-payments should be allowed to alter the dialysis treatment in any (possibly outcome improving) way is also getting more and more persuasively asked and reflects a general lack of knowledge what actually is the right treatment and how to administer it on a large scale which is operationally and economically feasible. While the extent to which these questions are prioritized varies between continents, country and essentially health-care systems, the basic question does not and usually remains for each individual caregiver to answer. The complexity of this situation is even further accentuated as a resultant of emerging technologies, the increase of healthcare costs in general and the increased need for governments to make healthcare more affordable. Since these aforementioned factors making dialysis in current times more and more a challenge for all involved, it also results in increased pressure on healthcare facilities to provide care at a quality resulting in the most desirable outcomes possible.

My thesis emphasizes the importance of dialysate glucose and sodium, both of which are associated with outcomes and its individualization has the potential to provide optimal care. Furthermore my thesis also addresses the need of the community to consider longitudinal observations and not just concentrate on cross-sectional data only answering a part of the questions asked.

\section{Interest of our research results and why?}

The results of the research presented in this thesis are not only of interest for the academic community but also for the entire nephrology community, as evidenced by 
the publication of my work in highly ranked nephrology journals. Research improving the interpretation of observed outcomes is of great importance for any patient population. In the specific case of the dialysis treatment, dialysis providers, which are not only striving to improve the quality of treatment but are also increasingly forced to be interested in cost-effectiveness while at the same time providing the same constantly increasing improvement of outcomes in their patient population, this may be considered to be even more accentuated. Due to this reason, research aiming to reduce the loading of substances from the dialysate into the patients is of great importance, particularly in regard of the outcomes reported in this thesis. Furthermore the superiority of longitudinal observations over single measurement cross-sectional assessments is also of increasing interest for the community as well as dialysis providers, thus an additional aspect of my thesis of ubiquitous interest.

\section{Into which concrete products, services, processes, activities or commercial activities will our results be translated and shaped?}

My thesis aims to address two aspects of treatment which had not yet been fully and internationally optimized due to a lack of evidence of their physiological and pathophysiological impact. The dialysate prescription is central to the effects of the treatment and as per the Food and Drug Administration (FDA) in the US considered the prescription of a drug. This indeed is a realistic assessment since dialysis does substantially change the physiology in the body. Not only does dialysis have the potential to lower levels of undesired substances, it also does allow the increase of concentrations quite substantially, thus affecting every physiologic system in the body.

Basically the dialysis treatment should be resulting in a normalization of the milieu interieur, as Claude Bernard so accurately termed it in the $19^{\text {th }}$ century, which essentially describes the body fluid volume. However as mentioned dialysis also has the potential to change the serum concentrations in a way so the treatment results in adverse consequences as outlined in Part A for dialysate glucose and in Part B for dialysate sodium. In addition to making the case that the selection of appropriate prescriptions has the potential to result in positive effects this thesis will also show evidence that all possible outcomes need to be considered in a longitudinal fashion, evaluating trends and variability. Only this kind of analysis does aid the identification of patients at elevated risk of death and in need of alteration of prescribed regimen (Part C).

In a population where diabetes and hyperinsulinism is highly prevalent (ranging from 24 to $56 \%$ depending on the continent) and often the reason for renal failure in a first place, glucose loading using dialysate glucose concentration of $200 \mathrm{mg} / \mathrm{dl}$ (11.1 mmol/l) is obviously disadvantageous. In Part A we are showing that the use of high dialysate glucose concentrations, as the standard in the US for decades, resulted in various consequences such as hyperglycemia, hyperinsulinism, effects on the autonomic 
nervous system and also on subjects' self-reported post-dialysis fatigue, when compared to lower dialysate glucose concentrations [i.e. $100 \mathrm{mg} / \mathrm{dl}(5.5 \mathrm{mmol} / \mathrm{dl})$ ]. As another aspect a patient population which cannot excrete salt and water like patients with functioning kidneys also needs to be subject of salt restriction on a dietary but also on a dialysis level. Thus the importance of the dialysate prescription in terms of sodium, as shown in Part B, is of greatest importance for the dialysis population.

The aspect of the importance of longitudinal observations is an increasingly important topic which is not only found in research and risk assessment for dialysis patients but also in other population. Thus Part $\mathbf{C}$ is an additional piece of evidence proving the superiority of longitudinal assessments.

\section{To what degree can our results be called innovative in respect to the existing range of products, services, processes, activities and commercial activities?}

At the time when these data was acquired the standard for the dialysate glucose concentration in the US with a dialysis population of around 300 to 350,000 patients, was still $200 \mathrm{mg} / \mathrm{dl}(11 \mathrm{mmol} / \mathrm{l})$, while a majority of other countries used either 100 $\mathrm{mg} / \mathrm{dl}$ (5.5 mmol/l) or glucose-free dialysate. The randomized controlled-cross over trial conducted in in 2008 under my supervision in clinics of the Renal Research Institute, was the first trial investigating the metabolic and cardiovascular differences between those two dialysate glucose concentrations in a randomized setting. The result, albeit (29 chronic hemodialysis patients) collected in a study of small sample size, was the first of its kind and associated with a large-scale change by the very same large-scale dialysis provider, which was the first choosing to change the dialysate glucose concentration to the lower concentration in mid-year 2009. Since then all other large and small dialysis providers have followed and at this date virtually every dialysis patients in the US receives hemodialysis with the lower dialysate glucose concentration of $100 \mathrm{mg} / \mathrm{dl}(5.5 \mathrm{mmol} / \mathrm{l})$. Not only was this expected to improve outcomes, but also resulted, by reducing the need of glucose to be added to the dialysate, in a decrease of the costs of dialysate production and thus an increase of cost-effectiveness of the dialysis treatment in a time where 'bundling' a stringent new reimbursement system, which puts increased pressure on the large but particularly small dialysis providers, was being introduced (and subsequently in the last years implemented).

Dialysate sodium is currently of great interest on an international level and some conflicting data is currently creating a controversy in the community about the choice of the optimal dialysate sodium. While this thesis will unfortunately not be able to entirely resolve the controversy it comprises the introduction (and subsequent validation testing) of an algorithm to align dialysate sodium to serum sodium based on historic monthly serum sodium measurements, thus, by not causing the need of additional blood draws prior to the hemodialysis treatment, increasing the probability of operational feasibility in the busy routine of a dialysis clinic. We know from the 
preliminary analysis of data resulting from the clinical implementation of this algorithm, of which an extended database and updated analysis is currently under development, and based on an earlier underpowered randomized trial in 27 subjects, that alignment does have significant effects on fluid intake and blood pressure management, without causing an increased occurrence of side-effects of the dialysis treatment. While the aforementioned underpowered randomized trial required regular measurements of serum sodium prior to the treatment, the novelty of the approach we are proposing in Part $\mathbf{B}$ allows the estimation of the current serum sodium based on the average of the last 4 preceding monthly routine serum sodium measurements with sufficient accuracy and precision, thus not requiring any additional measurements. This renders our approach, which was also granted a US patent last year (USPTO\#08518260), an operationally feasible way to align dialysate sodium to serum sodium without creating additional costs and substantial workforce needed, to improve outcomes. Since dialysate sodium consequentially also affects serum sodium levels an investigation of the effects of serum sodium on blood pressure, one of the strongest predictors of outcomes in dialysis patients, on an international levels is included, which renders the importance of sodium in dialysis an international and omnipresent concern. The actual relevance of sodium is further clearly corroborated by a body of literature corroborating the adverse effects of high dialysate sodium and dietary sodium intake, and the subsequent increased fluid intake in dialysis patients on the cardiovascular system and many other organ systems. Fluid intake during the interdialytic period is of particular interest not only because of its relationship to mortality but also from an economical side. In a report of national data from the Centers for Medicare \& Medicaid Renal Management Information System, a federal agency, amongst other tasks, also responsible for administering the Medicare health insurance to the dialysis population, it was shown that fluid overload (a possible consequence of sodium loading) requiring hospitalization to occur in $7 \%$ of all patients and result in an average cost of 6,372 US \$ per episode and a total of 266 Million US \$ over an observation period of 2 years. These numbers suggest a potential economic importance of research done on dialysate to serum sodium alignment, particularly when it can be implemented requiring such small effort.

Lastly, Part C is dedicated to the importance of longitudinal observations. Dialysate sodium and glucose prescription affects, as outlined above, various aspects of physiology in the body. The longitudinal data we show in Part $\mathbf{C}$ shows novel indicators of present or progressing disease and may aid to identify patients at risk. Research on what predicts outcomes, is necessary to understand which patients may actually benefit from alterations to their administered regimen. While the main focus of this thesis was the dialysate constituent prescriptions which were established in Part A and Part B, and tow show that suboptimal dialysate prescriptions may result in adverse outcomes, Part $\mathbf{C}$ suggests tools to identify those which may possibly benefit from an optimization of the dialysate prescription. It may be added that these possible 
alterations do not end with the prescriptions of dialysate constituents but also comprise aspects such as antihypertensive medication such as discussed in Part C.

\section{How will this/these plan(s) for valorization be shaped? What is the schedule, are there risks involved, what market opportunities are there and what are the costs involved?}

As mentioned above the proposed intervention of only using a dialysate glucose concentration of $100 \mathrm{mg} / \mathrm{dl}(5.5 \mathrm{mmol} / \mathrm{l})$ is already common practice in the US and has been embraced by a majority of dialysis providers. Dialysate sodium alignment as a means to reduce sodium loading and its consequences has already been successfully implemented in the clinical routine of 5 dialysis clinics of the Renal Research Institute. While this thesis is only showing some preliminary data, a larger-scale analysis of the largest dialysate to serum sodium alignment project is currently underway and to our believe become influential and possibly changing dialysis practices on an international level. In summary the data shown in Part A and Part B of this thesis do not only provide information of interest to the academic world, but also to governmental agencies, the entire nephrology community (including large- and small scale dialysis providers, healthcare worker, physicians as well as patients). It may be speculated that some particular parts of this thesis may also be subject of further research and may aid to generate new research ideas and hypothesis to be proven in prospective research.

The proposed need of an increased use of longitudinal analysis in Part C is already increasingly adapted by analysts of large datasets. While some registries are still performing cross-sectional analyses, others become more and more comfortable with analyses of longitudinal nature. However, it is without a doubt that this analytical approach will soon be adapted by the entire community and represents the future of data analysis. Once analysts and researchers have become more familiar with the approach and the methodology it can be assumed to become a widespread routine approach within the community quickly.

As a fascinating example of novel analytic tools which are of great value for the analysis of longitudinal analysis the novel approach using smoothing spline ANOVA logistic regression models to investigate the joint effect of serum sodium and serum sodium variability is emphasized. In addition to analyzing the relationship between serum sodium only, we were able by using this approach to analyze the relationship between both including variability (defined as the standard deviation of all serum sodium measurements over the period of one year) and in a second separate analysis of additionally slope estimates (from a fitted linear regression model to all serum sodium measurements in one year). This is a novel approach to this research question since previous authors only focused on the relationship between serum sodium and mortality. By analyzing trends and variability one is able to also identify present and progressing disease and, as shown in our analysis, the differences between the trends (increasing/decreasing slope estimate) appears to allow the identification of a patient 
who starts to improve and those who are deteriorating. From a bird's eye view, longitudinal analysis evaluating trends and variability can aid dialysis providers and caregivers to identify patients at risk, contact the immediate caregivers and adjust these patients' regimen to an optimized treatment strategy. This includes the dialysate and drug prescription and possibly many other aspects such as treatment time, frequency and other items listed to achieve optimal dialysis adequacy.

As the author of this thesis I am convinced that all aspects analyzed in this thesis are of importance to the dialysis community and hope that the conducted research will be of help to improve the outcome of a patient population with known low life expectancy, low quality of life and a great need of improvement of currently available treatment and diagnostic capabilities. 
Acknowledgement / Dankwoord 


\section{Acknowledgement / Dankwoord}

"It is the supreme art of the teacher to awaken joy in creative expression and knowledge."

Albert Einstein (1879-1955)

When I wrote my doctoral thesis at the Medical University Graz, Austria in 2007 I had commenced my acknowledgement section with this famous and, in my opinion, perfectly accurate quote. What I have felt as a student when I picked this quote for my thesis has become even more accentuated over the years. Having been blessed to work with the most inspiring teachers I could imagine, it was not only what they taught me, but also how they taught and guided me, and ultimately how they inspired me to feel joy in knowledge expansion and contributing to research. This guidance was even further promoted by the intellectually stimulating environment at the Renal Research Institute, which not only combines academic and personal well-being in an incomparable fashion, but also allows for personal and professional growth.

As for this thesis my deepest gratitude goes to my advisors and mentors from the Maastricht University Medical Center, Professor dr. Jeroen P. Kooman and Dr. Frank M. van der Sande. They have been key persons in making this thesis possible by their guidance with the completion of the main manuscripts, which have become part of this thesis. Also, during many meetings they have been central to creating, based on preliminary visions and ideas, a thesis which covers an immensely important and complex topic of dialysis therapy. Their efforts and commitment to promote innovative thoughts, to initiate and, even more importantly, maintain motivation is outstanding and one can almost not act differently than to share their enthusiasm for new discoveries and not yet discussed aspects of newly found data. I feel a very deep gratitude for them to make this thesis and doctorate possible.

Since the thought of doing research occurred to me for the first time, Dr. Peter Kotanko was on my side and guided me through all positive and negative aspects. He was an inspiring influence in my life and has been supportive in so many ways, professional as well as personal, that I feel unable to list them all in this acknowledgement. What I have learned from him over the years goes far beyond pure knowledge but (amongst other aspects) also involved insight into how to combine interpersonal relationships with being a marvelous teacher and supervisor. Many thanks to my great mentor for all these years of support.

I would also like to express my deepest gratitude to Dr. Nathan W. Levin, who has been an excellent and influential teacher for me. Always with a smile and in good humor, regardless of how stressful his day may have been, he is one of the highest intellectual 
references I have ever encountered and it is with true reason that the world of nephrology listens when he speaks. I feel privileged to have been working under his guidance for such a long (and very enjoyable and inspiring) time. Often when I thanked him for his insight and support he just modestly cited the Talmud: 'More than the calf wants to suckle, the cow wants to nurse' (Pesachim 112a). However, I feel immensely grateful for all his support with this thesis and various other professional aspects.

Many colleagues at the Renal Research Institute deserve my gratitude, they have been of great importance for my professional life up to this point. Mainly I would like to acknowledge Dr. Mary Carter, Dr. John Callegari and Dr. Stephan Thijssen.

I am also grateful to the Review Committee members Professor dr. P.W. de Leeuw, Professor dr. C.D.A.Stehouwer, Professor dr. R. Zietse, Dr. O. Bekers and Dr. C.F. Franssen for their review and approval of my thesis.

My next expression of gratitude I would like to direct to my co-workers and co-authors of my glucose-related publications. Particularly to highlight in this context are Dr. Anja Kruse, Dr. Viktoriya Kuntsevich, Dr. Pascal Dabel and Benjamin Arthur, who worked with me in the clinics studying the effects of dialysate glucose on metabolic and cardiovascular indices. Without them this study may not have been possible. I would like to extend my gratitude to the staff in the units who have been helpful and supportive to allow the proper and successful conduction of this study. Furthermore I would like to extend my thanks to our collaborators from Politecnico di Milan, Italy, Dr. Manuela Ferrario, Dr. Maria Gabriella Signorini and Dr. Sergio Cerutti who provided deep insight into the relationship between glucose and insulin metabolism and the cardiovascular system. I would also like to thank Dr. Jose Diaz-Buxo, for his scientific input in his area of expertise and support of the study, and Dr. Mostafa Bachar, for his support on the mathematical side in determining intradialytic glucose mass transfer and help with mathematical questions.

For the sodium alignment project, which is an exciting part of this thesis, I feel deeply thankful to the operational side of the Renal Research Institute and all involved key persons: Sandi Moore, Lisa Pacelli, Terry Sullivan and Dr. Paul Zabetakis; as well as to Dr. Jose Diaz-Buxo, Dr. Claudy Mullon, Dr. Linda Ficociello and Dr. Len Usvyat from Fresenius Medical Care North America who had been greatly supportive of this quality improvement initiative and were involved in many intellectually stimulating discussions. My thanks go out to Dr. Yuedong Wang for providing his scientific input and guidance on the analyses.

I would also like to express my deep gratitude to the Monitoring Dialysis Outcomes (MONDO) Initiative and its members for the opportunity to research and publish 
findings based on the MONDO data. In addition, I also thank the MONDO initiative members for their invaluable scientific input in the process of data analysis, drafting of abstracts or papers. Special thanks belongs to the committee members and my fellow coauthors. In particular I would like to thank Dr. Len Usvyat firstly, in his role as a key person of the MONDO initiative for allowing me to gain access to the database, and secondly (and more importantly) for being a supportive and invaluable colleague over the years who has always been a pleasure to work, write and publish with. Further I would like to highlight some of the MONDO members whose opinions were of great value to the completion of our manuscript: Dr. Bernard Canaud, Dr. Michael Etter, Dr. Aileen Grassmann, Dr. Daniele Marcelli, Dr. Christina Marelli, Dr. Albert Power, Dr. Xiaoqi Xu, and particularly Dr. Yuedong Wang for his valuable input to my many statistical questions and his expert guidance through the complex world of statistics.

Over the years I have also had the opportunity to collaborate and work with many interesting, amazing people. Research scientists, clinicians or statisticians all over the world have been part of my journey to obtain this degree and to contribute to the progress of science and medical technology. Namely these colleagues were Dr. Gerald Beck, Dr. Andrew Bomback, Dr. Chris Chan, Dr. Glenn Chertow, Dr. John Daugirdas, Dr. Frank Gotch, Dr. Tom Greene, Dr. Garry Handelman, Dr. Todd Ing, Dr. George Kaysen, Dr. Marcia Keen, Dr. Phillip Klemmer, Dr. Alan Kliger, Dr. Eduardo Lacson, Jr., Dr. Brett Larive, Dr. Robert Lindsay, Dr. E. L. Penne, Dr. Andreas Pierratos, Dr. Michael Rocco, Dr. John Rogus, Dr. Daniel Schneditz and Dr. Antonius Tzamaloukas.

It is of great importance to me to extend my thanks to those who supported me on my endeavors to become a permanent resident in the United States, which clearly was a precondition for my presence at the Renal Research Institute and consequently the development of the thesis as it stands right now. In this context I would like to thank of course Dr. Nathan Levin and Dr. Peter Kotanko, but also Dr. Mostafa Bachar, Dr. Anton Berger, Dr. Mary Carter, Dr. Sergio Cerutti, Dr. Jose Diaz-Buxo, Dr. Frank Gotch, Dr. James Hennessy, Dr. Martin Kuhlmann, Dr. Hans-Dietrich Polaschegg, Dr. Bernd Schroeppel, Dr. Falko Skrabal, Dr. Frank van der Sande and Dr. James Winchester. I would also like to thank my immigration lawyers Frances Berger, Greg Pietrzak and Barbara Macina.

My thanks also belong to those who supported me in my early medical career, especially to Dr. Stuart Baskin, for his invaluable help, to Dr. Margaret Baran, Dr. Anton Berger, Dr. William Chenitz, Dr. Hannah Hampl, Dr. Nikolas Harbord, Dr. James Hennessy, Dr. Neil Kothari, Dr. Neil Lyman, Dr. Joel Notkin, Dr. Herman Rosen, Dr. Shubo Sarkar, Dr. John Sensakovic, Dr. Falko Skrabal, Dr. Daniel Steinberg, Dr. Alf Michael Tannenberg, Dr. Barry Weiner and Dr. James Winchester. 
I would like to thank Tiny Wouters, Maastricht University Medical Center, for preparing the manuscript and lay-out.

Last but certainly not least I would like to emphasize that also personal well-being was necessary to take on the task of completing this thesis. Much support was given to me by people close to me and supportive of my ideas and plans. Firstly in this context I would like to name my parents, Dr. Dieter Raimann and Melitta Raimann, who always accepted my decisions, stood behind me and supported all my endeavors. Secondly my thanks also go to my entire family and also to my friends who have been a great emotional support and who were available whenever needed, regardless of time and distance. With so many people in my life it is virtually impossible to list them all, but I would like to send my special thanks to my paranimfs Stefan Weitzl and Dr. Ulrike Kotanko, as well as to Silvia Fischer, Drs. Doris and Stefan Fürtinger, Manuel Hadler, Darko Ibrahimpasic, Dr. Thomas Kitzler, Josef Scharl jr., Dr. Jochen Krenosz, Dr. Li Liu, Paulette Regnier, Josef Scharl, my dear cousin Astrid Moder, Savio Schäfmann, Karl und Marlies Pachler, Dr. Sascha and Anna Pätzold and Dr. Carmen Vlahu.

Lastly, I would like to say that this thesis and the underlying research is not only an academic accomplishment but mainly serves the purpose to improve the outcomes of a patient population suffering from numerous comorbidities, compromised quality of life, malnourishment and consequently poor long-term outcomes. My hopes are that the underlying research of this thesis will contribute to the knowledge and work of researchers and clinicians in the future and will help to improve the life and outcomes of dialysis patients! 
Curriculum vitae 


\section{Curriculum vitae}

Jochen G. Raimann was born on January $25^{\text {th }}, 1979$ in Graz, Austria, and grew up in the town of Sankt Anna am Aigen in South-East Styria, Austria. After finishing the gymnasium with special emphasis on information technology in Feldbach and obtaining an Associate degree at the College for Tourism and Leisure industry in Bad Gleichenberg, he commenced his studies at the Medical University Graz in Austria, where he graduated in April 2007, after approval of his doctoral thesis "Functional Examination of Pancreas Grafts by Mathematical Modelling of a Modified Intravenous Glucose Tolerance Test" under the guidance and supervision of Drs. Peter Kotanko and Mostafa Bachar. During his studies in Graz from 2000 to 2007 he was a committed team member of the Red Cross Austria, where he volunteered as an ambulance man and a Mobile Intensive Care Unit assistant. In May 2007 Dr. Raimann relocated to New York City, USA, and started his Research Fellowship at the Renal Research Institute under the guidance of Dr. Nathan W. Levin where he is working since. Dr. Raimann is a permanent resident in the United States since 2011 based on a petition filed in the EB-1 category and is furthermore certified as a Medical Doctor in the United States by the Educational Commission for Foreign Medical Graduates (ECFMG) since January 2009. During his research career he has first- and co-authored publications in numerous highranked journals, has been appointed as peer-reviewer of several international journals and has given scientific talks at various national and international conferences. Dr. Raimann currently holds the position of a Research Scientist at the Renal Research Institute under the guidance of Drs. Peter Kotanko and Nathan Levin. 
